ERNESTO CRISTOPHER VILLEGAS CASTILLO

\title{
DYAFNOC: SISTEMA DINAMICAMENTE RECONFIGURÁVEL BASEADO EM REDES INTRACHIP COM ALGORITMO DE ROTEAMENTO ORDENADO POR DIMENSÃO FLEXIBILIZADO
}

Dissertação apresentada à Escola Politécnica da Universidade de São Paulo para obtenção do Título de Mestre em Ciências. 
ERNESTO CRISTOPHER VILLEGAS CASTILLO

\title{
DYAFNOC: SISTEMA DINAMICAMENTE RECONFIGURÁVEL BASEADO EM REDES INTRACHIP COM ALGORITMO DE ROTEAMENTO ORDENADO POR DIMENSÃO FLEXIBILIZADO
}

\begin{abstract}
Dissertação apresentada à Escola Politécnica da Universidade de São Paulo para obtenção do Título de Mestre em Ciências.
\end{abstract}

Área de Concentração:

Engenharia Elétrica - Microeletrônica

Orientador:

Prof. Dr. Wang Jiang Chau 
Este exemplar foi revisado e alterado em relação à versão original, sob responsabilidade única do autor e com a anuência de seu orientador.

São Paulo, 9 de fevereiro de 2015.

Assinatura do autor

Assinatura do orientador

CATALOGAÇÃO-NA-PUBLICAÇÃO

Villegas Castillo, Ernesto Cristopher

DyAFNoC: Sistema Dinamicamente Reconfigurável Baseado em Redes Intrachip com Algoritmo de Roteamento Ordenado por Dimensão Flexibilizado / E.C. Villegas Castillo. - versão corr. - São Paulo, 2015.

$155 \mathrm{p}$.

Dissertação (Mestrado) - Escola Politécnica da Universidade de São Paulo. Departamento de Engenharia de Sistemas Eletrônicos.

1. Circuitos FPGA 2. Redes Intrachip 3. Algoritmos de Roteamento livres de deadlock I. Universidade de São Paulo. Escola Politécnica. Departamento de Engenharia de Sistemas Eletrônicos. II. t. 
Dedicado à memória de minha "mamita"Sucila que sempre estará em minha mente e coração ainda depois de sua partida; e para minha mãe Magda porque seu amor atravessa fronteiras. 


\section{O caminho não escolhido}

Num bosque amarelo dois caminhos se separavam, E lamentando não poder seguir os dois

E sendo apenas um viajante, fiquei muito tempo parado E olhei pra um deles tão distante quanto pude Até que se perdia na mata;

Então segui o outro, como sendo mais merecedor. E vendo talvez melhor direito. Porque coberto de mato e querendo uso Embora os que passaram por lá Os tenham percorrido de igual forma, E ambos ficaram essa manhã Com folhas que passo nenhum pisou.

Oh, guardei o primeiro para outro dia! Embora sabendo como um caminho leva pra longe, Duvidasse que algum dia voltasse novamente.

Direi isso suspirando Em algum lugar, daqui a muito e muito tempo: Dois caminhos se separaram em um bosque e eu...

Eu escolhi o menos percorrido E isso fez toda a diferença. 


\section{AGRADECIMENTOS}

Quero agradecer primeiramente a Deus e seu filho Jesus, por o imenso amor que me demonstram cada dia da minha vida, cuidando de mim, da minha família e demais seres queridos, e dando-nos as oportunidades necessárias para ir pelo caminho certo em cada uma de nossas vidas.

Ao meu orientador, Prof. Dr. Wang Jiang Chau, pela oportunidade de fazer mestrado sob sua orientação, participando do trabalho acadêmico e de pesquisa no grupo de Sistemas Eletrônicos Integrados e Software Aplicado (GSEIS). Graças à todo o apoio que recebi do Prof. Wang, tanto acadêmico como pessoal, consegui aprender muito sobre a pesquisa acadêmica moldando uma dissertação, focando sempre na qualidade do projeto de mestrado.

Á Mario Raffo, quem me motivo a fazer o mestrado na USP e pela sua amizade demostrada nos momentos de dificuldades durante a minha estança no Brasil. Também á sua namorada Izabella, por o apoio recebido durante meus primeiros dias no Brasil.

Á Gabriele Miorandi, pelas suas orientações recebidas, apoio e confiança recebida para continuar com seu projeto de pesquisa apesar da diferença horaria com a Itália.

Á toda minha família no Peru pelo constante apoio durante estes últimos anos, em especial para minha mãe Magda e minha tia Cecilia a quem não consegui agradecer no meu trabalho de conclusão de curso, mas que sua ajuda foi vital para que eu pudesse me formar.

Aos meus colegas do grupo com quem compartilhei muitos momentos agradáveis, Gustavo, Jorge, Carlos, Joel e Jonas, no hora do cafezinho, reuniões de grupo e cada dia de trabalho no laboratório. Do mesmo modo agradeço aos meus amigos com quem compartilhei bons momentos e intercambio cultural durante a minha estança no Brasil: Joaquin, Jose Luis, Mauricio, David e Diego.

Aos meus amigos e amigas, peruanos, brasileiros e colombianos, e de mais nacionalidades com que, compartilhei tantos momentos agradáveis, interessantes e de crescimentos pessoal durante estes últimos anos no Brasil.

À CAPES pelo financiamento deste trabalho de pesquisa através de uma bolsa de mestrado, e novamente ao Prof. Wang pelo auxílio econômico recebido para a inscrição de um artigo em um congresso internacional. 


\section{RESUMO}

O aumento da capacidade dos Sistemas sobre Silício (SoCs do inglês, System on-Chip) tem levado Redes Intrachip (NoCs do inglês, Network on-Chip) a serem utilizadas como interface de comunicação de Módulos de Processamento de sistemas complexos, e particularmente em Sistemas Dinamicamente Reconfiguráveis a serem implementados sobre FPGAs com capacidade de reconfiguração parcial. Algumas estratégias de reconfiguração geram cenários com NoCs irregulares e indiretas, fato que força o sistema a atualizar o seu algoritmo de roteamento a fim de se evitar problemas de comunicação de dados, como deadlock e livelock. O presente trabalho apresenta uma NoC Dinamicamente Reconfigurável (DRNoC do inglês, Dynamically Reconfigurable Newtwork on-Chip) utilizando o Algoritmo de Roteamento Ordenado por Dimensão Flexibilizado (FDOR do inglês, Flexible Dimension Order Routing) que se caracteriza principalmente sua simplicidade, baixa complexidade e ser livre de deadlock.

No presente trabalho, foi implementada a ferramenta DRSimGen, que gera código VHDL da arquitetura da NoC associada, para ser utilizado com aplicações específicas com reconfiguração parcial dinâmica que requeiram comunicações paralelas entre seus módulos de processamento. Esta ferramenta gera os roteadores, módulos de processamento, além de um Sistema de Controle de Reconfiguração Parcial Dinâmica que pode ser utilizado junto com o Sistema de Reconfiguração do algoritmo de roteamento baseado em FDOR, já desenvolvido por outros anteriormente.

A ferramenta também gera componentes de testbench para a simulação do sistema, baseados na técnica de Chaveamento Dinâmico de Circuitos; são utilizadas chaves de isolação para emular os processos de reconfiguração parcial dinâmica. Os resultados destes experimentos ajudaram a determinar o comportamento desejado do sistema. Também foram feitas simulações da implementação do FDOR em descrição de alto nível, com a finalidade de determinar seu desempenho na transferência de dados que ajudarão a definir o posicionamento dos módulos de processamento sobre a estrutura da rede. Os resultados dos experimentos tem demonstrado a viabilidade desta estratégia, levando à conclusão que o algoritmo FDOR é uma solução adequada para DRNoCs.

Palavras Chave: DRNoCs, FPGA, Algoritmo de Roteamento, Deadlock, Reconfiguração Parcial Dinâmica 


\begin{abstract}
The increased capacity of Systems on-Chip (SoCs) has led Networks on-Chip (NoC) to be used as communication interface for processing modules of complex systems, and particularly in Dynamically Reconfigurable Systems to be implemented over partially reconfigurable FPGAs. Some reconfiguration strategies work on irregular and indirect NoCs, fact that forces the system to update its routing algorithm in order to avoid data communication problems, such as deadlock and livelock. This paper presents a Dynamically Reconfigurable NoC (DRNoC) using Flexible Dimension Order Routing Algorithm (FDOR), mainly characterized by its simplicity, low complexity and deadlock freedom

In this work, the DyAFNoC tool was implemented, to generate the VHDL code of the associated NoC architecture to be used with specific applications with dynamic partial reconfiguration that require parallel communications between their processing modules. This tool generates routers, processing modules, and also a Partial Dynamic Reconfiguration Control System that can be used with the FDOR-based Reconfiguration System, developed elsewhere.

The tool also generates testbench components for the system simulation, based on the Dynamic Circuit Switching technique that uses isolation switches to emulate the dynamic partial reconfiguration processes. The results of these experiments have helped to determine the desired system behavior. Simulations of the FDOR implementation were also made in high level description in order to determine its data transfer performance that will help to define placement of the processing modules over the network structure. The experiments results have demonstrated the feasibility of this strategy, leading to the conclusion that the FDOR algorithm is a suitable solution for DRNoC.
\end{abstract}

Keywords: DRNoCs, FPGA, Routing Algorithm, Deadlock, Partial Dynamic Reconfiguration 


\section{LISTA DE ILUSTRAÇÕES}

1 Diagrama de tempo do funcionamento de um DRS. . . . . . . . . . . . . 22

2 Flexibilidade de funcionalidade, Redução da área do chip e Minimização do consumo de energia e dissipação de potência. . . . . . . . . . . . . . . 22

3 Exemplo de uma reconfiguração parcial dinâmica de uma NoC dinâmica com duas configurações diferentes. . . . . . . . . . . . . . . . . 24

4 Exemplo das duas configurações de deadlock num arranjo de unidades processantes sobre uma rede com topologia de malha bidimensional. . . . . . . . . . 26

5 Classificação dos FPGAS baseado na capacidade de configuração . . . . . . . 33

6 Processo de Reconfiguração Dinâmica de células lógicas de um DRFPGA . . . 35

7 Gráfico de Reconfiguração Dinâmica sobre um DRFPGA. . . . . . . . . . . 36

8 Duas técnicas de implementação do controlador de reconfiguração parcial dinâmica. . . . . . . . . . . . . . . . . 37

9 Estrutura de Simulação usando DCS. . . . . . . . . . . . . . . . . . . . 39

10 Principais Elementos da Arquitetura Genérica de um Roteador. . . . . . . . . . 45

11 Arquitetura de um nó genérico . . . . . . . . . . . . . 46

12 Topologias de redes diretas: Malha n-dimensional (a), Toroide 2D (b), Cubo 3D (c), Hipercubo (d) e Totalmente conectada (e) . . . . . . . . . . . . . . 47

13 Rede Indireta com Topologia Irregular . . . . . . . . . . . . . . . . . 47

14 Topologias Irregulares formadas pelo posicionamento de módulos de processamento sobre uma rede regular direta com topologia de malha bidimensional . . 48

15 Exemplo de uma configuração de deadlock. . . . . . . . . . . . . . . . . . 49 
16 Exemplo de transmissão de um pacote com o mecanismo Store-and-Forward. . 52

17 Virtual Cut-Through Switching . . . . . . . . . . . . 53

18 Exemplo de transmissão de um pacote com o mecanismo Wormhole Switching. 54

19 Exemplo de transmissão de pacotes utilizando Canais Virtuais. . . . . . . . . . 54

20 Interface de Comunicação do DyNoC . . . . . . . . . . . . . . . . 58

21 Exemplo de alocação de componentes na DyNoC . . . . . . . . . . . . . . 58

22 Estrutura Malha do CoNoChi. . . . . . . . . . . . . . . . . . 60

23 Exemplo de reconfiguração dinâmica no CoNoChi. . . . . . . . . . . . . . . 61

24 Estrutura do CuNoC conformada por UCs. . . . . . . . . . . . . . . 63

25 Fases de Configuração do CuNoC. . . . . . . . . . . . . . . . . . 63

26 Reconfiguração Dinâmica de módulos no CuNoC. . . . . . . . . . . . . . . . . 64

27 Posicionamento dinâmico de módulos no QNoC. . . . . . . . . . . . . . 65

28 Arquitetura de uma rede de submalhas hierárquicas. . . . . . . . . . . . . 67

29 Exemplos de topologias FDOR. . . . . . . . . . . . . . . . . 74

30 Exemplos de Transmissão de pacotes de ala para núcleo em topologias irregulares FDOR gerando linhas de congestionamento. . . . . . . . . . . . . . 76

31 Exemplos de Transmissão de pacotes de núcleo para as alas em topologias irregulares FDOR. . . . . . . . . . . . . . . 77

32 Esquemático do circuito lógico do algoritmo FDOR em um roteador para seleção de portos de saída. . . . . . . . . . . . . . . . . . . . . 78

33 Lógica AFDOR . . . . . . . . . . . . . . . . . . . . . . . 79

34 Funcionamento da lógica externa e a propagação dos sinais $\mathrm{Pci} / \mathrm{Pco}$ e $\mathrm{Cri} / \mathrm{Cro}$ (setas sólidas e pontilhadas, respectivamente) . . . . . . . . . . . . . 81 
35 Algumas topologias permitidas pela lógica AFDOR. . . . . . . . . . . . 82

36 Estrutura de malhas bidimensionais . . . . . . . . . . . . . . . . 84

37 Exemplo de Posicionamento de MPs sobre a estrutura de malha 2-D da DyAF-

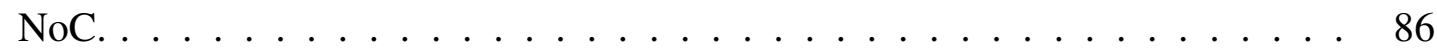

38 Sistema de Controle Reconfiguração de Malha (MRCS) baseado em TSR. . . . 87

39 Diferentes contextos que compõem um DRS indicando a ordem em que serão configurados sobre o dispositivo FPGA. . . . . . . . . . . . . . . . 90

40 Diagrama de tempo do DRS da aplicação de exemplo baseado em DyAFNoC com todas suas etapas envolvidas. . . . . . . . . . . . . . . . . 93

41 Exemplo de Regiões Reconfiguráveis (RR) com chaves de isolação posicionadas nos portos locais dos roteadores dentro de seus limites. . . . . . . . . . . . 97

42 Diagrama de blocos do Módulo de Controle de Chaves de Isolação para dois cenários diferentes. . . . . . . . . . . . . . . . . . . . . . 999

43 Diagrama de blocos do PDRCS indicando os 5 passos de execução. . . . . . . . 100

44 Diagrama do Processo de Geração do código VHDL de DyAFNoC utilizando a ferramenta baseada em MATLAB® . . . . . . . . . . . . . . . . . 102

45 Diagrama de tempo de um DRS baseado em DyAFNoC com todas as etapas implicadas.

46 Posicionamento das chaves de isolação sobre a rede indicando as regiões reconfiguráveis e seus cenários. . . . . . . . . . . . . . . . . . . . 106

47 Simulação do primeiro contexto imediatamente depois da inicialização do sistema.107

48 Simulação do primeiro contexto apresentando a quantidade de pacotes enviados pelos MPs fonte. 
49 Simulação do primeiro contexto quando os MPs S1, S2 e D3 terminam suas tarefas ativando os sinais task_done respectivos. . . . . . . . . . . . . . . 109

50 Formas de Onda Resultantes da Simulação do DyAFNoC . . . . . . . . . . . . 110

51 Simulação da reconfiguração parcial dinâmica das regiões reconfiguráveis RR1 e RR2 para implementar o módulo multiplicador x4.

52 Simulação de uma reconfiguração parcial dinâmica enquanto que os pacotes estão sendo transmitidos na rede.

53 Estrutura Hierárquica da NoC de $3 \times 3$ formada pelo Noxim. . . . . . . . . . . . 114

54 Topologias irregulares permitidas pelo algoritmo FDOR. . . . . . . . . . . . 118

55 Latência Média vs. Taxa de Injeção, para as topologias irregulares para uma malha 2-D de $8 \times 8$.

56 Throughput Médio vs. Taxa de Injeção, para as topologias irregulares para uma malha 2-D de $8 \times 8$. .

57 Latência Máxima vs. Taxa de Injeção, para as topologias irregulares para uma malha 2 -D de $8 \times 8$.

58 Topologias irregulares permitidas pelo algoritmo FDOR para uma malha 2-D de $12 \times 12$.

59 Latência Média vs. Taxa de Injeção, para as topologias irregulares para uma malha $2-\mathrm{D}$ de $12 \mathrm{x} 12 \ldots \ldots \ldots \ldots \ldots$

60 Throughput Médio vs. Taxa de Injeção, para as topologias irregulares para uma malha $2-\mathrm{D}$ de $12 \times 12$

61 Latência Máxima vs. Taxa de Injeção, para as topologias irregulares para uma malha $2-\mathrm{D}$ de $12 \times 12 \ldots \ldots \ldots \ldots$. . . . . . . . . . . . . . . . . . . . .

62 Topologias irregulares permitidas pelo algoritmo FDOR com dezessete (17) MPs ativos. 
63 Latência Média vs. Taxa de Injeção, para as topologias irregulares com dezessete (17) MPs ativos para uma malha de $5 \times 5 \ldots \ldots$. . . . . . . . . . . 128

64 Throughput Médio vs. Taxa de Injeção, para as topologias irregulares com dezessete (17) MPs ativos para uma malha de 5x5.

65 Latência Máxima vs. Taxa de Injeção, para as topologias irregulares com dezessete (17) MPs ativos para uma malha de 5x5 . . . . . . . . . . . . . . . . . 129

66 Mudança de contextos por reconfiguração parcial dinâmica para dois casos . . 132

67 Resultados de Latência Média vs. Taxa de Injeção. . . . . . . . . . . . . . . . 133

68 Resultados de Throughput Médio vs. Taxa de Injeção. . . . . . . . . . . . . . . . 133

69 Gráfico Comparativo dos resultados de síntese para o roteador de 5 portos, o módulo PDRCS e o MRCS nos casos 5x5, 8x8 e 12x12 . . . . . . . . . . . 136

70 Arquitetura de uma rede de submalhas hierárquicas. . . . . . . . . . . . . . . . . 140

71 Simulação da implementação do módulo multiplicador a partir do processo de reconfiguração da malha com o novo mapa de configuração e o processo de reconfiguração parcial dinâmica do módulo multiplicador x2 . . . . . . . . . . . 148

72 Simulação do envio e transmissão de pacotes a partir dos MPs fonte (Sx2 e Sx4) até os portos locais dos módulos multiplicadores x 2 e x4 respectivamente. . . . 148

73 Formas de onda das simulações. . . . . . . . . . . . . . . . . . . . . . . . 149

74 Resultados de Forma de Onda. . . . . . . . . . . . . . . . . . . . . . 150

75 Topologias irregulares permitidas pelo algoritmo FDOR com dezenove (19) MPs ativos. . . . . . . . . . . . . . . . . . 152

76 Latência Média vs. Taxa de Injeção, para as topologias irregulares com dezenove (19) MPs ativos para uma malha de 5x5 . . . . . . . . . . . . . . . 153 
77 Throughput vs. Taxa de Injeção, para as topologias irregulares com dezenove MPs (19) ativos para uma malha de 5 x5 . . . . . . . . . . . . . . . 153

78 Latência Máxima vs. Taxa de Injeção, para as topologias irregulares com dezenove (19) MPs ativos para uma malha de $5 \times 5 \ldots$. . . . . . . . . . . . 154

79 Latência Média vs. Taxa de Injeção, para as topologias irregulares com dezenove (19) MPs ativos para uma malha de $5 \times 5$ no intervalo de $[0 ; 0,4]$ flits/ciclos para taxa de injeção . . . . . . . . . . . . . . . . . . . . . 155

80 Latência Máxima vs. Taxa de Injeção, para as topologias irregulares com dezenove (19) MPs ativos para uma malha de 5x5 no intervalo de $[0 ; 0,4] \ldots 155$ 


\section{LISTA DE TABELAS}

1 Tabela de Verdade da Chave de Isolação . . . . . . . . . . . . . . . . . . . 39

2 Tabela de Características dos Portos de Configuração dos FPGAs da Xilinx. . 40

3 Resultados da síntese do QNoC em Virtex IV . . . . . . . . . . . . . . 66

4 Tabela Comparativa dos Trabalhos Prévios . . . . . . . . . . . . . 71

5 Tabela de Resultados de Síntese da arquitetura de DyAFNoC para os casos 5x5, 8 x8 e $12 x 12$ sobre o dispositivo Virtex-6. . . . . . . . . . . . . 135

6 Tabela de Resultados de Síntese para o MRCS (5x5, 8x8 e 12x12), PDRCS e o Roteador de 5 portos no dispositivo Virtex-6 . . . . . . . . . . . . . 135 


\title{
LISTA DE ABREVIATURAS E SIGLAS
}

\author{
AFDOR Automatic FDOR \\ ASIC Application Specific Integrated Circuit \\ CLB Configurable Logic Blocks \\ CoNoChi Configurable Network on-Chip \\ CUDA Compute Unified Device Architecture \\ CUgw To-give-away $C U$ \\ CuNoC Comunication Unit Network on-Chip \\ DBPR Difference Based Partial Reconfiguration \\ DCM Digital Clock Manager \\ DCS Dynamic Circuit Switching \\ DRFPGA Dynamically Reconfigurable Field Programmable Gate Array \\ DRS Dynamically Reconfigurable System \\ DyNoC Dynamic Network on-Chip \\ E2PROM Electrical Erasable Programmable Read-Only Memory \\ EP Elemento de Processamento \\ EPROM Electrically Programmable ROM \\ EPUSP Escola Politécnica da Universidade de São Paulo \\ FDOR Flexible Dimension Order Routing \\ FFT Fast Fourier Transform
}


FLIT Flow control unIT

FPGA Field Programmable Gate Array

FSM Finite State Machine

GPU Graphic Processing Unit

GSEIS Grupo de Projeto de Sistemas Eletrônicos Integrados e Software Aplicado

ICAP Internal Configuration Access Point

IOB Input/Output Block

ISE Integrated Software Enviroment

JTAG Joint Test Action Group

LBDR Logic-Based Distributed Routing

LME Laboratório de Microeletrônica

LRS Least Recently Served

LS Leaving Switch

LUT Look-Up Table

MJT Magnetic Tunnel Junction

MP Módulo de Processamento

MPSoC Multi-Processor System on-Chip

MRAM Magnetic RAM

NoC Network on-Chip

OSR Overlaped Static Reconfiguration

PUCRS Pontifícia Universidade Católica de Rio Grande do Sul 
RCC

RIT

ROM Read Only Memory

RR Reconfigurable Region

RTR Run-Time Reconfiguration

SAF $\quad$ Store and Forward

SoC System on-Chip

SRAM Static Random Access Memory

TSR

TSR

$\mathrm{UC}$

USP

VCT

VHDL
Table-Based Routing

Traditional Static Reconfiguration

Unidade de Comunicação

Universidade de São Paulo

Virtual Cut-Through

Very High Speed Integrated Circuit Hardware Description Language 


\section{SUMÁRIO}

1 Introdução $\quad 20$

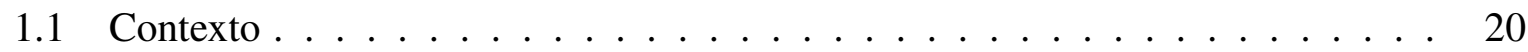

1.2 Motivação . . . . . . . . . . . . . . . . . . . . . 23

1.3 Justificativas . . . . . . . . . . . . . . . . . . . . . . . . . . . 29

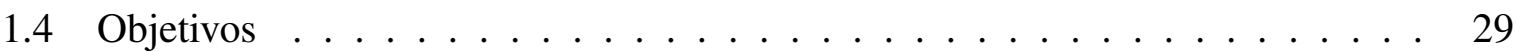

1.5 Organização da Dissertação . . . . . . . . . . . . . . . . . . . . . . . 31

2 Fundamentos Teóricos 32

2.1 Princípios Teóricos de Sistemas Dinamicamente Reconfiguráveis . . . . . . . . 32

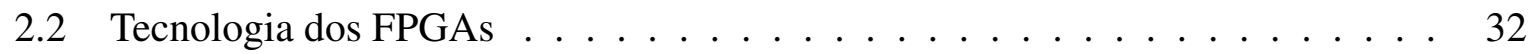

2.3 Reconfiguração Dinâmica . . . . . . . . . . . . . . . . . . . . . . . . . 34

2.3.1 Dispositivos Dinamicamente Reconfiguráveis . . . . . . . . . . . . . 36

2.3.2 Metodologia de Simulação de Sistemas Reconfiguráveis . . . . . . . 38

2.3.3 Tempos de Reconfiguração . . . . . . . . . . . . . . . . . . . . . . . . 39

2.4 Redes Intrachip . . . . . . . . . . . . . . . . . . . . . . . . 42

2.4.1 Topologia de Redes . . . . . . . . . . . . . . . . . . . . . . . . . . 44

2.4.1.1 Redes Diretas . . . . . . . . . . . . . . . . . 44

2.4.1.2 Redes Indiretas . . . . . . . . . . . . . . . . 46

2.4.2 Algoritmos de Roteamento - Routing . . . . . . . . . . . . . . 48

2.4.3 Mecanismos de Chaveamento - Switching . . . . . . . . . . . 51 
2.4 .4 Controle de Fluxo $\ldots \ldots \ldots \ldots 5$

2.4.5 Avaliação de Desempenho . . . . . . . . . . . . . . . . 55

2.4.5.1 Latência . . . . . . . . . . . . . . 55

2.4.5.2 Throughput ................... 56

3 Trabalhos Prévios $\quad 57$

3.1 Principais propostas de DRNoCs . . . . . . . . . . . . 57

3.1.1 Proposta de Bobda et al - DyNoC . . . . . . . . . . . 57

3.1.2 Proposta de Pionteck et al - CoNoChi . . . . . . . . . . . . 59

3.1.3 Proposta de Jovanovic et al - CuNoC . . . . . . . . . . . . 61

3.1.4 Proposta de Jovanovic et al - QNoC . . . . . . . . . . . . . . . 64

3.1.5 Proposta de Miorandi et al . . . . . . . . . . . . . . 66

3.2 Análise e Estudo do Comparativo das DRNoCs . . . . . . . . . . . . . 67

3.3 Algoritmos de Roteamento . . . . . . . . . . . . . . . . . . 69

4 Algoritmo de Roteamento Ordenado por Dimensão Flexibilizado 72

4.1 Fundamentos do Algoritmo . . . . . . . . . . . . . . . . . 72

4.2 Distribuição de tráfego com o Algoritmo FDOR . . . . . . . . . . . . . 75

4.3 Implementação do Algoritmo FDOR . . . . . . . . . . . . . . . . 77

4.4 Implementação da Lógica

FDOR Automática $($ AFDOR $) \ldots \ldots \ldots \ldots$. . . . . . . . . . . . . . . .

5 DyAFNoC: Dynamic AFDOR-Based Network on-Chip 83

5.1 Estrutura da malha de roteadores . . . . . . . . . . . . 83 
5.2 Sistema de Controle de Reconfiguração de Malha . . . . . . . . . . . . . . . 86

5.3 Sistema de Controle de Reconfiguração Parcial Dinâmica (PDRCS) . . . . . . 88

5.3.1 Funcionamento no domínio de tempo de DyAFNoC . . . . . . . . . 89

5.3.1.1 Elementos de um Contexto . . . . . . . . . . . . 89

5.3.1.2 Sequências de Contextos . . . . . . . . . . . 92

5.3.2 Posicionamento de Chaves de Isolação sobre a Rede . . . . . . . . . . 96

5.3 .3 Arquitetura do PDRCS . . . . . . . . . . . . . . . . . 98

5.4 Fluxo de Projeto . . . . . . . . . . . . . . . . . . . . . 101

6 Simulações e Resultados $\quad 104$

6.1 Simulações e Análise Comportamental do DyAFNoC . . . . . . . . . . . . . . 104

6.2 Análise de Desempenho . . . . . . . . . . . . . . . . . . . . 112

6.2 .1 Simulador Noxim . . . . . . . . . . . . . . . . . . 113

6.2.2 Modificações do Simulador Noxim para a implementação do algoritmo

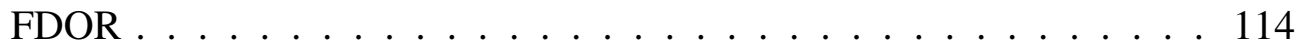

6.3 Avaliação dos Resultados das Simulações Utilizando a Ferramenta Noxim Ex-

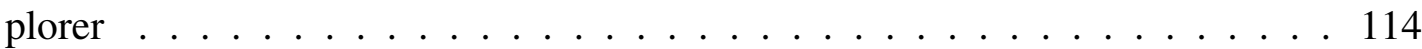

6.3.1 Avaliação de desempenho baseado na topologia irregular da rede . . . . 115

6.3.1.1 Análise para uma Malha 2-D de 8x8 . . . . . . . . . 117

6.3.1.2 Análise para uma Malha 2-D de 12x12 . . . . . . . . . . 122

6.3.1.3 Análise para uma Malha 2-D de 5x5 . . . . . . . . . . 126

6.3.2 Efeitos de posicionamento de módulos no desempenho da DRNoC . . . 130

6.4 Resultados da Síntese da Arquitetura da estrutura de DyAFNoC . . . . . . . 134 
8 Trabalhos Futuros $\quad 140$

Referências $\quad 142$

Apêndice A - Simulações do Comportamento de DyAFNoC

Apêndice B - Malha 5x5 com dezenove MPs 


\section{INTRODUÇÃO}

\subsection{Contexto}

Neste primeiro capítulo serão apresentados o contexto e as distintas justificativas sobre a necessidade e a viabilidade para desenvolver um Sistema Dinamicamente Reconfigurável baseado em Redes Intrachip. Além disso, são detalhados a motivação, as justificativas e os objetivos do trabalho a ser realizado.

Os constantes avanços nas tecnologias de fabricação em Microeletrônica têm permitido a construção de transistores com dimensões cada vez menores, o que permite um maior aproveitamento da área de silício, com maior quantidade de blocos de processamento (digitais ou analógicos) numa mesma área do chip.

As crescentes demandas do mercado de tecnologia obrigam aos fabricantes a criarem novas aplicações de complexidade crescente, exigindo dispositivos que sejam capazes de acomodar cada vez uma maior quantidade de funcionalidades. Isto levou aos projetistas a colocarem diferentes blocos de processamento complexos em uma só área de silício ou chip, conhecidos como Sistema-sobre-Silício (SoC do inglês, System on-Chip).

À medida que a quantidade de blocos de processamento cresce dentro dos chips, a transmissão de dados entre eles torna-se mais complexa. Para atender a este problema, foram propostas as Redes Intrachip (NoC do inglês, Network on-Chip), que consistem num arranjo de roteadores ligados entre si, responsáveis da transmissão de dados; a eles estão conectados os blocos de processamento, onde cada um deles tem um endereço característico (ID local) que serve para identificar a fonte e o destino dos dados. 
Uma das inovações observadas na última década são os Sistemas Dinamicamente Reconfiguráveis (DRS do inglês, Dynamically Reconfigurable Systems). Seu funcionamento está estritamente relacionado com a dimensão do tempo. Cada uma das configurações em hardware apresenta certo período de funcionamento dependendo das tarefas requeridas na aplicação; ao finalizar cada fase, o dispositivo, ou uma região parcial dele, é reconfigurado, retirando-se os blocos de processamento não necessários à execução, e alocando-se os novos blocos a serem utilizados nesse período.

Uma das formas possíveis de implementação de DRSs é através de dispositivos programáveis como os Arranjos de Portas Lógicas Programáveis em Campo (FPGAs, do inglês, Field Programmable Gate Arrays), com capacidade de reconfiguração parcial em tempo de operação. Os FPGAs com esta característica são conhecidos como FPGAs Dinamicamente Reconfiguráveis (DRFPGA do inglês, Dynamically Reconfigurable Field Programmable Gate Array), já que permitem a reconfiguração de uma região parcial da área do dispositivo durante seu funcionamento.

A Figura 1 (LYSAGHT; DUNLOP, 1993) apresenta um diagrama de tempo do funcionamento de um DRS implementado num DRFPGA. Primeiramente, o dispositivo passa por um processo de configuração inicial para poder implementar a primeira configuração composta pelos módulos M1, M2, M3, M4, M5 e M6. Cada módulo executa sua respectiva tarefa na Fase 1; quando os módulos M1, M3, M4 e M5 terminarem sua tarefa o sistema é reconfigurado parcialmente para implementar os módulos M7 e M8 enquanto os outros blocos continuam com sua operação. É por isso que este processo é conhecido como reconfiguração parcial dinâmica. Este processo requer certo período de tempo para reconfigurar as células lógicas do dispositivo FPGA por meio do seu porto de reconfiguração, o qual será explicado com mais detalhes no próximo capítulo. Na Fase 2, os módulos M2, M6, M7 e M8 continuam realizando sus tarefas respectivas até o M8 terminar sua tarefa, para ser substituído pelos módulos M9 e M11 durante a reconfiguração parcial dinâmica. Também durante este processo é implementado o módulo M10 nas células lógicas que não foram utilizadas ainda, como apresentados no FPGA Floorplan da Fase 3. 
Figura 1: Diagrama de tempo do funcionamento de um DRS.

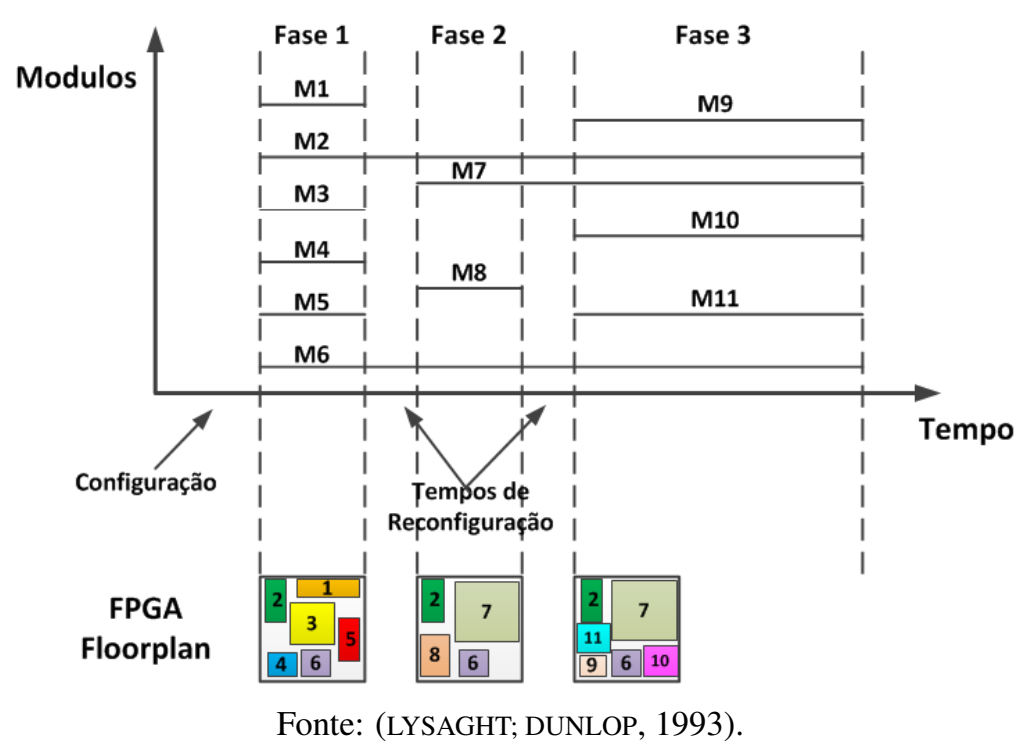

As principais vantagens da aplicação de DRS estão relacionadas com o alto nível de modularidade e flexibilidade, já que permite a implementação de uma maior quantidade de blocos de processamento sobre a mesma área de silício que os SoCs tradicionais, alterando sua configuração de acordo com as necessidades computacionais requeridas pela aplicação de destino. Outra vantagem é a redução dos recursos de hardware utilizados na implementação dos blocos de processamento, trazendo consigo, de forma geral, a redução da área de silício além do consumo de energia e potência (XILINX, 2012b). Tais propriedades dos DRSs são ilustradas na Figura 2 (XILINX, 2012b).

Figura 2: Flexibilidade de funcionalidade, Redução da área do chip e Minimização do consumo de energia e dissipação de potência.

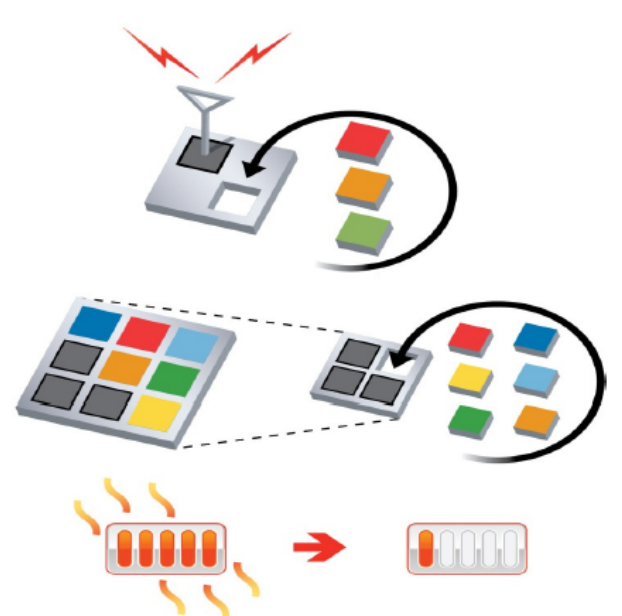

Fonte: (XILINX, 2012b). 


\subsection{Motivação}

Tradicionalmente, a forma mais comum de implementação de NoCs são as estáticas, ou seja, a sua estrutura permanece estável sem a capacidade de reconfiguração em tempo de execução. Na literatura existem diversos trabalhos sobre NoCs estáticas como: (GUERRIER; GREINER, 2000; DALLY; TOWLES, 2001; KARIM et al., 2001; KUMAR et al., 2002; KARIM; NGUYEN; DEY, 2002; MARESCAUX et al., 2002; PANDE et al., 2003; ANDRIAHANTENAINA; GREINER, 2003), onde cada uma destas arquiteturas está caraterizada por uma série de parâmetros, como topologia, mecanismo de comunicação, modo de comutação, algoritmo de roteamento, número de roteadores, desempenho em transferência de dados, etc. Todas estas características das NoCs estáticas tornam-nas infraestruturas de comunicação com muitas vantagens quando comparadas às plataformas baseadas em barramentos. Como, as NoCs estáticas são inflexíveis, já que apresentam uma estrutura estabelecida, invariável no tempo. Entretanto, a transmissão de dados dentro da rede é vulnerável a falhas, as quais podem interromper os caminhos pelos quais os dados são transmitidos, ocasionando perda de dados e deadlock. Neste caso, as NoCs estáticas poderiam possuir um algoritmo de roteamento com a propriedade de adaptabilidade, o que permitiria que a transferência de dados fosse adaptada ante mudanças na estrutura da rede ocasionadas pelas falhas. A propriedade de adaptabilidade é também aplicável para DRSs baseados em NoCs uma vez que a rede muda seus contextos em tempo de execução, modificando a estrutura da rede para dar passo a implementação de novos blocos de processamento, aproveitando-se de maneira otimizada a área de silício e ao mesmo tempo o consumo de potência.

Na literatura, existem diversas implementações de Redes Intrachip Dinamicamente Reconfiguráveis (DRNoCs do inglês, Dynamically Reconfigurable Networks on-Chip), podendo-se citar como importantes os exemplos: DyNoC (do inglês, Dynamic Network on-Chip) desenvolvido por (BOBDA; AHMADINIA, 2005; BOBDA et al., 2004) e proposta no ano 2004; CuNoC (do inglês, Comunication Unit Network on-Chip) proposto por (JOVANOVIC et al., 2007), e que foi novamente projetada para um dispositivo DRFPGA de maior envergadura (JOVANOVIC et al., 2009); QNoC que é uma versão melhorada do CuNoC proposta também por (JOVANOVIC; TA- 
NOUGAST; WEBER, 2008); CoNoChi (do inglês, Configurable Network on-Chip) desenvolvida por (PIONTECK; KOCH; ALBRECHT, 2006), e que foi novamente projetada para um dispositivo DRFPGA de maior envergadura (PIONTECK et al., 2008); e a arquitetura proposta por (RANA et al., 2010).

Na Figura 3, é apresentado um exemplo de reconfiguração dinâmica entre dois contextos em uma DRNoC, onde os blocos de processamento, ou módulos, e roteadores ocupam de forma alternada o mesmo espaço físico do dispositivo. Na primeira configuração (Figura 3a), os módulos M0, M1, M2, M3 e M4 estão posicionados junto com os roteadores, apesar de que nesta figura não fica explícito a qual roteador cada um dos processadores está ligado. Depois de realizados os respectivos processamentos de cada módulo durante certo período de tempo, o dispositivo reconfigura-se parcialmente obtendo-se a segunda configuração (Figura 3b). Observe-se que o módulo M4 foi removido para se posicionar os módulos M5 e M6, além de três roteadores associados; dá-se o nome de reconfiguração parcial já que os módulos M0, M1, M2 e M3 da primeira configuração não tiveram os seus posicionamentos alterados.

Figura 3: Exemplo de uma reconfiguração parcial dinâmica de uma NoC dinâmica com duas configurações diferentes.

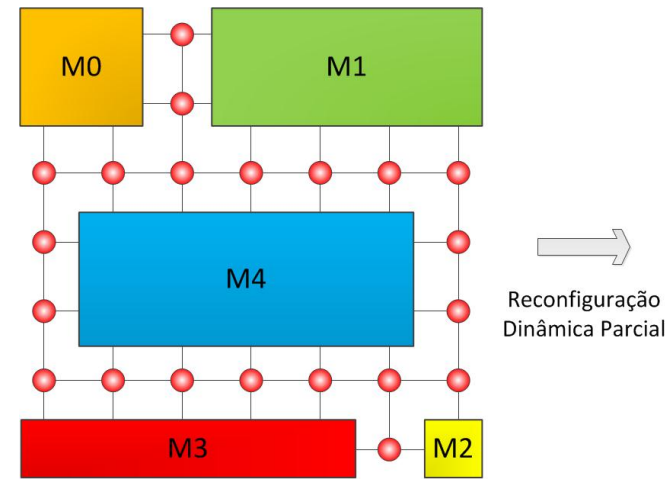

(a)

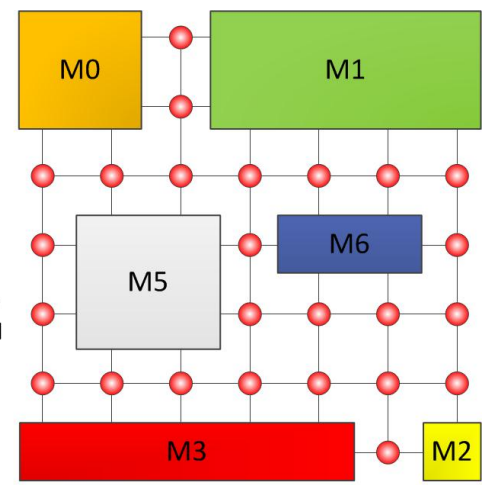

(b)

(a) Configuração 1 com Módulos M0, M1, M2, M3 e M4.

(b) Configuração 2 com Módulos M0, M1, M2, M3, M5, M6 e M7.

Fonte: (Autor, 2014).

O projeto de uma NoC para um sistema com módulos de processamento que são inseridos dinamicamente deve ter um algoritmo de roteamento capaz de adaptar-se a qualquer alteração da estrutura da NoC depois do processo de reconfiguração parcial dinâmica. Este é um aspecto funcional fundamental para DRNoCs, já que a mudança da estrutura da rede pode gerar casos de 
deadlock ${ }^{1}$ que ocasiona o travamento da circulação de pacotes, consequência de dependências cíclicas de seus caminhos na rede.

Em DRNoCs, o posicionamento dos módulos de processamento no interior da rede de topologia malha bidimensional (2-D), onde cada nó representa um roteador, influi nos caminhos que o algoritmo de roteamento escolhe para a transmissão de pacotes. Ao substituir certa quantidade de roteadores, que podem eventualmente ser restaurados em tempo posterior, surgem regiões com bloqueios (podendo impedir caminhos diretos entre pacotes que passam pelo módulo) na malha 2-D, gerando topologias irregulares onde podem ocorrer problemas de deadlock.

Assumindo o algoritmo de roteamento Surrounding-XY utilizado por (BOBDA; AHMADINIA, 2005) e uma topologia de rede malha 2-D, podem ocorrer dois tipos de configurações que geram deadlock (MIORANDI, 2012):

- Mid-Block Deadlock: ocorre quando, no percurso pela rede, os dados que estão sendo transmitidos são obrigados a realizar desvios inadequados, devido às regiões dos módulos de processamento que interrompem os caminhos de comunicação entre roteadores.

- Roundabout Deadlock: acontece quando um ciclo de dependência circunda a área ocupada por uma unidade processante.

Na Figura 4 são apresentados dois exemplos de configuração de módulos de processamento sobre uma rede malha 2-D proposta por (BOBDA; AHMADINIA, 2005), com as configurações de deadlock mencionadas anteriormente. Na Figura 4(a) um caso de Mid-Block deadlock é apresentado, com o uso do algoritmo normal de roteamento S-XY (do inglês, Surrounding XY) adotado por Bobda et al. em DyNoC (BOBDA; AHMADINIA, 2005). Pode-se observar como os caminhos dos pacotes com roteador fonte $S i$ geram caminhos até seus respectivos destinos $D i$, sendo $i$ o índice com valores $1,2,3 \& 4$. Estes caminhos geram um ciclo fechado ao redor das bordas dos quatro módulos de processamento, o qual é indicado com setas pretas. Outra situação de deadlock é o caso onde os pacotes circundam algum módulo de processamento,

\footnotetext{
${ }^{1}$ Além de ser considerado para NoCs, o deadlock deve ser considerado também para sistemas baseados em barramento.
} 
gerando um ciclo fechado ao seu redor, o qual foi chamado de Roundabout deadlock e cujo exemplo é ilustrado na Figura 4b. Pode-se observar nela também que os caminhos formados pelos pacotes com fonte $S i$ e destino $D i$, onde $i$ é o índice com valores a 1,2, $3 \& 4$, geram, indicado pelas setas pretas, um ciclo fechado ao redor do módulo de processamento amarelo.

Figura 4: Exemplo das duas configurações de deadlock num arranjo de unidades processantes sobre uma rede com topologia de malha bidimensional.

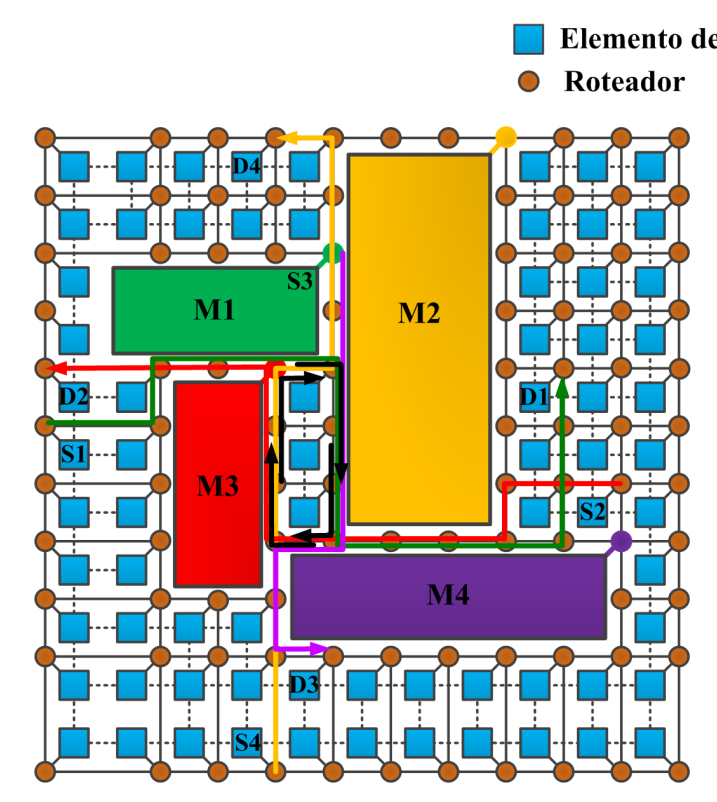

(a) Mid-block Deadlock

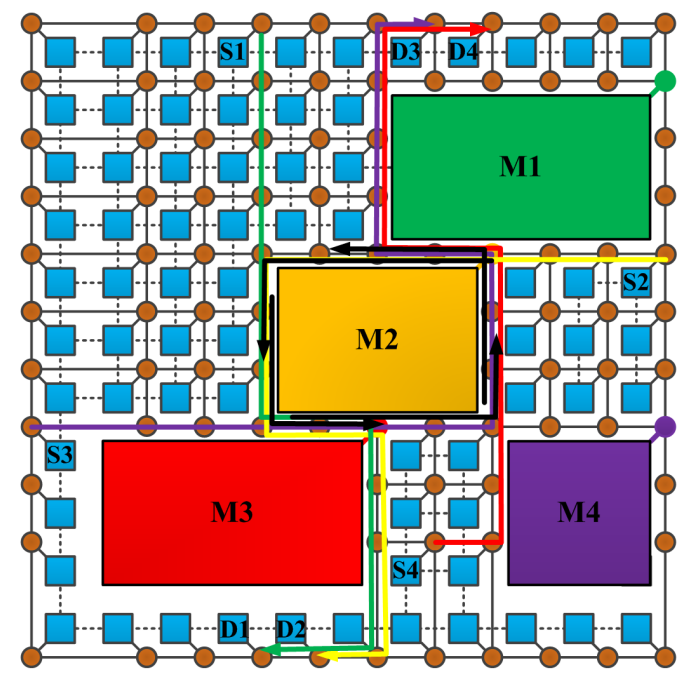

(b) Round-about Deadlock

Fonte: (Autor, 2014).

Dentro dos trabalhos da literatura sobre a arquitetura de NoCs mencionados anteriormente, diversos algoritmos de roteamento apresentam-se como deadlock-free (livre de deadlock), porém uma análise mais detalhada evidencia algumas inconsistências. Por exemplo, o trabalho de Bobda (BOBDA et al., 2004; BOBDA; AHMADINIA, 2005) apresenta uma DRNoC que utiliza estratégias de roteamento de dados baseadas no algoritmo de roteamento XY com algumas modificações para evitar os obstáculos gerados pelas módulos de processamento na rede. $\mathrm{O}$ algoritmo é denominado de "S-XY Routing"(do inglês, Surrounding XY Routing), já que o caminho dos dados é formado pelos roteadores que circundam (do inglês, surround) os módulos de processamento da configuração respectiva quando bloqueios ocorrem no caminho. De fato, o algoritmo de roteamento S-XY é livre de deadlock para os casos apresentados em (BOBDA; AHMADINIA, 2005), ou seja, evitando o surrounding na transmissão de pacotes e elegendo caminhos propositadamente longos; mas não soluciona a configuração Mid-Block Deadlock, mesmo 
utilizando canais virtuais que reduzem tal probabilidade.

Outros trabalhos como os de (JOVANOVIC et al., 2009; JOVANOVIC et al., 2007) garantem que o sistema seja livre de deadlock, porém exigindo um módulo especial, denominado de Unidade de Comunicação (do inglês Communication Unit) que executa um algoritmo de roteamento adaptativo para qualquer arranjo de módulos de processamento na rede. Além disso, a implementação deste algoritmo requer um alto custo na área do chip devido a sua alta complexidade.

Jovanovic et al. também propõe o QNoC (JOVANOVIC; TANOUGAST; WEBER, 2008), o qual utiliza um algoritmo de roteamento adaptativo livre de deadlock baseado no algoritmo do $\mathrm{Cu}$ NoC não permitindo certas viradas. O autor o chama de algoritmo MPA (do inglês, Module Proximity Algorithm). Como no caso do $\mathrm{CuNoC}$, a implementação desta estratégia requer uma alta quantidade de recursos de hardware devido a sua alta complexidade.

Outro caso, o CoNoChi (PIONTECK; KOCH; ALBRECHT, 2006) propõe um algoritmo de roteamento baseado em tabelas (TBR do inglês, Table-Based Routing), o qual garante que a rede seja deadlock-free, mas durante a reconfiguração parcial dinâmica, todas as tabelas, tanto locais como global, devem ser atualizadas para uma nova configuração. Esta não é uma solução escalável para um DRS, uma vez que cada tabela de roteamento é composta de 32 bits cada uma, expressando os endereços físicos e lógicos de cada roteador. Isto requer um alto custo de implementação em termos de espaço de área do chip (hardware) e o tempo de reconfiguração.

Outros algoritmos de roteamento livres de deadlock também são encontrados na implementação de NoCs tolerantes a falhas, com a finalidade de trocar o esquema de roteamento no caso de aparecimento de regiões com falhas dentro da rede, que implicam em interrupção de caminhos entre roteadores da rede, como os casos de MAZENOC (WACHTER; MORAES, 2012) e OSR-Lite (STRANO et al., 2012). Este último possui uma implementação baseada em Roteamento Distribuído baseado em Lógica (LBDR do inglês, Logic-Based Distributed Routing) (FLICH; DUATO, 2008), o qual permite transmitir pacotes sobre topologias irregulares em malha bidimensional de nós com menor custo de implementação, assim como maior rapidez em tempo de reconfiguração que no caso de TBR. 
A questão de se ter um algoritmo deadlock-free em uma arquitetura eficiente é tratada na proposta desenvolvida no trabalho (MIORANDI, 2012), onde uma opção de arquitetura de NoC deadlock-free que utiliza o algoritmo $\mathrm{FDOR}^{2}$ é apresentada. As características principais deste algoritmo é primeiramente ser livre de deadlock para diversas topologias irregulares baseadas em malha bidimensional. As outras características tem a ver com sua simplicidade e baixa complexidade, o qual faz que sua implementação baseada em lógica combinacional seja simples sem requerer alto custo de recursos computacionais expressados no espaço na área do chip. Finalmente, por ser uma implementação baseada em lógica combinacional, o tempo de atualização da configuração do esquema de roteamento só depende do tempo em que a rede fique disponível para aplicar a nova configuração, isto será mais detalhado no Capítulo 4.

A base desta dissertação será a rede desenvolvida por (MIORANDI, 2012) cuja arquitetura está baseada na rede HERMES (MORAES et al., 2004) desenvolvida na Pontifícia Universidade Católica de Rio Grande do Sul (PUCRS). A estrutura da rede é baseada em quatro submalhas hierárquicas interligadas por meio de roteadores hierárquicos. Cada submalha tem um sistema de controle de reconfiguração do algoritmo de roteamento baseado na lógica FDOR. Apesar da implementação dos roteadores com o algoritmo FDOR, a estratégia de reconfiguração parcial dinâmica do sistema não foi desenvolvida, assim como as características das possíveis topologias permitidas pelo algoritmo FDOR que não foram exploradas.

Então, o propósito desta dissertação será desenvolver, implementar e testar o sistema de reconfiguração parcial dinâmica para uma malha da DRNoC proposta por Miorandi et al. que possa ser utilizado junto com o sistema de controle de reconfiguração ${ }^{3}$ dos roteadores. A ideia é que resulte em uma plataforma com todas as características de um DRS para aplicações de alta envergadura, onde o uso de uma NoC seja justificável para atingir os requisitos de comunicação entre os módulos de processamento.

\footnotetext{
${ }^{2} \mathrm{O}$ conceito de FDOR será explicado na Capítulo 4.

${ }^{3}$ Este sistema refere-se ao sistema que configura os roteadores, indicando se eles devem ser utilizados como roteadores ou devem estar desativados, assim como o algoritmo DOR respectivo.
} 


\subsection{Justificativas}

O presente trabalho faz parte das contribuições científicas do Grupo de Projeto de Sistemas Eletrônicos Integrados e Software Aplicado (GSEIS) do Laboratório de Microeletrônica (LME) da Universidade de São Paulo (USP) na área de metodologias de projeto de sistemas digitais, principalmente no desenvolvimento de núcleos e sistemas dinamicamente reconfiguráveis. As principais contribuições do grupo têm sido o desenvolvimento de metodologias e ferramentas de projeto. Em termos de metodologias de reconfiguração dinâmica, vários trabalhos foram realizados como (QUILICI, 2006) com ênfase em particionamento temporal de circuitos; (ESQUIAGOLA, 2006) e (KOJIMA, 2007) sobre a implementação de um DRS para um controlador de Bluetooth; e (FILHO, 2010) sobre a implementação e simulação de DRSs utilizando a técnica de chaveamento dinâmico de circuitos (LYSAGHT; STOCKWOOD, 1996). Outros trabalhos desenvolvidos na área de reconfiguração dinâmica focaram NoCs, como por exemplo, o desenvolvimento de uma ferramenta para posicionamento automático de módulos que compõem um DRS, considerando restrições reais do dispositivo e da metodologia Early Access (RAFFO, 2010; RAFFO et al., 2010).

\subsection{Objetivos}

O objetivo geral do presente trabalho é desenvolver uma arquitetura dinamicamente reconfigurável baseado em uma Rede Intrachip, com um algoritmo garantidamente deadlock-free e eficiente em termos de tempo de reconfiguração e consumo de recursos de hardware como o FDOR. Tal algoritmo poderá ser utilizada para múltiplas plataformas e aplicações, onde o uso de uma DRNoC seja justificável para seus requerimentos de desempenho na comunicação entre os Elementos de Processamento.

Este trabalho prevê o atendimento dos seguintes objetivos específicos:

- Desenvolver e projetar (em VHDL) um Sistema de Controle de Reconfiguração Parcial Dinâmica que possa ser utilizado junto com o Sistema de Reconfiguração baseado no 
algoritmo FDOR para a NoC desenvolvida no trabalho (MIORANDI, 2012);

- Desenvolver e projetar uma ferramenta para a geração automática da arquitetura da DRNoC descrita em VHDL junto com seus respectivos testbenches, com a finalidade de verificar e simular o comportamento de um DRS, baseado na técnica de simulação de Chaveamento Dinâmico de Circuitos utilizando chaves de isolação. A descrição em VHDL da arquitetura da rede é obtida a partir de determinados parâmetros como: as dimensões da rede, o posicionamento dos módulos de processamento sobre a malha 2-D e a localização das regiões parcialmente reconfiguráveis, onde deve-se efetivar a reconfiguração parcial dinâmica para a geração da nova configuração;

- Simular e testar a DRNoC composta pelo Sistema de Controle de Reconfiguração Parcial Dinâmica, e demais blocos VHDL; elementos processantes simples como módulos aritméticos serão utilizados uma vez que o objetivo é validar a funcionalidade da DRNoC nos processos de reconfiguração parcial dinâmica;

- Avaliar o desempenho da DRNoC implementada com algoritmo FDOR em diferentes cenários de configuração; métricas como latência (média e máxima) e throughput devem ser utilizadas para avaliar de forma comparativa a transmissão de dados entre os elementos processantes;

- Avaliar a importância do posicionamento de módulos processantes dentro de uma topologia de rede da DRNoC implementada com algoritmo FDOR, através de medidas de desempenho;

- Demostrar em base aos resultados de síntese da arquitetura do Sistema de Reconfiguração baseada no algoritmo FDOR e do Sistema de Reconfiguração Parcial Dinâmica, que a estratégia adotada é uma solução adequada para DRNoCs em termos de área e de recursos de hardware utilizados na sua implementação. 


\subsection{Organização da Dissertação}

Capítulo 2: Fundamentos Teóricos, apresenta os conceitos de Redes Intrachip, Sistemas Dinamicamente Reconfiguráveis, algoritmos de roteamento, etc., que serão necessários no decorrer da dissertação.

Capítulo 3: Trabalhos Relacionados, apresenta o estado da arte nas pesquisas sobre DRNoCs que têm relação estreita com este trabalho de dissertação, especificamente sobre o algoritmo de roteamento utilizado.

Capítulo 4: Flexible Dimension Order Routing, apresenta as definições principais relacionadas com o algoritmo de roteamento FDOR, como suas regras, topologias permitidas e não permitidas e sua implementação utilizando lógica combinacional.

Capítulo 5: DyAFNoC: Dynamic AFDOR-Based Network on-Chip, onde descreve-se o sistema da DRNoC desenvolvida para esta dissertação, a qual é composta da rede com topologia de malha bidimensional, o sistema de reconfiguração baseado na lógica FDOR e o sistema de controle de reconfiguração parcial dinâmica.

Capítulo 6: Simulações e Resultados, apresenta os resultados das simulações no nível RTL do DyAFNoC, validando-se o comportamento desejado das arquiteturas dos sistemas que o compõem. Também são apresentadas as simulações em alto nível do sistema para analisar o desempenho da arquitetura para diferentes topologias irregulares permitidas pelo algoritmo FDOR e o desempenho para um caso de reconfiguração parcial dinâmica. Finalmente, os resultados de síntese da arquitetura da DRNoC sobre a família Virtex 6 de FPGAs da Xilinx são apresentados.

Capítulo 7: Conclusões, apresentam as principais conclusões da dissertação.

Capítulo 8: Trabalhos Futuros, são propostos trabalhos de continuidade de pesquisa sobre os tópicos tratados nesta dissertação. 


\section{FUNDAMENTOS TEÓRICOS}

\subsection{Princípios Teóricos de Sistemas Dinamicamente Reconfi- guráveis}

Dispositivos complexos configuráveis surgiram como uma forma intermediária entre os Circuitos Integrados de Aplicação Específica (ASICs do inglês, Application Specific Integrated Circuits) e processadores, permitindo ao usuário a alteração do hardware (portanto, da aplicação) na mesma área de um Circuito Integrado (CI). Os Arranjos de Portas Programáveis em Campo (FPGAs, do inglês Field Programmable Gate-Arrays)(OLDFIELD; DORF, 1994) são compostos de arranjos de elementos lógicos conectados por elementos programáveis de roteamento. Inicialmente, utilizados como protótipos em projeto de ASICs, a partir da metade dos anos 90, passou a ser uma alternativa de implementação de aplicações em CIs colocados no mercado. A tecnologia FPGA propõe uma solução que alcança um desempenho potencialmente maior que os microprocessadores mantendo ao mesmo tempo um elevado nível de flexibilidade, superando as limitações dos ASICs (HAUCK, 1998).

\subsection{Tecnologia dos FPGAs}

A maioria dos FPGAs é baseada no uso de células de configuração de tecnologia de Memória de Acesso Aleatório Estático (SRAM, do inglês, Static Random Access Memory) podendo ser configurado quantas vezes o projetista desejar, permitindo que novos projetos possam ser implementados e testados rapidamente. Porém, os dispositivos baseados nesta tecnologia apresentam volatilidade de dados, tendo que ser reconfigurados cada vez que o sistema é ligado, o 
que leva à necessidade de se usar um dispositivo de memória externa (tipo EPROM) para fazer a configuração inicial (MAXFIELD, 2004).

Para superar esta limitação, nos últimos anos foram desenvolvidas novas tecnologias para obter FPGA não-voláteis, como E2PROM (acrônimo do inglês, Electrical Erasable Programmable Read-Only Memory) e Flash, semelhantes à tecnologia SRAM com respeito à possibilidade dos dispositivos serem reconfigurados novamente. Outra tecnologia não-volátil para FPGAS, são aqueles baseados em memória RAM magnética (MRAM do inglês, Magnetic RAM) (ZHAO et al., 2007; ZHAO et al., 2006), os quais permitem armazenar dados em células de memoria magnéticas baseadas em MJTs (do inglês, Magnetic Tunnel Junction). Tais estruturas permitem que os dados de configuração permaneçam no dispositivo mesmo sem alimentação elétrica. Por outro lado também existem os dispositivos baseados em tecnologia anti-fuse, a qual também é não volátil, mas não é reconfigurável, isto é, o dispositivo pode ser configurado apenas uma única vez, permanecendo com a sua configuração original inalterável (MAXFIELD, 2004).

De acordo com estes conceitos, (LYSAGHT; DUNLOP, 1993) propõem uma nomenclatura para os tipos de configuração dos FPGAs classificando-os como indicando na Figura 5 (LYSAGHT; DUNLOP, 1993). Todos os dispositivos FPGAs são definidos como programáveis, mas aqueles de tecnologia anti-fuse não podem ser chamados de reconfiguráveis. Os FPGAs de tecnologias E2PROM, Flash ou SRAM são definidos como reconfiguráveis pelas definições descritas anteriormente.

Figura 5: Classificação dos FPGAS baseado na capacidade de configuração

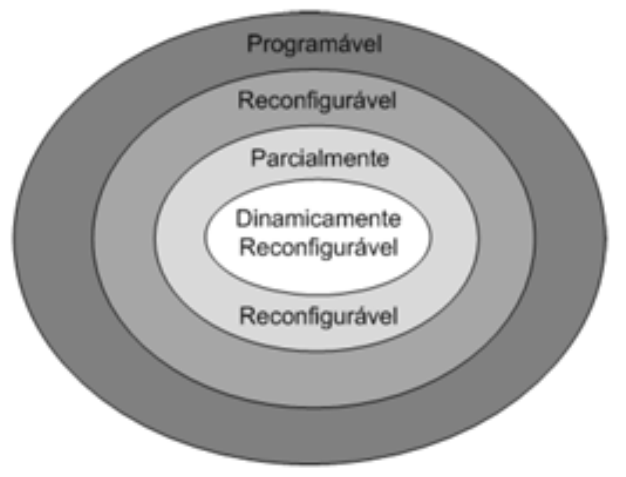

Fonte: (LYSAGHT; DUNLOP, 1993). 
Por outro lado, alguns FPGAs baseados em tecnologia SRAM têm capacidade de serem parcialmente reconfiguráveis, isto é, só algumas regiões do dispositivo FPGA escolhidas pelo projetista serão reconfiguradas enquanto as outras regiões do dispositivo retêm a configuração anterior. Finalmente, a maior capacidade de reconfiguração dos FPGAs é ser dinamicamente reconfigurável, onde qualquer região do dispositivo, pode ser reconfigurada "on-line", enquanto que as regiões restantes do dispositivo continuam operando sem interrupção com a mesma configuração ${ }^{4}$.

\subsection{Reconfiguração Dinâmica}

A estratégia de reconfiguração dinâmica é motivada por duas situações que podem ocorrer num dispositivo FPGA:

- A presença de módulos de hardware inativos ou não mais utilizáveis da arquitetura configurada no FPGA (localidade temporal);

- Uma determinada aplicação necessitar hardware maior do que os recursos disponíveis no FPGA para a sua implementação (localidade funcional).

De acordo com (ZHANG; NG, 2000), outros termos utilizados para reconfiguração dinâmica são: reconfiguração em tempo de execução (RTR, do inglês, Run-Time Reconfiguration), reconfiguração "on-line"(em inglês, on-line reconfiguration), hardware virtual (em inglês, virtual hardware), sendo mais comummente utilizado o termo de RTR.

Nesta dissertação será utilizado o termo reconfiguração parcial dinâmica, devido a que se reconfigurará uma certa região específica do FPGA durante o tempo de operação do sistema (RTR). Na Figura 6 (LYSAGHT; STOCKWOOD, 1996) se apresenta o processo de reconfiguração parcial dinâmica sobre um FPGA. Consistem, respectivamente, das células que representam blocos em funcionamento ou lógica ativa (quadradinhos azuis); as células que já foram parte da

\footnotetext{
${ }^{4}$ Em muitos contextos, os termos reconfiguração parcial e reconfiguração dinâmica são utilizados indistintamente, porém, neste texto consideramo-los diferentes, pois a reconfiguração parcial poderia ser tanto estática como dinâmica.
} 
lógica ativa, porém que não estão mais realizando um processamento, conhecidos como lógica inativa (quadradinhos laranjas); e a lógica não utilizada, isto é, aquela que não foi configurada quando foi inicializado o dispositivo FPGA, porém pode ser utilizada no futuro. O processo de reconfiguração parcial dinâmica ocorre quando a lógica inativa ou a não utilizada é substituída por uma nova configuração de lógica ativa contida na memória de configuração do sistema. Este processo ocorre por sua vez com o processamento dos circuitos implementados na lógica ativa, sem interrompê-la. Depois deste processo, uma nova configuração fica em funcionamento sobre o FPGA executando suas respectivas tarefas. Como uma aplicação pode requerer mais de um processo de reconfiguração, então o dispositivo conterá diferentes configurações as quais são conhecidas como contextos.

Figura 6: Processo de Reconfiguração Dinâmica de células lógicas de um DRFPGA

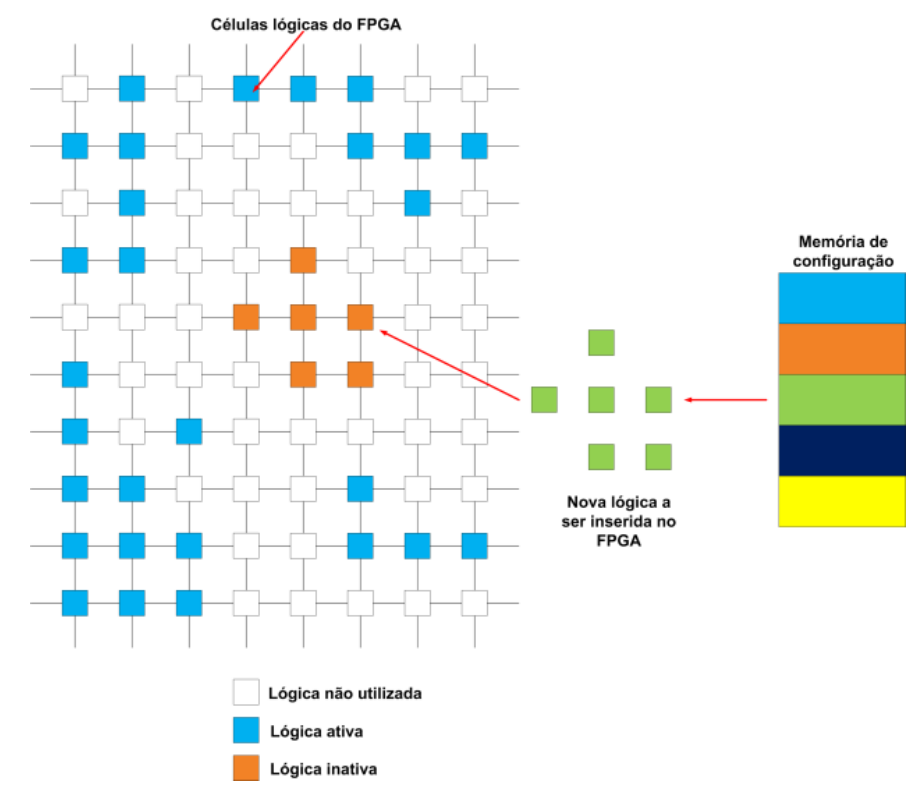

Fonte: (LYSAGHT; STOCKWOOD, 1996).

Como já foi mencionado, a reconfiguração dinâmica está ligada diretamente com o espaço temporal. Na Figura 7 (KOJIMA, 2007) um gráfico do RTR de um DRS implementado sobre DRFPGA é apresentado. Os eixos x e y representam o plano de posicionamento dos módulos funcionais formando os diferentes contextos ou configurações no tempo, as quais são sequenciadas ao longo do eixo z. 
Figura 7: Gráfico de Reconfiguração Dinâmica sobre um DRFPGA.

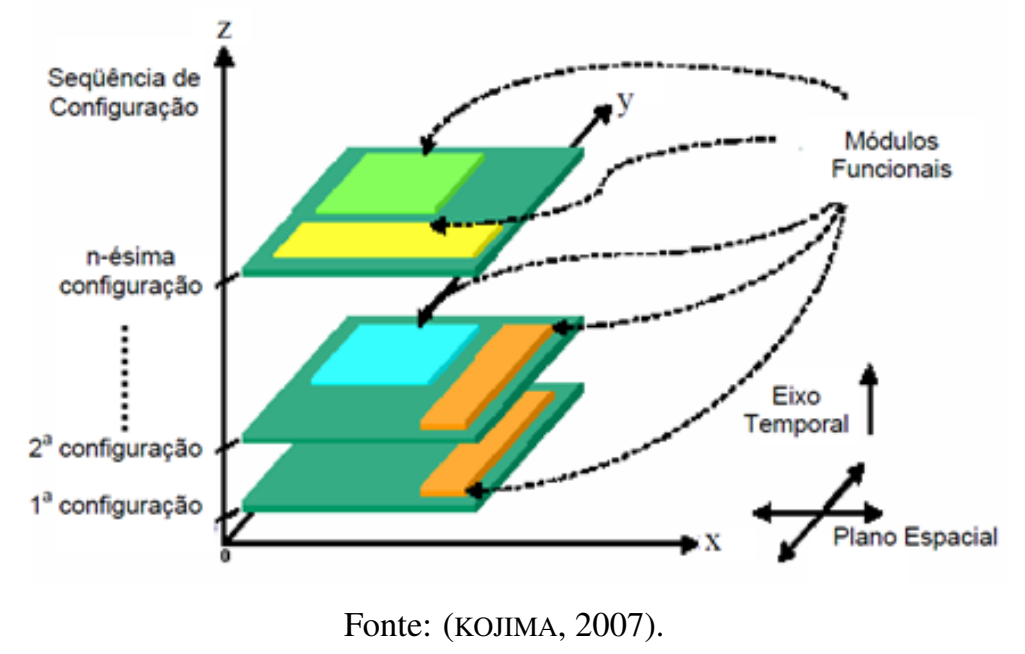

\subsubsection{Dispositivos Dinamicamente Reconfiguráveis}

Nos últimos anos a pesquisa na área mostrou um grande avanço, criando-se novas ferramentas para projeto de DRS assim como novas arquiteturas, iniciativa promovida especialmente pela Xilinx, sendo a primeira a única que oferece dispositivos de grande porte para este fim, como as famílias de dispositivos Virtex®-4, Virtex-5, Virtex-6, Artix ${ }^{\mathrm{TM}}-7$, Kintex ${ }^{\mathrm{TM}}-7$, Virtex-7, e

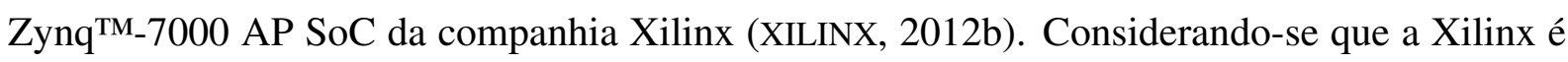
aquela mais antiga e que mais investiu na pesquisa sobre reconfiguração dinâmica, a maioria de conteúdo bibliográfico é referente ao seu fluxo de projeto, portanto o presente trabalho só abordará os DRFPGAs da Xilinx.

Para o projeto de um DRS, a área do dispositivo é separada em uma Região Estática, a qual não será reconfigurada; e as Partições Reconfiguráveis, as quais são as regiões parciais do dispositivo definidas pelo projetista para ser reconfiguradas dinamicamente. Sobre cada Partição Reconfigurável são implementados diferentes Módulos Reconfiguráveis, um por vez formando um contexto junto com a Região Estática (XILINX, 2012b).

O projeto de DRSs sobre FPGAs está baseado em arquivos de bits, os quais contêm a informação sobre a lógica do sistema a ser implementado. Estes arquivos são armazenados em uma memória Flash externa ao dispositivo. O arquivo que contém a configuração do dispositivo é chamado de Full Bit File, o qual consiste da lógica estática e a lógica da primeira configuração 
de cada partição reconfigurável. Os outros arquivos contém as lógicas dos módulos reconfiguráveis que serão implementados sobre as partições reconfiguráveis conhecidos como Partial Bit Files. Para que estes arquivos sejam aplicados sobre o FPGA, é utilizado um porto de configuração para carregar o bitstream sobre a partição reconfigurável. Este porto pode variar de acordo com o modelo do FPGA, os quais podem ser: Slave SelectMAP, Slave Serial, JTAG, ou Internal Configuration Access Port (ICAP). O envio dos bitstreams pode ser controlado por meio do microprocessador interno do FPGA, uma máquina de estado ou outra lógica. Este controlador é encarregado dos processos de inicialização da reconfiguração, assim como a leitura dos arquivos da memória Flash para depois enviar os bitstreams parciais pelo porto de configuração do FPGA. Isto pode ser implementado por meio de diversas técnicas, das quais duas são apresentadas na Figura 8 (XILINX, 2012b). No lado esquerdo da Figura é apresentado um FPGA reconfigurável por si mesmo, o qual implementa o controlador com os próprios recursos do dispositivo; e por outro lado, no lado direito da Figura 8 é apresentado um FPGA reconfigurado por um controlador externo baseado em algum microprocessador (XILINX, 2012b).

Figura 8: Duas técnicas de implementação do controlador de reconfiguração parcial dinâmica.

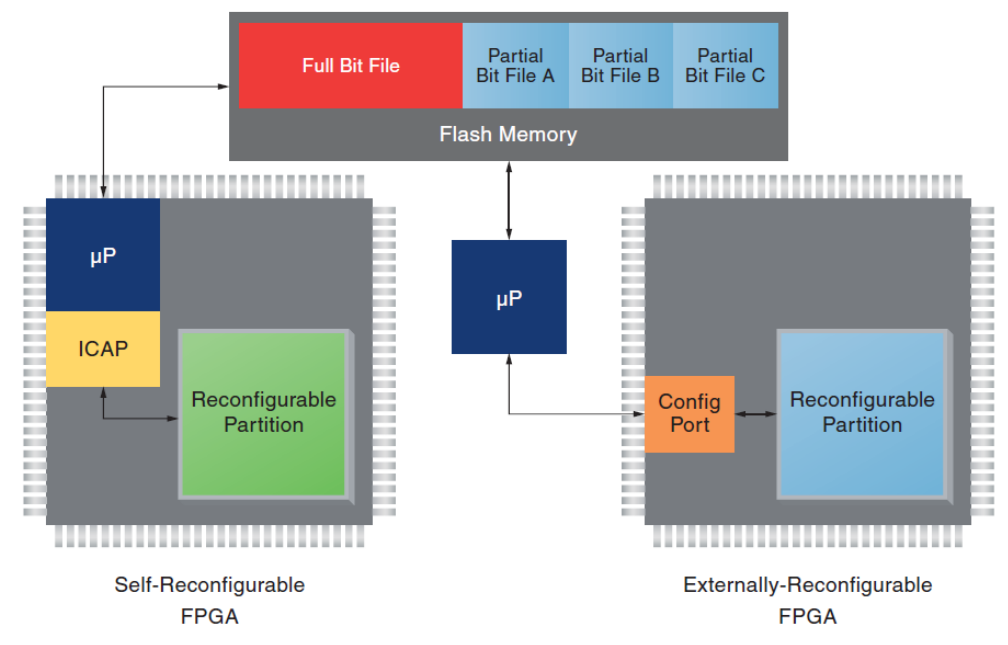

Fonte: (XILINX, 2012b).

Neste trabalho de dissertação, será utilizada a implementação do FPGA reconfigurável por si mesmo, o qual estará baseado em uma máquina de estados interna implementada com os recursos lógicos do FPGA, o qual será explicado nos próximos capítulos.

É importante mencionar que para o projeto de um DRS baseado em FPGAs da Xilinx, é 
utilizada uma ferramenta de CAD conhecida como PlanAhead (XILINX, 2012c), a qual possui diversas utilidades para o projetista, principalmente para a especificação das partições reconfiguráveis, os módulos reconfiguráveis a serem implementados sobre elas, assim como os arquivos de bits para formar os bitstreams parciais para ser enviados pelos porto de configuração.

\subsubsection{Metodologia de Simulação de Sistemas Reconfiguráveis}

Para confirmar a correção do projeto de sistemas DRS, o passo de simulação é fundamental. Para isso, é utilizada a técnica de Chaveamento Dinâmico de Circuitos (DCS, do inglês, Dynamic Circuit Switching) (LYSAGHT; STOCKWOOD, 1996; BRUNELLI, 2005; ROBINSON; LYSAGHT, 2000). Esta técnica é bastante tradicional, baseando-se numa aproximação (sem perda de informação útil do projeto) que permite representar o efeito da reconfiguração parcial dinâmica durante a troca de contextos na simulação. Para atingir tal objetivo, chaves de isolação são usadas para que os módulos reconfiguráveis ativos sejam conectados com os módulos estáticos ou outros módulos reconfiguráveis. Outros parâmetros fundamentais nas simulações de DRSs, como o intervalo de tempo de reconfiguração de um módulo também são modelados com esta técnica.

A Figura 9 (KOJIMA, 2007) apresenta um esquema virtual do circuito sintetizado após a inclusão de chaves de isolação. Todos os módulos reconfiguráveis são agrupados e conectados aos módulos estáticos por meio das chaves. Uma chave de isolação possui uma entrada, uma saída e uma variável de controle, no exemplo da Figura 9, um controlador de reconfiguração é o encarregado de controlar as variáveis de controle para todas as chaves de isolação do DRS. Este controlador tem como parâmetro o tempo de reconfiguração de cada um dos módulos reconfiguráveis.

As chaves de isolação permitem colocar uma tarefa em um dos seguintes estados: inativa, ativa e transição. Para poder estabelecer estes estados, utiliza-se o sinal de controle da chave de isolação; na Tabela 1, se ilustra a tabela de verdade de todos os estados com o respectivo valor de saída. 
Figura 9: Estrutura de Simulação usando DCS.

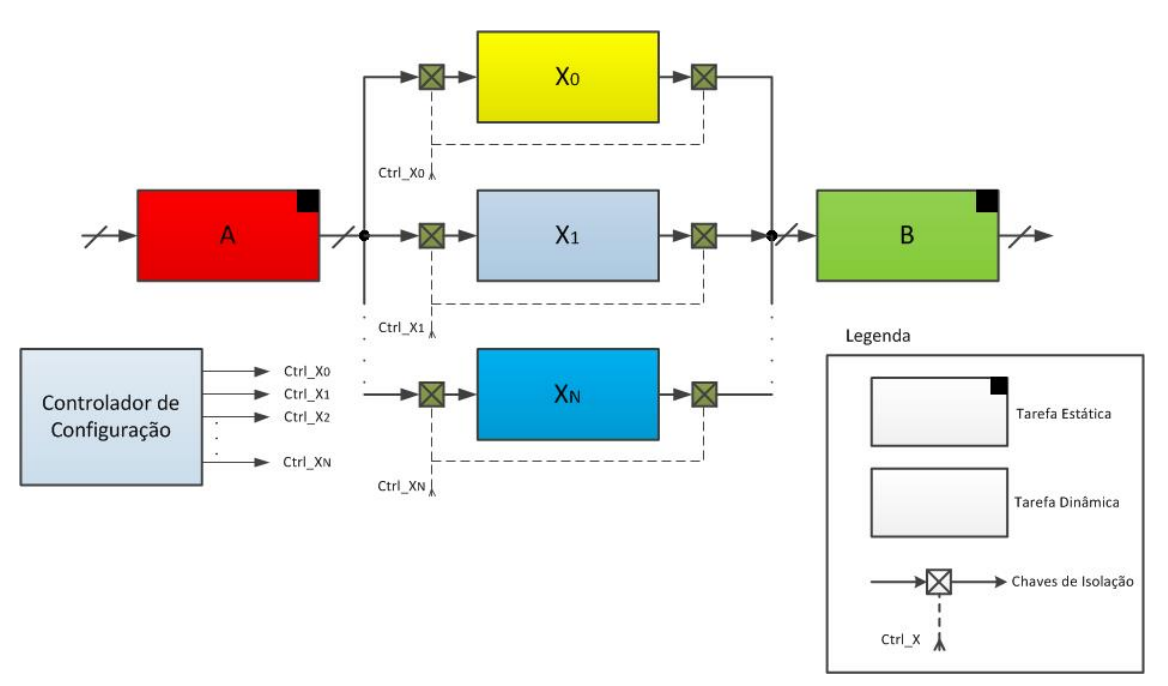

Fonte: (KOJIMA, 2007).

Tabela 1: Tabela de Verdade da Chave de Isolação

\begin{tabular}{|c|c|c|}
\hline Sinal de Controle & Estado de Conjunto & Saida \\
\hline \hline 0 & Ativo & Entrada \\
\hline 1 & Transição & $\mathrm{X}$ \\
\hline $\mathrm{Z}$ & Inativo & $\mathrm{Z}$ \\
\hline $\mathrm{X}$ & Inativo (adotado) & $\mathrm{Z}$ \\
\hline
\end{tabular}

Fonte: (Autor, 2014).

\subsubsection{Tempos de Reconfiguração}

O controlador das chaves de isolação é um bloco lógico que tem como parâmetro os tempos de reconfiguração de cada módulo que faz parte do DRS. Este parâmetro deve ser interpretado como o tempo necessário para que a informação dos arquivos de bits, contida na memória Flash, seja transmitida em forma de bitstream e ingresse no FPGA pelos portos de configuração como o SelectMap, ICAPs ou JTAG. Este tempo depende do tamanho do bitstream (em número de bits transmitidos) de configuração e da frequência de relógio. A Tabela 2 (XILINX, 2012a) apresenta as características de cada porto de configuração com suas respectivas frequências de relógio e largura de dados, os quais determinam sua largura de banda de configuração.

O tamanho do bitstream de configuração se define como a informação que contêm a configuração da área que se quer configurar mais seu overhead, ambos expressados em palavras. 
Tabela 2: Tabela de Características dos Portos de Configuração dos FPGAs da Xilinx.

\begin{tabular}{|l|c|c|c|}
\hline $\begin{array}{c}\text { Modo de } \\
\text { Configuração }\end{array}$ & $\begin{array}{c}\text { Frequência } \\
\text { Máxima de } \\
\text { Relógio }\end{array}$ & $\begin{array}{c}\text { Largura de } \\
\text { Dados }\end{array}$ & $\begin{array}{c}\text { Largura de } \\
\text { Banda } \\
\text { Máxima }\end{array}$ \\
\hline \hline SelectMap/ICAP & $100 \mathrm{MHz}$ & $32-\mathrm{bit}$ & $3.2 \mathrm{Gbps}$ \\
\hline Serial Mode & $100 \mathrm{MHz}$ & $1-\mathrm{bit}$ & $100 \mathrm{Mbps}$ \\
\hline JTAG & $66 \mathrm{MHz}$ & $1-\mathrm{bit}$ & $66 \mathrm{Mbps}$ \\
\hline
\end{tabular}

Fonte: (XILINX, 2012a).

Também pode ser expressado em bits considerando que cada palavra equivale a 32 bits. Como já tinha sido explicado anteriormente, esta informação da configuração do FPGA é implementada sobre as células de memória conhecidas como memória de configuração (do inglês, Configuration Memory), a qual está composta por frames.

Um frame é a menor unidade da memória de configuração, portanto o tamanho da configuração do dispositivo é contabilizada nesta unidade. Cada frame tem um tamanho diferente de palavras para cada dispositivo, por exemplo no caso da família Virtex-4 (XILINX, 2009) e Virtex-5 (XILINX, 2012d), um frame de configuração tem um comprimento de 41 palavras, 81 no caso da família Virtex-6 (XILINX, 2013a) e 101 no caso da Virtex-7 (XILINX, 2013b). A quantidade de frames de configuração disponíveis para cada dispositivo estão disponibilizados nos manuais técnicos da Xilinx. Em reconfiguração parcial dinâmica são utilizados frames de configuração conhecidos como frames de reconfiguração (do inglês, reconfiguration frames) cuja composição depende da família do dispositivo, como apresentado a seguir (XILINX, 2012b):

- Família Virtex 7: 50 CLBs de largura por 1 CLB de comprimento.

- Família Virtex 6: 40 CLBs de largura por 1 CLB de comprimento.

- Família Virtex 5: 20 CLBs de largura por 1 CLB de comprimento.

- Família Virtex 4: 16 CLBs de largura por 1 CLB de comprimento.

Um frame de reconfiguração é a unidade mínima para construção de blocos reconfiguráveis, portanto não pode ser particionada em unidades menores; se uma área menor que um frame de 
reconfiguração é selecionada, então o frame inteiro será reconfigurado (XILINX, 2012b).

O bitstream para reconfiguração parcial dinâmica depende então da quantidade de frames de reconfiguração para a região parcial selecionada expressada em bytes, somado com a quantidade de bytes extras de configuração (do inglês, Configuration Overhead), cujo valor depende da família de dispositivos FPGA, os quais se encontram no manual do fabricante. A Equação 2.1 apresenta um exemplo de como é calculado o tamanho do bitstream de uma região parcialmente reconfigurável (PRR do inglês, Partially Reconfigurable Region) composta por 636 frames para o dispositivo Virtex-4, onde cada frame está composto por 41 palavras de 32-bits (4 bytes).

$$
\begin{aligned}
\text { TamanhoBitstream }_{\text {Frames }_{P R R}} & =\text { Frames }_{P R R} . \text { Palavras Frame. Bytes Palavra } \\
& =636 \times 41 \times 4 \\
& =104304 \text { Bytes }
\end{aligned}
$$

A este valor, adiciona-se o valor extra de configuração expressado em bytes para obter o tamanho do bitstream total que será enviado ao dispositivo por meio do porto de configuração. Para o dispositivo Virtex-4, o valor adicional é 1312 palavras, o qual será somado ao valor anterior como a Equação 2.2 apresenta.

$$
\begin{aligned}
\text { TamanhoBitstream }_{\text {Total }}= & \text { TamanhoBitstream }_{\text {Frames } P R}+ \\
& \text { Palavras Overhead.Bytes Palavra } \\
= & 104304+1312 x 4 \\
= & 109552 \text { Bytes }
\end{aligned}
$$

Já com o tamanho do bitstream total calculado, é possível obter o tempo de reconfiguração da PRR como apresentado na Equação 2.3. Neste caso, $T_{r}$ é o tempo de reconfiguração,

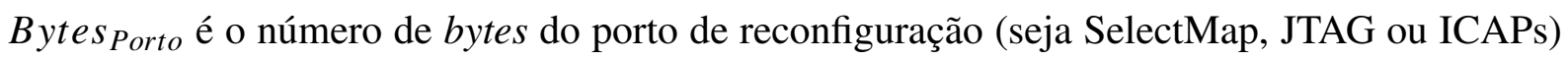


e $f_{\text {Porto }}$ sua frequência de envio de dados correspondente. Neste caso, se considerou uma frequência de $100 \mathrm{MHz}$ e uma largura de dados de 4 bytes.

$$
\begin{aligned}
T_{r} & =\frac{\text { TamanhoBitstream }_{\text {Total }}}{\text { NroBytes Porto }} f_{\text {Porto }} \\
& =\frac{109552 \text { Bytes }}{4 \text { Bytes.100 } \mathrm{MHz}} \\
& =274 \mu \mathrm{seg}
\end{aligned}
$$

\subsection{Redes Intrachip}

Como mencionado no Capítulo 1, o uso de redes de interconexão como interface de comunicação para SoCs, em sua maioria, deu-se por barramentos, porém os requisitos para uma comunicação entre módulos de processamento em sistemas mais complexos têm feito com tais interfaces evidenciem as suas limitações em termos de escalabilidade, reusabilidade e eficiência no consumo energético (BENINI; MICHELI, 2002). A alternativa mais recente são as Redes IntraChip ou NoCs, cuja principal vantagem é comunicação em paralelo entre os módulos de processamento do SoC (escalabilidade e modularidade), isto é, blocos podem enviar dados para outros ao mesmo tempo, em contraste com os barramentos de dados, onde só um módulo pode utilizar o barramento por vez (MIORANDI, 2012). Tal capacidade apresenta o seu potencial de bom desempenho para sistemas com grande número de módulos (BENINI; MICHELI, 2002; JANTSCH; TENHUNEN, 2003).

Uma Rede Intrachip é composta principalmente por roteadores, pelos quais a informação será transmitida entre fonte e destino, gerando um caminho através de roteadores. A forma em que é implementado um roteador determina certos parâmetros importantes na eficiência de transmissão de dados como o tempo de operação do roteador e consequentemente a latência resultante das mensagens e a largura de banda da rede (DUATO; YALAMANCHILI; LIONEL, 2002). 
A arquitetura genérica de um roteador apresentada na Figura 10(a) (DUATO; YALAMANCHILI; LIONEL, 2002), consiste de cinco canais ou portos bidirecionais (norte, sul, leste, oeste e o núcleo local). A sua composição consiste principalmente dos seguintes componentes:

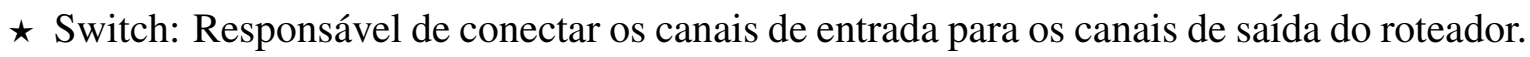
Os roteadores de alta velocidade utilizam redes de tipo crossbar como apresentado na Figura 10(b) (MIORANDI, 2012), composto de n multiplexadores, onde n é o número de portos de saída do switch. A vantagem do crossbar sobre um multiplexador simples, é a capacidade de fazer múltiplas conexões ao mesmo tempo. Na Figura 10(a), há quatro canais de entrada à esquerda e quatro de saída do lado direito, correspondendo às direções norte, sul, leste e oeste. Além disso, no lado superior existem dois canais de entrada e saída correspondentes ao porto local o qual injeta os dados na rede além de receber os dados provenientes dos outros canais de entrada.

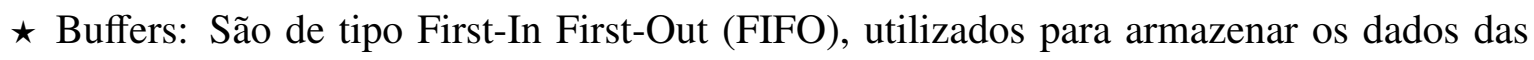
mensagens entrantes do roteador. Um buffer é associado a cada entrada e saída de cada um dos canais do roteador, como apresentado na Figura 10(a).

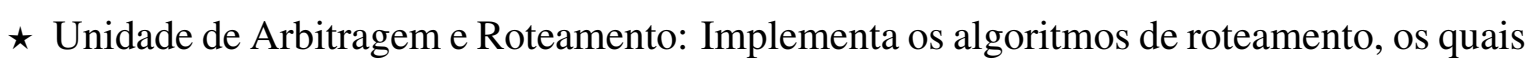
consistem em decidir por qual porto de saída uma mensagem entrante, em qualquer dos canais, deve sair; de acordo com isso, o switch é configurado da forma correspondente. No caso onde se tem múltiplas mensagens entrantes que simultaneamente requerem o mesmo canal de saída, esta unidade faz uma arbitragem para manter as mensagens armazenadas nos seus respectivos buffers de entrada até que o canal de saída requerido seja liberado.

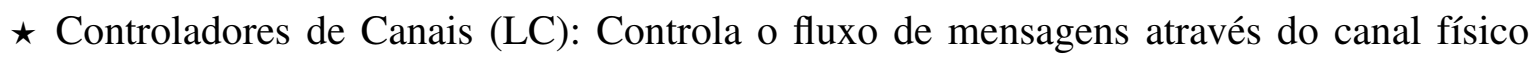
entre roteadores adjacentes. A técnica mais comum para o controle de fluxo de mensagens é o protocolo Handshake, com os sinais de pedido (do inglês, request) e de confirmação (do inglês, acknowledge). O roteador de origem envia um sinal de pedido $(R Q)$ quando tem uma mensagem para transmitir ao roteador adjacente e este último responde com um 
sinal de confirmação $(A C K)$ para comunicar a disponibilidade de espaço no buffer. A Figura 10(c) ilustra esta situação com os roteadores R1 e R2.

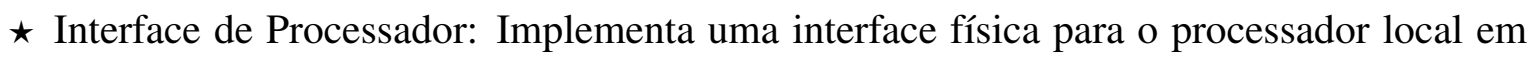
um ou mais canais de injeção que saem do processador e um ou mais canais de ejeção que entram nele, como ilustrado na Figura 10(d). Basicamente trata-se de uma interface de rede que faz uma rápida conversão entre os protocolos de comunicação da rede e do processador local.

A partir do conceito de roteador, a NoC é construída com base em um arranjo de roteadores, o qual é definido como topologia, a qual transmite e controla o fluxo de pacotes de acordo com um algoritmo de roteamento (em inglês, routing algorithm), um mecanismo de roteamento (em inglês, switching), um controle de fluxo e a arbitragem de pacotes, os quais serão tratados nos itens seguintes.

\subsubsection{Topologia de Redes}

Topologia refere-se à forma de interconexão entre os nós que constituem a rede; ela é representada por grafos. Os nós são conectados através de ramos que correspondem a canais de comunicação. Antes de apresentar alguns exemplos de topologias, se explicará que as redes podem ser classificadas em: diretas e indiretas.

\subsubsection{Redes Diretas}

As redes diretas são definidas como aquelas onde cada um dos seus nós está constituído por um par roteador-módulo, estes ligados entre si por meio de conexões fixas. Todo roteador que se conecta a um módulo é denominado como ponto de acesso, sendo tal conexão feita pelo canal local; além disso, cada nó possui conexões diretas ponto a ponto para um determinado número de nós vizinhos. Os módulos são também identificados por Elemento de Processamento (EP). Um exemplo de um nó genérico é ilustrado na Figura 11, composto pelo roteador com seus respectivos canais de comunicação para a comunicação com os outros nós vizinhos, e 
Figura 10: Principais Elementos da Arquitetura Genérica de um Roteador.

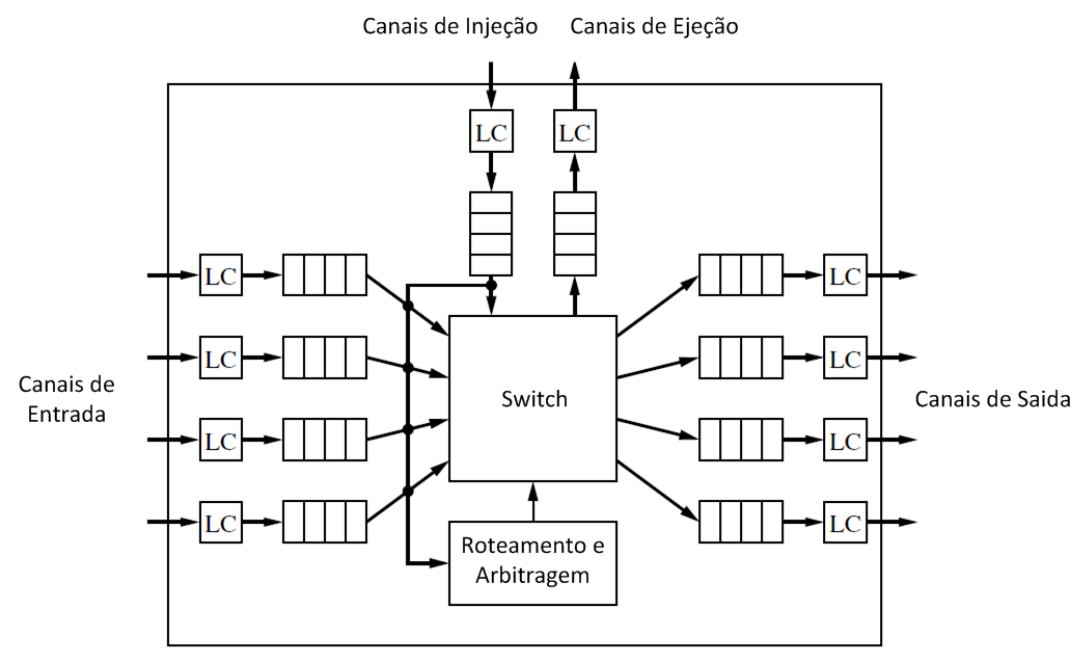

(a) Arquitetura Genérica de um roteador

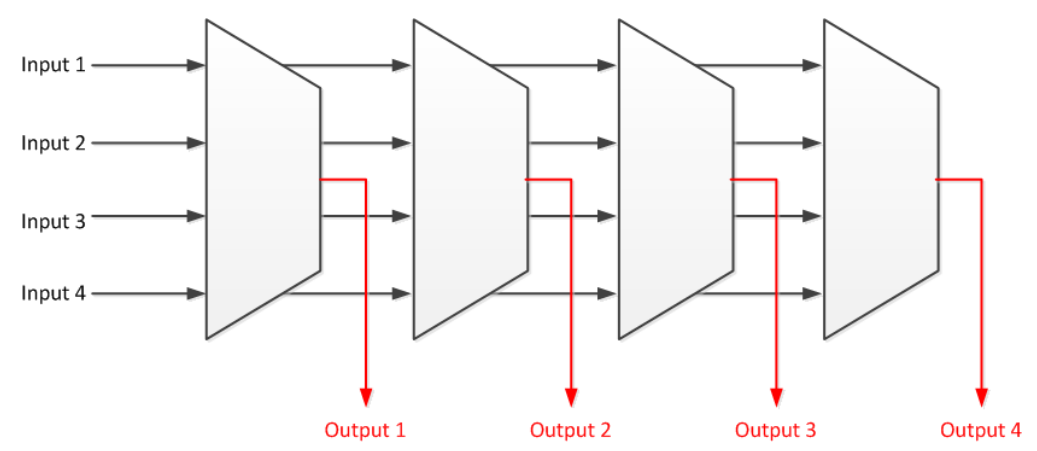

(b) Arquitetura interna básica de um switch com topologia crossbar
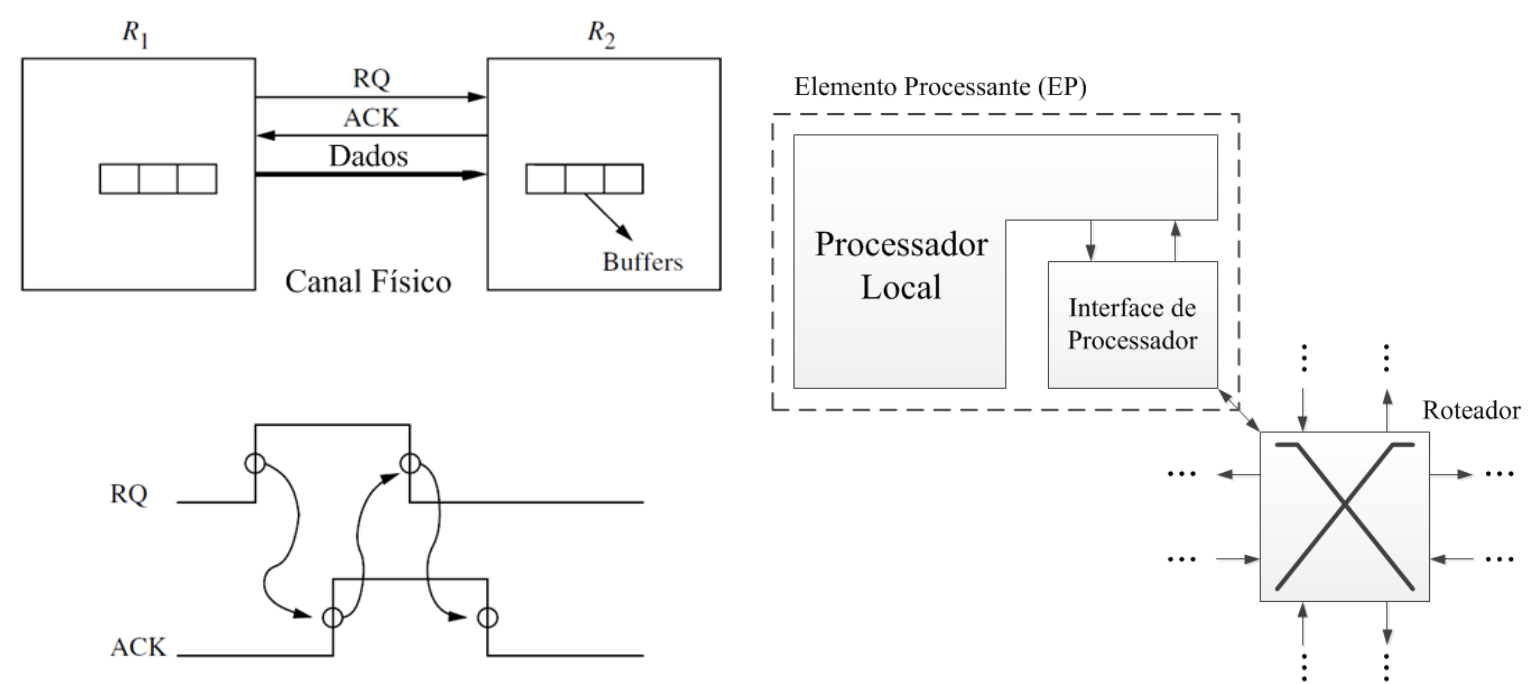

(c) Controle de Canais através do protocolo (d) Interface de comunicação entre o processador e o Handshake entre dois roteadores adjacentes roteador

Fonte: (DUATO; YALAMANCHILI; LIONEL, 2002). 
o EP composto por seu processador, memória local e outros periféricos com sua respectiva funcionalidade. Cada nó pode ter uma funcionalidade especifica de acordo com a aplicação de destino (ex. processador de gráficos, de vetores, DSPs, etc.) (DUATO; YALAMANCHILI; LIONEL, 2002).

Figura 11: Arquitetura de um nó genérico

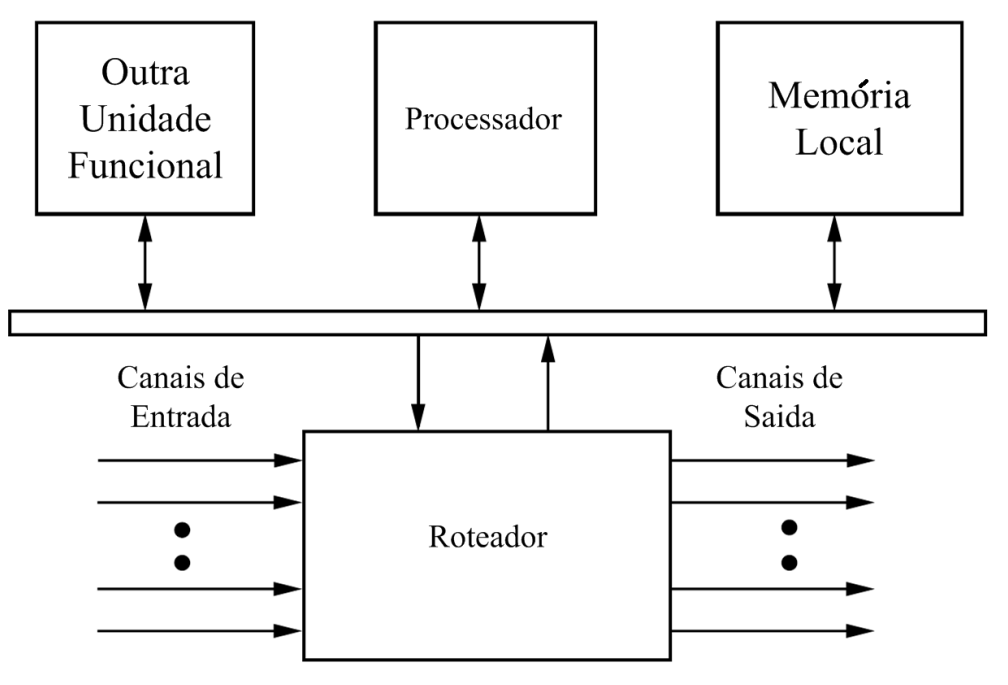

Fonte: (DUATO; YALAMANCHILI; LIONEL, 2002).

Diferentes topologias de redes diretas foram propostas na tentativa de se obter uma boa relação entre desempenho-custo. Entre elas temos: malha (em inglês, mesh) n-dimensional, toroide 2-D, cubo 3-D, hipercubo (cubo 4-D) e totalmente conectada, as quais são apresentadas na Figura 12.

\subsubsection{Redes Indiretas}

Nas redes indiretas, não é obrigatório o par roteador-módulo para se formar um nó. Cada um dos nós terminais está ligado a uma rede de switches por meio de um adaptador de rede. Cada switch possui um conjunto de portos (entrada e saída) para conexão com os outros switches com a finalidade de manter a comunicação entre processadores. Estas conexões podem ser unidirecionais ou bidirecionais. Alguns portos estão ligados a EPs, ou podem ficar em aberto, sem conexão a nada.

A diferença entre as redes diretas e indiretas é que neste último caso um switch pode estar ligado a uma quantidade de zero, um ou mais EPs portanto só alguns switches que estiverem li- 
Figura 12: Topologias de redes diretas: Malha n-dimensional (a), Toroide 2D (b), Cubo 3D (c), Hipercubo (d) e Totalmente conectada (e)

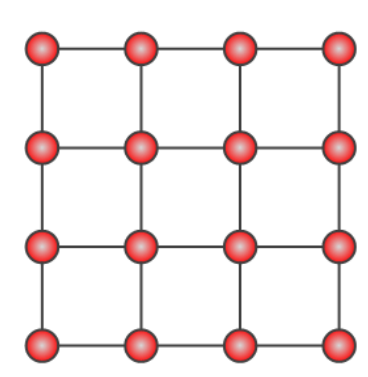

(a)

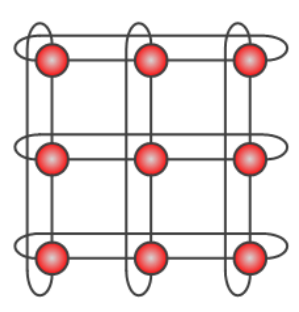

(b)

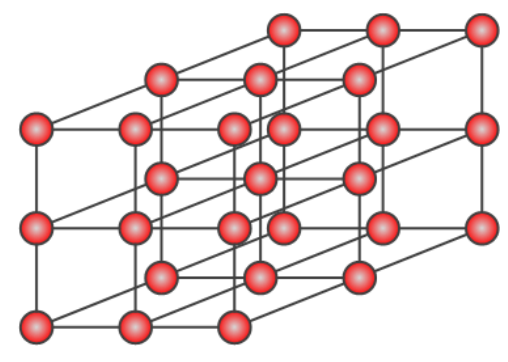

(c)

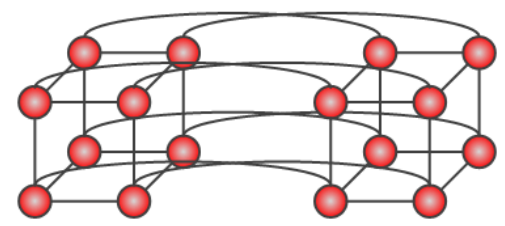

(d)

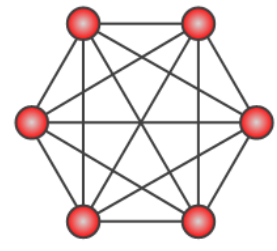

(e)

Fonte: (DUATO; YALAMANCHILI; LIONEL, 2002).

gados a EPs podem ser considerados como fonte e destino de mensagens. A interconexão entre estes nós pode formar topologias regulares se eles estiveram baseados em um padrão definido de conexão, e irregulares se tal padrão não existir, podendo ter qualquer forma. Um exemplo de uma topologia irregular típica para uma rede indireta é ilustrado na Figura 13 (DUATO; YALAMANCHILI; LIONEL, 2002).

Figura 13: Rede Indireta com Topologia Irregular

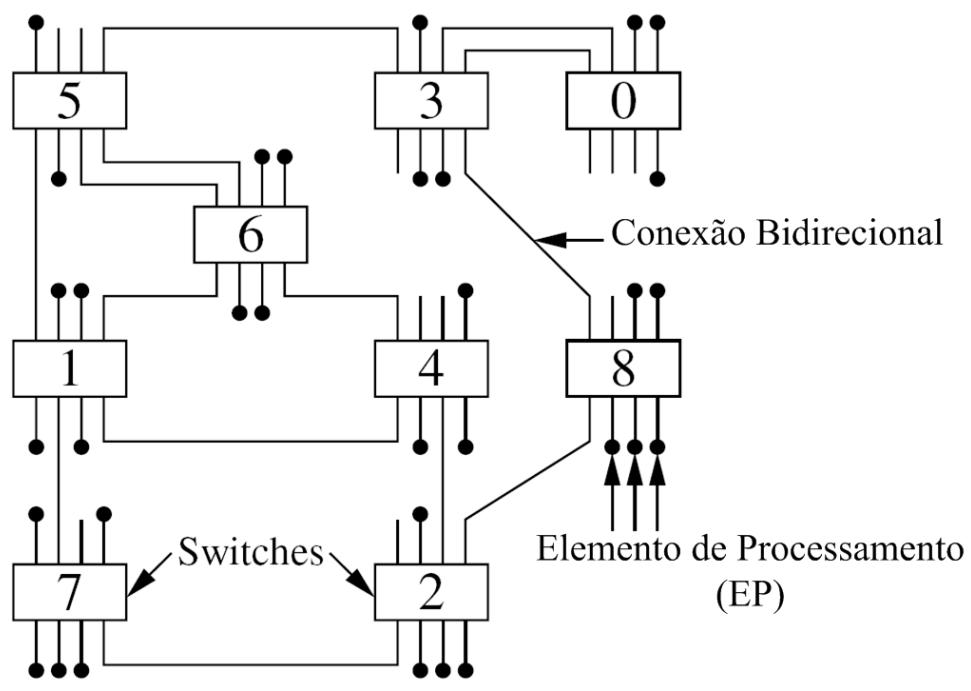

Fonte: (DUATO; YALAMANCHILI; LIONEL, 2002).

A partir destas definições pode-se afirmar que, para o caso de DRNoCs, como alguns mó- 
dulos de processamento requerem mais recursos de hardware para sua implementação que a quantidade utilizada por um nó, então se formam-se diversas topologias irregulares para cada contexto do DRSs conforme os exemplos da Figura 14. Estes exemplos são também casos de redes indiretas uma vez que há nós que são compostos somente por roteadores, portanto não estando nem todos ligados a algum EP.

Figura 14: Topologias Irregulares formadas pelo posicionamento de módulos de processamento sobre uma rede regular direta com topologia de malha bidimensional
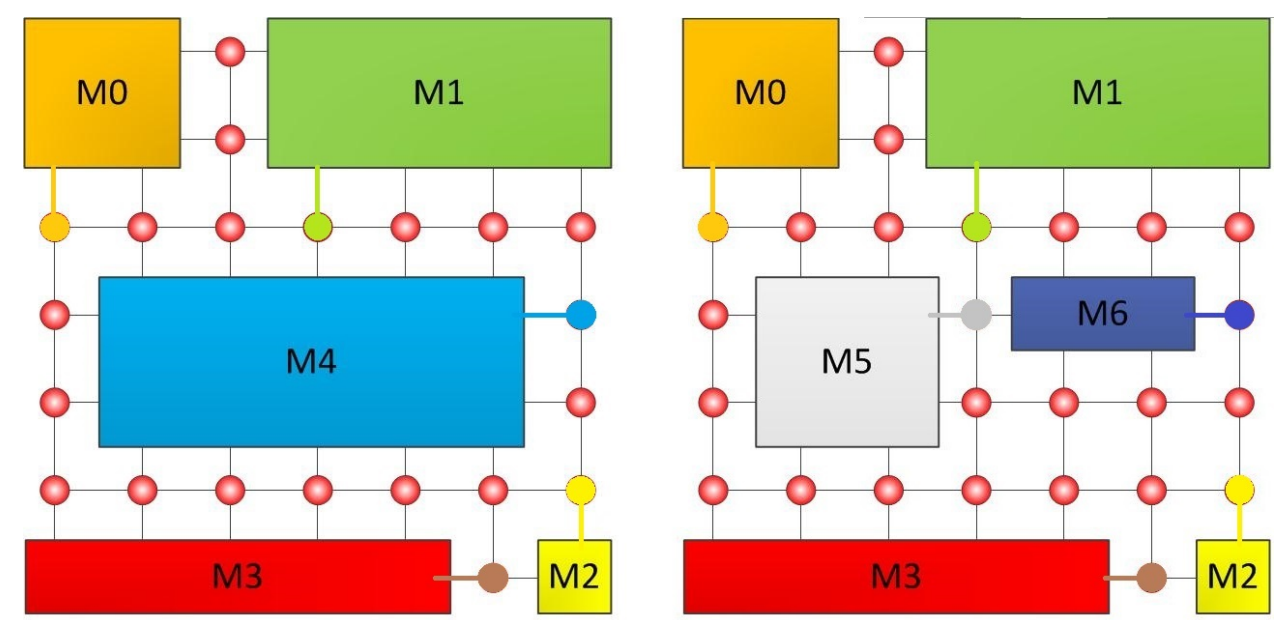

Fonte: (Autor, 2014).

\subsubsection{Algoritmos de Roteamento - Routing}

Os algoritmos de roteamento estabelecem o caminho a ser percorrido pelos dados numa rede entre o nó de fonte (em inglês, source) e destino (em inglês, destination). Estes algoritmos estão diretamente relacionados com a parte decisória da rede e têm a finalidade de garantir certas propriedades que uma Rede Intrachip deve possuir, principalmente entre elas temos (DUATO; YALAMANCHILI; LIONEL, 2002):

- Conectividade: a capacidade de rotear pacotes de dados de qualquer nó fonte até qualquer nó de destino.

- Adaptabilidade: a capacidade de rotear pacotes através de caminhos alternativos no caso de ter elementos de contenção como módulos de processamento ou regiões com falhas. 
- Tolerância a Falhas: capacidade de rotear pacotes na presença de falhas. Mesmo que esta falha implique adaptabilidade, também se considera o caso em que um pacote é roteado em duas ou mais fases, armazenando os pacotes em nós intermédios, sem necessidade de adaptabilidade.

- Ausência de Deadlock (Deadlock-Freeness): evita-se que não ocorra o travamento da rede. Deadlock é uma situação que acontece quando alguns pacotes de dados não podem avançar em direção aos seus destinos devido ao fato que os buffers de armazenamento solicitados estão completamente cheios, somado a isto, não ocorre a liberação de nenhum destes buffers porque os buffers dos nós de destino também estão cheios. Acontecendo isto de forma circular, o deadlock está estabelecido. A Figura 15 (DUATO; YALAMANCHILI; LIONEL, 2002) ilustra um exemplo de deadlock, onde o número dentro de cada buffer representa o nó de destino e as setas representam a direção de cada pacote adotada pelo algoritmo de roteamento.

Figura 15: Exemplo de uma configuração de deadlock.

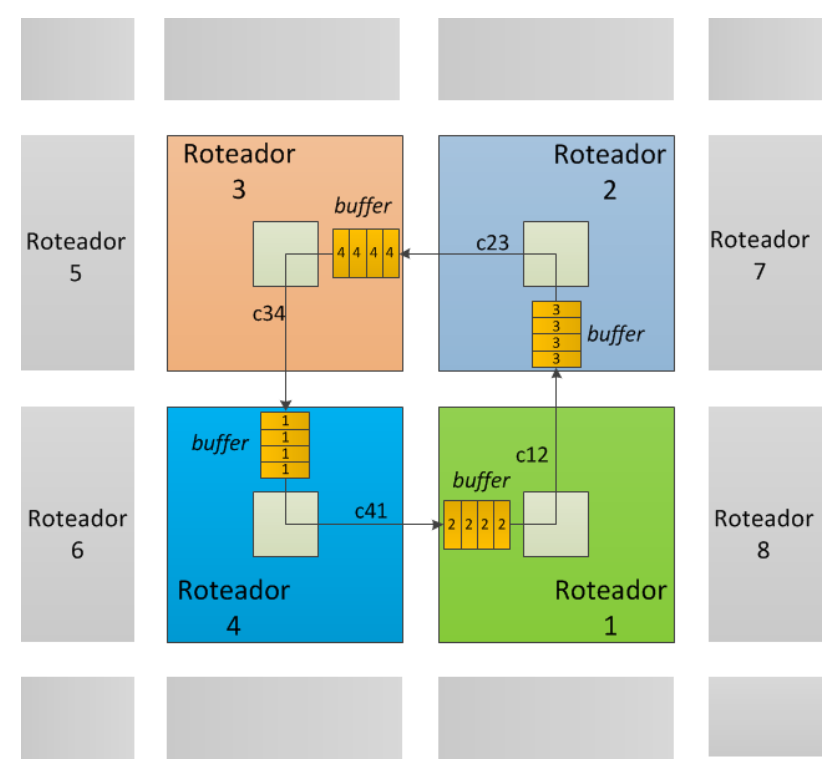

Fonte: (DUATO; YALAMANCHILI; LIONEL, 2002).

As propriedades acima dependerão do tipo de algoritmo de roteamento que será utilizado na rede, podendo-se fazer a seguinte classificação:

$\triangleright$ Determinísticos: são aqueles que determinam um caminho fixo definido entre o nó fonte 
e o nó destino do pacote de dados, não levam em conta as condições da rede no momento da transmissão. Um algoritmo determinístico muito referenciado é o algoritmo XY ou YX que estão classificados como Roteamento Ordenado por Dimensão (DOR do inglês, Dimension Order Routing)(DUATO; YALAMANCHILI; LIONEL, 2002).

$\triangleright$ Adaptativos: são aqueles que definem o caminho a ser percorrido por um pacote dependendo das condições da rede no momento da transmissão. Isto permite homogeneizar o tráfego de pacotes, diminuindo a possibilidade de ter problemas como deadlock, livelock ou starvation, caso a rede não seja regular.

Outra classificação dos algoritmos de roteamento é baseado no local de implementação do algoritmo, que podem ser os seguintes:

$\star$ Roteamento Fonte (Source Routing Algorithm): o elemento de processamento que envia os pacotes para a rede determina o caminho a ser percorrido, incluindo tal informação no pacote, acrescentando-se uma quantidade extra de bits.

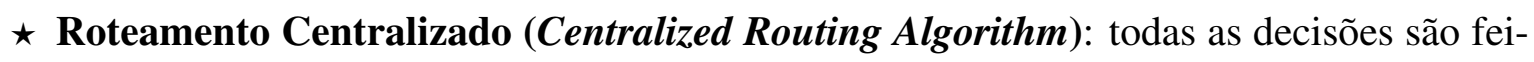
tas por um controlador chamado de Centro de Controle do Roteamento (RCC, do inglês, Routing Control Center). Este módulo recebe a informação de status dos roteadores mais próximos a ele, para depois retornar para os roteadores uma tabela de informação de roteamento (RIT, do inglês, Routing Information Table). Esta alternativa apresenta um problema quando há tráfego intenso, pois somente os roteadores próximos ao RCC poderiam ter acesso rápido à informação de roteamento, enquanto que para os outros roteadores mais distantes, o acesso seria lento.

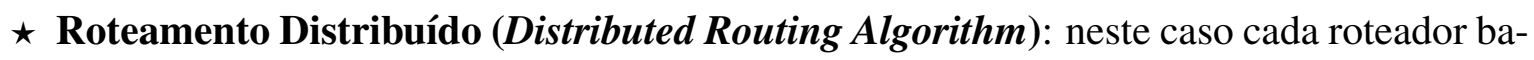
seado em um conhecimento local ou global, define se o pacote de dados deve ser enviado para o seu elemento de processamento local ou para outro roteador da sua vizinhança. Esta solução minimiza a informação adicional que deve ser enviada junto ao pacote. 
No caso de roteamento distribuído, cada um dos roteadores tem duas opções para desenvolver o algoritmo de roteamento:

- Utilizar uma tabela de roteamento dentro de cada roteador para tomar as decisões, esta opção é conhecida como roteamento baseado em tabelas (em inglês, Table-Based Routing).

- Adotar um hardware, que é mais otimizado que a primeira opção no que tange a área, já que é mais escalável com o aumento da quantidade de nós. Esta opção é conhecida como roteamento baseado em lógica distribuída (em inglês, Logic-Based Distributed Routing).

\subsubsection{Mecanismos de Chaveamento - Switching}

Os mecanismos de chaveamento (em inglês, Switching Techniques) definem a forma pela qual os dados são transferidos através dos roteadores da rede. Estes mecanismos podem ser classificados em dois tipos:

- Chaveamento de Circuito - Circuit Switching: o caminho dos dados é estabelecido antes de a mensagem ser enviada, não permitindo que nenhuma outra comunicação utilize os canais já associados. Para definir este caminho, é utilizado um pacote de teste dentro da rede, começando do nó fonte até que alcance seu destino, depois do qual, um pacote de confirmação é enviado de volta para a fonte. Finalmente, a mensagem completa é enviada através do caminho resultante.

- Chaveamento de Pacote - Packet Switching: neste caso, o caminho de dados não é determinado e os roteadores devem armazenar os dados do pacote enquanto esperam que as saídas estejam disponíveis. Diz-se que o caminho é estabelecido dinamicamente neste caso.

Os modos mais comuns de mecanismos de chaveamento de pacotes são os seguintes (BENINI; MICHELLI, 2006): 
- Store and Forward (SAF): Um pacote é enviado de um roteador ao seguinte somente quando o roteador receptor tiver espaço no seu buffer para o pacote completo. Os roteadores enviam o pacote somente após este ter sido inteiramente recebido. Existe uma latência de roteamento na transmissão de pacotes entre dois roteadores, devido à fase de estabelecimento (em inglês, set-up) deve ser completada antes de a transmissão começar. A Figura 16 (BENINI; MICHELLI, 2006) ilustra um diagrama de tempos do modo SAF, neste caso um pacote é transmitido por três roteadores (1, 2 e 3). Pode-se observar que primeiramente é transmitido o cabeçalho com a informação do destino do pacote e, depois, finalmente os dados.

Figura 16: Exemplo de transmissão de um pacote com o mecanismo Store-and-Forward.

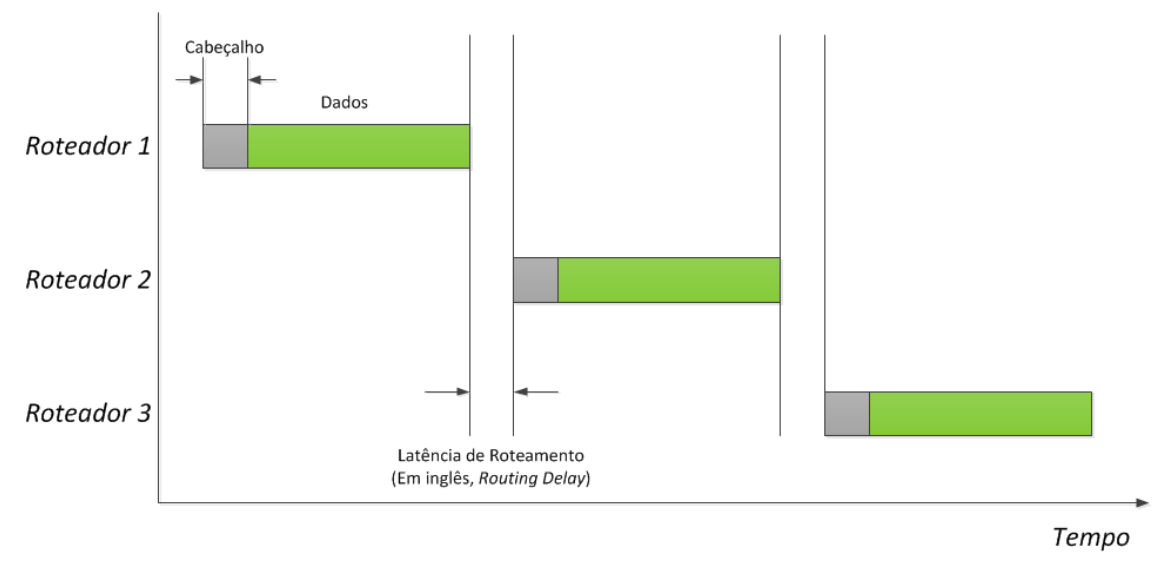

Fonte: (BENINI; MICHELLI, 2006).

- Virtual Cut-Through Switching (VCT): para explicar o modo VCT, deve-se introduzir o conceito de flit - unidade de controle de fluxo (em inglês, FLow control unIT); cada pacote é composto de um grupo destas unidades menores. Na maioria de casos, os primeiros flits contêm a informação de roteamento (cabeçalho), enquanto que os flits restantes contêm os bytes de dados como ilustrado na Figura 17(a) (BENINI; MICHELLI, 2006). No modo VCT, se o próximo roteador indica que pode receber um pacote, então o roteador atual começa a enviar o primeiro flit do pacote, diminuindo, assim, a latência do roteador. Em seguida, outros flits continuam sendo transmitidos sem nenhum atraso. No caso de não haver mais espaço no buffer seguinte, o pacote fica armazenado no buffer de origem. A Figura 17(b) (BENINI; MICHELLI, 2006) ilustra um exemplo de transmissão de dados no 
modo VCT, por exemplo, na transmissão de roteador 2 para o roteador 3 ocorre o caso que este último não pode receber mais informação, então ocorrerá um retardo e todo o pacote será armazenado.

Figura 17: Virtual Cut-Through Switching

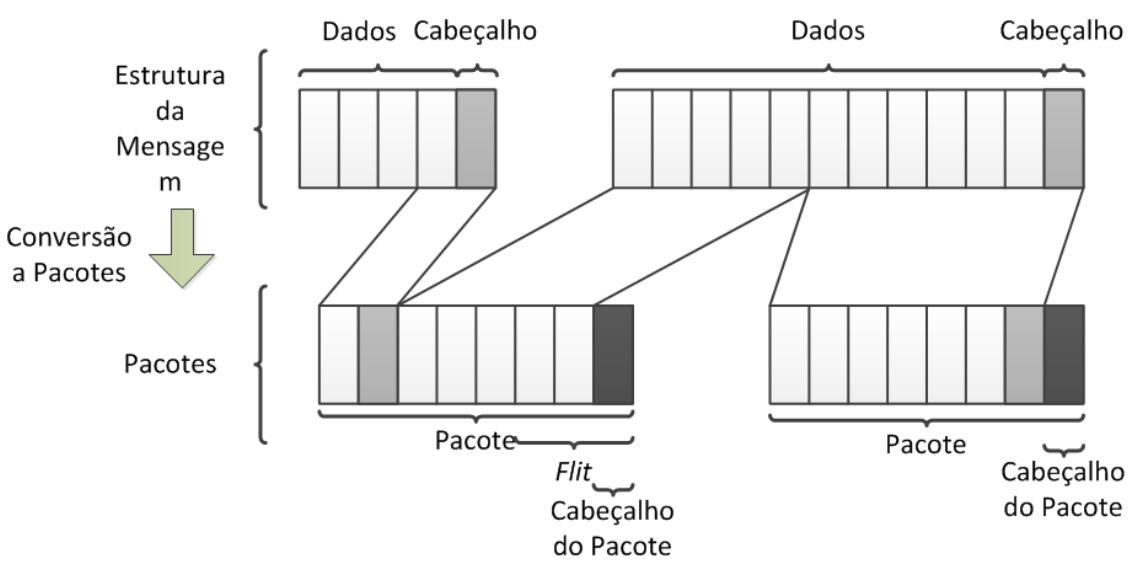

(a) Conversão das mensagens em pacotes formados por flits

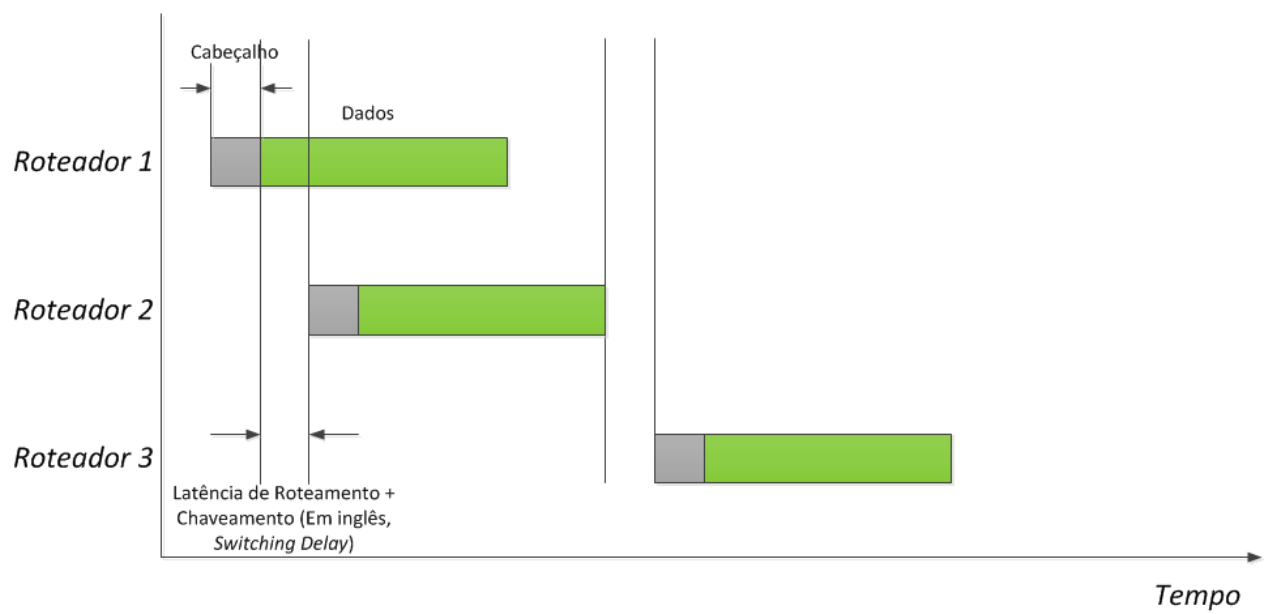

(b) Exemplo de transmissão de um pacote com o mecanismo VCT

Fonte: (BENINI; MICHELLI, 2006).

- Wormhole Switching: Este modo busca melhorar o modo VCT reduzindo o tamanho do buffer para um flit. Então, cada flit de um pacote é enviado quando se tem espaço para armazená-lo no roteador receptor. No caso de não se ter espaço disponível, os flits que formam o pacote ficam armazenados em dois ou mais roteadores, de acordo com o tamanho do pacote, aguardando até que o buffer do roteador receptor esteja liberado. A principal vantagem é que há um baixo custo de implementação, uma vez que o tamanho do buffer é mínimo (um flit). A Figura 18 (BENINI; MICHELLI, 2006) ilustra um exemplo 
de transmissão de dados no modo Wormhole. Diferente do modo VCT, onde todo pacote é armazenado em um roteador até que o próximo roteador seja liberado, o modo Wormhole faz que o pacote fique armazenado em mais de um roteador até que o próximo roteador seja liberado.

Figura 18: Exemplo de transmissão de um pacote com o mecanismo Wormhole Switching.

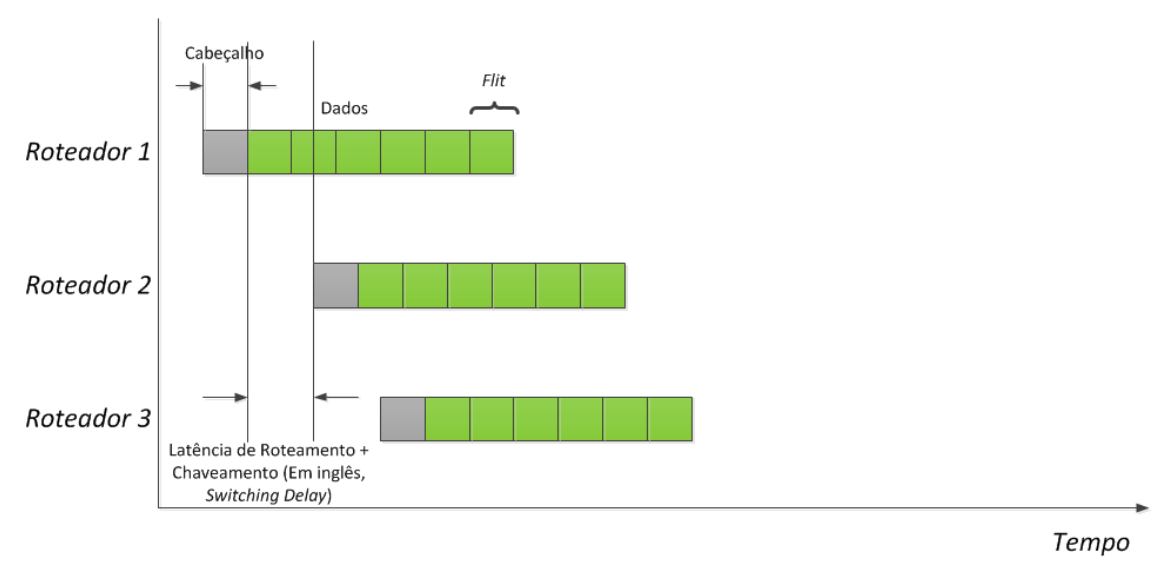

Fonte: (BENINI; MICHELLI, 2006).

Existe um mecanismo adicional conhecido como Canais Virtuais (em inglês, Virtual Channels) que consiste em multiplexar diversos buffers sobre o mesmo canal físico. A Figura 19 (DUATO; YALAMANCHILI; LIONEL, 2002) ilustra um exemplo do funcionamento dos canais virtuais. As entradas A e B utilizam dois canais virtuais diferentes sobre os três roteadores do exemplo. Neste caso os canais virtuais são o preto e a cinza, os quais não tem relação nenhuma entre si, mas é como se existissem duas redes sobre uma mesma rede física.

Figura 19: Exemplo de transmissão de pacotes utilizando Canais Virtuais.

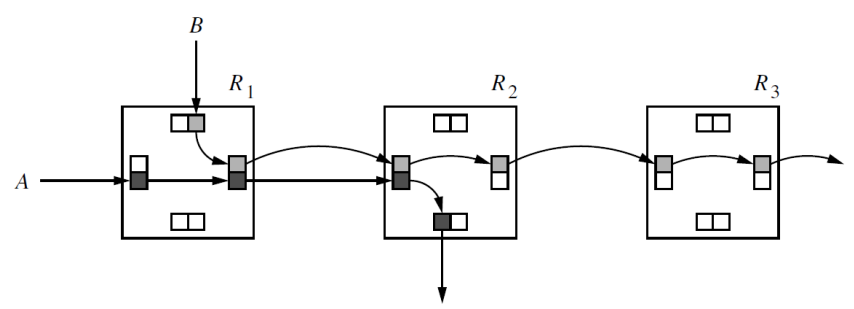

Fonte: (DUATO; YALAMANCHILI; LIONEL, 2002). 


\subsubsection{Controle de Fluxo}

Um controle de fluxo muito comum é pelo protocolo handshake, o qual consiste em que o transmissor informa ao receptor sua intenção de enviar um pacote e este deve responder enviando uma confirmação de que o buffer tem disponibilidade para armazenar o pacote. Outro exemplo de controle de fluxo é aquele que utiliza o protocolo baseado em créditos, o qual consiste na interpretação de espaço disponível do buffer em função de créditos. Finalmente, também temos o controle de fluxo por meio de canais virtuais, o que já foi explicado anteriormente.

\subsubsection{Avaliação de Desempenho}

O desempenho de um roteador pode ser analisado a partir das seguintes métricas:

\subsubsection{Latência}

Esta métrica é definida geralmente como o tempo transcorrido a partir do início da transmissão de uma mensagem no nó fonte até que ela seja totalmente recebida no nó de destino. Porém, esta definição depende das considerações do caso de estudo; por exemplo, se o hardware da rede é incluído na análise, então a latência é considerada como o tempo transcorrido a partir da injeção do cabeçalho da mensagem na rede pelo nó fonte até que o último flit seja recebido pelo nó de destino. Além disso, pode-se considerar o tempo de fila (do inglês, queing time), mas que resulta desprezível quando a rede está quase saturada (DUATO; YALAMANCHILI; LIONEL, 2002).

A latência pode também ser definida para operações com comunicações coletivas, considerando-se o tempo transcorrido a partir do início da operação em algum nó até que todos os nós envolvidos na operação finalizem suas respectivas tarefas. Geralmente o que mais importa o projetista é a latência média, uma vez que as cargas de trabalho específicas de operação não são conhecidas, e pode-se ter então uma melhor ideia do comportamento da rede sobre cargas sintéticas (DUATO; YALAMANCHILI; LIONEL, 2002). 
A latência é medida em unidades de tempo, pode ser em tempo absoluto ou em ciclos de relógio. Considerando-se que muitas comparações são feitas utilizando-se simuladores que podem ser executadas em máquinas diferentes, é comum, então, utilizar-se ciclos de relógio para medir a latência (DUATO; YALAMANCHILI; LIONEL, 2002). Nesta dissertação, serão considerados os ciclos de relógio para se expressar a latência, já que se utilizará um simulador de NoCs para comparar diferentes casos de operação, e será considerado o tempo transcorrido como aquele medido a partir do momento que o cabeçalho da mensagem é injetado na rede pelo roteador fonte até que o último flit do mesmo seja recebido no roteador de destino.

\subsubsection{Throughput}

Esta métrica é definida como a quantidade de informação enviada por unidade de tempo, também é definida como a quantidade de tráfego aceito pela rede. O Throughput máximo refere-se ao máximo valor medido ou observado. O Throughput pode ser medido na unidade "mensagens por tempo absoluto (segundos, microsegundos, etc.) ou em "mensagens por ciclo de relógio", para tempo relativo. Por depender do tamanho das mensagens e da rede, então ele pode ser normalizado, dividindo-se a unidade anterior pelos valores do tamanho das mensagens e do tamanho da rede, então as unidades de Throughput podem ser apresentadas, por exemplo, em bits por nó e micro segundos", para tempo absoluto, e em "bits por nó e ciclo de relógio", para tempo relativo. Para simulações onde devem-se comparar diferentes casos, e assumindo a largura de canal igual ao tamanho de flit, então o Throughput se mediria em flits por nó e ciclo de relógio (DUATO; YALAMANCHILI; LIONEL, 2002). Nesta dissertação, um simulador específico de NoCs será utilizado e esta última métrica será a utilizada. 


\section{TRABALHOS PRÉVIOS}

\subsection{Principais propostas de DRNoCs}

\subsubsection{Proposta de Bobda et al - DyNoC}

Esta proposta de (BOBDA et al., 2004) conhecida como DyNoC (pelas suas siglas em inglês, Dynamic Network on-Chip) é o sistema que usamos como referência nesta dissertação. Trata-se de um sistema baseado em uma NoC de topologia malha 2-D, que consiste em nós terminais ou elementos de processamento (EPs) e nós de roteamento ou roteadores. A Figura 20 (BOBDA, 2007) apresenta esta interface de comunicação composta pelos elementos mencionados, em uma rede com topologia em malha 2-D. Pontos vermelhos correspondem a roteadores e os azuis a EPs. Pode-se observar que na configuração proposta, existem roteadores em todas as bordas da rede, o que permite que qualquer módulo de processamento (MPs) tenha roteadores a seu redor.

A arquitetura dos roteadores consiste de 5 portos de comunicação: um porto local para a comunicação com o EP, e as outras quatro (Norte, Sul, Leste e Oeste) para a comunicação com os roteadores adjacentes, cada um com seu respectivo buffer. Cada tarefa do sistema é implementada como um MP, representado como uma caixa retangular, o qual utilizará os recursos de uma área dada (lógica dos roteadores e EPs). Todos os novos MPs serão colocados no dispositivo em tempo de operação, desativando os roteadores e EPs existentes anteriormente no espaço onde serão colocados, os quais serão eventualmente restaurados quando aqueles novos MPs completem sua tarefa em execução.

Cada MP é rodeado em seu limite por roteadores utilizando aquele localizado no seu canto 
Figura 20: Interface de Comunicação do DyNoC.

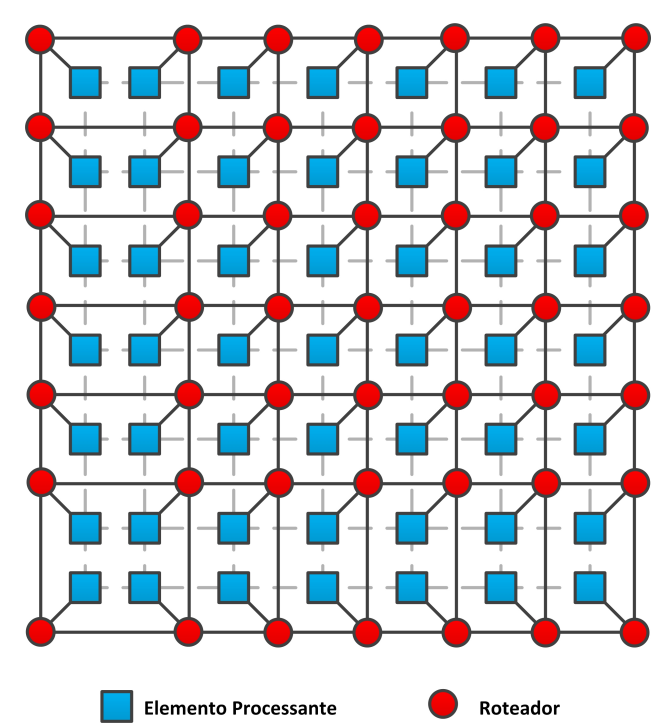

Fonte: (BOBDA, 2007).

superior direito para estar comunicado por meio da rede. O espaço (área) a ocupar por cada módulo tem que ser calculado em termos do espaço de um EP nominal, como por exemplo, no caso da Figura 21 (BOBDA, 2007), onde o módulo C1 é composto de um número de seis EPs para ocupar um espaço na rede. De forma equivalente, comparecem outros módulos como C2, C3 e C4 no interior da rede 5 .

Figura 21: Exemplo de alocação de componentes na DyNoC.

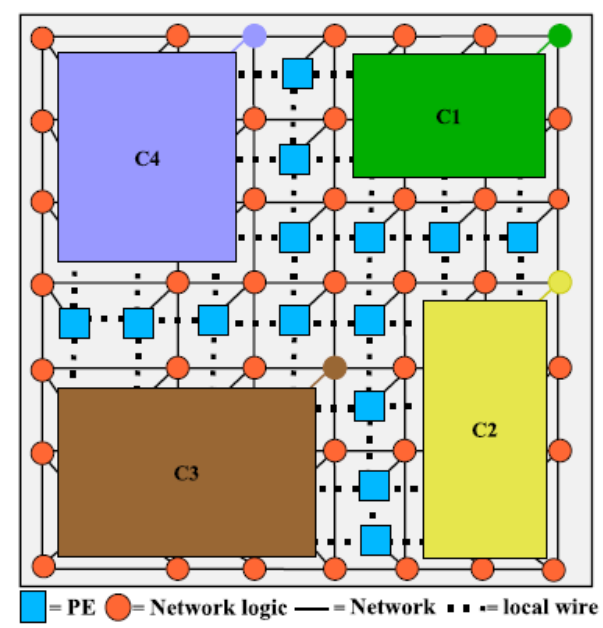

Fonte: (BOBDA, 2007).

O algoritmo de roteamento utilizado é uma modificação do algoritmo de Roteamento Ordenado por Dimensão (DOR do inglês, Dimension Order Routing) como XY routing, adaptado

\footnotetext{
${ }^{5}$ No Capítulo 5 será feita uma distinção mais exata entre EP e MP para os propósitos desta dissertação.
} 
para o DyNoC, já que a alocação de módulos em tempo de operação altera a estrutura da rede gerando obstáculos ao encaminhamento de pacotes. O algoritmo modificado é chamado de algoritmo S-XY (pelas suas siglas em inglês, Surrounding XY) adaptando o algoritmo XY para os casos onde se tenham obstáculos nas direções X ou Y. Bobda afirma que a probabilidade de ocorrer bloqueio infinito de pacotes que compõem uma mensagem é baixa, significando que a arquitetura seja completamente deadlock-free. De fato, Bobda não especifica uma solução para o problema da configuração Mid-Block deadlock, descrito no Capítulo 1.

Este sistema foi implementado para os FPGAs VirtexII-1000 e VirtexII-6000 da companhia Xilinx utilizando-se duas aplicações de vídeo. Uma das limitações deste sistema é sua implementação em DRFPGAs do tipo 1-D, enquanto que o DyNoC é estruturalmente do tipo 2-D, já que no momento de fazer a reconfiguração de um módulo qualquer, além dos CLBs referentes a ele, todos os outros circuitos que estejam configurados na mesma coluna de CLBs também serão reconfigurados, paralisando alguma comunicação existente, o qual reduz o desempenho do sistema.

\subsubsection{Proposta de Pionteck et al - CoNoChi}

A proposta de (PIONTECK et al., 2008) é conhecida como CoNoChi (pelas suas siglas em inglês, COnfigurable Network on-CHIp), onde a reconfiguração do sistema é feita para toda a NoC e não só dos MPs como foi o caso do DyNoC.

O componente principal do CoNoChi é o switch, o qual consiste de uma unidade de controle geral (NoC/Switch Control) encarregado de dar prioridade aos pacotes entrantes e da arbitragem; e 4 portos de entrada (Norte, Sul, Leste e Oeste). Para a saída de dados se têm 4 portos nas mesmas direções dos portos de entrada, os quais utilizam multiplexadores controlados pela unidade de controle geral.

O mecanismo de roteamento utilizado é o VCT e as decisões de roteamento estão baseadas em tabelas de roteamento geradas por uma unidade central e distribuídas na rede via uma rede de sobreposição baseada em árvore. Devido ao uso de um algoritmo de caminho curto (em 
inglês, Shortest Path Algorithm), o problema de deadlock raramente ocorre. A ocorrência seria maior durante a mudança de partições reconfiguráveis na rede, a qual, segundo o autor, pode ser evitado ao se garantir que o tempo de transição entre duas configurações seja maior do que o tempo de vida dos pacotes. Por outro lado, o problema de deadlock é minimizado utilizando-se um método baseado no ordenamento das conexões em um conjunto de camadas, contendo uma árvore de expansão por cada uma (CHIU et al., 2002).

Para reduzir a quantidade de dados de configuração e facilitar o processo de reconfiguração, o posicionamento dos switches e MPs estará limitado a uma malha fixa como apresentado na Figura 22 (PIONTECK et al., 2008). Cada subárea pode ser configurada como um switch, linhas de comunicação verticais ou horizontais, ou como parte de um MP. Note-se que o autor utiliza o termo switch para referenciar a um roteador, já que podem ser utilizados como sinônimos, porém neste trabalho se diferençou entre os termos switch e roteador para referir-se às redes de topologia indireta (baseados em switches) e direta (baseados em roteadores) (DUATO; YALAMANCHILI; LIONEL, 2002), como foi explicado no Capítulo 2.

Figura 22: Estrutura Malha do CoNoChi.

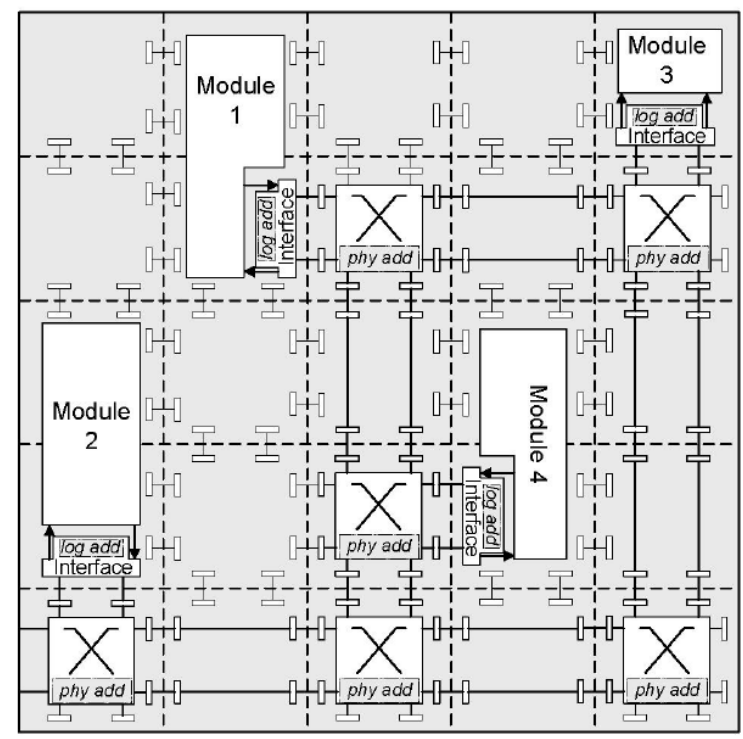

Fonte: (PIONTECK et al., 2008).

Um exemplo de reconfiguração é ilustrado na Figura 23, onde o módulo M3 é trocado por outros menores como M4 e M5. Pode-se apreciar que um novo roteador é inserido para que M4 tenha acesso à rede, enquanto que M5 utiliza o mesmo roteador do M3. As tabelas de 
roteamento têm que ser atualizadas antes e depois do processo de reconfiguração, já que neste exemplo os pacotes que normalmente foram enviados entre os roteadores 1 e 2 têm que ser redirecionados pelos roteadores 3, 4 e 5, para o qual suas tabelas de roteamento têm que ser atualizadas pelo controlador global do CoNoChi. Depois da reconfiguração, o enlace entre os roteadores 1, 6 e 2 tem que ser reativado para que finalmente o controlador global atualize suas tabelas de roteamento.

Figura 23: Exemplo de reconfiguração dinâmica no CoNoChi.

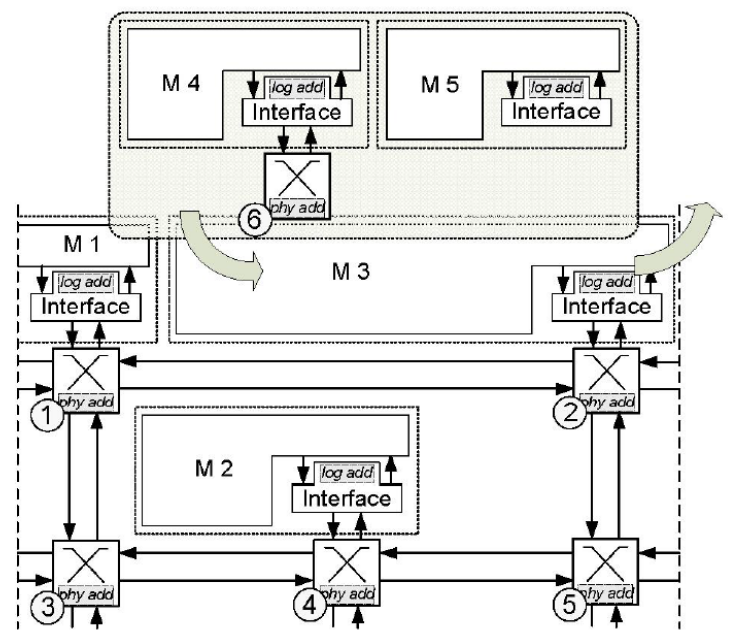

Fonte: (PIONTECK et al., 2008).

O sistema CoNoChi foi implementado no dispositivo DRFPGA Virtex-II Pro 1000 da Xilinx, com a limitação de que uma coluna de CLBs deste dispositivo só pode ser reconfigurada em tempo de operação (reconfiguração parcial 1-D). Para superar este problema, o mesmo sistema foi implementado para o dispositivo DRFPGA Virtex-4 FX da Xilinx, permitindo a reconfiguração mais seletiva dos recursos lógicos do FPGA, em conjuntos conhecidos como frames.

\subsubsection{Proposta de Jovanovic et al - CuNoC}

A proposta de (JOVANOVIC et al., 2009) conhecida como CuNoC (pelas suas siglas em inglês, Communication Unit Network on-Chip) é um sistema baseado em uma unidade de comunicação escalável chamada de UC (Unidade de Comunicação).

A arquitetura da UC é composta de 4 portos de comunicação (Norte, Sul, Leste e Oeste), os quais não têm buffers de armazenamento de pacotes na entrada, mas existem buffers internos 
para as 4 entradas para os casos de gargalo. Além disso, têm uma unidade de roteamento e arbitragem, que de acordo com suas políticas, alocam os pacotes entrantes dentro dos buffers internos para depois os encaminhar pela saída correspondente por meio de multiplexadores e demultiplexadores.

O algoritmo de roteamento utilizado neste sistema está baseado em uma modificação do algoritmo de roteamento S-XY utilizado por (BOBDA; AHMADINIA, 2005), só que além de alternar a direção dos pacotes entre vertical e horizontal no caso de obstáculos, também se faz o mesmo no caso de tráfego na rede até encontrar um caminho livre para seu destino final através dos roteadores. Além, este algoritmo não permite que os pacotes recebidos em um roteador, tomem a mesma direção de origem. Isso faz que este algoritmo de roteamento dar um caminho mais longo para o destino final que o algoritmo S-XY usado no DyNoC. Finalmente, o modo de roteamento utilizado é o SAF, o qual foi explicado na capítulo anterior.

A estrutura da rede é composta por dois tipos de UCs: a UC clássica e a UC gerenciadora de caminho (UCgw do inglês, to-give-away UC). Num primeiro instante os UCs recebem pacotes e verificam a disponibilidade dos UCs adjacentes, depois no caso em que todos os UCs adjacentes estiver ocupados (caso de gargalo), os UCgw passam a um estado de disponibilidade e recebem todos os pacotes dos UCs adjacentes. Uma vez que todos os pacotes foram recebidos, o UCgw envia cada um destes para seus respectivos destinos. A Figura 24 ilustra a estrutura do CuNoC conformado pelos UCs clássicos e UCgw.

O processo de reconfiguração dinâmica da rede consiste primeiramente em alocar cada um dos MPs na rede de forma que estejam rodeados por UCs para que possam ser alcançados pelos pacotes que circulam a rede. A comunicação com os roteadores é feita através de um de seus quatro portos. Cada MP, com uma área maior do que um UC, substituirá toda uma zona de UCs cuja área seja maior ou igual à área do módulo. Os endereços dos UCs substituídos são herdados pelo módulo inserido, com o qual terá 4 pontos de acesso para a rede. A Figura 25 ilustra as fases sucessivas da construção da rede e a alocação de módulos.

Um controlador de reconfiguração é encarregado de decidir em que zona da rede será alo- 
Figura 24: Estrutura do CuNoC conformada por UCs.

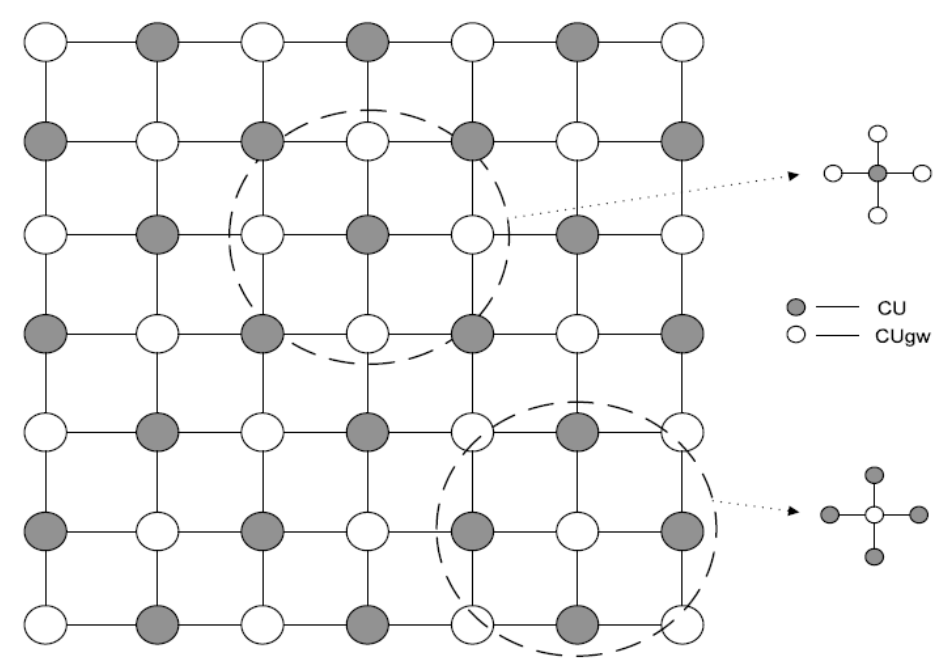

Fonte: (JOVANOVIC et al., 2007).

Figura 25: Fases de Configuração do CuNoC.

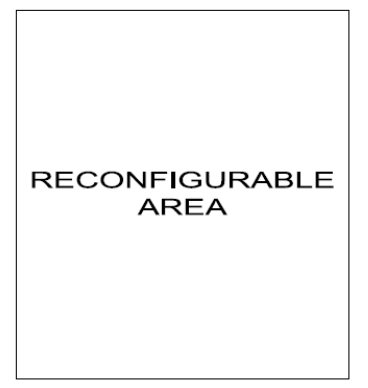

1st phase

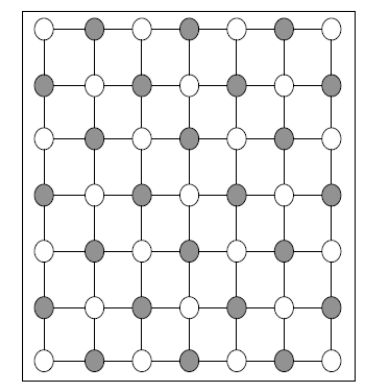

2nd phase

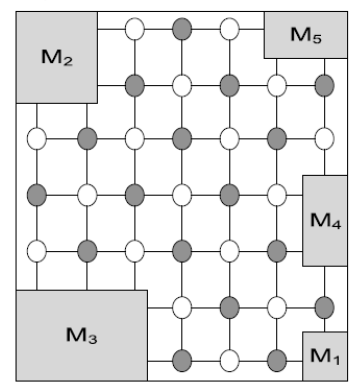

3rd phase

Fonte: (JOVANOVIC et al., 2007).

cada um novo MP, para o qual é necessário analisar uma área reconfigurável disponível dentro da rede. Depois desta análise, o controlador de reconfiguração informa aos UCs a serem substituídos, para que possam esvaziar seus buffers e mudar seus estados para serem configurados como MP. Os outros elementos da rede também são informados para que considerem a área reconfigurada como obstáculo e não enviem pacotes por esse caminho. A Figura 26a ilustra um exemplo de uma rede onde será inserido o módulo M6 por reconfiguração dinâmica, e a Figura 26b ilustra a nova configuração com os novos caminhos a serem adotados.

O CuNoC foi implementado em dispositivos das famílias Virtex II e Virtex IV da Xilinx para diversos tamanhos do $\mathrm{CuNoC}(2 \times 2,3 \times 3$ e $4 \times 4 \mathrm{UCs})$ e diferentes quantidades de bits de dados, obtendo uma frequência de operação máxima de 549.3 MHz para esta ultima família. A 
Figura 26: Reconfiguração Dinâmica de módulos no CuNoC.

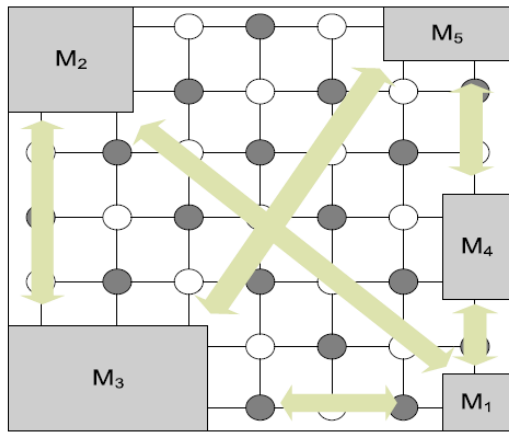

a

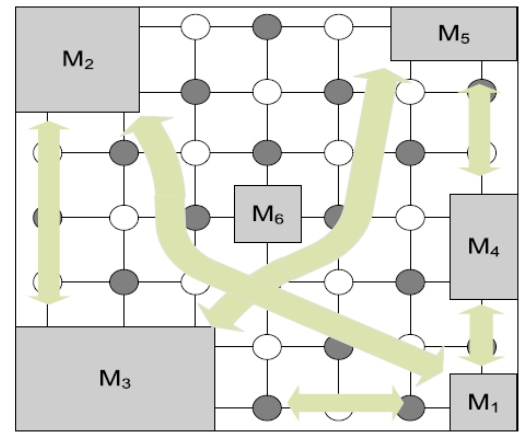

b

Fonte: (JOVANOVIC et al., 2007).

latência de cada UC está entre 2 até 8 ciclos de relógio dependendo da quantidade de pacotes recebidos no momento. A partir destes parâmetros, é possível determinar a taxa de transferência, a qual é maior no caso da família Virtex IV devido a que possui a tecnologia mais avançada.

\subsubsection{Proposta de Jovanovic et al - QNoC}

A outra proposta de (JOVANOVIC; TANOUGAST; WEBER, 2008) é outra DRNoC baseada em roteadores inteligentes chamados Q-switches, o qual segundo o autor é uma versão melhorada do $\mathrm{CuNoC}$, já que melhora o algoritmo de roteamento com a finalidade de escolher um caminho mínimo entre os MPs e desta forma melhorar o desempenho.

Assim como o UC no CuNoC, o elemento básico no QNoC é o Q-switch consiste de 4 portos bidirecionais com um registrador em cada porto de entrada para armazenar os pacotes entrantes. Uma vez que os pacotes são recebidos e armazenados, um bloco de controle de roteamento (em inglês, Routing Block) processa seus endereços de destino para enviá-los às respectivas lógicas de saída. No caso de ter mais de 3 pacotes tomando a mesma direção de saída, aplica-se a política de arbitragem baseada na mesma regra que a do CuNoC (priority to-the-right).

O modo de roteamento utilizado é o SAF (como o CuNoC), além disso, o algoritmo de roteamento utilizado é chamado de MPA (do inglês, Module Proximity Algorithm) o qual segundo Jovanovic et al. é livre de deadlock já que tem certas regras sobre as viradas permitidas 
dos pacotes para evitar ciclos fechados (JOVANOVIC, 2009). Este algoritmo está baseado em tabelas de roteamento, além disso foi validado e comparado com outro algoritmo do mesmo tipo, demonstrando ter maior eficiência devido a sua menor latência na transmissão de pacotes e capacidade de adaptação.

A alocação de MPs na malha QNoC consiste em 3 fases: primeiro, a construção da rede a partir dos roteadores; segundo, a alocação dos MPs. Como o caso do CuNoC, aqueles módulos substituem os Q-switches necessários que ocupem o mesmo tamanho de área no chip. A terceira fase consiste na reconfiguração parcial dos outros MPs. O algoritmo de roteamento utilizado permite a reconfiguração parcial em tempo de operação, por exemplo, se um módulo é alocado no meio de uma comunicação importante entre dois módulos, sua comunicação não será afetada devido a que o caminho dos pacotes é determinado em tempo de operação. A Figura 27 (JOVANOVIC; TANOUGAST; WEBER, 2008) ilustra um exemplo de reconfiguração parcial dinâmica do módulo M7 dentro de uma configuração composta por M1, M2, M3, M4, M5 e M6.

Figura 27: Posicionamento dinâmico de módulos no QNoC.

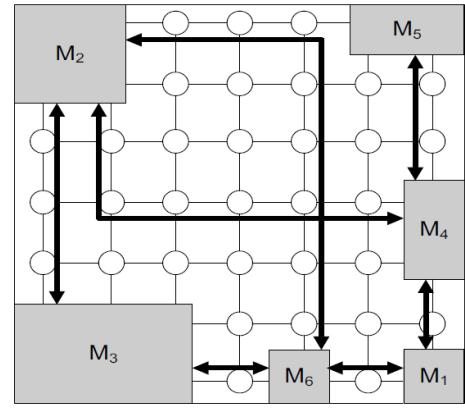

a)

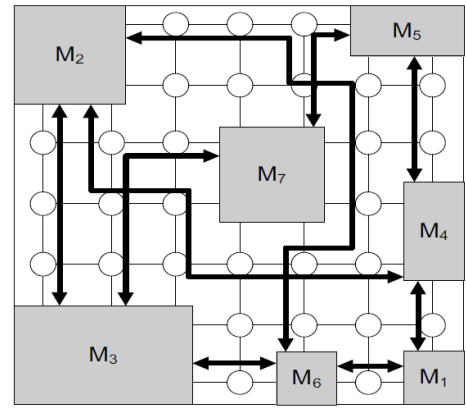

b)

Fonte: (JOVANOVIC; TANOUGAST; WEBER, 2008).

O QNoC foi sintetizado e implementado para a família de dispositivos Virtex IV da Xilinx. A Tabela 3 (JOVANOVIC; TANOUGAST; WEBER, 2008) apresenta os resultados da síntese de um Q-switch para diferentes tamanhos de bits de dados; para todos os casos a frequência máxima de operação é de $249.3 \mathrm{MHz}$ com a qual é possível obter a taxa de transferência de dados de 3.2 Gbps para um tamanho de dados de 8 bits. 
Tabela 3: Resultados da síntese do QNoC em Virtex IV

\begin{tabular}{|c|c|c|}
\hline \multicolumn{3}{|c|}{ Q-switch } \\
\hline Tamanho de Dados & CLB Slices & Virtex IV f[MHz] \\
\hline \hline 8 bit & 365 & 249.3 \\
\hline 16 bit & 434 & 249.3 \\
\hline 32 bit & 504 & 249.3 \\
\hline 64 bit & 598 & 249.3 \\
\hline
\end{tabular}

Fonte: (JOVANOVIC; TANOUGAST; WEBER, 2008).

\subsubsection{Proposta de Miorandi et al}

A proposta de (MIORANDI, 2012) consiste de uma arquitetura de 4 submalhas ligadas entre si por meio de uma rede hierárquica composta de 4 roteadores (cada um ligado a um roteador da submalha), como ilustrado na Figura 28. O sistema de controle de reconfiguração parcial dinâmica para alocação de módulos reconfiguráveis não foi desenvolvido, nem implementado, assim como a caracterização de desempenho de submalhas não foi feita.

Esta proposta foi desenvolvida começando a partir da versão básica do roteador da rede Hermes apresentada por (MORAES et al., 2004) da Pontifícia Universidade Católica de Rio Grande do Sul (PUCRS). Sua arquitetura é composta de roteadores com 5 portos bidirecionais: Norte, Sul, Leste, Oeste e Local, este último para se conectar com um EP local. Todos os portos de entrada têm um buffer de 2 registradores de 16-bits para armazenar os pacotes entrantes, cuja dimensão se adapta ao modo de roteamento Wormhole Switching.

A arquitetura do roteador está composta por um bloco de arbitragem (em inglês, Arbitration Block) que determina a ordem em que serão transmitidos os flits armazenados nos buffers do roteador, e um bloco de chaveamento (em inglês, Switching Block) baseado em uma arquitetura crossbar. O algoritmo de roteamento utilizado é o algoritmo FDOR (Flexible Dimension Order Routing), o qual será detalhado no próximo Capítulo.

A estrutura desta proposta está baseada em submalhas, as quais possuem um algoritmo de roteamento independentes entre si. A comunicação entre elas é realizada por meio de roteadores hierárquicos conhecidos como roteadores pai (em inglês, Parent Switch). A metodologia 
garante que, dentro de cada submalha, o algoritmo de roteamento é livre de deadlock, então quando se conectam por meio da malha hierárquica, toda a estrutura da rede é considerada livre de deadlock. A Figura 28 (MIORANDI, 2012) ilustra a estrutura da rede com topologia de submalhas hierárquicas com uma configuração de módulos de processamento sobre ela, alguns elementos se podem distinguir como os pontos de acesso (AP, do inglês Access Point) que conecta os EPs com a rede, os roteadores pais, e os roteadores LS (do inglês, Leaving Switch), os quais estão localizados em um canto da malha para se conectar com a rede hierárquica. Os caminhos de roteamento P1 e P3 são determinados pelas regras de roteamento do algoritmo FDOR, as quais serão explicadas com todo detalhe na seção posterior.

Figura 28: Arquitetura de uma rede de submalhas hierárquicas.

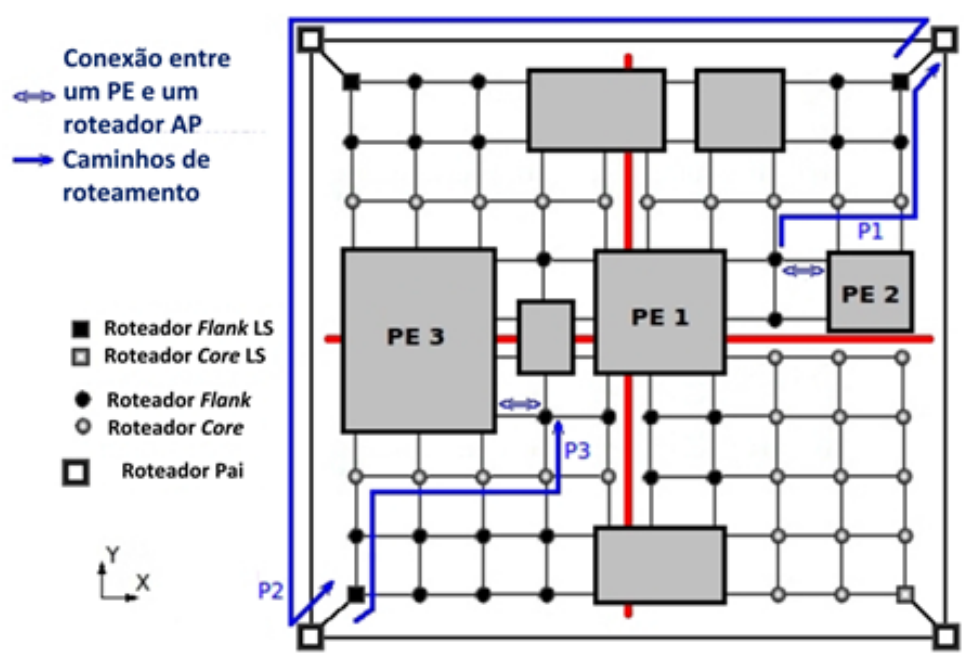

Fonte: (MIORANDI, 2012).

\subsection{Análise e Estudo do Comparativo das DRNoCs}

O principal aspecto em comum das propostas anteriores é que todas elas estão baseadas em uma topologia malha 2-D, composta por nós de roteamento onde os módulos de processamento são alocados durante o processo de reconfiguração parcial dinâmica. Com a finalidade de fazer um estudo comparativo entre estas arquiteturas, foram levadas em conta as seguintes propriedades arquiteturais: flexibilidade, escalabilidade, extensibilidade, modularidade, simplicidade e uso de recursos. 
Com respeito à flexibilidade, o CoNoChi e o QNoC possuem uma alta flexibilidade devido ao uso de tabelas de roteamento distribuídas em cada roteador e, nos casos de reconfiguração, as tabelas são rapidamente atualizadas para redirecionar os pacotes por caminhos alternativos. No caso de DyNoC e CuNoC, a flexibilidade é baixa já que seus algoritmos de roteamento baseados em S-XY routing são livres de deadlock, porém para uma quantidade limitada de topologias irregulares. A arquitetura de Miorandi et al. apresenta uma flexibilidade média, já que o uso de malhas hierárquicas permite que os módulos sejam posicionados sobre a rede formando topologias irregulares, condicionado a que cada submalha tenha uma topologia irregular permitida pelo algoritmo FDOR.

Com respeito à escalabilidade, esta depende da latência de chaveamento dos roteadores em cada um dos sistemas. No caso do DyNoC, sua escalabilidade é baixa, uma vez que a latência de chaveamento é muito alta por ser um sistema de tipo 2-D, mas implementado num dispositivo 1-D como o Virtex II da Xilinx; a implementação em dispositivos 2-D (família Virtex 4 em diante) traria melhores resultados. Nos outros casos a escalabilidade é alta, já que a latência de chaveamento não deteriora o desempenho da comunicação.

No caso da extensibilidade, que é uma propriedade que determina o tamanho máximo de uma NoC e a quantidade de módulos a ser alocados, o DyNoC está limitado na extensão vertical, por ser implementado em um dispositivo 1-D que não permite o uso mais seletivo de recursos lógicos. No caso das outras redes, elas têm uma extensibilidade alta e só estão limitadas pelas dimensões do DRFPGA de tipo 2D.

Com respeito à modularidade, os módulos de processamento a serem alocados dentro das redes CoNoChi, CuNoC, QNoC e Miorandi et al., são de tamanho variável, podendo substituir roteadores, no espaço físico do dispositivo apresentado, então, sua modularidade é alta. O DyNoC apresenta modularidade média, já que os módulos de processamento devem ser de tamanho múltiplo do EP nominal e não substituem de fato os roteadores, sendo estes apenas desativados.

Quanto à simplicidade, o DyNoC se destaca, pois, na sua arquitetura utilizam-se poucos 
recursos lógicos para a implementação, já que só consiste das malhas de roteadores e EPs nominais e não requer módulos especiais como os casos de CuNoC e QNoC. Além disso, o algoritmo de roteamento S-XY, embora não garanta ser livre de deadlock, requer baixa quantidade de recursos lógicos para sua implementação em comparação com as outras propostas que são mais complexas.

O uso de recursos está relacionado diretamente com a simplicidade, por exemplo para os casos de CoNoChi e QNoC, a quantidade de recursos para a implementação das tabelas de roteamento é alta em comparação com o CuNoC e o DyNoC, que utilizam menos recursos para implementação dos algoritmos de roteamento baseados no algoritmo S-XY. No caso de Miorandi et al., o uso de recursos também é considerado como médio, já que sua arquitetura é simples, mas o uso de recursos dependeria do tamanho das submalhas. Entretanto a implementação do algoritmo FDOR em hardware é de baixo custo como será visto no próximo capítulo.

\subsection{Algoritmos de Roteamento}

O estudo dos algoritmos de roteamento utilizados por cada uma das propostas acima é importante, já que é um dos focos principais desta dissertação. Com respeito à DyNoC, o algoritmo de roteamento utilizado, o S-XY routing, é baseado em algoritmos DOR (por exemplo, XY ou YX routing), modificado para ser utilizado em uma rede 2-D irregular (resultante de bloqueios realizados por módulos). Entretanto, ele não garante que o DRNoC seja livre de deadlock - devido a que o autor menciona que a rede tem uma alta probabilidade de ser livre de deadlock pelo uso de canais virtuais.

No caso de CuNoC, o algoritmo de roteamento é uma modificação do S-XY, com algumas viradas proibidas nas rota dos pacotes, como forma de evitar casos de deadlock. O número de topologias irregulares permitidas é reduzido, o que faz que a rede seja mais inflexível. O QNoC possui uma estrutura baseada no $\mathrm{CuNoC}$, mas utiliza o algoritmo de roteamento MPA que se caracteriza por ser livre de deadlock e tolerante a falhas. Este algoritmo está baseado em tabelas de roteamento (TBR do inglês, Table-Based Routing), o qual permite maior flexibilidade que as 
outras propostas, porém o custo de implementação é alto. Além disso, a atualização das tabelas de roteamento requer um tempo considerável, o qual não é escalável para um DRS.

Embora o CoNoChi tenha uma alta flexibilidade por usar um roteamento TBR, a implementação requer muitos recursos lógicos, assim como exige grande tempo de projeto para obter uma topologia de rede dependente da aplicação (HAIYUN, 2011). Além, durante a reconfiguração parcial dinâmica, todas as tabelas de roteamento, locais e a global, devem ser atualizadas, o que não é uma boa solução escalável para DRSs, considerando-se que a rede não pode enviar mensagens por um alto período de tempo até que as tabelas sejam atualizadas.

Outros algoritmos de roteamento livres de deadlock também são encontrados na implementação de NoCs tolerantes a falhas, como o caso de MAZENOC (WACHTER; MORAES, 2012) e OSR-Lite (STRANO et al., 2012). Em NoCs tolerantes a falhas, os algoritmos também devem estar aptos a fazer com que pacotes evitem regiões bloqueadas, derivadas de falhas ocorridas. As soluções apresentadas caracterizam-se por utilizar grande quantidade de recursos para a sua implementação. O MAZENOC apresenta uma solução de dois canais para os pacotes, com mais um canal extra de comunicação para atividade de backtracking com a finalidade de executar um roteamento adaptativo. Já no caso de OSR-Lite, a estratégia é baseada em LBDR e dois canais virtuais, o qual requer que uma configuração de 18 bits por cada canal, a qual é modificada sempre que ocorrer uma reconfiguração.

A Tabela 4 apresenta um quadro comparativo dos trabalhos prévios com seus respectivos algoritmos de roteamento e descrevendo as suas características principais, as quais justificam o uso do algoritmo FDOR para uma DRNoC, como uma proposta ótima que supera as limitações de cada uma das propostas anteriores. 
Tabela 4: Tabela Comparativa dos Trabalhos Prévios

\begin{tabular}{|c|c|c|}
\hline DRNoC & Algoritmo de Roteamento & Características \\
\hline DyNoC (Bobda, 2005) & Roteamento S-XY (Surrounding-XY) & \multirow[t]{2}{*}{$\begin{array}{l}\text { - Baseado no algoritmo Direction-Order-Routing } \\
\text { (DOR) ex. roteamento XY ou YX, } \\
\text { - Não livres de Deadlock, } \\
\text { - Alto custo de implementação. }\end{array}$} \\
\hline $\begin{array}{c}\text { CuNoC (Jovanovic, } \\
2008 \text { ) }\end{array}$ & Modificação do Roteamento S-XY & \\
\hline $\begin{array}{c}\text { QNoC (Jovanovic, } \\
\text { 2009) }\end{array}$ & $\begin{array}{l}\text { Force-Directed } \\
\text { Wormhole } \\
\text { Routing }\end{array}$ & \multirow[t]{2}{*}{$\begin{array}{l}\text { - Roteamento Baseado em Tabelas } \\
\text { (TBR do inglês, Table-Based Routing), } \\
\text { - Livre de Deadlock, }\end{array}$} \\
\hline $\begin{array}{l}\text { CoNoChi } \\
\text { (Pionteck, } \\
\text { 2008) }\end{array}$ & Tabelas de Roteamento & \\
\hline $\begin{array}{l}\text { MAZENOC (Strano, } \\
\text { 2012) }\end{array}$ & Algoritmo de Busca de Caminho & $\begin{array}{l}\text { - Usa FSM para busca do melhor caminho, } \\
\text { - Livre de Deadlock, } \\
\text { - Alto Custo de implementação } \\
\text { (ex. } 100 \text { bits, e dois canais físicos de dados). }\end{array}$ \\
\hline $\begin{array}{c}\text { OSR-Lite (Strano, } \\
\text { 2012) }\end{array}$ & $\begin{array}{c}\text { Reconfiguração Estática } \\
\text { Sobreposta (OSR, Overlapping } \\
\text { Static } \\
\text { Reconfiguration) }\end{array}$ & $\begin{array}{l}\text { - Roteamento Distribuído Baseado em Lógica } \\
\text { (LBDR, do inglês Logic Based Distributed Routing), } \\
\text { - Livre de Deadlock, } \\
\text { - Alto Custo de Implementação } \\
\text { (ex. } 18 \text { bits de configuração nos dois canais de } \\
\text { transmissão). }\end{array}$ \\
\hline
\end{tabular}

Fonte: Autor, 2014. 


\section{ALGORITMO DE ROTEAMENTO ORDENADO POR DIMENSÃO FLEXIBILIZADO}

\subsection{Fundamentos do Algoritmo}

Este capítulo explicará os conceitos básicos do algoritmo FDOR de roteamento em NoCs e suas vantagens sobre os outros algoritmos de roteamento utilizados nos trabalhos prévios. Depois, será apresentada sua implementação em lógica combinacional proposta por (MIORANDI, 2012) baseada na proposta de (SKEIE et al., 2009).

O algoritmo FDOR foi proposto inicialmente por (SKEIE et al., 2009), caraterizando-se por permitir o roteamento de pacotes sobre estruturas (topologias) irregulares em malhas 2-D, e garantindo a conectividade e a característica de ser livre de deadlock. Este algoritmo é de tipo roteamento baseado em lógica (em inglês, Logic-Based Routing), cujo custo de implementação é baixo em comparação com as implementações de outros tipos de algoritmos como Roteamento por Ordem de Dimensão (DOR do inglês, Dimension Order Routing), Roteamento baseado em Lógica Distribuída (LBDR do inglês, Logic-Based Distributed Routing) ou roteamento baseado em Tabelas (TBR do inglês, Table-Based Routing).

A implementação do algoritmo FDOR requer um grupo de portas lógicas combinacionais e somente um bit de configuração por roteador, o que o torna significativamente menos complexo que as outras técnicas de roteamento mencionadas anteriormente. Por exemplo, Skeie et al. demonstram que um roteador com algoritmo de roteamento FDOR ocupa menor área no chip que no caso de um roteador com algoritmo DOR (ex. XY ou YX) e que com um algoritmo LBDR; este último, por exemplo, requer três bits extras para configuração e algumas portas lógicas extras por roteador. 
O FDOR é proposto para uma rede de malha 2-D, onde um conjunto de roteadores estão desativados formando uma topologia irregular, seja devido a falhas, como é o cenário original definido por Skeie et al., ou a esquemas de reconfiguração dinâmica como é o caso da proposta desta dissertação. A existência de áreas onde os roteadores estão desativados acaba por definir, na área de roteadores ativos, um padrão de topologia de roteadores que consiste em três ou duas sub-regiões.

Estas sub-regiões são definidas da seguinte forma: o núcleo (em inglês, core), a ala X(em inglês, $\mathrm{X}$ - flank) e a ala $\mathrm{X}+($ em inglês, $\mathrm{X}+$ flank), onde as coordenadas $X$ dos roteadores na sub-região ala $X$ - devem ser menores que as coordenadas $X$ dos roteadores na sub-região núcleo; e estas últimas menores que as coordenadas $X$ dos roteadores na sub-região $\mathrm{X}+$, como apresentado na Figura 29(a). No caso em que a topologia consistir em duas sub-regiões, existem apenas um núcleo e uma ala, como, por exemplo, a topologia apresentada na Figura 29(b). Estas sub-regiões permitem a formação de uma grande variedade de topologias irregulares ${ }^{6}$.

Os pontos vermelhos na Figura 29(a) representam os roteadores que pertencem ao núcleo, enquanto que os pontos verdes representam um grupo de roteadores que pertencem às alas. $\mathrm{O}$ núcleo e as alas possuem um algoritmo DOR simples (ex. XY ou YX). Por exemplo, na Figura 29(a), o caminho de um pacote a partir da coordenada $(0,1)$, na ala X-, até a coordenada $(4,4)$, na ala X+, é apresentada: primeiro, o algoritmo FDOR usa um roteamento XY dentro da ala X(em direção X); depois quando o pacote alcança a sub-região núcleo, o algoritmo de roteamento muda para YX (em direção $Y$ e depois em direção $X$ ) até que o pacote tenha alcançado a ala $\mathrm{X}+$; finalmente o pacote alcança seu destino entrando na ala $\mathrm{X}+$ ao longo da direção $\mathrm{X}$ usando o algoritmo de roteamento XY novamente.

As Figuras 29(a), (b) e (c) apresentam exemplos de topologias permitidas pelo algoritmo FDOR, com formas irregulares como 'S', 'P' e 'd' respectivamente. A Figura 29(d) apresenta um exemplo conhecido como topologia '+', para a qual as alas podem também estar posicionadas ao longo da direção Y-. A diferença em relação às topologias anteriormente apresentadas

\footnotetext{
${ }^{6}$ Pode ocorrer que o(s) conjunto(s) de roteadores desativado(s) levem à formação de um núcleo ao longo do eixo $\mathrm{X}$ com ala(s) $\mathrm{Y}$ - (e $\mathrm{Y}+$ ). Todas as propriedades do caso $\mathrm{X}$ - e/ou $\mathrm{X}+$ se mantêm, apenas com a mudança de características relativas ao eixo $\mathrm{X}$ para o $\mathrm{Y}$, e vice-versa.
} 
é que o núcleo agora executa o roteamento XY e as alas, o roteamento YX. Outro exemplo é apresentado na Figura 29(h), semelhante ao caso (a), mas girado em 90 graus, resultando com o alinhamento ala-núcleo-ala ao longo do eixo Y. Outros exemplos de topologias FDOR permitidas são aquelas que seguem um formato ' $\mathrm{L}$ ' ou ' $T$ '.

A restrição do algoritmo FDOR para as topologias permitidas ou válidas, é que elas não podem ser côncavas. No esquema proposto, não seria possível a comunicação entre duas alas posicionadas no mesmo lado de um núcleo, porque o caminho dos pacotes precisaria de alguns roteadores que estariam fora do domínio permitido. As Figuras 29(e)-(g) apresentam algumas topologias côncavas que o algoritmo FDOR considera como inválidas.

Figura 29: Exemplos de topologias FDOR.

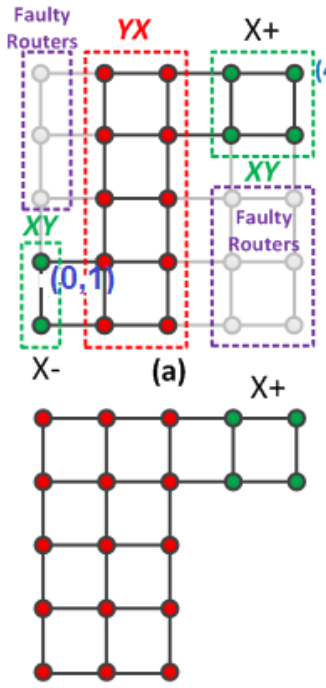

(b)

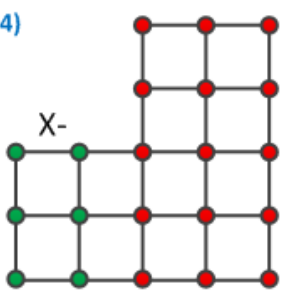

(c)

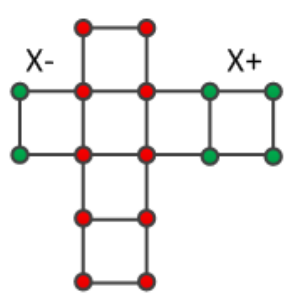

(d)

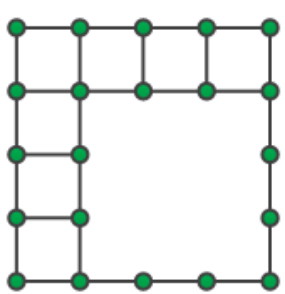

(e)

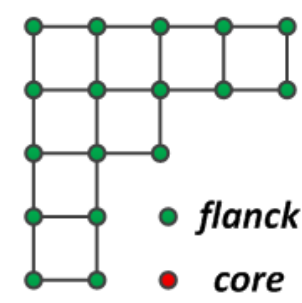

(f)

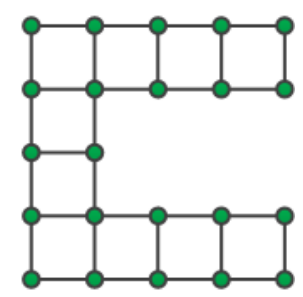

(g)

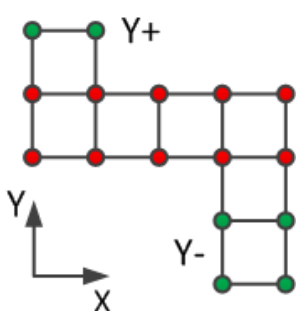

(h)

(a,b,c,d) Permitidas com o núcleo ao longo do eixo Y $(\mathrm{e}, \mathrm{f}, \mathrm{g})$ Não permitidas

(h) Com o alinhamento ala-núcleo-ala ao longo do eixo Y.

Fonte: (Autor, 2014).

O trabalho (SKEIE et al., 2009), prova que o algoritmo FDOR, aplicado a topologias permitidas, é livre de deadlock, já que as regiões de núcleo e alas estão governadas por um algoritmo de roteamento DOR (XY or YX) diferente o qual é livre de deadlock localmente. Como não existem dependências na transmissão de pacotes de núcleo para as alas ou vice-versa, uma vez que o núcleo utiliza um algoritmo DOR diferente daquele usado nas alas, leva-se então à conclusão que o algoritmo FDOR é livre de deadlock. 


\subsection{Distribuição de tráfego com o Algoritmo FDOR}

O roteamento de pacotes sobre uma topologia irregular que segue o algoritmo FDOR utiliza algoritmos DOR (XY ou YX) para cada sub-região da topologia, como já foi explicado, garantindo um comportamento determinístico. A mudança do algoritmo DOR na transição entre ala e núcleo estimula o surgimento de congestionamentos em certas regiões da topologia. Isso faz que a distribuição de tráfego seja não uniforme sobre a topologia irregular, obtendo certas regiões com maior congestionamento nas bordas formadas por linhas de roteadores que separam as sub-regiões de alas e do núcleo.

A Figura 30 apresenta os caminhos mais congestionados para as topologias irregulares permitidas pelo algoritmo FDOR para o caso de transmissão de pacotes a partir de um nó em uma das alas até um nó de destino no núcleo. Os caminhos são indicados pelas setas coloridas. Podese observar que os caminhos dos pacotes são determinados pelo algoritmo DOR da sub-região FDOR específica. Primeiro, um algoritmo XY é seguido para os casos (a), (b), (c), (d) \& (f), enquanto o YX é realizado para o caso (e). Ao sair da ala, ou das alas quando tiver mais que uma, o algoritmo passa de XY para YX e vice-versa para o caso (e). Neste ponto, observa-se que todos os pacotes percorrem uma coluna ou fila (apenas para o caso (e)) de roteadores do núcleo que faz limite com a ala de origem dentro de linhas vermelhas, indicando que aí é onde se tem maior congestionamento de pacotes. Estas colunas ou filas serão denominadas de linhas de congestionamento.

No caso de transmissões de pacotes do núcleo para as alas, elas são feitas de maneira mais distribuída, sem se concentrar em uma determinada linha de roteadores ao ocorrer a transição do núcleo para as alas. As Figuras 31(b) e (c) (topologias 'p' e 'd' respectivamente) apresentam como todos os pacotes provenientes do núcleo transitam, primeiro, na direção Y até que o valor de sua coordenada $Y$ seja igual à do destino para depois serem transmitidos em direção $X$, cruzando a borda. Isto ocorre, pois o núcleo é sempre mais longo que as alas, contendo todas as suas coordenadas $Y$.

Nos casos particulares das topologias apresentadas nas Figuras 31(a), (d), (e) e (f), as trans- 
Figura 30: Exemplos de Transmissão de pacotes de ala para núcleo em topologias irregulares FDOR gerando linhas de congestionamento.

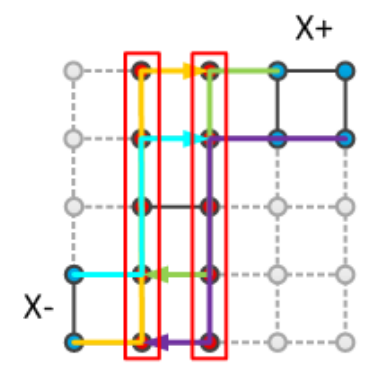

(a)

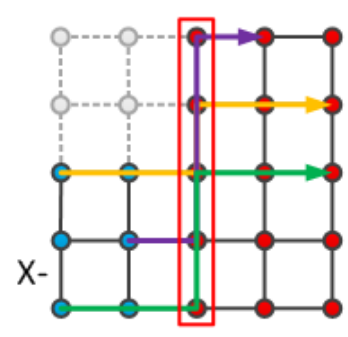

(c)

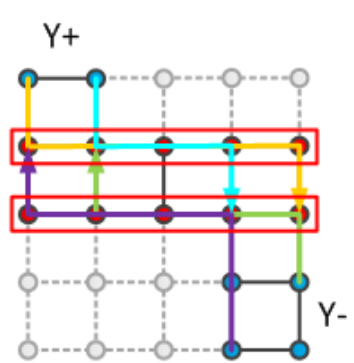

(e)

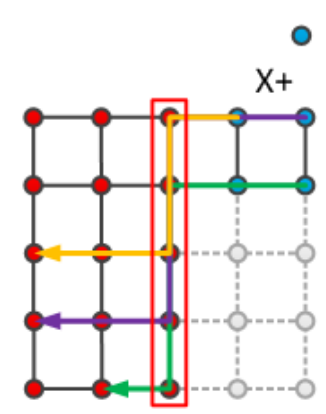

(b)

Ala

- Núcleo

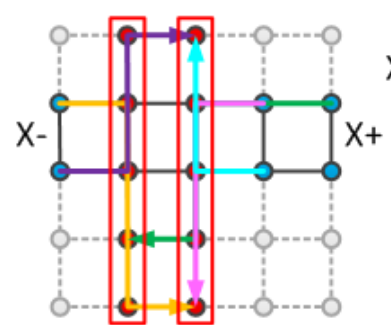

(d)

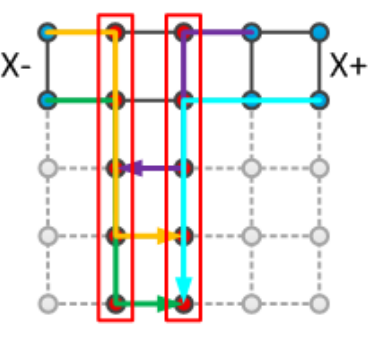

(f)

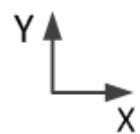

Fonte: (Autor, 2014).

missões de pacotes tendem a formar algumas linhas de congestionamento, porém tal situação deve-se a que o núcleo possui significativamente mais linhas que as alas e à pequena quantidade de colunas (filas no caso da Figura31(e)) que formam o núcleo, igual a dois. Se o número de colunas fosse maior, como no caso das topologias 'd' e 'p' (casos b e c), não se formariam estas linhas de congestionamento já que a tráfego se distribuiria sobre várias colunas.

Ao juntar-se ambos cenários de transmissões, o congestionamento aumenta nas topologias apresentadas, resultando na redução de desempenho na transmissão da dados. Por outro lado, ainda não tem um estudo sobre este problema de desempenho no algoritmo FDOR, então nesta dissertação será elaborada uma avaliação de desempenho na transmissão de pacotes para as diferentes topologias irregulares permitidas pelo algoritmo FDOR, o qual será apresentado no Capítulo 6. 
Figura 31: Exemplos de Transmissão de pacotes de núcleo para as alas em topologias irregulares FDOR.

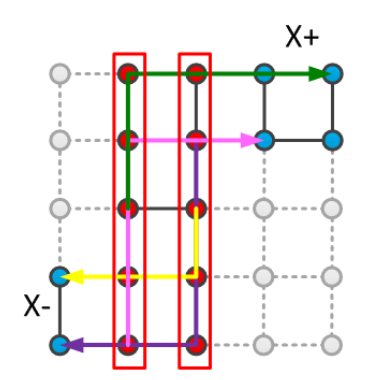

(a)

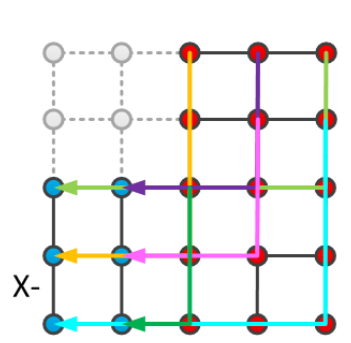

(c)

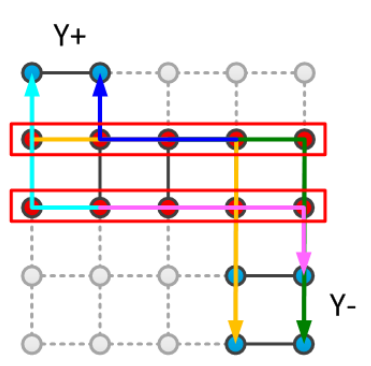

(e)

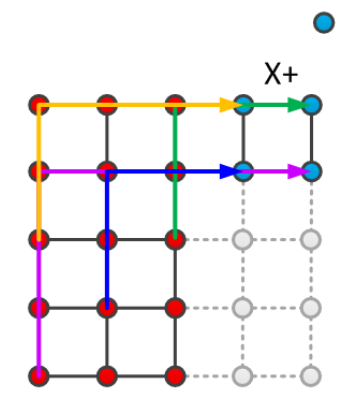

(b)

○ Alas

- Núcleo

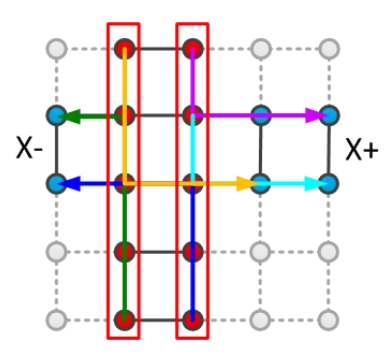

(d)

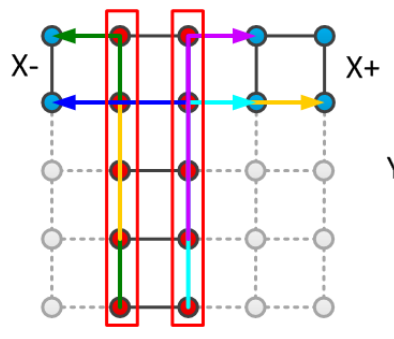

(f)

Fonte: (Autor, 2014).

\subsection{Implementação do Algoritmo FDOR}

(SKEIE et al., 2009) propuseram um circuito de portas lógicas, implementado dentro de cada roteador, para determinar o algoritmo de roteamento a partir das coordenadas atuais do pacote sendo transmitido e as coordenadas do destino. A comparação entre estas coordenadas produz dois sinais $X_{0}$ e $Y_{0}$. O sinal $X_{0}$ será igual a '1' lógico quando a coordenada $X$ do roteador onde se encontra o pacote atualmente é igual a coordenada $X$ do roteador de destino, o mesmo ocorre para a coordenada $Y$. Outro sinal deste circuito é $C$ que indica com ' 1 ' lógico quando o roteador pertence à região de núcleo ou '0' lógico se pertencer às alas. O circuito lógico determina que tipo de roteamento será feito, ativando os buffers tri-estado com os sinais resultantes da lógica combinatória dos sinais $X_{0}, Y_{0}$ e $C$. As saídas dos buffers $X_{+}, X_{-}, Y_{+}$e $Y_{-}$indicam por qual porto de saída tem que ser enviados os pacotes. No caso em que $X_{0}$ e $Y_{0}$ tenham valores de '1' lógico, então o porto de saída dos pacotes será o local. A Figura 32 (SKEIE et al., 2009) apresenta este circuito lógico. Apesar de que a Figura 32 refira-se a um circuito para uma rede 2-D, Skeie et al. propuseram uma lógica FDOR para uma rede de três dimensões (XYZ). 
Figura 32: Esquemático do circuito lógico do algoritmo FDOR em um roteador para seleção de portos de saída.

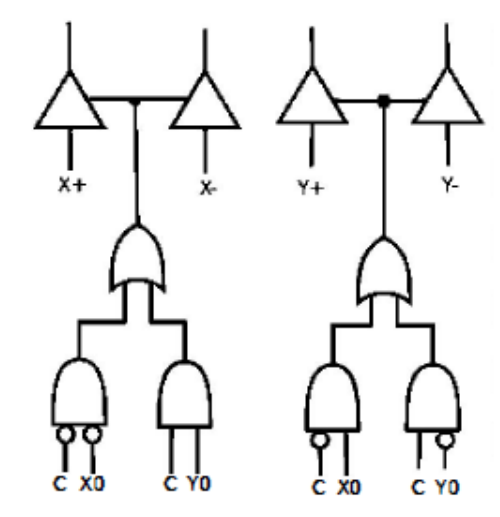

Fonte: (SKEIE et al., 2009).

\subsection{Implementação da Lógica FDOR Automática (AFDOR)}

Os autores não se preocuparam com o desenvolvimento de uma lógica que determinasse o roteamento de cada roteador a partir das informações sobre a forma da topologia irregular da rede. Esta tarefa foi incorporada por (MIORANDI, 2012), onde é proposta uma lógica combinacional chamada de FDOR Automática (AFDOR do inglês, Automatic FDOR) que recebe as informações da topologia irregular da rede malha 2-D provenientes de uma interface externa. A técnica proposta é bastante adequada à arquitetura alvo desta dissertação, de sistema dinamicamente reconfigurável, a lógica será utilizada cada vez que se precise reconfigurar dinamicamente a estrutura da rede, o que terá que ser feito automaticamente a partir das informações da topologia que a rede terá logo após o posicionamento de novos módulos de processamento sobre a malha 2-D.

A Figura 33(a) apresenta o circuito lógico de configuração de um roteador só que se interliga com os outros circuitos de configuração correspondentes aos outros roteadores, formando entre si uma matriz das mesmas dimensões da rede que, adicionado com uma lógica externa, compõem a lógica AFDOR. A Figura 33(b) (MIORANDI, 2012), por sua vez, apresenta a lógica AFDOR correspondente a uma malha de $4 \times 4$ roteadores.

No caso do bloco lógico apresentado na Figura 33(a), os sinais $P c i \_D$ e $C r i \_D$, onde $D$ 
Figura 33: Lógica AFDOR

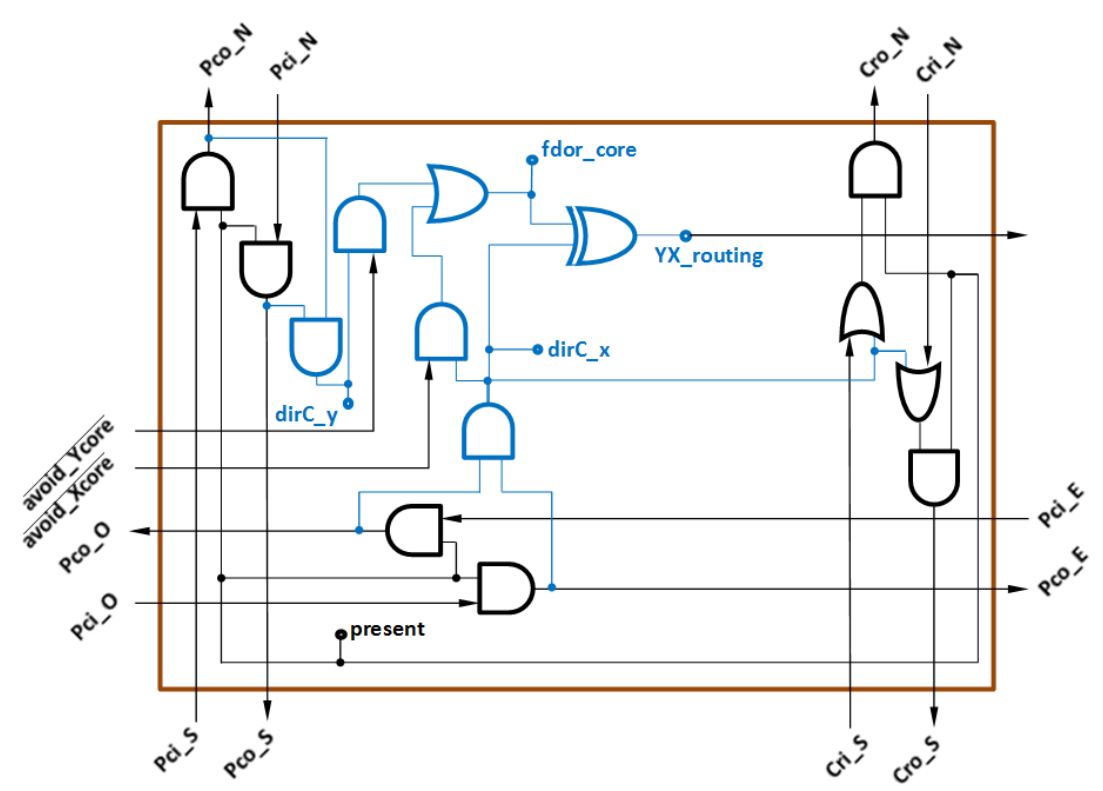

(a) Lógica AFDOR interna correspondente a um roteador

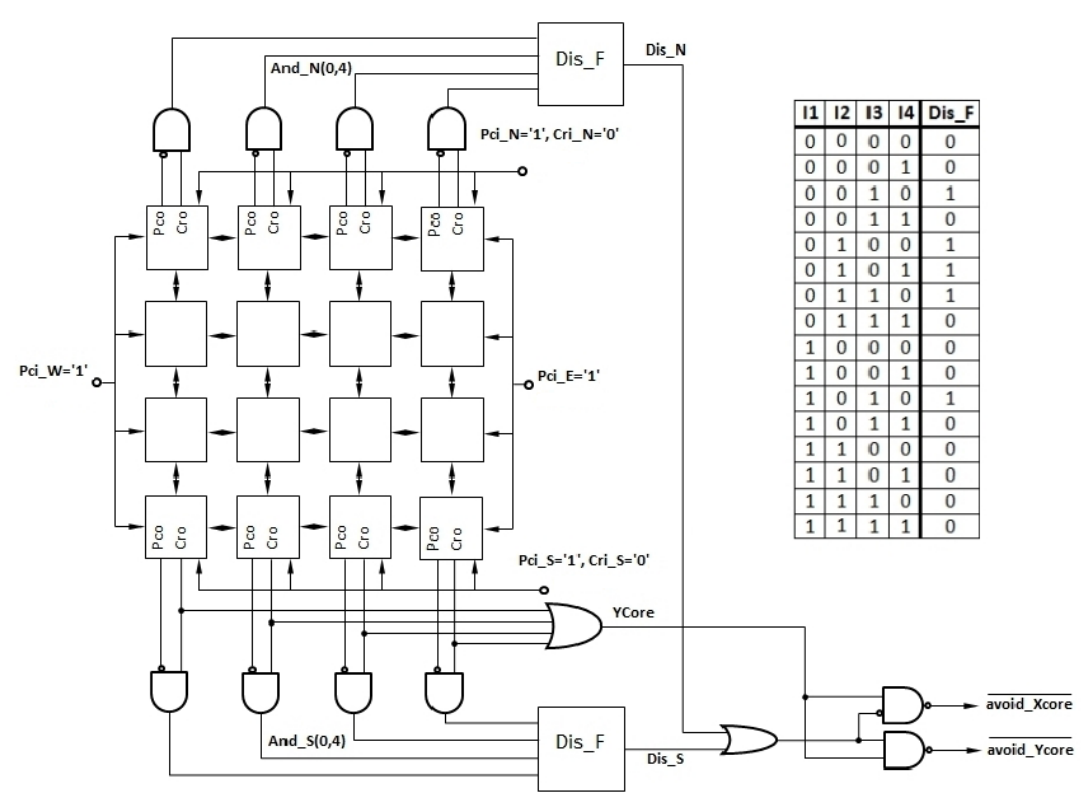

(b) Lógica externa AFDOR para uma malha de $4 \times 4$ roteadores

Fonte: (MIORANDI, 2012).

representa a direção de origem ( $N$ : Norte, $S$ : Sul, $E$ : Leste e $W$ : Oeste), são entradas da lógica interna que se propagam através dos roteadores posicionados na mesma direção. Por exemplo, o sinal Pci_D só será propagado se o roteador estiver ativado ( present $={ }^{\prime} 1$ '), então a saída $P c o \_D=$ ' 1 '; caso o roteador esteja desativado (present $=$ '0') Pco_D = '0'. Os sinais $C r i \_D$ e $C r o \_D$ indicam a propagação de uma sub-região núcleo em direção do eixo $X$ se o roteador 
estiver ativado (present $=$ ' 1 ') e o sinal $\operatorname{dir} C_{-} x={ }^{\prime} 1$ '. Se o núcleo não se propagar mais na direção $Y, C r o \_D=$ '0'.

Observa-se que nos limites da matriz de blocos lógicos, os sinais $P c i \_D$ têm valor de ' 1 ' lógico em todas as direções ( $N$ : Norte, $S$ : Sul, $E$ : Leste e $W$ : Oeste) para que possam ser propagados até encontrar um roteador desativado (present $=$ '0') e a partir de aí se propagará o valor de '0' lógico. Além, os sinais $C r o \_N$ e $C r o \_S$ são iguais a '0' lógico nos limites superior e inferior respectivamente, para que possam ser propagados até detectar a presença de um núcleo em direção $X\left(\operatorname{dir} C \_x=\right.$ '1'), mudando seus valores para '1' lógico.

Observa-se na Figura 33(b) que nas bordas superior e inferior da matriz de blocos, os pares de sinais de propagação $P c o \_N, C r o \_N$ e $P c o \_S, C r o \_S$, respectivamente, passam por um bloco de portas AND onde a função [Cro AND $\overline{P c o}]$ é efetuada. Os 4 bits resultantes de cada bloco AND passam por um bloco lógico chamado de Função de Deslocamento (Dis_F do inglês, Dislocation Function), que determina um potencial núcleo tipo X (um núcleo expandido em direção $X$ ). A saída da tabela de verdade é ' 1 ' lógico se os bits de entrada formam uma sequência com a seguinte forma: ...010..., ...0110..., ...01110... e assim por diante, como apresentada na Tabela de Verdade da Figura 33(b).

O resultado dos blocos Dis_F passam pela lógica apresentada na Figura 34 cuja tarefa é calcular os sinais $\overline{\text { avoid_Xcore }}$ e $\overline{\text { avoid_Ycore }}$, os quais ajudam a determinar em que direção $(Y$ ou $X)$ o núcleo FDOR vai se propagar. Estes sinais entram novamente nos blocos lógicos FDOR de cada roteador e junto com os sinais $\operatorname{dir} C_{-} x$ e dirC_y determinam se o roteador pertence à região núcleo $\left(f d o r \_c o r e=' 1\right.$ ') ou não $\left(f d o r \_c o r e=' 0\right.$ '). Finalmente, o sinal $Y X \_r o u t i n g$ é resultado da operação XOR entre $f d o r \_c o r e$ e $d i r C \_x$ indicando se o roteador executará o roteamento YX $\left(Y X \_\right.$routing $=$'1') ou XY $\left(Y X \_\right.$routing $=$'0') .

A Figura 34 (MIORANDI, 2012), apresenta dois exemplos de topologias diferentes e seus respectivos resultados da lógica FDOR. Com referência ao exemplo (b), como existe um deslocamento $X$ das duas regiões com roteadores desativados no lado Leste da malha, então $D i S_{-} N=$ '1', determinado pelos sinais de propagação e a lógica externa. Por outro lado, não existe deslo- 
camento no lado Oeste da malha (Dis_S $={ }^{\prime} 0$ '). Estes valores passam por uma lógica adicional, apresentada na parte inferior da Figura 34, junto com a tabela de verdade, para determinar os valores dos sinais $\overline{\text { avoid_Xcore }}$ e $\overline{\text { avoid_Ycore }}$.

Figura 34: Funcionamento da lógica externa e a propagação dos sinais $P c i / P c o$ e $C r i / C r o$ (setas sólidas e pontilhadas, respectivamente).

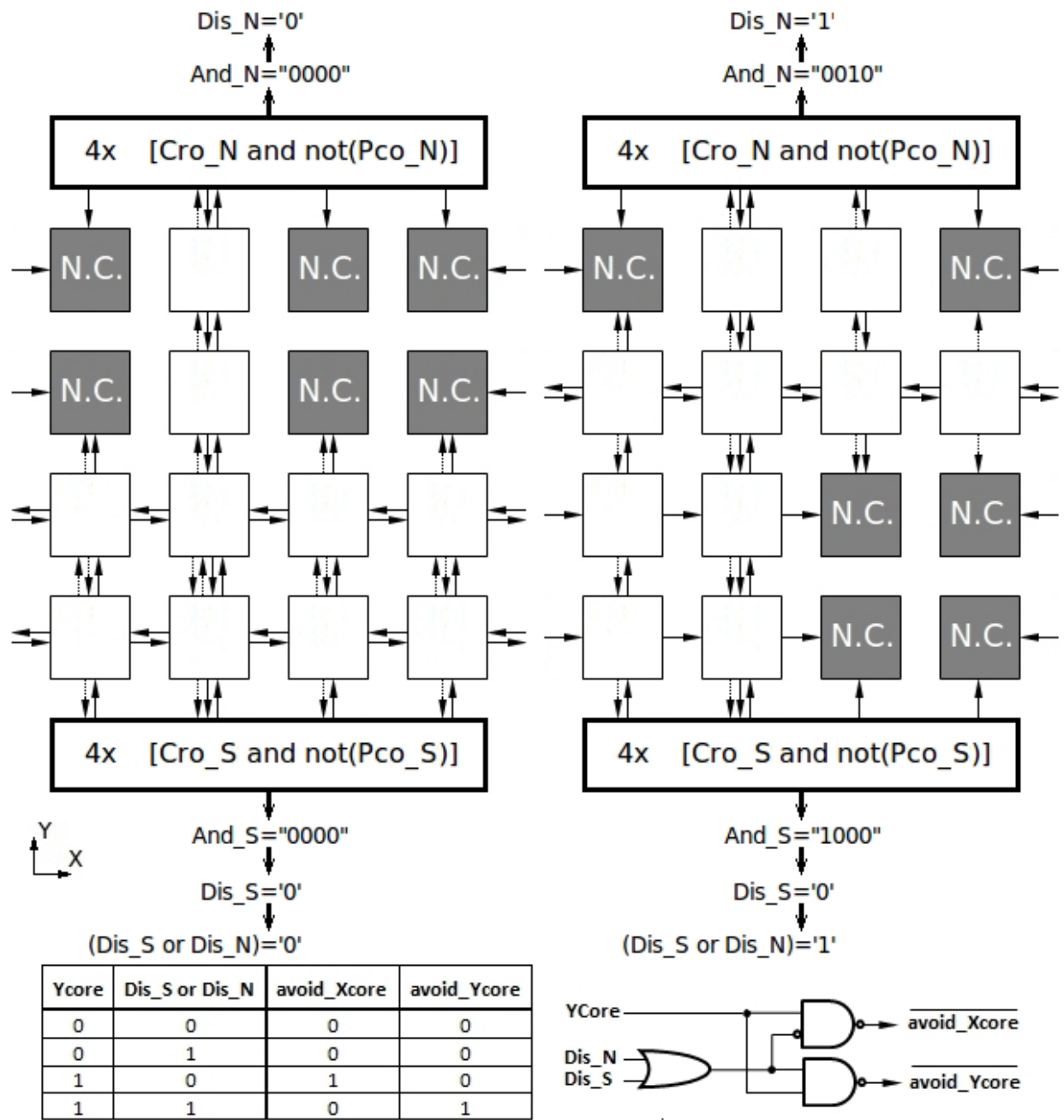

Fonte: (MIORANDI, 2012).

(MIORANDI, 2012), explica a tabela de verdade da seguinte maneira:

- Se $Y \_C o r e=$ '1', mas não houver um deslocamento $X$, todos os possíveis núcleos tipo $X$ devem ser evitados, com a finalidade de que as topologias "L", "T"e "+"possam ser consideradas válidas pela lógica AFDOR.

- Se $Y \_C o r e=$ '1', mas houver um deslocamento $X$, todos os possíveis núcleos tipo $Y$ devem ser evitados, mas no caso em que também exista um deslocamento $Y$ ao longo do 
eixo $Y$, será automaticamente resolvido pela criação de um núcleo $Y$ pela lógica AFDOR, que invalidará a topologia (já que não podem existir dois deslocamentos ao mesmo tempo) ou gerando um núcleo tipo $Y$ se for possível.

- Nos outros casos, a lógica AFDOR é livre para determinar o núcleo e as alas.

Outras topologias são apresentadas na Figura 35 (MIORANDI, 2012), as quais têm características que podem ser consideradas como não permitidas de acordo com o algoritmo FDOR, mas cujos bits de configuração de cada roteador são calculados da forma correta pela lógica AFDOR. Um caso especial é o exemplo (d), onde existe um roteador inacessível, fazendo que a topologia seja não permitida, mesmo assim a lógica AFDOR determina de forma correta os bits de configuração dos outros roteadores.

Figura 35: Algumas topologias permitidas pela lógica AFDOR.

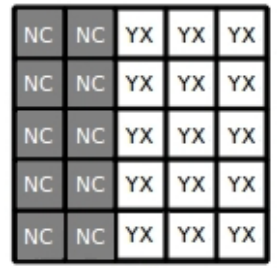

(a)

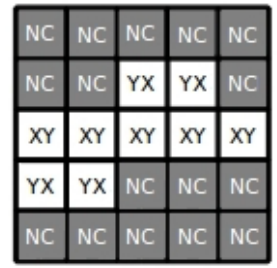

(b)

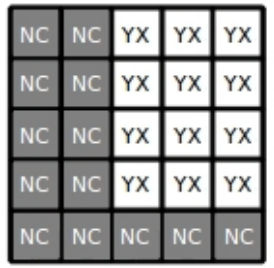

(c)

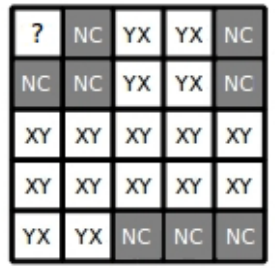

(d)

Fonte: (MIORANDI, 2012). 


\section{DYAFNOC: DYNAMIC AFDOR-BASED NETWORK ON-CHIP}

\subsection{Estrutura da malha de roteadores}

Apresenta-se neste capítulo a arquitetura da Rede Intrachip Dinamicamente Reconfigurável baseada em Lógica AFDOR, DyAFNoC (do inglês, Dynamic AFDOR-Based Network onChip), proposta para esta dissertação. Ela é composta pela estrutura de malha 2-D de roteadores, o Sistema de Controle de Reconfiguração da Malha, desenvolvido por (MIORANDI, 2012), e o Sistema de Reconfiguração Parcial Dinâmica que controlará o processo de Reconfiguração Parcial Dinâmica dos Módulos de Processamento, EPs e roteadores que formam a estrutura da rede.

A arquitetura da DyAFNoC, está baseada na estrutura de malha 2-D. Como o posicionamento passa a ter relevância no contexto da reconfiguração dinâmica,, será feita uma distinção para os blocos responsáveis pelo processamento de acordo com o contexto utilizado:

- Elemento Processante, EP - bloco responsável pelo processamento de dados do ponto de vista apenas funcional. Todo roteador pode estar conectado ou não a um EP;

- Módulo de Processamento, MP - bloco responsável pelo processamento de dados do ponto de vista funcional e geométrico. Todo MP tem um tamanho associado, ocupando um espaço determinado na malha 2-D. Podemos dizer que os MPs são EPs em que seu aspecto geométrico é conhecido. Por facilidade, vamos considerar que existem MPs de tamanho unitário (de referência) e todos os demais serão múltiplos deste tamanho unitário. 
A DyAFNoC segue a estrutura de roteadores proposta por (BOBDA; AHMADINIA, 2005), porém, esta teve que ser modificada com a finalidade de obter topologias permitidas pelo algoritmo FDOR obtidas pelo posicionamento dos MPs. A Figura 36(a) (idêntica à Figura 20, replicada por comodidade) apresenta a estrutura básica da DyNoC originalmente proposta por Bobda et al., enquanto que as Figura 36(b) \& (c) apresentam as estruturas modificadas para poder se implementar as topologias permitidas pelo FDOR. No caso em que o número de colunas ou fileiras seja $N x M$ e $N$ for ímpar, será formada uma estrutura assimétrica com $(N-1) / 2$ roteadores para o lado esquerdo, e $(N+1) / 2$ no lado direito, apresentado na Figura 36(b). Caso contrário, com $N$ par, será formada uma estrutura simétrica com $N / 2$ roteadores divididos simetricamente sobre o eixo horizontal na rede, como indicado na Figura 36(c). O mesmo acontece com as dimensões verticais, formando uma estrutura com $(M-1) / 2$ roteadores para o lado inferior e $(M+1) / 2$ roteadores para o lado superior no caso em que $M$ for ímpar (Figura 36(b)), caso contrário será formada uma estrutura simétrica com $M / 2$ roteadores divididos simetricamente sobre o eixo vertical da rede (Figura 36(c)). Também é ilustrado na Figura que a estrutura básica da rede é composta apenas por MPs de tamanho mínimo (MP unitário) ligados a um roteador por meio do porto local.

Figura 36: Estrutura de malhas bidimensionais

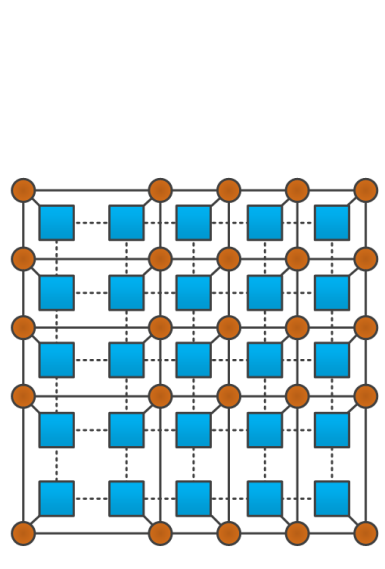

(a)
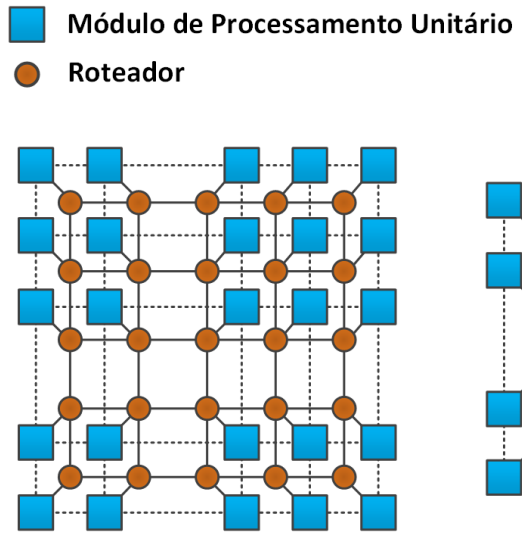

(b)

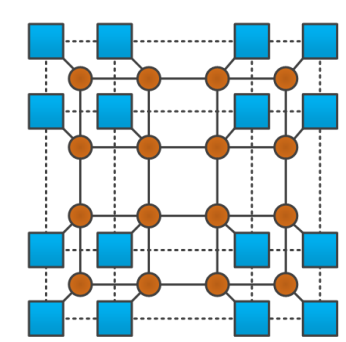

(c)
(a) DyNoC
(b) Modificada da DyAFNoC não-simétrica
(c) Simétrica

Fonte: (Autor, 2014).

Observe-se que na DyNoC todos os MPs são posicionados à esquerda e abaixo do roteador 
associado, com excepção da primeira coluna e a última fileira. Esta regra de posicionamento de MPs existe para que eles sempre estejam inteiramente rodeados por roteadores, de forma a garantir a conectividade e acessibilidade entre dois MPs quaisquer. Porém, no caso da DyAFNoC, a regra é que as topologias permitidas pelo algoritmo FDOR, apresentadas na seção anterior, possam ser garantidas, sendo então evitado o posicionamento de roteadores nas bordas da malha 2-D. Como pode-se observar pelas Figuras 36(b) e (c), os MPs são posicionados, a partir do centro da malha, sempre em uma localidade mais externa em relação aos pontos de acesso, seja no sentido superior/inferior, quanto da esquerda para direita.

As regras para os MPs é que eles tenham forma retangular e que sejam implementados utilizando os recursos lógicos dos MPs unitários. No caso de qualquer MP de tamanho não unitário, o ponto de acesso correspondente será alocado para o roteador adjacente que estiver mais perto ao centro da malha. A Figura 37 apresenta alguns exemplos de posicionamento de MPs sobre a estrutura de DyAFNoC formando topologias permitidas pelo FDOR.

O caso (a) apresenta um exemplo simples de posicionamento de MPs sobre a malha 2-D formando uma topologia permitida, com um núcleo (área pontilhada em azul escuro) e duas alas (área pontilhada em vermelho) posicionadas pelo eixo $X$. O exemplo (b) apresenta um caso onde os MPs formam uma topologia FDOR já com as alas posicionadas no eixo $Y$. No exemplo (c) os módulos formam uma topologia onde também é possível que as alas estejam posicionadas ao longo eixo Y, mas por definição o algoritmo FDOR considera-os ao longo do eixo X. Finalmente, o exemplo (d) apresenta um caso em que os módulos M13/M14 e M15/M16 são posicionados de forma contígua, não havendo necessidade de estarem rodeados individualmente por uma borda de roteadores a fim de se garantir a conectividade ou accessibilidade entre si. Basta que dois módulos contíguos tenham forma rectangular. Em todos os exemplos, fica evidente que os MPs têm os seus pontos de acesso na forma mais próxima possível ao centro da rede.

No processo de reconfiguração dinâmica, contextos diferentes (como nos exemplos acima) são alternados entre si e os algoritmos de roteamento para os núcleos e alas de cada contexto 
Figura 37: Exemplo de Posicionamento de MPs sobre a estrutura de malha 2-D da DyAFNoC.

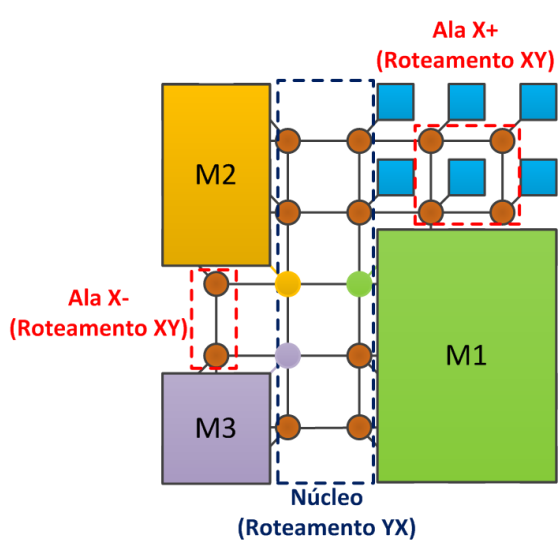

(a)

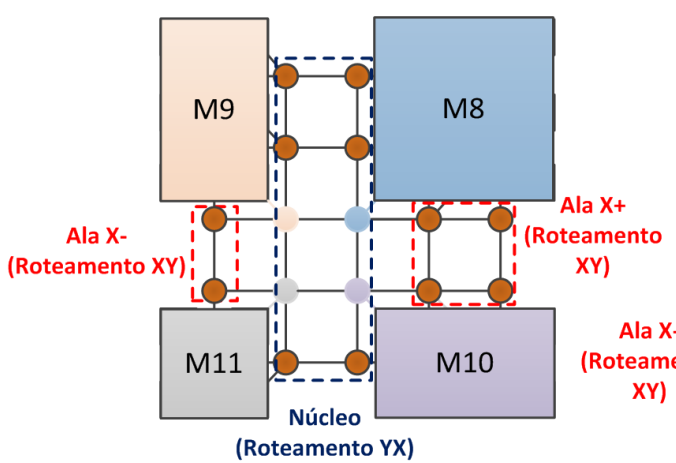

(c)

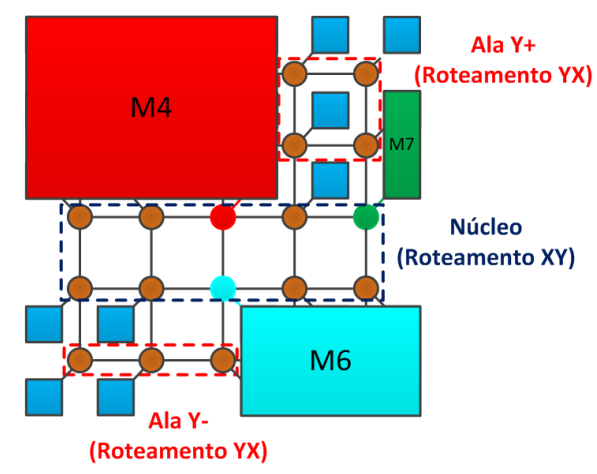

(b)

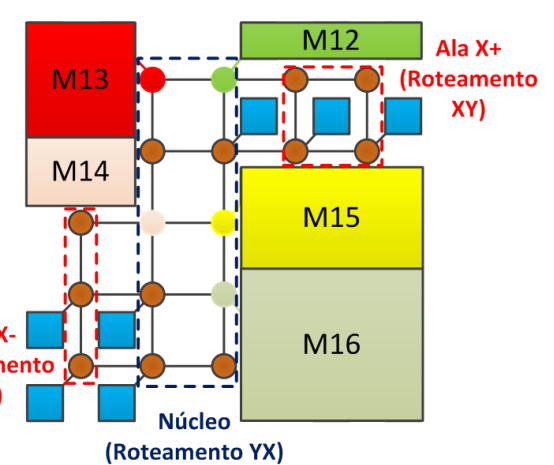

(d)

Fonte: (Autor, 2014).

são alterados correspondentemente. A forma de reconfiguração é apresentada na seção a seguir.

\subsection{Sistema de Controle de Reconfiguração de Malha}

O Sistema de Controle Reconfiguração de Malha, MRCS (do inglês, Mesh Reconfiguration Control System), foi desenvolvido por (MIORANDI, 2012) com a finalidade de alterar a configuração de cada roteador que compõe a rede, isto é, mudar o algoritmo de roteamento da rede (no roteador específico) para aplicar outro novo. Esta transição de configurações pode gerar problemas na transmissão de dados, uma vez que diferentes esquemas de roteamento rodando ao mesmo tempo dentro de um contexto, podem gerar dependências que levam ao deadlock.

Para evitar o problema acima, uma solução é drenar a rede, i.e., deixar todos os pacotes ativos chegarem a seus destinos, para depois configurar a rede com o novo algoritmo de rotea- 
mento. Somente após a conclusão é que deve-se recomeçar a injeção de tráfego. Esta solução é conhecida como Reconfiguração Estática Tradicional (TSR do inglês, Traditional Static Reconfiguration). Existe uma solução mais rápida que o TSR que não requer a drenagem total da rede, porém à custa de uma complexidade adicional. Esta segunda é conhecida como Reconfiguração Estática Sobreposta (OSR do inglês, Overlapped Static Reconfiguration) (STRANO et al., 2012), mas não foi utilizada por (MIORANDI, 2012) e não será tratado nesta dissertação. O MRCS é apresentado na Figura 38 (MIORANDI, 2012) para uma NoC malha de 5x5, baseado em TSR.

Figura 38: Sistema de Controle Reconfiguração de Malha (MRCS) baseado em TSR.

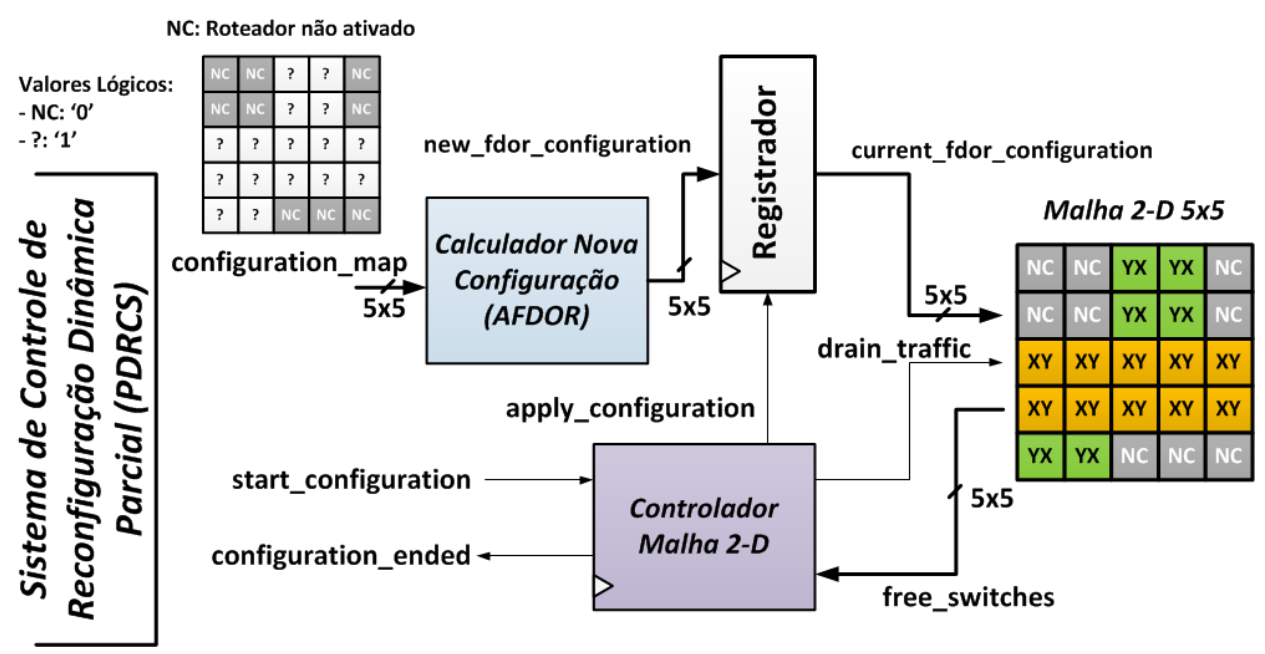

Fonte: (MIORANDI, 2012).

O funcionamento do MRCS dá-se através dos seguintes passos:

1. O Sistema de Controle de Reconfiguração Parcial Dinâmica (PDRCS, que será explicado na seção seguinte) propõe um novo mapa de configuração (configuration_map), colocando o sinal start_configuration $=1$.

2. Depois de ter recebido a solicitação, o controlador do MRCS (Controlador de Malha 2D) ativa o sinal de drenagem de tráfego residente na rede (drain_traf fic $=1)$, enquanto que o circuito Cálculo de Nova Configuração ou AFDOR (explicado no capítulo anterior) calcula a nova configuração da rede (new_fdor_configuration).

3. Quando o sinal drain_traffic $=1$, todos os roteadores retêm os pacotes, provenientes dos MPs, que querem ingressar na rede pelo porto local. Porém, os pacotes restantes 
provenientes das outras direções (Norte, Sul, Leste ou Oeste) são transmitidos até chegar aos seus destinos.

4. Quando o roteador não está mais transmitindo pacotes, ou seja, todos seus buffers e o crossbar foram esvaziados, um sinal de alerta é enviado ao controlador comunicando tal status. Então, quando toda a rede é completamente esvaziada de pacotes (free_switches $=1111 \ldots)$, a nova configuração é aplicada.

5. Finalmente, o controlador (Controlador de Malha 2-D) permite que a nova configuração seja armazenada em um registrador com saída current_fdor_configuration, por meio do sinal de habilitação (apply_configuration $=1$ ). O controlador avisará ao PDRCS que a nova configuração foi aplicada (configuration_ended $=1$ ).

\subsection{Sistema de Controle de Reconfiguração Parcial Dinâmica (PDRCS)}

Nesta dissertação, se desenvolverá um sistema denominado Sistema de Controle de Reconfiguração Parcial Dinâmica, PDRCS (do inglês, Partial Dynamic Reconfiguration Control System), com a finalidade de controlar os processos de reconfiguração dinâmica parcial da arquitetura da DyAFNoC. Com isto, os recursos lógicos de uma determinada área do FPGA são reconfigurados com a finalidade de implementar outra funcionalidade, como foi explicado no capítulo 2 de Fundamentos Teóricos. No trabalho realizado por (MIORANDI, 2012), uma versão simplificada do sistema de reconfiguração foi proposta, onde somente na verificação funcional, novos mapas de configuração eram recebidos a partir de um testbench. Nenhuma reconfiguração real poderia ser aplicada, uma vez que os MPs eram elementos descritos em VHDL comportamental não-sintetizável e não poderiam ser fisicamente posicionados. 


\subsubsection{Funcionamento no domínio de tempo de DyAFNoC}

\subsubsection{Elementos de um Contexto}

Analisar o funcionamento da DyAFNoC no domínio do tempo permite entender melhor o papel do PDRCS nas etapas de reconfiguração dinâmica. Um Sistema Dinamicamente Reconfigurável (DRS) é composto de diversos contextos que se alternam no tempo e podem ser definidos como "fotografias"durante um período de tempo em que a aplicação requer que determinadas tarefas sejam executadas. No caso de DyAFNoC, um contexto será definido como um arranjo de MPs comunicando-se por meio da malha de roteadores, obedecendo a regra de posicionamento para obter uma topologia permitida pelo algoritmo FDOR.

O PDRCS permite a um projetista de DRS organizar os diversos contextos em uma linha de tempo, determinando quais eventos ocorrerão para que uma mudança de contexto seja ativada e os processos necessários para reconfigurar a rede durante a transição de um contexto para outro novo.

Para ilustrar melhor o funcionamento do PDRCS, um exemplo de um DRS baseado em DyAFNoC será utilizado, o qual executará operações aritméticas simples em cada contexto. Esta medida foi levada em conta devido a que o particionamento de um DRS para uma aplicação real (ex. aplicações de processamento de vídeo ou imagem, DSP, telecomunicações, etc.) é um processo complexo que demandaria um tempo considerável, portanto não foi considerado devido a que o foco principal desta dissertação será de desenvolver o sistema de controle de reconfiguração, para ser proporcionado ao projetista e que possa ser utilizado quando o particionamento de um sistema com aplicação real, tinha sido feito previamente. Na Figura 39, os diferentes contextos que compõem o DRS de exemplo de aplicação são apresentados, na ordem em que serão configurados sobre o dispositivo FPGA.

Cada contexto está composto por uma certa quantidade de MPs de tamanho mínimo em execução (com sua respectiva etiqueta, por exemplo S3, S6, D5, D2, etc.). Em particular, existem os MPs de tamanho maior que representam operações aritméticas simples como multiplicação (x), divisão $(\div)$, soma $(+)$ e subtração $(-)$. O exemplo assume a existência de um particionamento 
Figura 39: Diferentes contextos que compõem um DRS indicando a ordem em que serão configurados sobre o dispositivo FPGA.

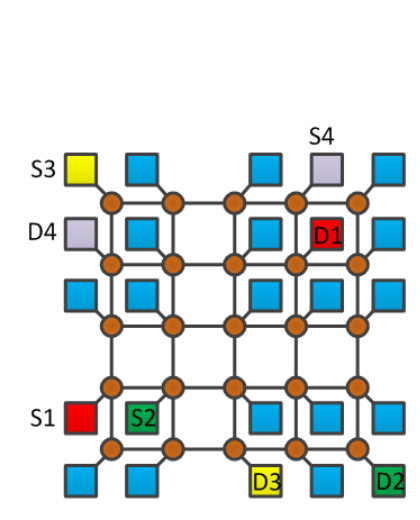

(1)

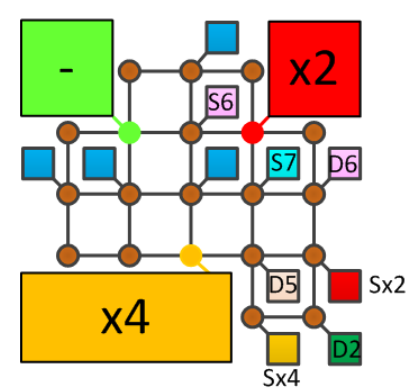

(4)

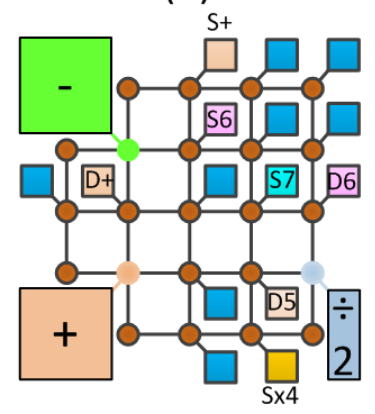

(7)

\section{Módulo de Processamento Unitário \\ O Roteador}

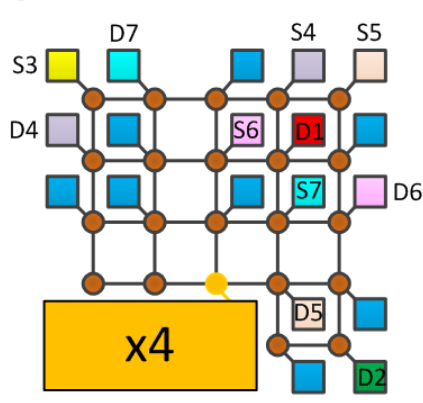

(2)

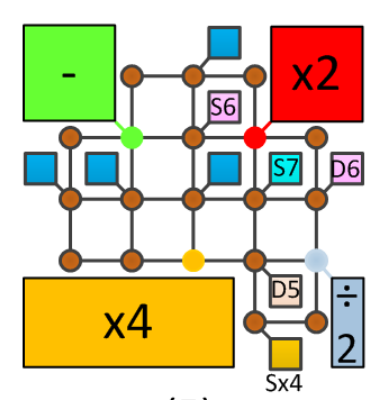

(5)

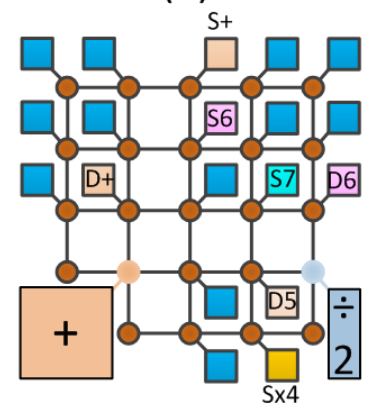

(8)

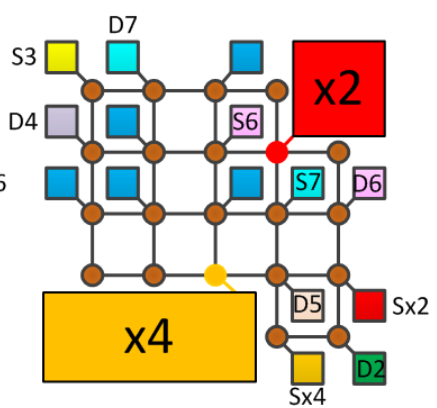

(3)

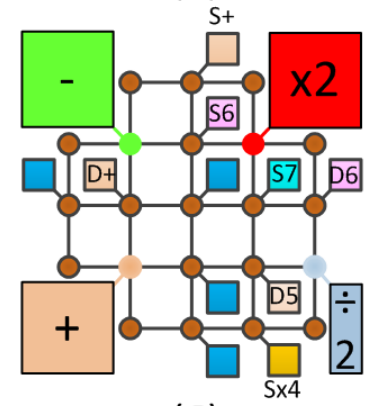

(6)

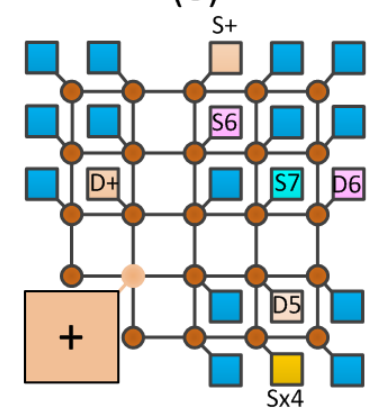

(9)

Fonte: (Autor, 2014).

prévio da aplicação dos módulos e partições dos contextos ${ }^{7}$. Mesmo assim, o projetista deve levar em conta que o mapeamento de módulos tem que cumprir a regra de formar topologias permitidas pelo algoritmo FDOR, como os contextos na Figura 39.

As entidades dos MPs descritos em VHDL sintetizável para esta aplicação exemplo têm uma série de parâmetros em comum, qualquer que seja a operação vinculada (na Figura 39,

\footnotetext{
${ }^{7} \mathrm{O}$ particionamento dos MPs em diferentes contextos assim como o mapeamento deles sobre a malha bidimensional não foi levado em conta nesta dissertação. Porém, existem algoritmos de mapeamento e posicionamento de módulo em DRNoCs que podem ajudar o projetista definir a melhor localização topológica na NoC (FILHO; CHAU, 2013).
} 
apresentam-se diversas operações aritméticas). Estes parâmetros definem, do ponto de vista da aplicação geral, as características de processamento e transferência de dados em forma de pacotes. Alguns parâmetros importantes são:

- Endereço do Ponto de Acesso: endereço do roteador que atuará como ponto de acesso do MP.

- Endereço da Fonte: endereço do roteador fonte ligado a um MP que envia pacotes a um roteador de destino ligado com um MP que processará os dados recebidos. S1, S2, S3, etc. são exemplos de MPs que atuam como fonte de dados na Figura 39. Estes endereços serão fixos para cada contexto.

- Endereço do Destino : endereço de destino dos pacotes composta dos dados já processados pelos módulos D1, D2, D3, etc. da Figura 39, por exemplo.

- Número de Dados por pacote: quantidade de dados que compõem um pacote que ingressa no MP pelo ponto de acesso. A quantidade de flits de um pacote será igual a este parâmetro mais dois, por causa do acréscimo de dois flits de cabeçalho do pacote.

- Número de bits para Dados por pacote: quantidade de bits necessários para o contador de dados por pacote; como a quantidade de dados é parametrizável, é necessário um contador com uma quantidade adequada de bits para emular a quantidade de dados processados.

- Número de pacotes: quantidade de pacotes que o MP espera receber e processar.

- Número de bits para pacotes: quantidade de bits necessários para o contador de pacotes; como a quantidade de pacotes é parametrizável, é necessário um contador com uma quantidade certa de bits para emular a quantidade de pacotes processados.

- Número de bits para tamanho do buffer: quantidade de bits que determina o tamanho máximo do buffer de entrada do MP, sendo igual a $2^{N}$, onde $N$ é este parâmetro. 
- Número de ciclos de processamento: este parâmetro é utilizado pelo MP para acrescentar a quantidade de ciclos de processamento que realiza este o módulo emulando um processamento de maior complexidade que a operação aritmética simples que representa. Para isso, o módulo possui um contador interno dos ciclos de processamento até chegar ao número dado como parâmetro.

- Número de bits para ciclos de processamento: quantidade de bits do contador de ciclos de processamento; como o número de ciclos de processamento é parametrizável, então o mesmo ocorre para a quantidade de bits do contador.

O projetista conhece de antemão estes parâmetros para cada um dos MPs (unitários e de maior complexidade), assim como a sequência de reconfiguração de todos os contextos, dando funcionalidade ao DRS. Porém, não tem informação sobre o tráfego que será gerado durante a transferência de dados na rede e portanto, desconhece o tempo em que os pacotes chegam aos seus destinos. Além disso, o tempo de reconfiguração do esquema de roteamento depende do tempo de drenagem de pacotes a partir do momento que se requer uma mudança de contexto, como será demostrado nos próximos capítulos.

\subsubsection{Sequências de Contextos}

Com os contextos já definidos, o projetista precisa definir a sequência em que eles serão implementados sobre o dispositivo FPGA e os processos de reconfiguração envolvidos, como a reconfiguração do algoritmo de roteamento da rede e o processo de reconfiguração dinâmica parcial da região específica do FPGA (envio do bitstream de reconfiguração ao FPGA). É de grande auxílio para o entendimento dos eventos envolvidos o uso de um diagrama de tempo onde são apresentadas todas as etapas de processamento do DRS como: os contextos e as etapas intermédias entre eles; os eventos que ocasionam a mudança de configuração; os processos de reconfiguração do algoritmo de roteamento e reconfiguração parcial dinâmica. A Figura 40 apresenta um exemplo deste diagrama de tempo.

Nesta ilustração, podem-se observar as diversas etapas de funcionamento do DRS separadas 
Figura 40: Diagrama de tempo do DRS da aplicação de exemplo baseado em DyAFNoC com todas suas etapas envolvidas.

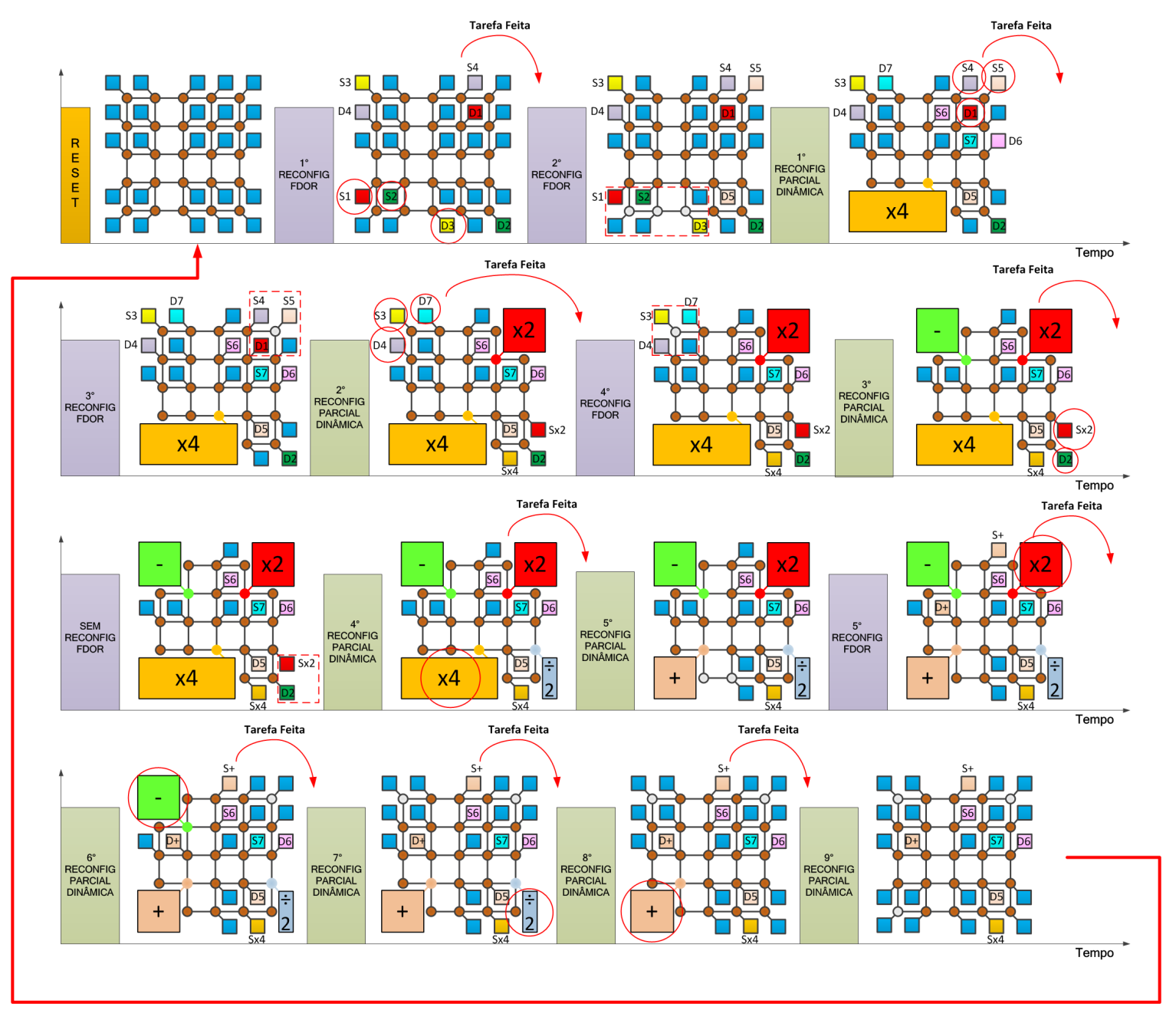

Fonte: (Autor, 2014).

por blocos que representam os processos de reconfiguração do algoritmo de roteamento (Reconfiguração FDOR) e Reconfiguração Parcial Dinâmica. Também são ilustrados os eventos que ocasionam a mudança de contexto, isto é, quando um grupo de MPs que estejam localizadas dentro de uma região reconfigurável (dentro dos círculos vermelhos em cada contexto) indiquem que suas respectivas tarefas de processamento foram terminadas (Tarefa concluída, indicada com setas de arcos vermelhos) e que os recursos lógicos que estão sendo ocupados para sua implementação estão disponíveis para reconfiguração. Nota-se que nos processos intermediários, nem sempre se executa a Reconfiguração FDOR. Não é necessário desativar alguns roteadores para implementar outros MPs no processo de Reconfiguração Parcial Dinâmica.

A partir destas definições será explicado o exemplo da Figura 40, cujo modelo pode ser 
utilizado para outros projetos de DRS baseados em DyAFNoC. O funcionamento de um DRS consiste no seguinte:

1. Primeiramente, o processo de Reset do FPGA é feito. Com isso, a arquitetura da rede de roteadores em malha 2-D é configurada sobre o dispositivo com os MPs ligados aos portos locais dos roteadores.

2. Depois, o primeiro mapa de configuração é enviado para que o MRCS calcule o algoritmo de roteamento; neste caso, todos os roteadores estarão configurados com o algoritmo YX. Esta primeira reconfiguração FDOR é necessária porque depois do processo de reset os roteadores estão com uma configuração desconhecida.

3. Com a configuração, obtêm-se o primeiro contexto do DRS, composto pelos MPs S1, S2, S3 e S4 como fontes de pacotes aleatórios que têm como destino os MPs D1, D2, D3 e D4 respectivamente. Quando os MPs S1 e S2 terminam de transmitir todos os seu pacotes e D3 recebe todos os pacotes esperados, eles encerram as suas tarefas, e o PDRCS recebe o alerta por meio de sinais indicativos de tarefa terminada, para que o processo de reconfiguração da rede comece.

4. Antes do processo de reconfiguração dinâmica, os roteadores que se encontram dentro da área limitada pelas bordas de linhas vermelhas tracejadas, como se ilustra na Figura 40, são configurados como desativados para que o módulo de multiplicação (x4) possa ser implementado, reconfigurando os MPs que se encontram dentro deste mesmo limite. Além disso, os roteadores são desativados com a finalidade de que não exista comunicação com eles durante a reconfiguração dinâmica. Este processo é a segunda reconfiguração FDOR efetuada pelo MRCS.

5. Nesta etapa será efetuado o primeiro processo de reconfiguração parcial dinâmica para implementar o módulo de multiplicação (x4) por parte do PDRCS. Durante este processo, os outros MPs estão em funcionamento, transmitindo pacotes pela rede sem interrupção, já que a drenagem da rede foi feita. Ao terminar a reconfiguração dinâmica, o módulo 
de multiplicação estará pronto para receber dados e processá-los. Por esta razão, neste contexto outros MPs são ativados para que comecem a transmitir e receber dados como é o caso de S6/D6 e S7/D7. Neste contexto, também se espera que os MPs, S4, S5 e D1, finalizem suas tarefas para que possam ser reconfigurados posteriormente.

6. Aqui é aplicada a terceira Reconfiguração FDOR para desativar os roteadores delimitados pela borda vermelhas descontínua para poder implementar o módulo de multiplicação (x2). Os processos que serão efetuados são os mesmos que na configuração do módulo de multiplicação anterior (x4).

7. Para o caso do módulo de subtração (-) será necessário aplicar a Reconfiguração FDOR, uma vez que os MPs que serão reconfigurados para sua implementação encerram a região de um roteador, portanto se aplica a Reconfiguração FDOR para que nenhum pacote se perca na comunicação.

8. Depois, para a implementação do módulo de divisão $(\div 2)$, se executarão os mesmos passos explicados até agora, nesta vez não será efetuado o processo de Reconfiguração FDOR, uma vez que os MPs que serão reconfigurados se localizam fora da rede de roteadores, portanto não precisa de mudar o esquema de roteamento. Porém, no caso da reconfiguração do módulo de multiplicação (x4) para implementar o módulo de soma, primeiro deverá ser efetuada a quinta reconfiguração dinâmica para se obter o módulo de soma e mais dois MPs localizados na sua parte superior. Depois se efetuará a quinta Reconfiguração FDOR para reativar os roteadores que permitirão a comunicação do módulo de soma com a rede.

9. Daqui por diante, os outros MPs remanescentes serão reconfigurados para voltar para sua configuração inicial de MPs unitários. Por esta razão, a maioria dos processos efetuados serão de reconfiguração dinâmica.

10. Finalmente, quando a rede voltar para sua configuração inicial de MPs unitários e roteadores, caso a aplicação implique na nova realização de todos os processos, o PDRCS repetirá toda a sequência, como se a rede tivesse sido reiniciada (Reset). 


\subsubsection{Posicionamento de Chaves de Isolação sobre a Rede}

Enfatizamos que era objetivo primordial desta dissertação realizar uma validação do sistema de reconfiguração proposto, através de sua simulação. É deixado para um trabalho futuro a implementação física do sistema sobre uma placa de desenvolvimento com algum dispositivo FPGA com a capacidade de reconfiguração parcial dinâmica. A simulação do sistema é realizada emulando o envio do bitstream de configuração ao FPGA e o tempo de reconfiguração dos recursos lógicos (CLBs, RAMs, DSPs, etc.). Para isso foram construídos testbenches descritos em VHDL como ambientes de funcionamento da arquitetura do DyAFNoC.

A reconfiguração parcial dinâmica de MPs sintetizáveis é emulada com a técnica de Chaveamento Dinâmico de Circuitos (DCS do inglês, Dynamic Circuit Switching) (LYSAGHT; STOCKWOOD, 1996; LYSAGHT; DUNLOP, 1993), explicada no capítulo 2. Em cada um dos portos locais dos roteadores que formam a região reconfigurável serão incorporadas chaves de isolação para cada sinal correspondente ao porto local do roteador. A região reconfigurável se define como a região que mudará sua funcionalidade cada vez que o PDRCS requisitar. Aquela região que não será reconfigurada será chamada de região estática. A Figura 41 apresenta uns exemplos de regiões reconfiguráveis delimitadas com linhas tracejadas sobre a malha 2-D de DyAFNoC (RR1, RR2, RR3 e RR4).

Observe-se que todos os MPs unitários dentro das regiões reconfiguráveis têm chaves de isolação na conexão com os portos locais dos roteadores que servem como ponto de acesso à rede. As chaves de isolação são posicionadas nos portos locais dos roteadores, pois, os MPs maiores utilizam os recursos lógicos dos MPs unitários para sua implementação durante o processo de reconfiguração dinâmica. Então, quando mudar de configuração, as chaves de isolação isolam os portos da configuração antiga deixando-os em alta impedância ('Z'), e habilitam os portos da nova configuração conectando-os com o porto local dos roteadores dentro da região reconfigurável. Em particular, são apresentadas as outras configurações possíveis para RR3 na Figura 41, as quais serão implementadas durante o processamento de DyAFNoC. Desta forma, as partições $\mathrm{A}, \mathrm{B}$ e $\mathrm{C}$ conectadas às chaves de isolação (como quadrados pequenos) são utiliza- 
das alternadamente.

Figura 41: Exemplo de Regiões Reconfiguráveis (RR) com chaves de isolação posicionadas nos portos locais dos roteadores dentro de seus limites.

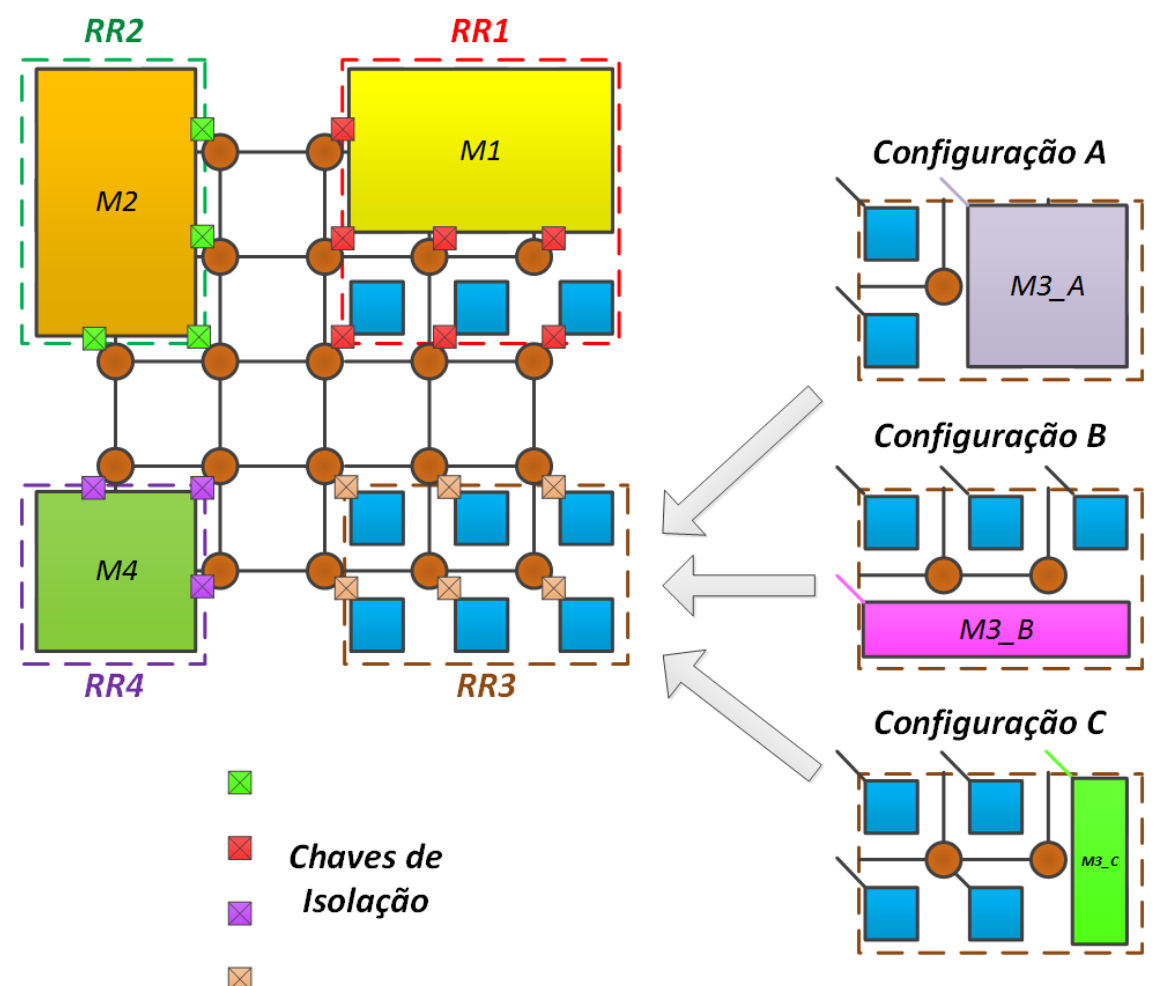

Fonte: (Autor, 2014).

Não se considerou colocar chaves de isolação nos outros portos dos roteadores da região reconfigurável com a finalidade de reduzir a complexidade durante a simulação do sistema. Por exemplo, quando um MP é implementado sobre um grupo de roteadores, eles só serão desativados antes que o módulo seja implementado, não permitindo alguma comunicação com os roteadores da região estática.

É importante mencionar que esta ideia é compatível com a implementação prevista para a DyNoC (BOBDA; AHMADINIA, 2005) que implementa os MPs utilizando só os recursos dos MPs unitários, enquanto que os roteadores dentro dos limites do módulo são apenas desativados. Esta medida foi tomada por Bobda et al., porque a tecnologia de FPGAs, como Virtex II e Virtex II Pro (XILINX, 2001; XILINX, 2007) na época em que foi projetado o DyNoC eram de tipo 1-D, necessitando reconfigurar a coluna inteira de CLBs, onde estavam implementados os MPs unitários, cada vez que é necessário mudar a configuração de qualquer quantidade de CLBs. 
Para as novas tecnologias 2-D de FPGAs como Virtex 4, Virtex 5, Virtex 6 e outras mais modernas, não é necessário reconfigurar uma coluna inteira de CLBs, já que as ferramentas para projeto de sistemas com Reconfiguração Parcial, como o PlanAhead da Xilinx (XILINX, 2012c), permitem a escolha de uma área determinada de CLBs para reconfiguração parcial dinâmica. Isto permitiria simplesmente reconfigurar inteiramente a área definida para a troca de contexto.

\subsubsection{Arquitetura do PDRCS}

A arquitetura do PDRCS está dividida em dois blocos processantes: o Árbitro Geral e o Bloco de Envio de Mapas de Configuração. O Árbitro Geral controla a sequência de funcionamento baseado no diagrama de tempo apresentado na Figura 40. Ele está baseado numa máquina de estados finitos (FSM do inglês, Finite State Machine) que contém a sequência de estados que representam os processos de reconfiguração executados sobre a DyAFNoC: a Implementação da Configuração Inicial, os processos de Reconfiguração FDOR e Reconfiguração Parcial Dinâmica. Além disso, o Árbitro Geral tem estados de espera, onde se aguarda que os MPs correspondentes a uma ou mais Regiões Reconfiguráveis finalizem suas tarefas de processamento para depois passar a estados que executem os processos de Reconfiguração FDOR e/ou Reconfiguração Parcial Dinâmica.

O Bloco de Envio de Mapas de Configuração é um bloco de controle que recebe pedidos do Árbitro Geral para enviar os novos mapas de configuração ao MRCS por cada processo de Reconfiguração FDOR. Estes mapas estão armazenados numa memória que o projetista definiu no diagrama de tempo da Figura 40.

Outros blocos que trabalham em conjunto com o PDRCS são os controladores das Chaves de Isolação, mas eles não são de fato módulos físicos já que tanto eles como as chaves de isolação são elementos virtuais utilizados na simulação de um DRS, mas não são considerados para o processo de síntese.

A Figura 42 representa o módulo de controle das chaves de isolação, junto com um exemplo para ilustrar que as chaves de isolação são posicionadas nos portos de entradas e saídas para 
dois cenários diferentes: um MP unitário e um módulo de multiplicação (x4). Cabe ressaltar que o conjunto de chaves de isolação apresentado nesta Figura é para uma conexão local entre o roteador e o MP, porém há uma replicação para todos os roteadores que fazem parte de uma região reconfigurável, sendo assim controladas pelo mesmo módulo de controle. Deve-se levar em conta que para o caso destes grupos de chaves, o segundo cenário estará vazio com valores desconhecidos, uma vez que o MP só pode estar conectado com um roteador só.

Figura 42: Diagrama de blocos do Módulo de Controle de Chaves de Isolação para dois cenários diferentes.
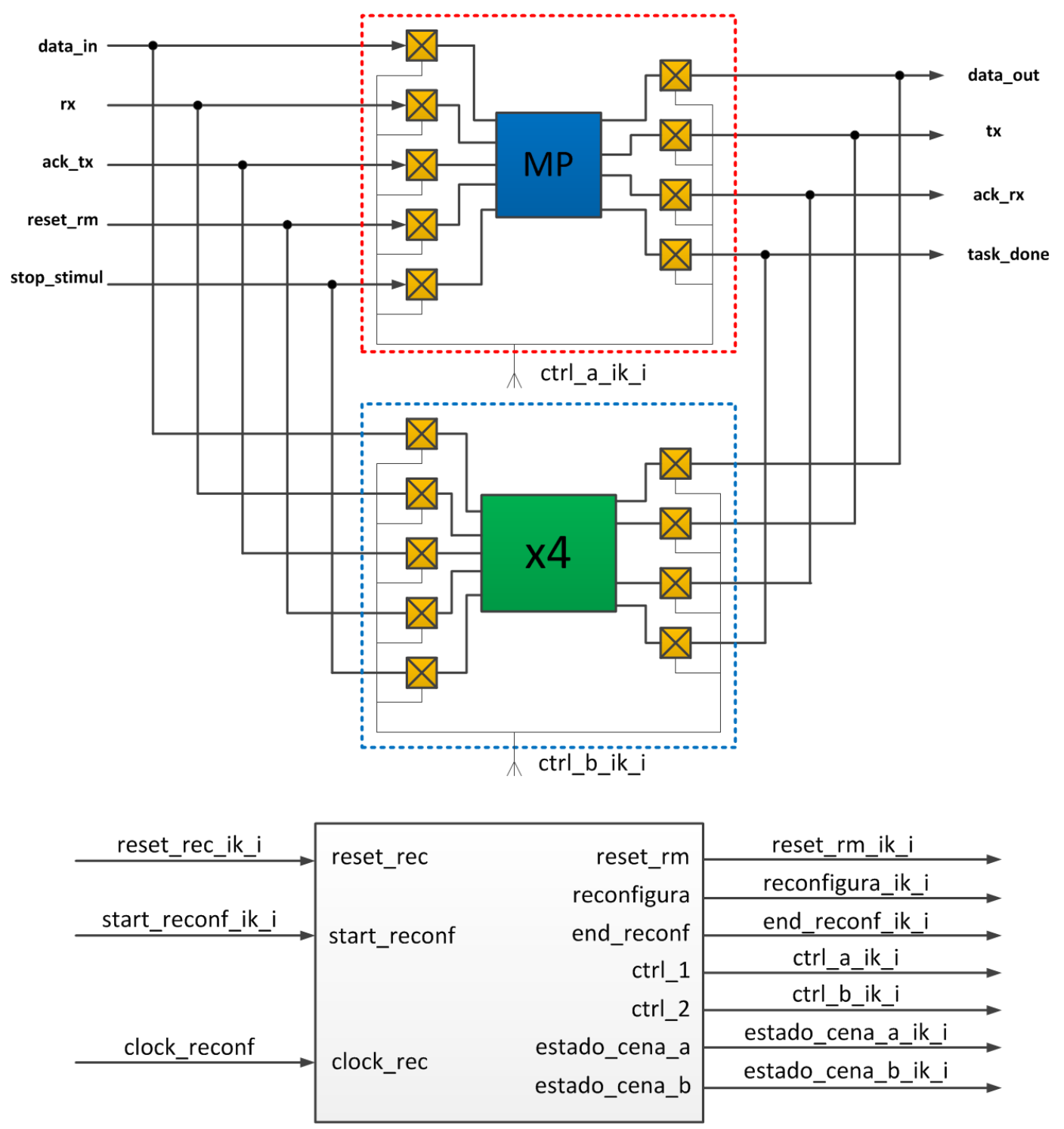

Fonte: (Autor, 2014).

A Figura 43 apresenta o diagrama de blocos do PDRCS formado pelo Árbitro Geral e o Bloco de Envio da Mapas de Configuração. Além disso, são apresentados os Controladores de Chaves de Isolação para cada Região Reconfigurável (RR) dentro da NoC. Estas regiões estão 
delimitadas por linhas descontínuas, cujos roteadores internos possuem um grupo de chaves de isolação por cada porto local.

Figura 43: Diagrama de blocos do PDRCS indicando os 5 passos de execução.

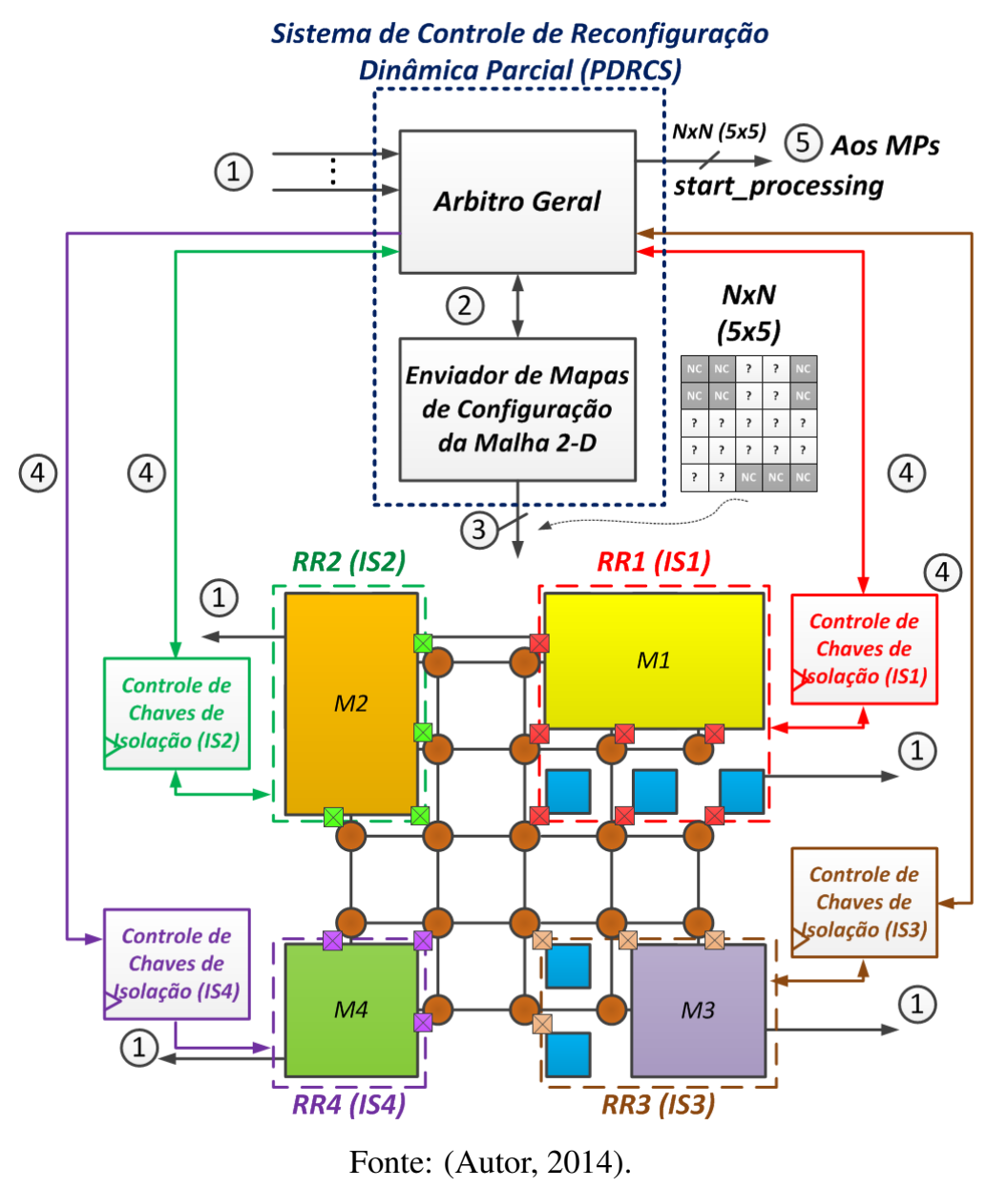

A numeração colocada na Figura 43 indica a sequência de funcionamento do PDRCS para executar um processo de reconfiguração dentro da rede. Estes passos são explicados abaixo:

1. Os MPs correspondentes a uma determinada região reconfigurável comunicam por meio de um grupo de sinais ao PDRCS que sua tarefa foi terminada e que seus recursos lógicos estão disponíveis para serem reconfigurados.

2. Este passo é executado se for necessário, isto é, se alguns roteadores tiverem que ser desativados, então o Árbitro Geral faz o pedido para o Bloco de Envio de Mapas de Configuração para enviar o próximo mapa de bits de configuração ao MRCS. Se não for preciso que os roteadores da RR sejam desativados, então este passo é pulado até o passo 
4.

3. Depois de receber o pedido, o Bloco de Envio de Mapas, ativa o sinal de start_reconfiguration do MRCS para que o novo mapa seja processado e que a rede seja configurada com o novo algoritmo FDOR. Quando terminar este processo, o MRCS confirma ao Bloco de Envio que a nova configuração foi aplicada. Se o passo 2 foi pulado, então este passo não precisa ser realizado.

4. Neste passo é executado o processo de reconfiguração parcial dinâmica para o qual serão utilizados os Controladores de Chaves de Isolação utilizados para a simulação de Reconfiguração Dinâmica como já foi explicado. O Árbitro Geral envia um sinal de ativação para os respectivos controladores das regiões ou região que se quer reconfigurar. O controlador de chaves de isolação entra em funcionamento simulando o processo de reconfiguração dinâmica e quando terminar confirmam ao Árbitro Geral.

5. O último passo consiste em ativar os MPs respectivos para começar seu funcionamento no novo contexto.

\subsection{Fluxo de Projeto}

A partir de todo o arcabouço descrito nas seções anteriores, pode-se, a partir de alguma aplicação, projetar outros DRSs baseados em DyAFNoC. Isto é facilitado pelo fato o PDRCS ser um sistema descrito em VHDL. Para facilitar o fluxo de projeto, se desenvolveu neste trabalho uma ferramenta denominada DRSimGen, baseada em scripts de MATLABß, que permite gerar automaticamente os blocos VHDL do sistema, além dos blocos referentes à técnica de chaveamento dinâmico de circuitos. Os principais parâmetros de entrada da ferramenta são os seguintes:

- Dimensões da NoC, ex. 5x5, 8x8, 10x10, etc.

- Número de Regiões Reconfiguráveis (RRs). 
- Tamanho das Regiões Reconfiguráveis (em número de roteadores e MPs unitários).

- Posição das Regiões Reconfiguráveis na malha bidimensional.

- Quantidade de Configurações por Região Reconfigurável.

- A sequência em que as diferentes configurações serão implementadas sobre cada Região Reconfigurável.

A Figura 44 apresenta um diagrama do fluxo de projeto/simulação da DyAFNoC. Após o processo de geração do código VHDL de DyAFNoC, ele é editado para ser sintetizado pelo software ISE da Xilinx para finalmente ser simulado e verificado pela interface de simulação ISim da mesma empresa.

Figura 44: Diagrama do Processo de Geração do código VHDL de DyAFNoC utilizando a ferramenta baseada em MATLABß.

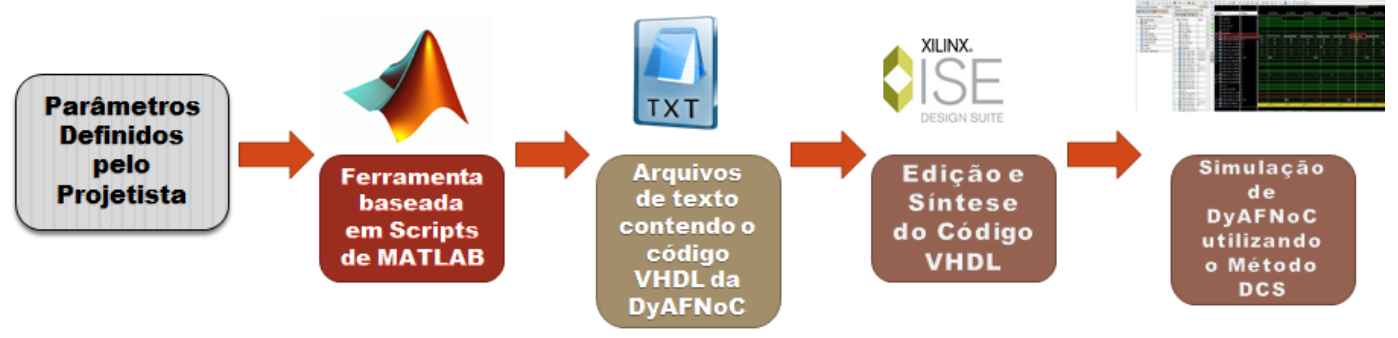

Fonte: (Autor, 2014).

Os MPs unitários que estarão presentes na rede são configurados de acordo com os parâmetros descritos na secção 5.3.1.1. Cada MP unitário é configurado como gerador de tráfego ou só como receptor de pacotes. O tráfego é gerado a partir dos parâmetros: número de pacotes, de dados por pacote, de ciclos de relógio entre pacotes e flits, portanto o tipo de tráfego é sintético. Além disso, os MPs unitários possuem um parâmetro que indica a coordenada de destino dos pacotes gerados, associados a um MP unitário ou um MP de maior complexidade de maiores recursos de hardware.

Depois de rodar a ferramenta de geração automática de código VHDL da DyAFNoC, algumas linhas de código são editadas diretamente pelo projetista diretamente para depois sintetizar 
o código usando a ferramenta ISE da Xilinx. Quando este processo for concluído, os testbenches são utilizados para simular o sistema utilizando a ferramenta ISim da Xilinx. Os resultados das simulações comportamentais serão mostrados nas próximas secções. 


\section{SIMULAÇÕES E RESULTADOS}

\subsection{Simulações e Análise Comportamental do DyAFNoC}

Neste capítulo, serão apresentadas as simulações comportamentais dos sistemas explicados no capítulo anterior: o Sistema de Controle de Reconfiguração da Malha (MRCS) e o Sistema de Controle de Reconfiguração Parcial Dinâmica (PDRCS). São apresentados os resultados das simulações com a finalidade de verificar o funcionamento de cada sistema para diversos casos de estudo para DRSs baseados em DRNoCs. Finalmente, resultados para a análise de desempenho da NoC são apresentados para diversas topologias permitidas pelo algoritmo FDOR, caracterizando-se assim todos os possíveis casos de posicionamento de MPs sobre a malha 2-D.

Em seu trabalho, (MIORANDI, 2012) fez uma análise do funcionamento de seu sistema com a transmissão de dados realizada utilizando-se geradores de tráfego não sintetizáveis. Nesta dissertação foram utilizados MPs sintetizáveis descritos em VHDL. Entretanto, considerando-se a dificuldade de encontrar um exemplo existente de aplicação real em forma de DRS e que a tarefa de particionamento de um DRS em diferentes contextos é bastante complexa, a aplicação aqui utilizada será sintética e estará baseada em MPs que executam aplicações aritméticas básicas; resultou em um DRS simples, mas útil para a verificação funcional dos sistemas de reconfiguração, MRCS e PDRCS.

Para simular o DyAFNoC, foi utilizado o exemplo da Figura 40 que é aqui replicado por conveniência como Figura 45. São seguidas as características descritas no diagrama, como as dimensões da NoC, neste caso em 5x5; a posição dos MPs fontes, assim como dos destinos (considerando as coordenadas dos roteadores aos quais estarão conectados), com seus respec- 
tivos parâmetros. Também foi determinada a quantidade de regiões reconfiguráveis, com os cenários para cada uma delas (configurações diferentes que uma região terá durante cada vez que ocorrer a reconfiguração parcial nessa região), seus tamanhos em termos de MPs unitários e suas posições na NoC. Estes parâmetros são ilustrados na Figura 46, os quais são obtidos a partir de uma análise dos diferentes contextos conforme o digrama de tempo na Figura 45.

Figura 45: Diagrama de tempo de um DRS baseado em DyAFNoC com todas as etapas implicadas.

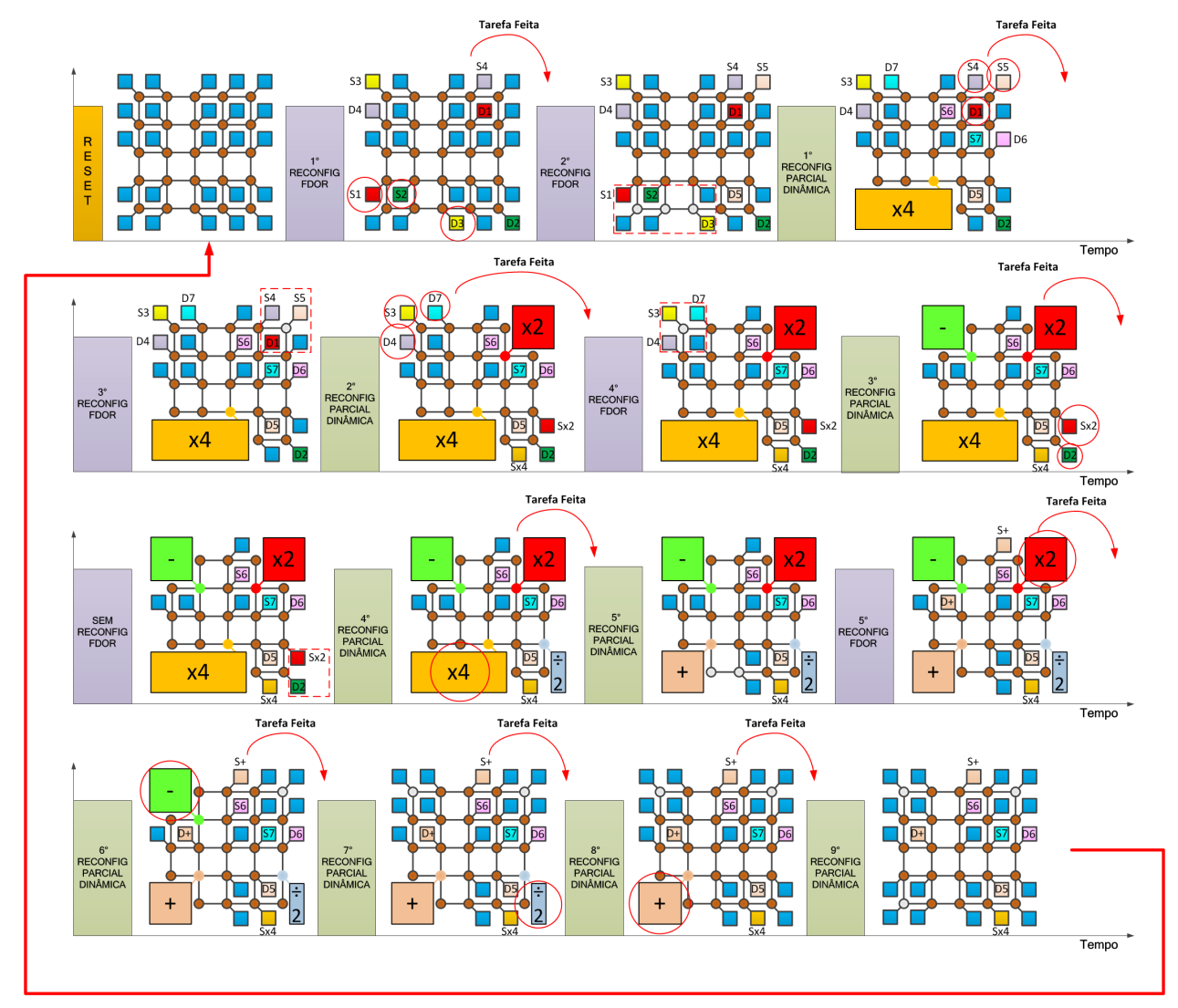

Fonte: (Autor, 2014).

Estes parâmetros são dados como entrada para a ferramenta DRSimGen, apresentada no Capítulo anterior, por meio de arquivos de planilhas, para serem processados e gerar os arquivos contendo a descrição em VHDL da arquitetura do sistema. O arquivo de testbench utilizado para a simulação do sistema também é gerado neste momento. Posteriormente, com ajuda das ferramentas da Xilinx como ISE e ISim, faz-se a simulação do sistema com o qual se verificará o seu correto funcionamento.

A seguir, uma sequência de figuras será apresentada com o intuito de ilustrar o comportamento do sistema durante a transição entre diferentes contextos. 
Figura 46: Posicionamento das chaves de isolação sobre a rede indicando as regiões reconfiguráveis e seus cenários.

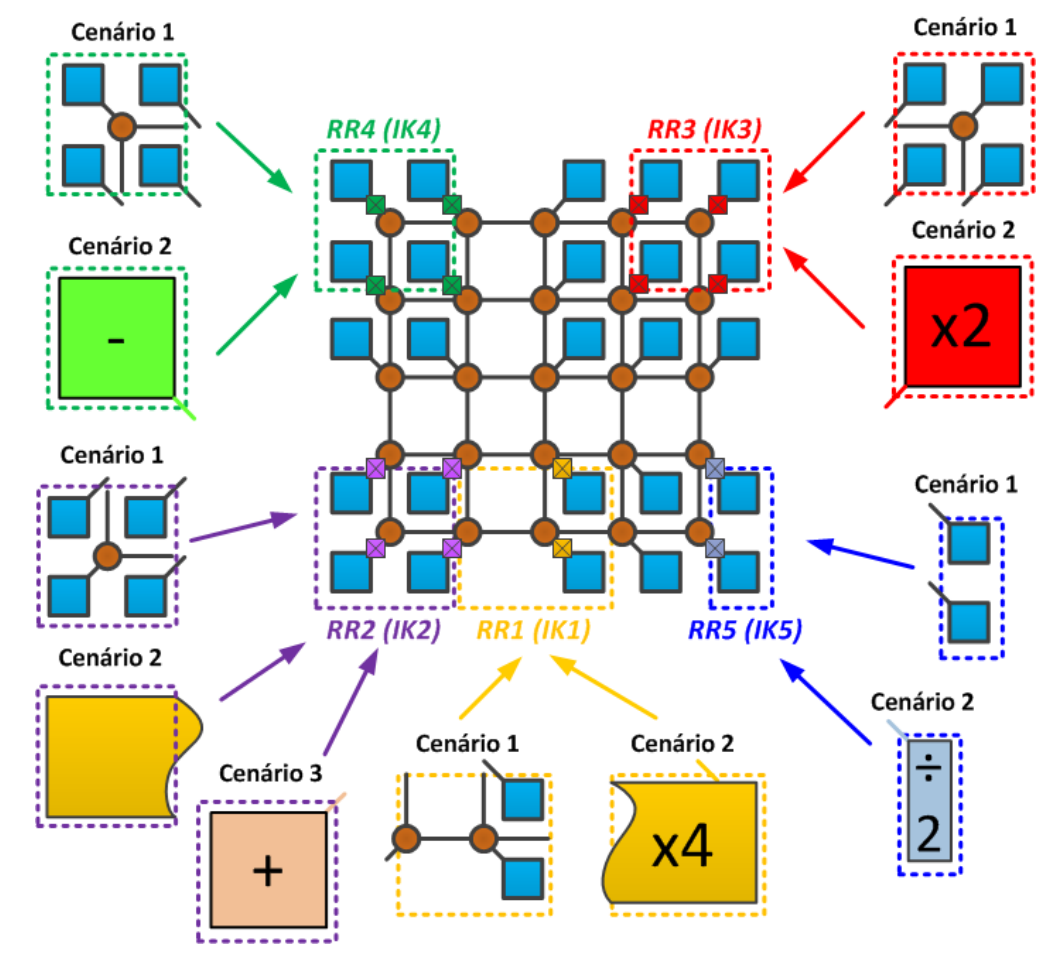

Fonte: (Autor, 2014).

A Figura 47 apresenta um trecho de simulação do primeiro contexto do sistema obtido imediatamente depois da inicialização do sistema, isto é um pulso do sinal reset, e o envio do primeiro mapa de configuração da malha config_map. Nesta simulação, pode-se observar que os MPs unitários ligados aos roteadores com coordenadas $(0 ; 1),(0 ; 4),(1 ; 1)$ e $(3 ; 4)$ começam a enviar seus pacotes de dados quando os respectivos bits do vetor sinal stop_stimul, mudam seu valor de ' 0 ' para ' 1 ' proveniente do bloco PDRCS. Enquanto um dos bits do vetor stop_stimul se mantiver com valor ' 1 ', nenhum pacote proveniente do MP unitário correspondente será injetado na rede; por outro lado, quando o valor for ' 0 ', o MP unitário começará a injetar pacotes dentro da rede.

Como cada roteador da rede está ligado a um MP unitário, então stop_stimul será um vector de $N x N$ bits, onde $N$ corresponde as dimensões da rede, neste caso 25 bits $(5 \times 5)$. A ordem em que os bits correspondem a cada MP unitário está relacionado com as coordenadas do roteador ao qual está ligado. Por exemplo, o bit $b$ do vetor corresponde ao MP unitário ligado ao roteador com coordenadas $(x, y)$, onde $b=N * x+y$. Na Figura 47, pode-se observar que os 
bits $1,4,6$ e 19 do vetor stop_stimul correspondem às coordenadas $(0 ; 1),(0 ; 4),(1 ; 1)$ e $(3 ; 4)$ respectivamente. Estes bits mudam seus valores de '1' para '0' para ativar seus respectivos MPs unitários. Pode-se observar que também os bits 3, 10, 18 e 20 passam de '1' para '0', entretanto, seus respectivos MPs unitários não são apresentados neste trecho de simulação.

Após a ativação destes MPs, pode-se observar que os pacotes começam a ser injetados dentro da rede, ativando-se em ' 1 ' os sinais de petição $R x$ dos roteadores locais. Os flits são colocados nos portos de saída dos MPs os quais estão ligados com o porto de entrada dos roteadores, data_in, e serão armazenados nos buffers cada vez que o roteador pulsa o sinal $a c k \_r x$, como apresentado na simulação. Pode-se observar também que o primeiro flit de cada pacote é representado por quatro algarismos hexadecimais (16 bits no total do flit), compostos pelas coordenadas da fonte e o destino do pacote. Como exemplo, observe-se o sinal data_in_l01, correspondente ao roteador com coordenadas $(0,1)$, que tem como primeiro flit o valor de 0133 indicando que a fonte tem coordenada $(0,1)$ e como destino o roteador de coordenada $(3,3)$, o qual estará ligado com o MP que receberá e processará os pacotes. No caso dos outros MPs, os destinos são os MPs ligados aos roteadores com coordenadas $(2,0) ;(4,0)$ e $(0,3)$ respectivamente como pode ser observado na Figura 47.

Figura 47: Simulação do primeiro contexto imediatamente depois da inicialização do sistema.

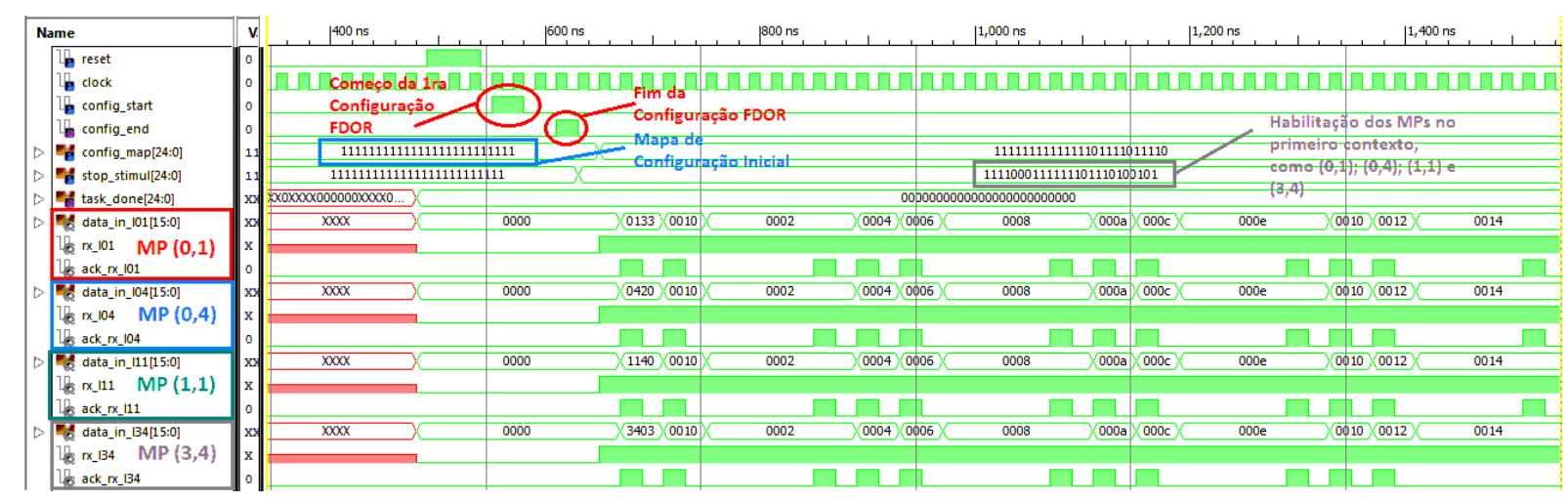

Fonte: (Autor, 2014).

O segundo flit contém a informação da quantidade de dados (expressos em número de flits) nos 8 primeiros bits, enquanto que os 8 bits restantes do flit estão disponíveis para qualquer outra informação extra que se quiser transmitir ${ }^{8}$; pela figura, cada pacote é composto de 16 flits

\footnotetext{
${ }^{8}$ Os bits adicionais podem ser utilizados para endereços de submalhas, por exemplo; o conceito de submalhas
} 
de dados. Por outro lado, a quantidade de pacotes que cada MP transmite é diferente como pode ser observado na Figura 48, contando-se a quantidade de pulsos dos sinais $R x$ de cada roteador, onde aqueles ligados aos roteadores com coordenadas $(0 ; 1),(0 ; 4),(1 ; 1)$ e $(3 ; 4)$ enviam 10 , 3,5 e 5 pacotes, respectivamente.

Figura 48: Simulação do primeiro contexto apresentando a quantidade de pacotes enviados pelos MPs fonte.

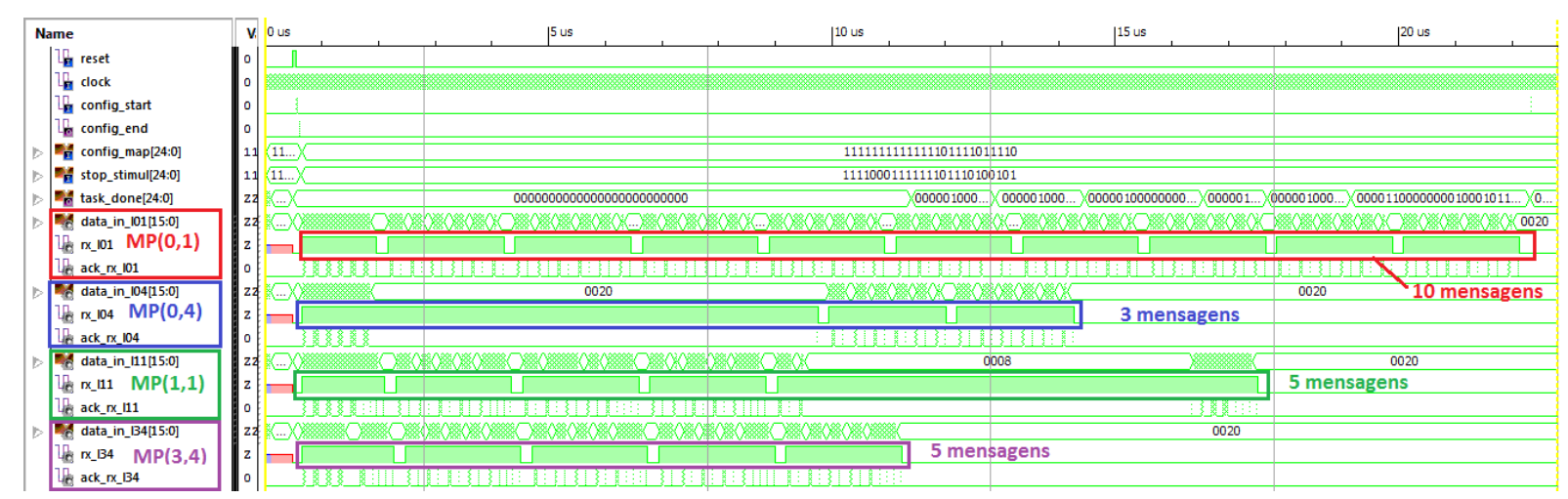

Fonte: (Autor, 2014).

Para passar ao contexto seguinte, o sistema deve aguardar que as tarefas dos MPs unitários dentro das regiões reconfiguráveis 1 e 2 (RR1 e RR2 da Figura 46), próximas a ser reconfiguradas, terminem suas respectivas tarefas. Estes MPs ativam seus respectivos sinais task_done indicando ao PDRCS que o novo mapa de configuração deve ser enviado ao MRCS. Os MPs unitários implicados são aqueles que estão ligados aos roteadores com coordenadas $(0,1)(\mathrm{S} 1)$, $(1,1)(\mathrm{S} 2)$ e $(2,0)(\mathrm{D} 3)$, casos conforme a Figura 45, na primeira linha. Na Figura 49, pode-se observar que os sinais task_done_l20,task_done_l11 e task_done_l01 são ativados nessa ordem, com a mudança de seus valores de '0' para ' 1 ', indicando que as tarefas dos MPs unitários, S1 (em amarelo), S2 (em azul) e D3 (em vermelho) foram terminadas. Mais exatamente, S1 e S2 terminam de enviar todos seus pacotes e no caso de D3, de receber todos aqueles que S3 lhe envia.

A Figura 50(a) apresenta o zoom da simulação anterior quando o Árbitro Geral do PDRCS recebe o sinal indicando que as tarefas dos MPs das regiões reconfiguráveis RR1 e RR2 foram feitas. Conforme a Figura 50(a), um pulso do sinal de start_conf ativa o Módulo de Envio de Mapas de Configuração que encarrega-se de enviar o mapa de configuração na saída será explicado no capítulo de trabalhos futuros. 
Figura 49: Simulação do primeiro contexto quando os MPs S1, S2 e D3 terminam suas tarefas ativando os sinais task_done respectivos.

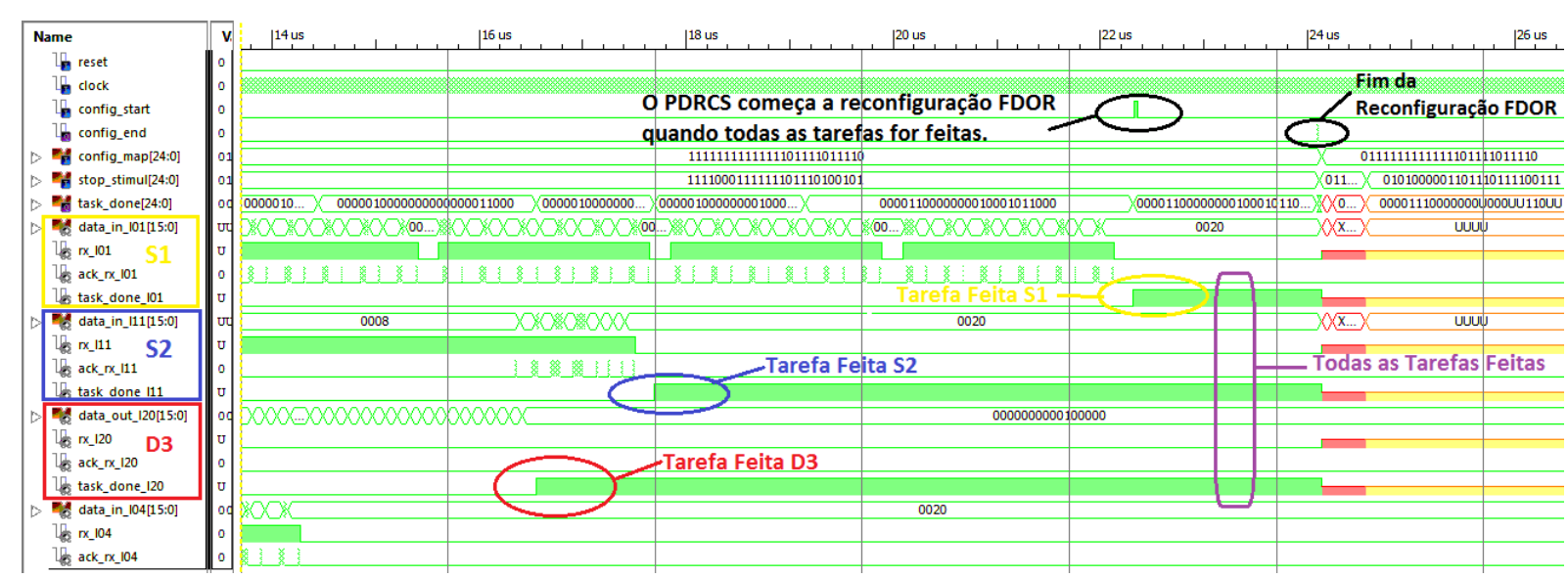

Fonte: (Autor, 2014).

config_map ao MRCS a fim de reconfigurar a malha. Para isso, este último módulo manda um pulso pela saída config_start ao MRCS, que responderá ativando o sinal config_stall em ' 1 ' para começar a drenagem da rede, conforme a Figura 50(b).

O sinal config_stall está ligado a todos os MPs e, no momento em que é ativado, os MPs param de injetar pacotes na rede; este sinal fica ativado até que todos os pacotes remanescentes dentro da rede cheguem aos seus respectivos destinos. Isto é ilustrado na Figura 50(b), na simulação para o caso dos pacotes que saem pelo porto local do roteador $(3,3)$, composto pelos sinais data_out_rm1_l33,tx_rm1_l33 e ack_tx_rm1_l33. Quando todos os pacotes chegarem ao seu destinos e a rede estiver esvaziada, os roteadores ativam o seu sinal correspondente do vetor config_ack em ' 1 ' para informar ao MRCS que a rede foi esvaziada e que o novo mapa de configuração pode ser aplicado. Depois disso, o MRCS manda um pulso do sinal config_end ao PDRCS para informar que a configuração foi realizada.

Após o novo mapa de configuração ser aplicado e a lógica MRCS ter computado o algoritmo de roteamento por meio da lógica FDOR, o passo seguinte é a reconfiguração parcial dinâmica do DyAFNoC. Na Figura 51, pode-se observar a simulação deste processo controlado pelos sinais de controle das chaves de isolação: ctrl_1_ik1 e ctrl_2_ik1 para os cenários 1 e 2 da região reconfigurável 1, respectivamente; e ctrl_1_ik2, ctrl_2_ik2 e ctrl_3_ik2 para os cenários 1, 2 e 3 da região reconfigurável RR2, respectivamente. 
Figura 50: Formas de Onda Resultantes da Simulação do DyAFNoC

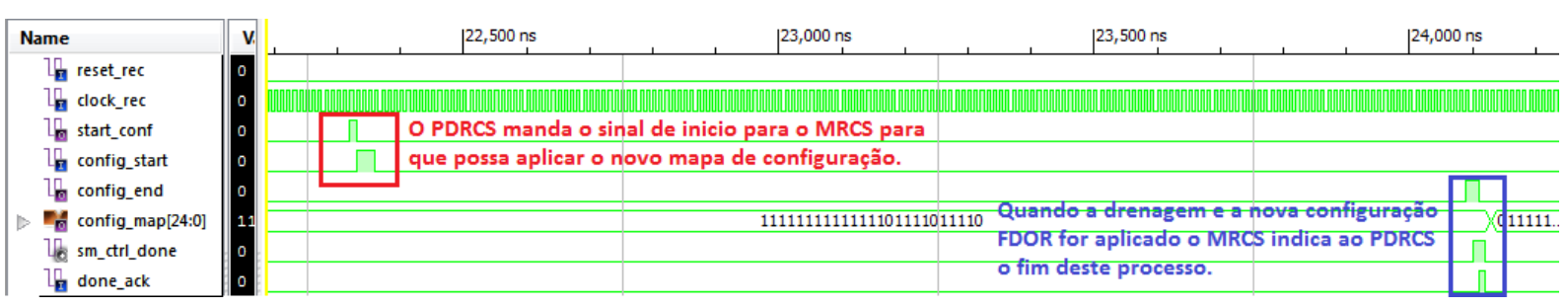

(a) Simulação do Módulo de Envio de Mapas de Configuração

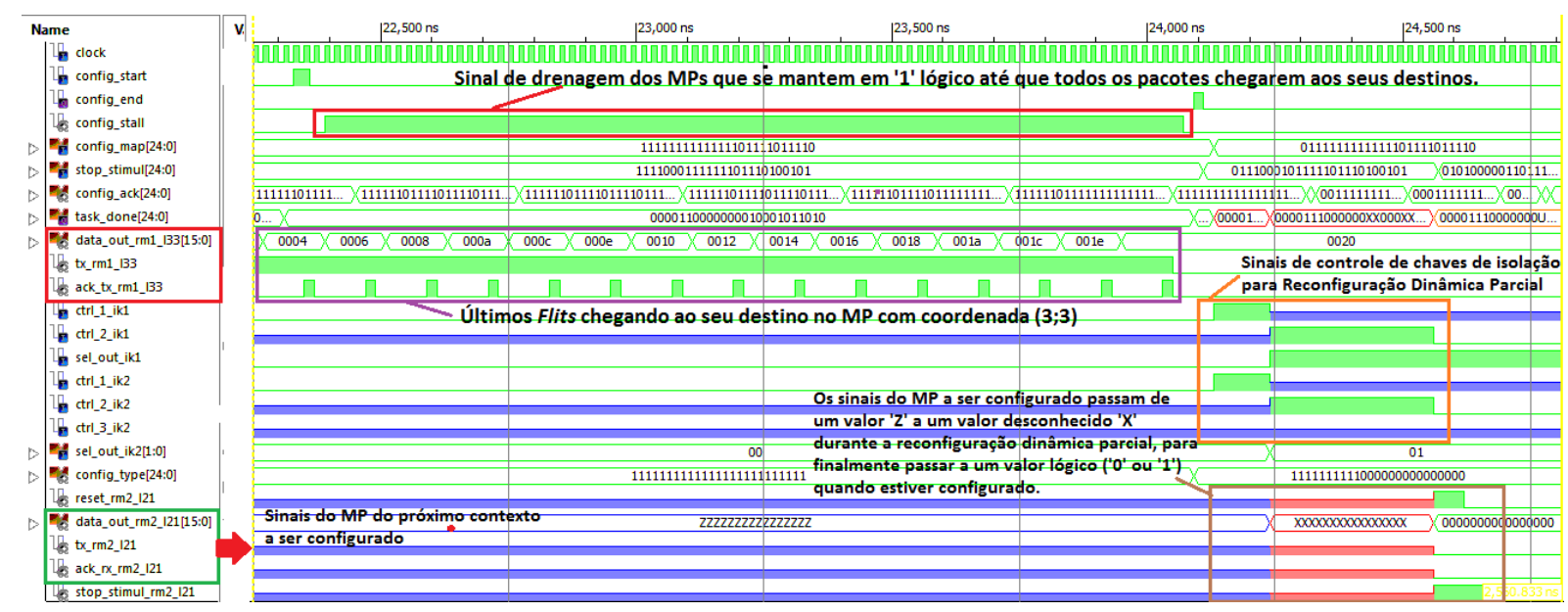

(b) Simulação de drenagem da rede para aplicar a nova configuração

Fonte: (Autor, 2014).

Também, pode-se observar na simulação, que os sinais $c t r l \_1 \_i k 1$ e $c t r l \_1 \_i k 2$ permanecem em ' 1 ' em um número de ciclos de relógio que emula o comportamento do envio do bitstream de configuração aos CLBs da região reconfigurável RR1 e RR2; e a remoção da configuração anterior sobre o hardware do FPGA. Quando este processo tiver terminado, o sinal $c t r l \_1 \_i k 1$ passa a um valor de alta impedância ' $Z$ ', enquanto que os sinais $c t r l \_2 \_i k 1$ e $c t r l \_2 i k 2$ mudam seus valores de ' $Z$ ' para ' 1 ' emulando, por sua vez, a reconfiguração do FPGA aplicando a carga diferencial para obter configuração do módulo multiplicador x4. Quando tiver finalizado a configuração, o controlador muda os valores destes sinais de ' 1 ' para ' 0 ' e pulsa o sinal reset_rm2_l21 para iniciar o módulo multiplicador.

O processo de reconfiguração parcial dinâmica é feito durante tempo de operação do sistema, isto é, durante o processamento dos outros MPs e com transmissão de pacotes na rede. Isto pode ser visto na Figura 52, com os sinais referentes aos dados presentes nos sinais, data_out_e14, tx_e14 e $a c k \_t x \_e 14$, onde apresenta-se esta situação com mais detalhe, os 
Figura 51: Simulação da reconfiguração parcial dinâmica das regiões reconfiguráveis RR1 e RR2 para implementar o módulo multiplicador $\mathrm{x} 4$.
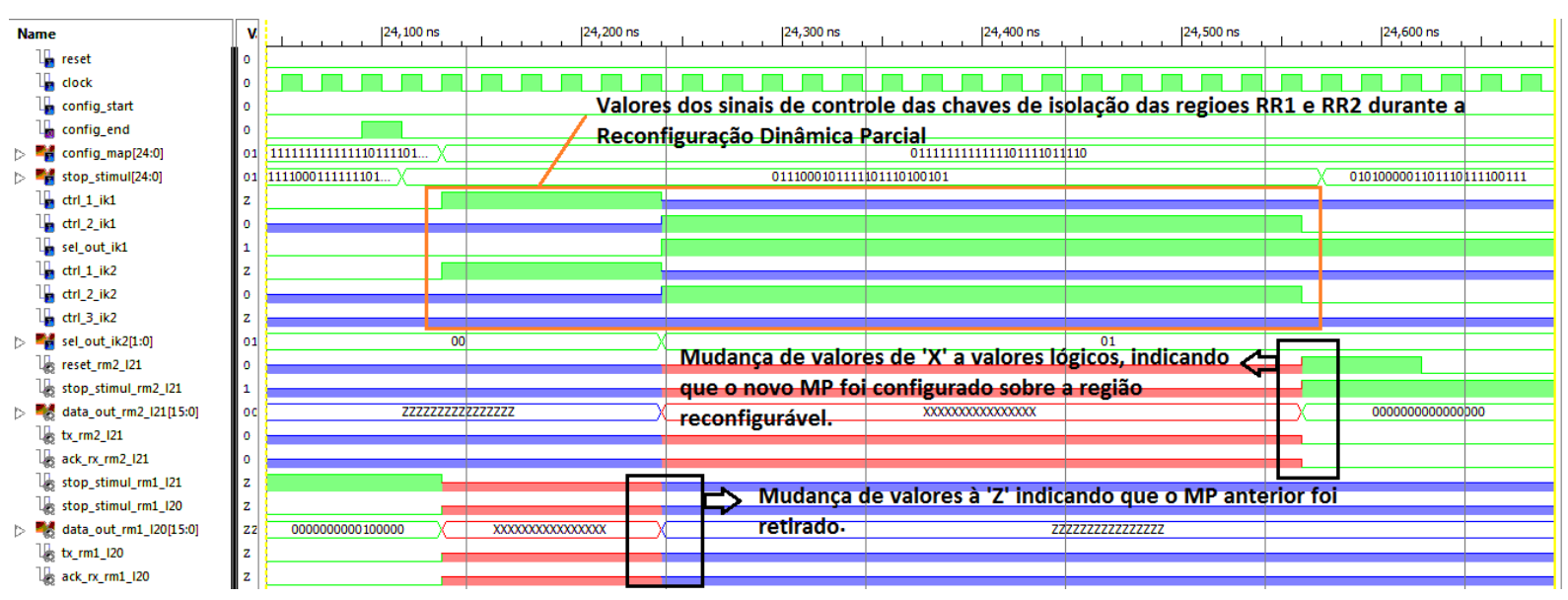

Fonte: (Autor, 2014).

pacotes continuam sendo transmitidos na rede enquanto ocorre o processo de reconfiguração parcial dinâmica.

Figura 52: Simulação de uma reconfiguração parcial dinâmica enquanto que os pacotes estão sendo transmitidos na rede.

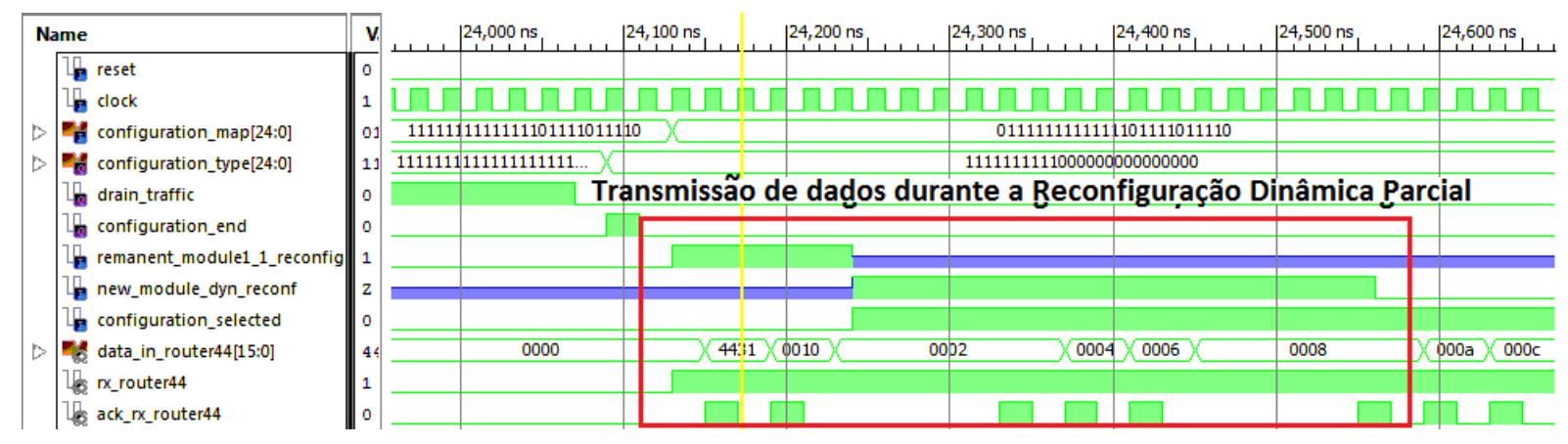

Fonte: (Autor, 2014).

Após o módulo multiplicador x4 ser configurado sobre as regiões reconfiguráveis RR1 e RR2, os MPs unitários S4, S5 e D1 devem terminar suas tarefas para que o novo mapa de configuração possa ser aplicado para desativar os roteadores dentro da região rectangular onde será implementado o módulo multiplicador x2. Depois, o PDRCS ativa os controladores das chaves de isolação correspondentes à região reconfigurável RR3 para emular sua reconfiguração parcial dinâmica e implementar o módulo multiplicador x2.

A sinalização que se segue no sistema é similar àquela apresentada nas figuras mostradas até o momento, então não há aporte importante em se apresentar mais simulações, destes processos, 
já que o principio de funcionamento é o mesmo. Desta forma, os demais trechos da simulação realizada com o exemplo de aplicação usado, com as demais transições entre os contextos e o processamento dos MPs não serão aqui apresentados, porém, podem ser acompanhados em detalhes no Apêndice A.

Para finalizar, se apresentaram as simulações da FSM do Árbitro Geral do PDRCS, o qual controla a sequência de funcionamento do sistema, enviando os mapas de configuração ao MRCS, ativando os controladores de chaves de isolação e ativando os MPs quando for necessário.

\subsection{Análise de Desempenho}

É objetivo desta dissertação fazer uma análise de desempenho da DyAFNoC, o que significaria avaliar as características do DyAFNoC durante a sua operação, como, por exemplo, parâmetros temporais da transmissão de dados sobre a rede, a área do chip utilizada e a potência consumida. Considerando que existem muitas topologias, deve-se testar o efeito do tipo de reconfigurabilidade sobre o desempenho do sistema.

Nesta dissertação, são avaliadas apenas os parâmetros temporais frente a diferentes topologias FDOR.

Para se fazer uma análise a partir de diferentes perfis de tráfego de forma confiável, exige-se uma grande quantidade de resultados, o que não é prático de se obter via simulação RTL, dada a: 1) dificuldade de se obter diferentes implementações em código VHDL para diferentes topologias; 2) complexidade de se gerar diferentes perfis de estímulo para cada roteador presente na rede.

Para avaliação de desempenho da transmissão de dados na rede, fez-se uma análise do sistema com descrição em alto nível (do inglês, High Level Description), através do simulador Noxim (PALESI; PATTI; FAZZINO, 2007). Foi necessária a modificação do código-fonte do simulador descrito em linguagem System C (PANDA, 2001) para poder incluir o algoritmo de 
roteamento FDOR para as diversas topologias permitidas.

\subsubsection{Simulador Noxim}

O Noxim é um simulador de Redes Intrachip (NoCs) desenvolvido pela equipe de Arquitetura de Computadoras da Universidade de Catânia (Itália), consistindo de uma interface de linha de comandos onde o usuário pode definir os parâmetros da NoC a ser simulada. Os principais parâmetros utilizados são as dimensões da rede, tamanho do buffer, distribuição do tamanho de pacotes, algoritmo de roteamento, seleção de estratégia de roteamento, taxa de injeção de pacotes, distribuição de tempo de tráfego, padrão de tráfego e distribuição de tráfego de hot-spots.

Os resultados da simulação são expressos em termos de Latência, Throughput e Consumo de energia, os quais podem ser dados ao usuário em termos de valor médio ou máximo. Além disso, o simulador Noxim disponibiliza resultados mais detalhados como o número total de pacotes/flits recebidos, Throughput global médio, max/min Latência Global, Consumo de energia total, Latência/Throughput/Energia por comunicação, etc (PALESI; PATTI; FAZZINO, 2007).

O simulador Noxim possui uma ferramenta associada, denominada Noxim Explorer que permite a execução de diferentes simulações no Noxim em batch, variando os parâmetros de cada simulação, para depois disponibilizar gráficos de Latência/Throughput/Latência Máxima/Energia vs. Taxa de Injeção. O Noxim Explorer lê as informações de um script de exploração para gerar seus resultados em formato de MATLABß. Os autores de Noxim chamam a este processo como fase de exploração do espaço de projeto (do inglês, Design Space Exploration Phase) (PALESI; PATTI; FAZZINO, 2007).

A partir dos parâmetros de dimensão da rede, o Noxim constrói a estrutura da NoC composta por Tiles, os quais consistem de um roteador, uma memória e um EP. A Figura 53 (WU, 2009) ilustra a estrutura hierárquica de uma NoC de dimensões $3 \times 3$ formada pelo Noxim para a simulação. Após formada a estrutura principal da rede, a simulação começa. Primeiramente os EPs geram os pacotes e injetam-los sobre a rede de acordo com os parâmetros de tráfego definidos pelo usuário. Os pacotes são roteados de acordo com a função de roteamento e selecionam 
o melhor canal de saída de acordo com a função de seleção (WU, 2009).

Figura 53: Estrutura Hierárquica da $\mathrm{NoC}$ de $3 \times 3$ formada pelo Noxim.

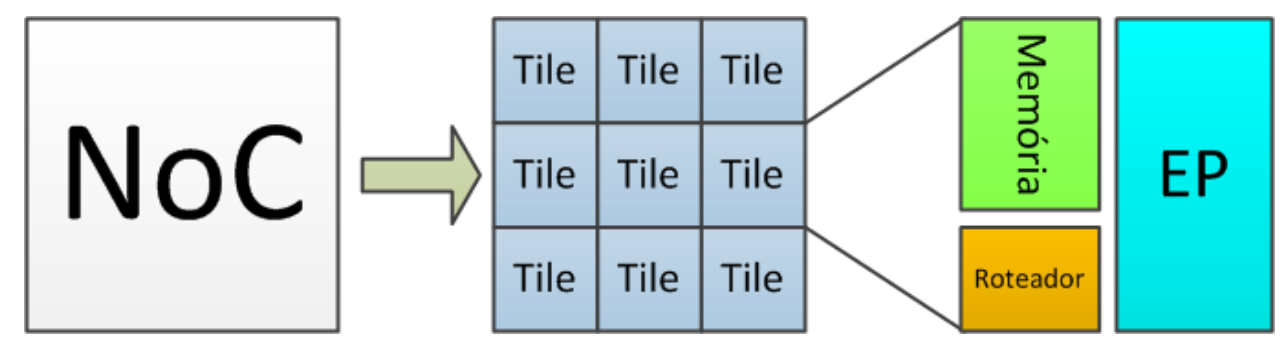

Fonte: (Autor, 2014).

\subsubsection{Modificações do Simulador Noxim para a implementação do algo- ritmo FDOR}

As modificações feitas ao Noxim, no âmbito desta dissertação, para a implementação do algoritmo FDOR consistiram na adição de uma nova função de roteamento; para isto, deve-se ler um arquivo de texto, que determina qual algoritmo de roteamento os roteadores iriam usar e a configuração de cada EP, que determina se estão ou não disponíveis para injetar pacotes na rede. Dessa forma, o Noxim pode ser alterado para implementar NoCs com topologia irregular.

Com estas modificações, o usuário pode inserir qualquer tipo de topologia por meio de arquivos de texto, selecionar o algoritmo de roteamento FDOR e utilizar a ferramenta Noxim Explorer.

\subsection{Avaliação dos Resultados das Simulações Utilizando a Ferramenta Noxim Explorer}

As simulações no Noxim foram utilizadas em duas diferentes avaliações. Primeiro, avaliouse o desempenho das redes nas diferentes topologias irregulares permitidas pelo algoritmo FDOR, de forma comparativa. A segunda parte consistiu em analisar os aspectos do posicionamento de módulos no caso de uma reconfiguração dinâmica e verificar o desempenho correspondente frente a uma mudança de contexto. A distribuição de tráfego de pacotes será aleatória com a finalidade de avaliar a rede para diversas situações, já que seria computacional- 
mente oneroso avaliar todas as situações possíveis de tamanho de pacotes e todos os roteadores de destinos possíveis.

\subsubsection{Avaliação de desempenho baseado na topologia irregular da rede}

Esta seção apresenta um conjunto de simulações com o Noxim, cujo objetivo foi verificar a influência de diferentes topologias permitidas pelo algoritmo FDOR sobre o desempenho da rede. Uma vez que o mapeamento (HU; MARCULESCU, 2003; LEI; KUMAR, 2003; SRINIVASAN; CHATHA, 2005; MARCON et al., 2007; CARVALHO; CALAZANS; MORAES, 2007; CHOU; MARCULESCU, 2007; RANA et al., 2010; BERETTA et al., 2010; BERETTA et al., 2011) de MPs junto aos roteadores pode ser realizada de várias formas, gerando topologias diferentes, todas válidas funcionalmente, é objetivo deste estudo trazer subsídios que auxiliem o projetista em suas decisões.

Primeiramente, fez-se uma avaliação do desempenho das topologias irregulares 'd', 'p' '+', 't', 's', permitidas pelo algoritmo FDOR. Em relação à topologia 's', duas variações adicionais foram consideradas: a forma simétrica do mesmo e outra, com o núcleo na direção $X$. Para a análise foram adotados três tamanhos diferentes de rede: $5 \times 5,8 \times 8$ e 12x12, possibilitando observar a influência do tamanho da rede no seu desempenho e como a escolha de determinadas topologias pode ser mais benéfica para alguns casos e não para outros.

As métricas de desempenho analisadas foram a Latência Média, Latência Máxima e Throughput em função da Taxa de Injeção dos MPs associados aos roteadores. Resultados de energia não foram incluídos, pois isto depende da tecnologia utilizada para a implementação da arquitetura o qual requereria uma análise elétrica de cada dispositivo FPGA sobre o qual se implementaria o sistema, porém esta análise se deixara para um trabalho futuro. Para entender os resultados, nos apoiamos nas seguintes considerações:

1. A Latência Média depende dos seguintes fatores na rede: distância (média) entre MPs que se comunicam (em número de roteadores pelos quais os pacotes devem passar), tamanho dos pacotes utilizados e as prioridades existentes nos caminhos (dadas pelo árbitro), pois 
bloqueios por falta de prioridade pode fazer com que o envio de flits de um pacote não seja contínuo (podendo ser interrompido momentaneamente) e tempo de trânsito de um pacote aumente. O tamanho dos pacotes é decidido de forma aleatória no Noxim, não sendo então relevante no comparativo entre as diferentes topologias.

2. A Latência Máxima depende dos seguintes fatores na rede: o(s) caminho(s) mais longo(s) existente(s) na rede entre dois roteadores que realizam a comunicação, tamanho dos pacotes utilizados e as prioridades existentes nos caminhos, o que é dado pelo árbitro. $\mathrm{O}$ valor de Latência Máxima é estabelecido por algum caso individual em que o seu caminho para o destino é de baixa prioridade, além de ser um caminho longo. Assim, como para a Latência Média, o tamanho dos pacotes não é relevante no comparativo entre as diferentes topologias, uma vez que ele é definido de forma aleatória no Noxim.

3. O Throughput é dado pelo número de flits que transitam na rede em um intervalo de tempo, ou seja, é afetado negativamente quando pacotes devem esperar para serem colocados na rede. O Throughput depende, então, basicamente da espera imposta aos pacotes seja para serem lançados na rede, seja no caminho para o seu destino. São aspectos negativos para o Throughput, a concentração de envio de pacotes por certos caminhos específicos (sendo fundamental que se tenha o maior número de caminhos) e a falta de prioridade nestes caminhos de alta concentração de tráfego.

Dois aspectos devem ser observados:

- Quanto maior a taxa de injeção dos MPs, maior é a possibilidade de congestionamento na rede, ou seja a retenção de pacotes em seu caminho;

- No Noxim, em particular, a arbitragem dentro dos roteadores é estabelecida na seguinte ordem: prioriza-se primeiro dados vindo pela porto local, depois na direção norte, sul, oeste, e finalmente leste. 


\subsubsection{Análise para uma Malha 2-D de 8x8}

A Figura 54 ilustra as topologias propostas para o caso de uma NoC com dimensões 8x8; as regiões de núcleo contém roteamento YX (vermelho), com excepção das topologias das Figuras 54(f) e (g), onde encontramos núcleos com roteamento XY (em verde). É importante notar que todos os roteadores ativados estão ligados ao seus respectivos MPs, os quais também encontram-se ativados. A distribuição de tráfego utilizada foi de tipo randômico pelas razões explicadas anteriormente.

Não é óbvio obter topologias em que roteadores e MPs tenham influências externas médias idênticas, o que seria desejável para uma comparação justa. Para aproximar o máximo da situação ideal de comparação, as topologias foram elaboradas para que a quantidade de MPs ativos em cada uma tivessem valores próximos entre si. Por exemplo, para o caso das topologias 'd' e 'p', estão presentes na malha 49 MPs e para os casos '+', 't', 's', 's-x' e seu simétrico, estão presentes 48 MPs.

A Figura 55 apresenta os resultados das simulações de Latência Média vs. Taxa de Injeção para diferentes topologias, sendo adotada como definição para latência aquela descrita na seção 2.4.6.1 (capítulo 2). Foi utilizado um intervalo [0;0,4] para a taxa de injeção, que é onde melhor se apresentam os valores da simulação para se fazer as comparações entre os casos, já que para Taxas de Injeção maiores, há uma saturação dos valores de Latência Média. Pode-se observar pelas curvas que a topologia 'd' (Figura 54(a)) tem a maior Latência Média devido a um tráfego intenso na fronteira do núcleo para a ala X-. A fronteira é grande, como pode ser visto na Figura 54(a), provocando uma longa coluna de congestionamento, como foi explicado na seção 4.2. Os pacotes oriundos da ala X-, ao adentrarem no núcleo, adotarão o roteamento YX, concentrando o trânsito na primeira coluna, congestionando esta linha vertical- observar a existência de um grande número de MPs na ala X-, gerando tráfego nestas condições; por outro lado, todo o tráfego oriundo do núcleo para a ala X-tem baixa prioridade, pois caminham pelo eixo $X$, tendo dificuldade de cruzar a fronteira entre o núcleo e ala $\mathrm{X}$-. Mais um fator que aumenta a Latência Média é o formato da área ativa, pois não há uma região central, que 
Figura 54: Topologias irregulares permitidas pelo algoritmo FDOR.

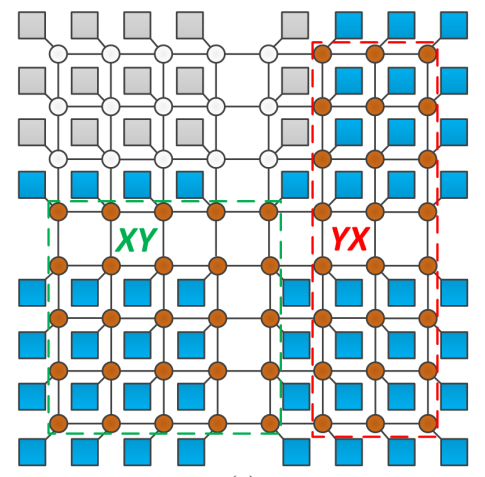

(a)

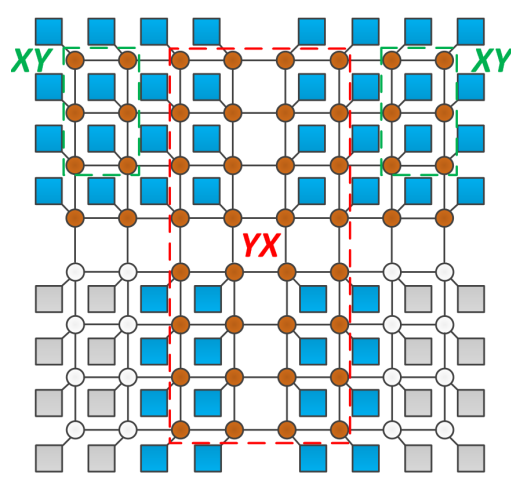

(d)

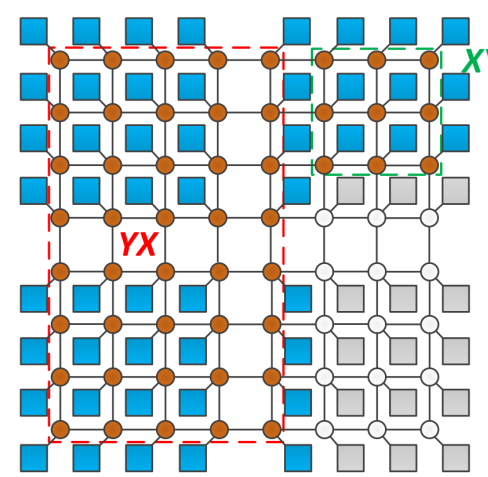

(b)

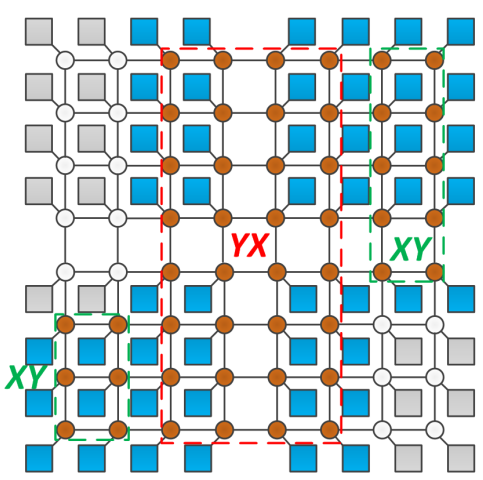

(e)

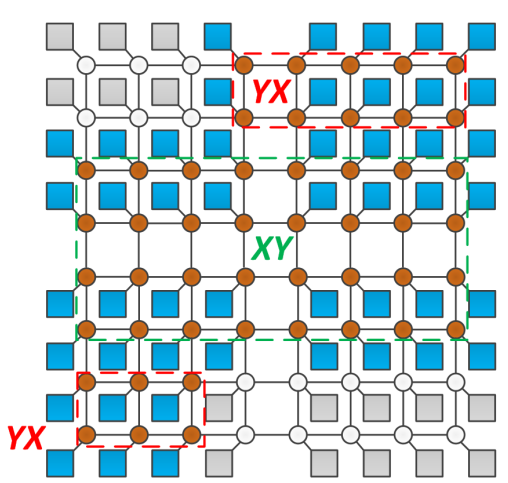

(g)

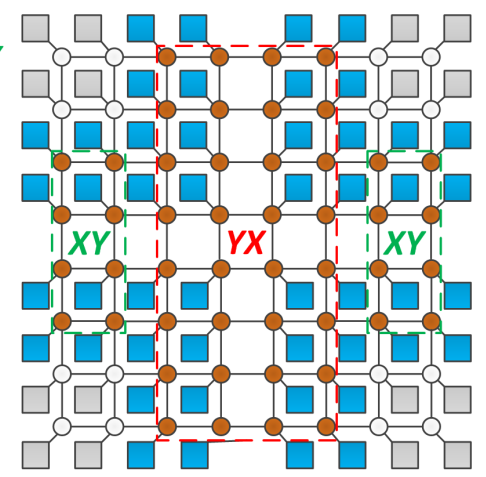

(c)

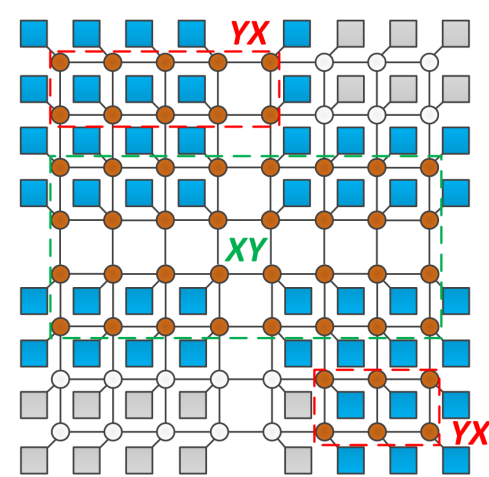

(f)
(a) 'd' (49 MPs)
(b) 'p' (49 MPs)
(c) ' + ' (48 MPs)
(d) 't' (48 MPs)
(e) 's' (48 MPs)
(f) 's' com núcleo em direção X (48 MPs)
(g) Simétrico do (f)(48 MPs).

Fonte: (Autor, 2014).

veremos existir nas outras topologias; tal situação faz aumentar as distâncias médias.

As topologias que têm menor Latência Média são as 's-x' e seu simétrico porque as fronteiras entre o núcleo e as alas são largas, mas a passagem de pacotes é feita na direção $Y$ com maior prioridade; além disso, a região de núcleo, que é centralizada, possui um bom número de 
MPs, sendo que grande parte do tráfego concentra-se nessa região. No caso da topologia 's', a latência já é maior, uma vez que, na comunicação da região do núcleo com as alas $\mathrm{X}$ - e $\mathrm{X}+$, os pacotes que percorrem as colunas de roteadores que formam o núcleo têm prioridade maior e os pacotes que vêm das alas na direção $X$ aguardam mais tempo, gerando congestionamento na rede. A topologia ' $t$ ' apresenta um resultado similar, levemente melhor, que o da topologia 's'. Neste caso, as mesmas condições se repetem, com a fronteira entre núcleo e alas sendo do mesmo tamanho; entretanto, como as duas alas estão na mesma altura, a distância média entre roteadores é menor. A topologia 'p' é semelhante à topologia 'd' no formato, o que torna as suas distâncias médias maiores comparado a outras topologias; por outro lado, a topologia apresenta uma pequena fronteira entre o núcleo e ala $\mathrm{X}+$, o que acaba melhorando a Latência Média, fazendo os resultados similares aos da topologia 's'.

Finalmente, no caso da topologia '+', os valores de Latência Média são piores que os da 't' e 'p'. Estruturalmente, a topologia é muito similar que à 't', com as regiões das alas posicionadas simetricamente, gerando situações similares. O que torna os resultados piores nesta topologia, entretanto, é o fato de o cruzamento dos pacotes oriundos de uma ala para outra com os pacotes do núcleo ocorrer na media-altura $Y$ da rede; estes pacotes são de prioridade mais baixa e ao atravessarem o núcleo na direção $X$, acabam por sofrer mais interferência, pois há comparativamente mais pacotes que vão de cima a baixo (ou vice-versa) no núcleo, dificultando a sua passagem.

Os resultados de Throughput vs. Taxa de Injeção para diferentes topologias são apresentados na Figura 56, sendo adotada como definição de Throughput aquela descrita na seção 2.4.6.2 (capítulo 2). Pelas curvas, observa-se que o menor valor ocorre para a topologia 'd', devido à grande quantidade de MPs na ala X-. Todos os pacotes que saem daquela região para o núcleo, ao passar para o roteamento Y-X seguem por uma única primeira coluna do núcleo. A redução do número de caminhos determina uma baixo trânsito de flits pela rede.

O maior valor de Throughput Médio é da topologia 'p', que apesar de ter topologia com formato similar ao do 'd', apresenta poucos MPs na ala. Isto faz com que existam poucos 
Figura 55: Latência Média vs. Taxa de Injeção, para as topologias irregulares para uma malha 2-D de 8x8.

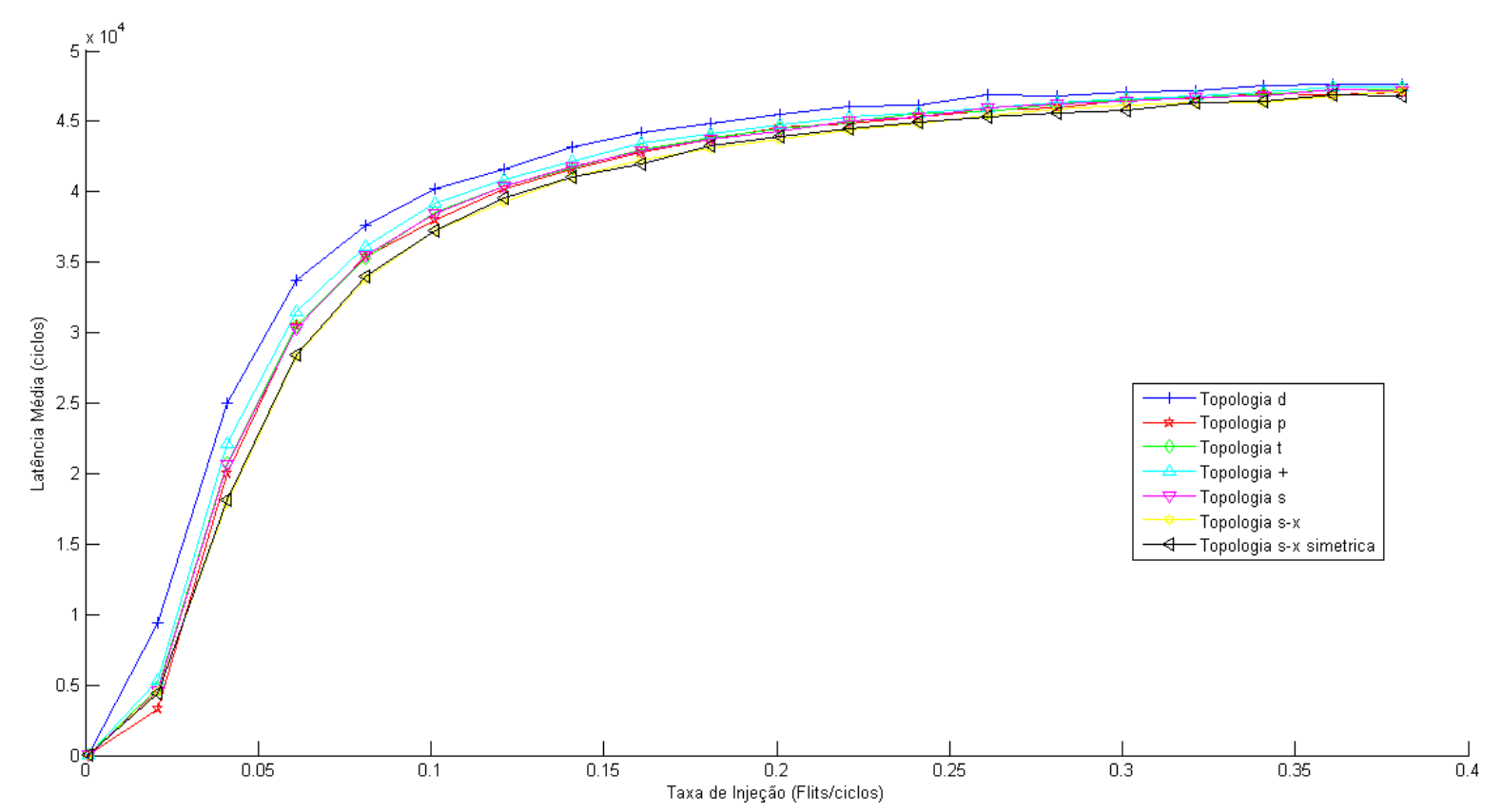

Fonte: (Autor, 2014).

caminhos diretos na direção $X$ entre a ala e o núcleo, com baixa prioridade, assim como, raros caminhos longos de travamento quando pacotes vão da ala para o núcleo (virando na primeira coluna - direção $Y$ ). A grande parte do tráfego ocorre no grande núcleo que opera como uma NoC regular em Y-X.

Depois da topologia 'p', os melhores resultados ocorrem as topologias '+' e 't', muito próximos entre si. Devido à similaridade de suas estruturas, a quantidade de caminhos é próxima. Em ambas as topologias, as duas alas opostas estão dispostas na mesma altura, contendo efeitos semelhantes quando pacotes atravessam o núcleo. Ocorre também que o congestionamento aumenta no centro da malha, isto é uma parte central da região do núcleo que é adjacente às alas. Isto é devido a pacotes vindo e saindo deste centro em todas as direções.

Nos casos anteriores, o Throughput Médio é maior que para os casos das topologias 's', 's-X' e seu simétrico. Para o caso da topologia 's', o Throughput Médio é maior que no caso de 's-X' e seu simétrico, mas com uma diferença aproximada de 0.01 flits/ciclos, o que não é muito significativo. Os valores de Throughput Médio para os casos 's-x' e seu simétrico são similares. Então, podemos concluir que o valor de Throughput Médio depende da orientação 
da região de núcleo, ou seja, do esquema de arbitragem, já que a prioridade é dos dados que vem das direções NORTE e SUL. Neste caso, nas topologias 's-x' e seu simétrico, o caminho de congestionamento formado na primeira fileira do núcleo (na direção X) após os pacotes cruzarem das alas acabam por tornar maior o efeito de bloqueio aos pacotes.

Figura 56: Throughput Médio vs. Taxa de Injeção, para as topologias irregulares para uma malha 2-D de $8 \times 8$.

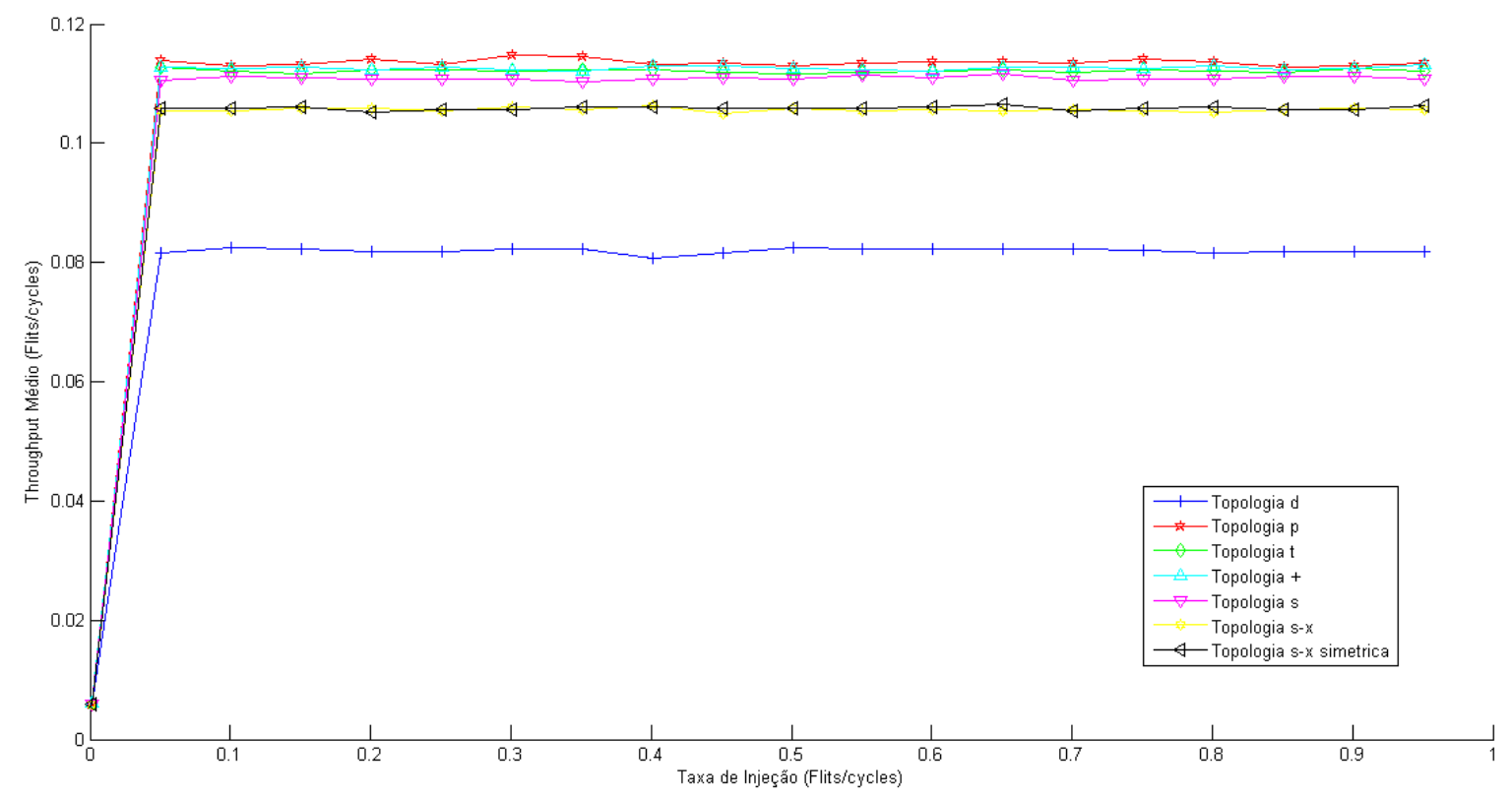

Fonte: (Autor, 2014).

A Figura 57 apresenta os resultados de Latência Máxima, onde as topologias 't' e '+' obtiveram os menores valores, uma vez que comparadas às outras topologias, têm caminhos críticos (dados por roteadores nas diagonais opostas) mais curtos. A diferença verificada entre os valores da topologia '+' e 't' também reside no comprimento máximo do caminho de roteadores a ser percorrido por um pacote. No caso da topologia '+', o caminho consiste de onze (11) roteadores e no caso de ' $t$ ' é de treze (13) roteadores. Os valores de outras topologias são bastante semelhantes entre si, pois todos possuem caminhos igualmente longos entre dois pontos opostos pela diagonal. 
Figura 57: Latência Máxima vs. Taxa de Injeção, para as topologias irregulares para uma malha 2-D de 8x8.

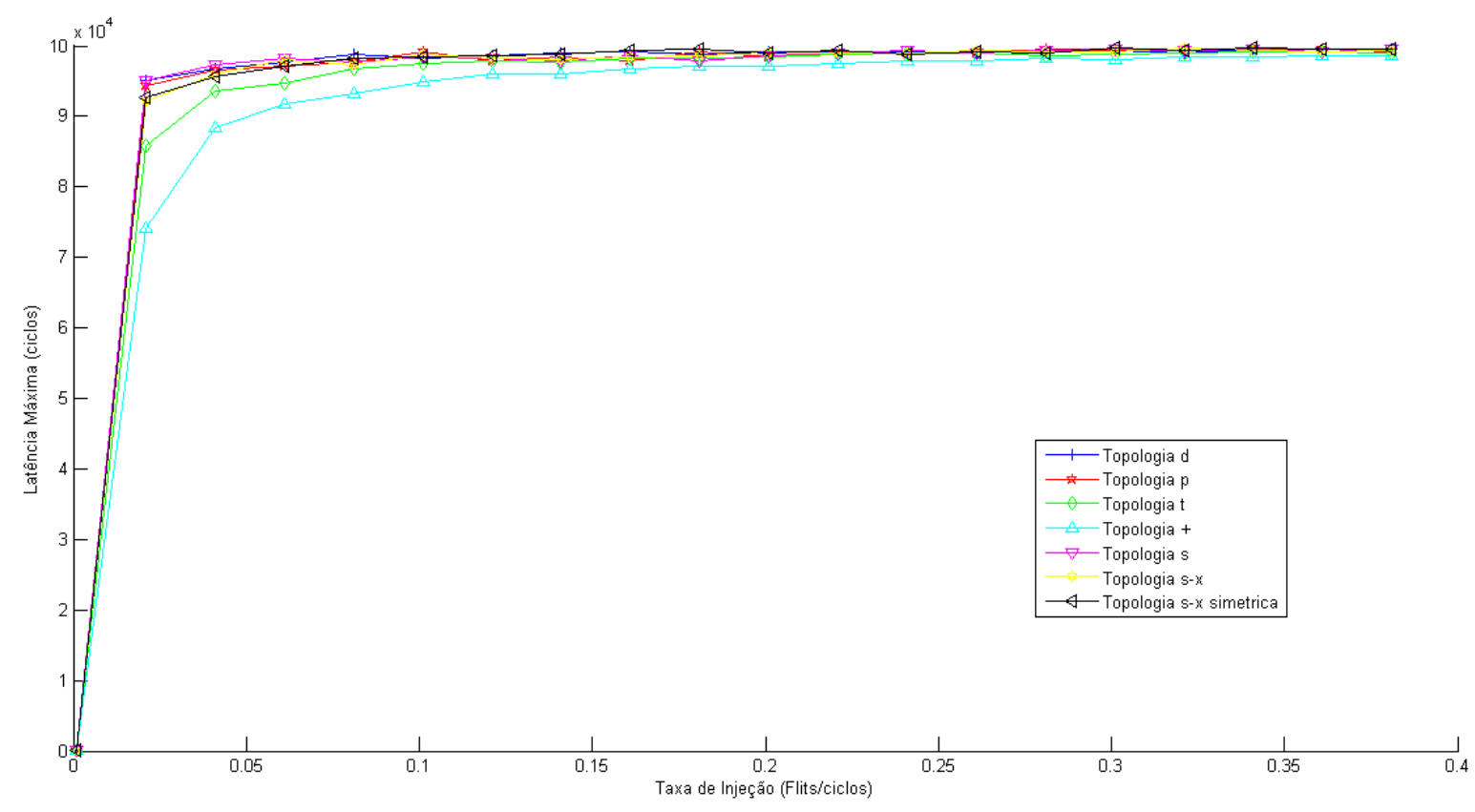

Fonte: (Autor, 2014).

\subsubsection{Análise para uma Malha 2-D de $12 \times 12$}

Para comparar os efeitos de geometria sobre as medidas de latência e throughput, foram realizadas simulações para uma rede de dimensões $12 \times 12$, para as mesmas topologias apresentadas anteriormente. A Figura 58 ilustra estas topologias irregulares como as topologias 'd' (a) e 'p' (b) com 99 MPs ativos, a topologia '+' (c) com 96 MPs ativos, as topologias 't' (d), 's' (e) 's-X' (f) e seu simétrico (g), com 102 MPs ativos. Estas simulações foram feitas para o intervalo $[0 ; 0,4]$ flits/ciclos de taxa de injeção de pacotes, região em que os resultados podem ser mais bem visualizados.

Com excepção dos valores de latência mais altos e de throughptut mais baixos, os resultados da simulação são similares aos resultados obtidas para as topologias implementadas sobre a malha de 8x8. Evidencia-se pela Figura 59 que, novamente, no caso da Latência Média, a topologia 'd' é quem obteve maiores valores, consistindo no pior caso independente do tamanho da rede; as justificativas são as mesmas apresentadas na seção anterior. Da mesma forma, os menores valores de Latência Média foram das topologias 's-X' e seu simétrico. Para os casos das topologias '+', 's', 'p' e 't' os resultados também têm a mesma ordem que no caso da malha 
Figura 58: Topologias irregulares permitidas pelo algoritmo FDOR para uma malha 2-D de 12x12.

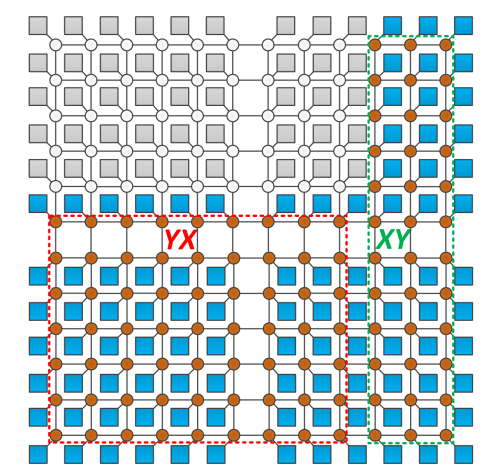

(a)

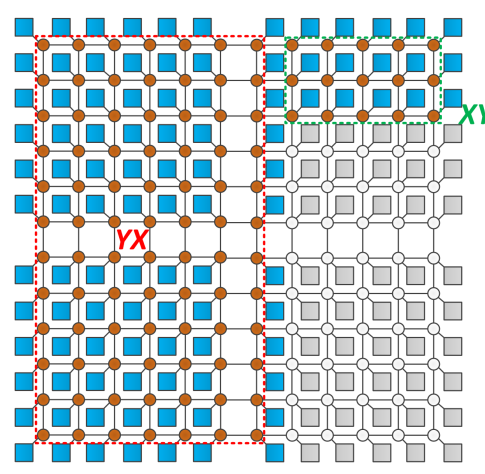

(b)

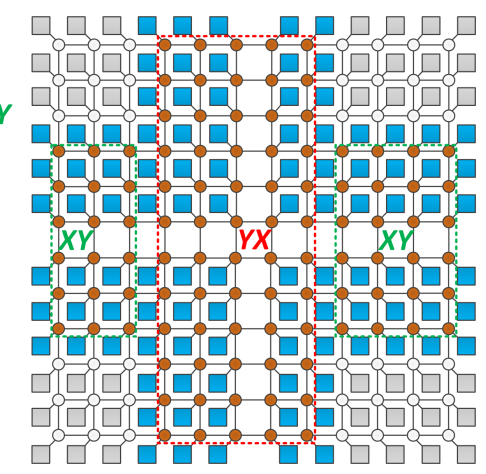

(c)

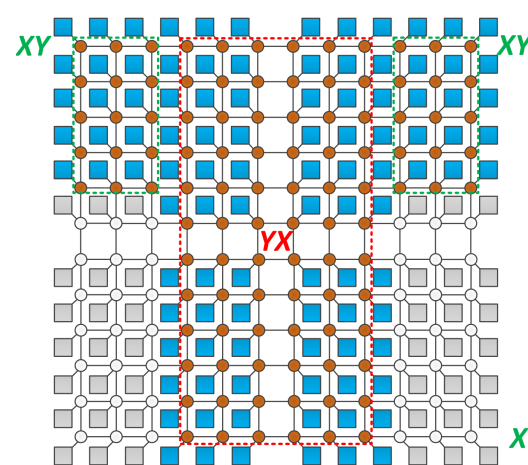

(d)

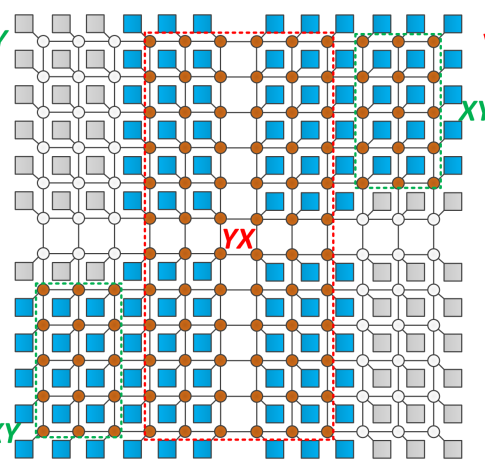

(e)

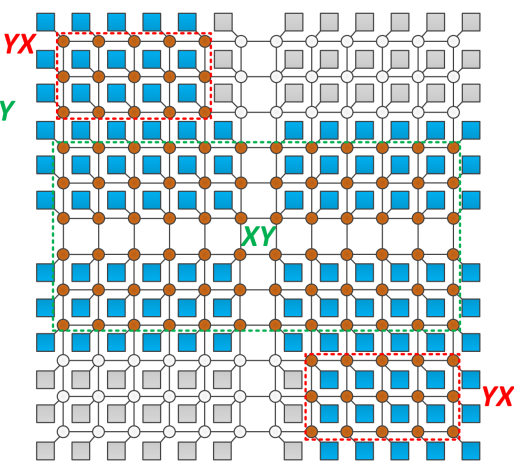

(f)

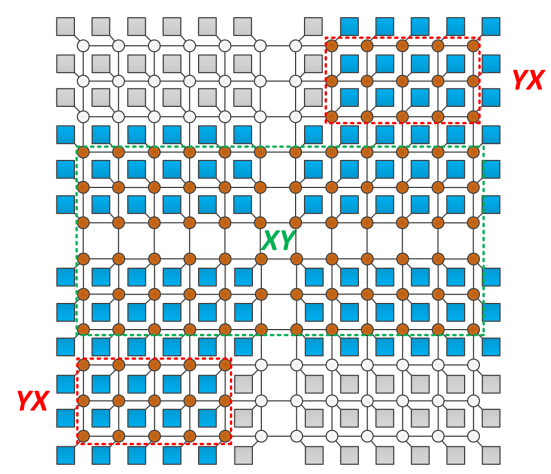

(g)
(a) 'd'
(b) 'p'
(c) ' ',
(d) ' $t$ ')
(e) 's'
(f) 's' com núcleo em direção $\mathrm{X}$
(g) Simétrico do (f).

Fonte: (Autor, 2014).

de $8 \times 8$, porém muito mais próximos, fenômeno que atribuímos ao fato de ser uma rede maior, cujos comprimentos de caminhos passam a ser razoavelmente equivalentes na média. É obvio que os valores absolutos de Latência Média serão sempre maiores à medida que se aumentem as dimensões da rede, uma vez que os caminhos de pacotes serão mais longos. 
Figura 59: Latência Média vs. Taxa de Injeção, para as topologias irregulares para uma malha 2-D de 12x12.

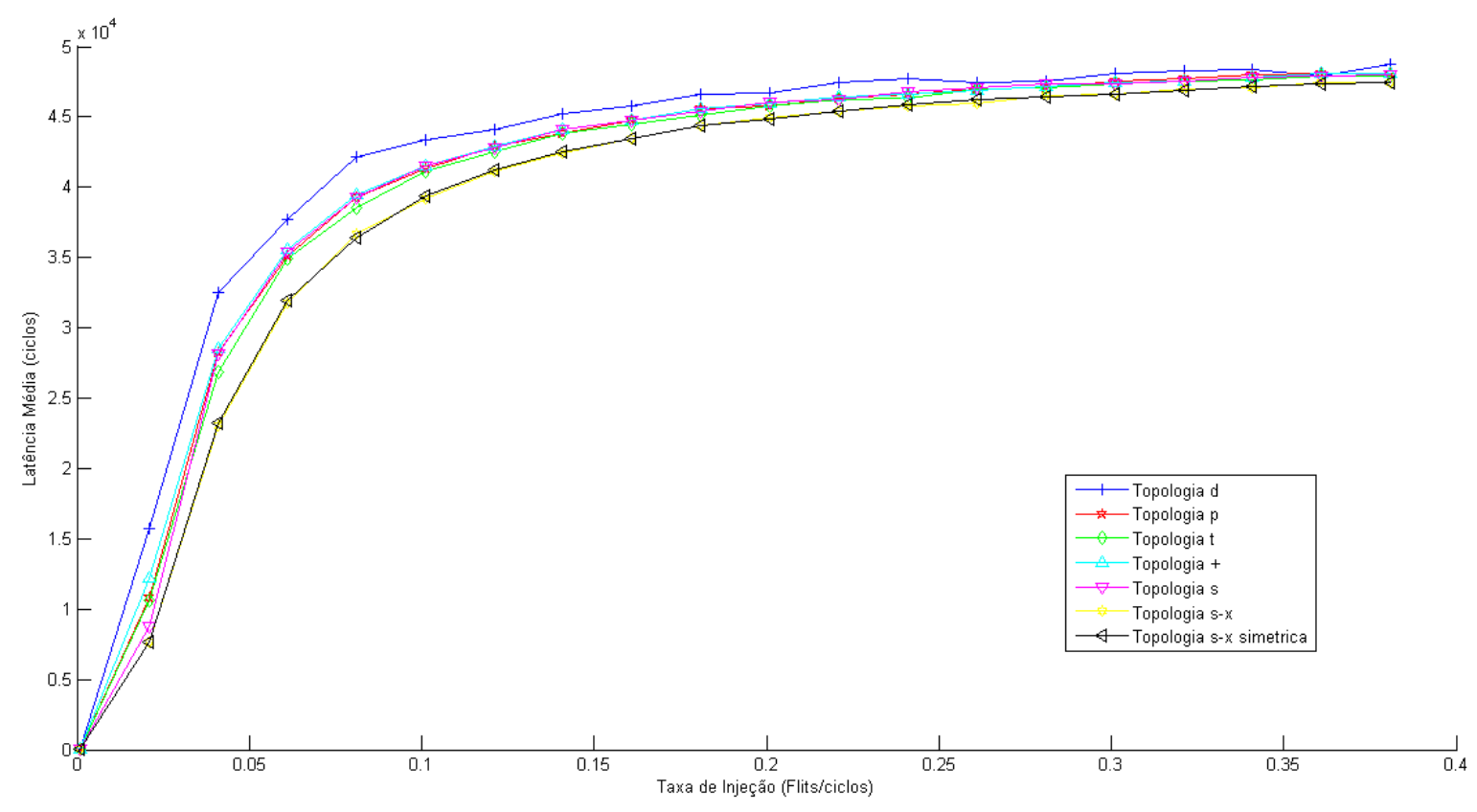

Fonte: (Autor, 2014).

Em relação aos resultados de Throughput Médio, apresentados na Figura 60 , há algumas mudanças na comparação com as simulações da malha de 8x8. Primeiramente, como esperado, os valores de Throughput Médio, no todo, são menores para o caso da malha de 12x12, uma vez que mais mais pacotes originados de mais localidades de roteadores devem seguir pelos mesmos caminhos congestionados na borda do núcleo quando adentram pelas alas. São mantidos os padrões verificados na malha $8 \times 8$, no comparativo de resultados de throughput de várias topologias: o menor throughput ocorre para a topologia 'd', com o 's-x' e o seu simétrico (muito similares entre si) com taxas mais altas; segue com Throughput ainda maiores, as topologias 's' e 't', também, bastante próximos entre si, como na malha 8x8. É interessante notar que o throughput verificado para a topologia 'd' está relativamente pior que na malha 8x8; tal situação pode ser atribuída à ala X- relativamente maior no caso $12 \times 12$, o que gera mais casos de caminhos que, indo da ala para o núcleo, são obrigados a seguir pela coluna da borda do núcleo.

Duas topologias apresentaram resultados de Throughput Médio diferentes em relação ao caso 8x8: 1) a topologia '+' que apresentou resultados só melhores que a topologia 'd'- isto pode ser explicado pelo fato de que apresenta um núcleo mais estreito que nas outras topologias, enquanto no caso $8 \times 8$ todos tinham a mesma largura; ademais a ala direita é relativamente 
maior (com mais MPs) que no caso '+' da malha 8x8; estas variações fazem com que, relativamente, mais pacotes seguirão pela coluna de congestionamento na borda interna do núcleo; 2) a topologia 'p' que apresentava o melhor resultado na malha $8 \times 8$ e que, agora, tem resultados só melhores que a topologia 'p'; a perda de desempenho pode ser explicada pelo aumento da relação de altura núcleo-ala, que gera um aumento de pacotes que seguem do núcleo para a ala utilizando-se os mesmos caminhos.

Figura 60: Throughput Médio vs. Taxa de Injeção, para as topologias irregulares para uma malha 2-D de $12 \times 12$.

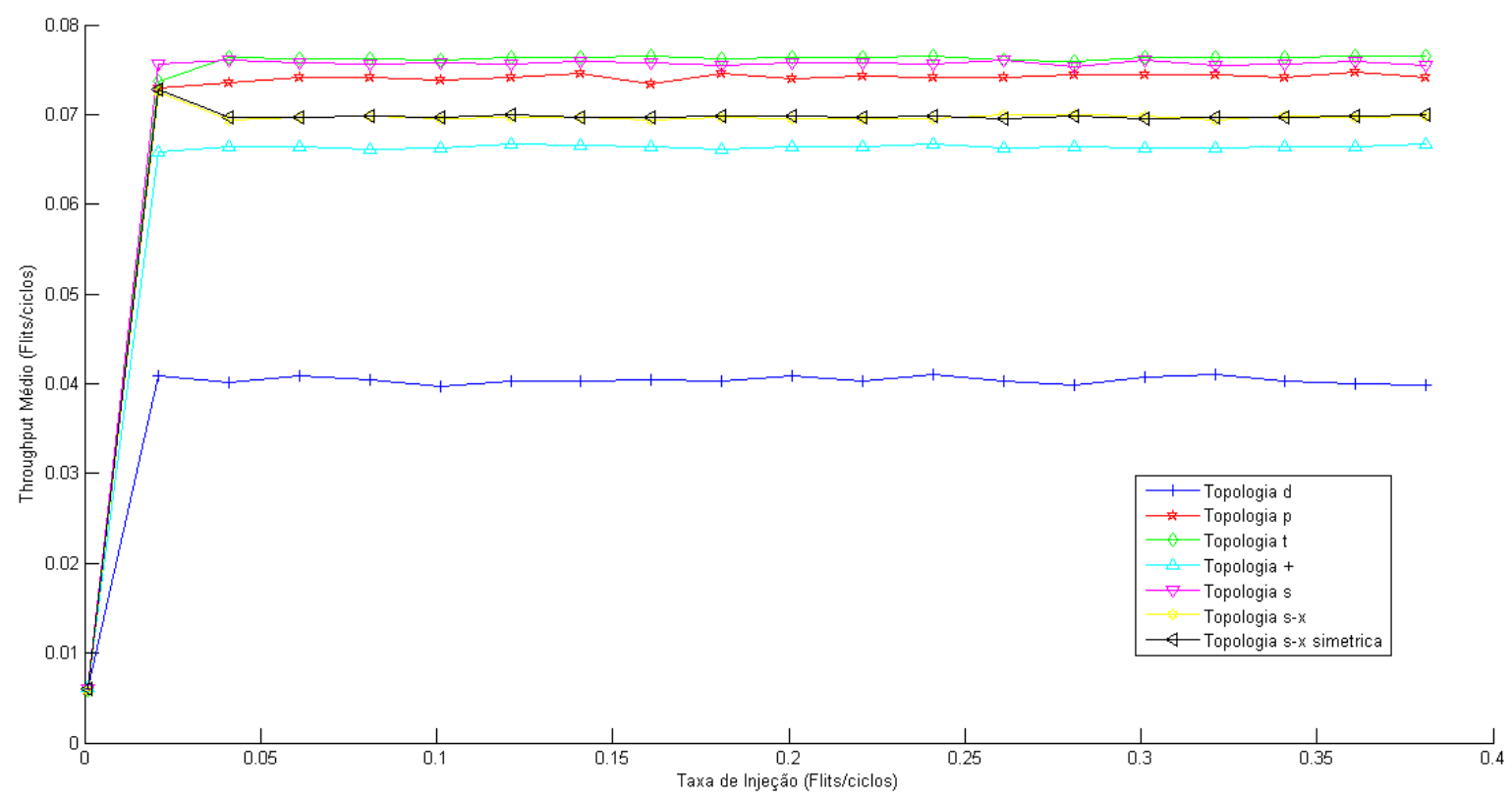

Fonte: (Autor, 2014).

Com respeito aos resultados de Latência Máxima, apresentados na Figura 61, o comportamento também é similar aos resultados obtidos na simulação para uma malha de $8 \times 8$. Entretanto, desta vez os valores de Latência Máxima para os casos das topologias '+' e 't' estão mais próximos aos valores obtidos pelas outras topologias. Isto ocorre porque, uma vez que a Latência Máxima depende dos caminhos de maior comprimento na topologia, tal valor nas topologias ' + ' e 't' da malha 12x12 aumentaram e estão relativamente mais próximas do comprimento máximo de caminho encontrado nas demais topologias. 
Figura 61: Latência Máxima vs. Taxa de Injeção, para as topologias irregulares para uma malha 2-D de $12 \times 12$.

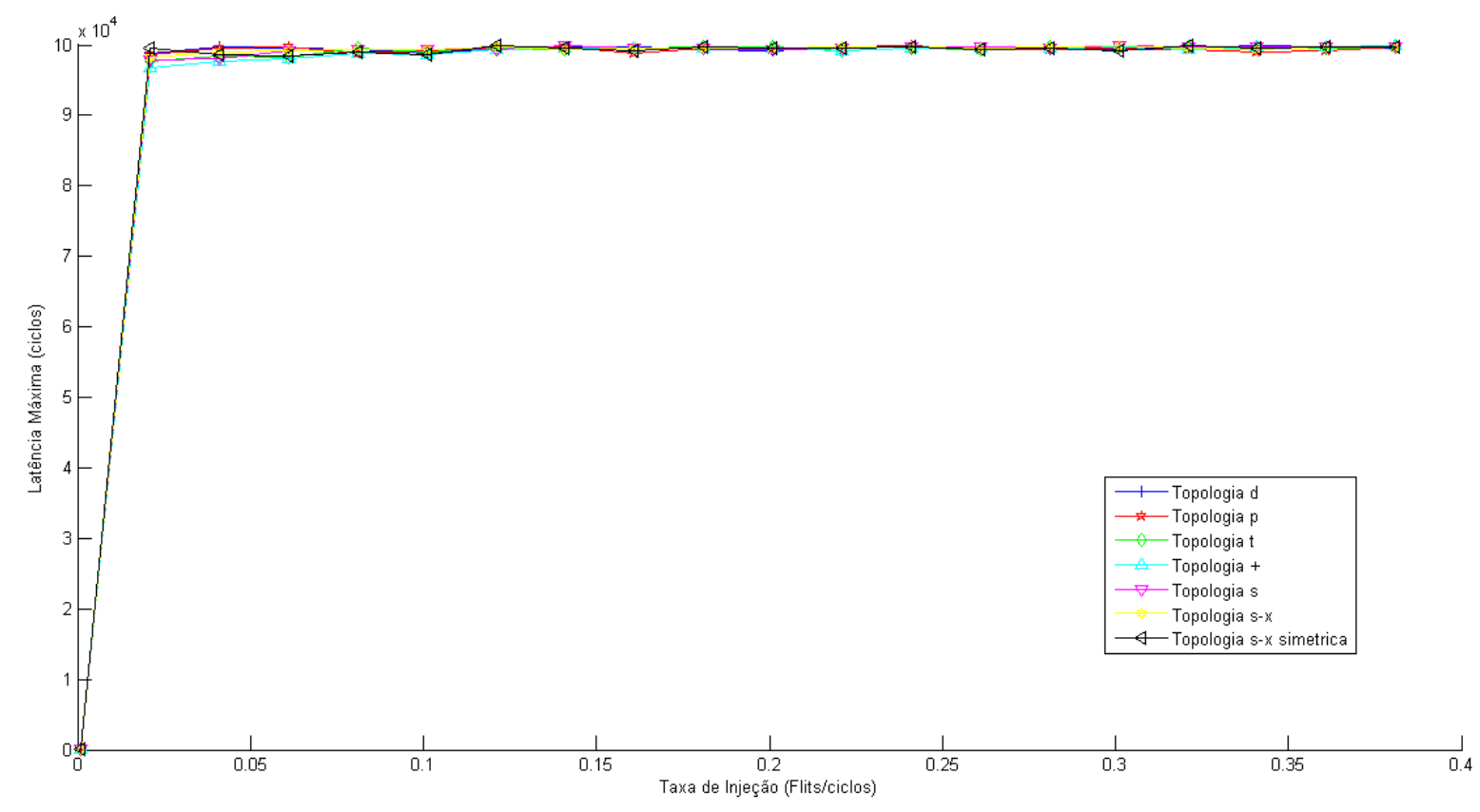

Fonte: (Autor, 2014).

\subsubsection{Análise para uma Malha 2-D de 5x5}

Para aprofundar o estudo dos efeitos de geometria sobre as medidas de Latência e Throughput, foram realizadas, também, simulações para uma rede de dimensões 5x5, para as mesmas topologias apresentadas anteriormente. A Figura 62 ilustra as topologias testadas para o caso de uma NoC com dimensões 5x5 montadas com dezessete (17) MPs, à exceção da topologia ' $t$ ', por falta de viabilidade, com dezesseis MPs (16).

As Figuras 63, 64 e 65 apresentam os resultados da simulação utilizando a ferramenta Noxim Explorer para as topologias anteriores com os valores de Latência Média, Throughput e Latência Máxima vs. Taxa de Injeção, respectivamente. Nestas simulações, os resultados são apresentados para uma Taxa de Injeção de 20 mostras no intervalo de 0.001 até 1 flit/ciclo.

Em termos de resultados de latências, quando comparados com aqueles obtidos na análise das malhas 8x8 e 12x12, verificam-se várias alterações. Os resultados de Latência Média da Figura 63, por exemplo, indicam que, todos os valores estão muito próximos, com excepção daqueles da topologia 'd' que continua consistentemente os piores de todos. O que ocorre para 
Figura 62: Topologias irregulares permitidas pelo algoritmo FDOR com dezessete (17) MPs ativos.

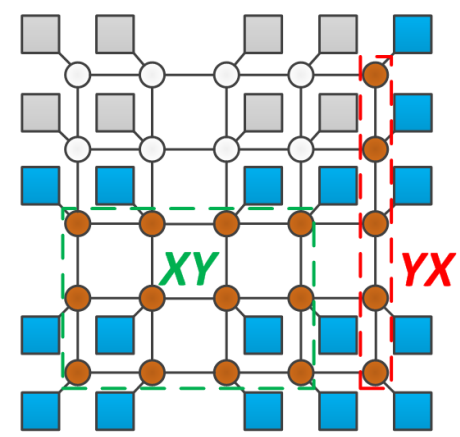

(a)

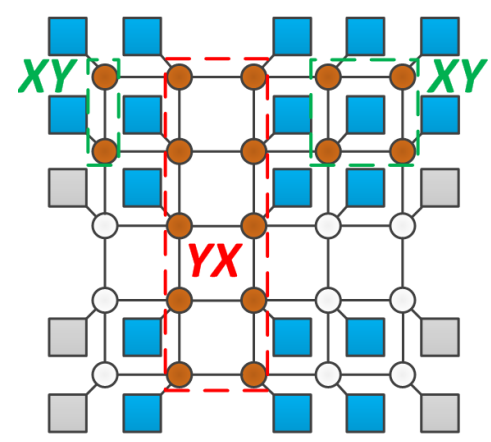

(d)

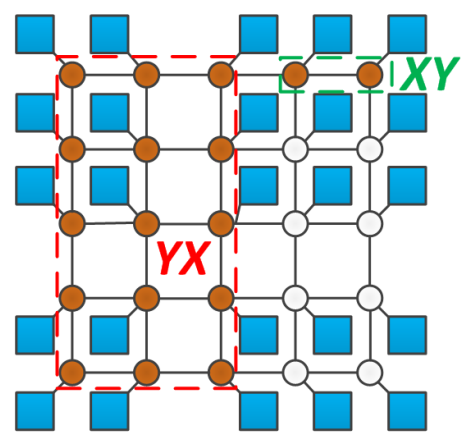

(b)

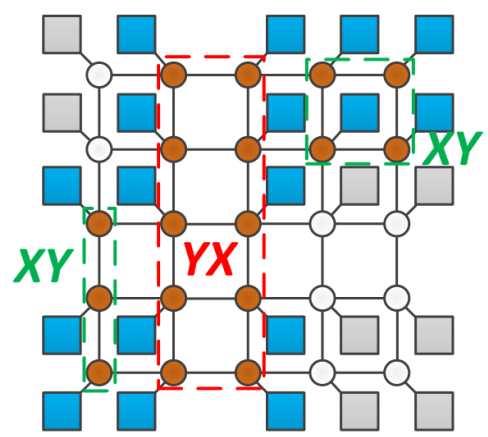

(e)

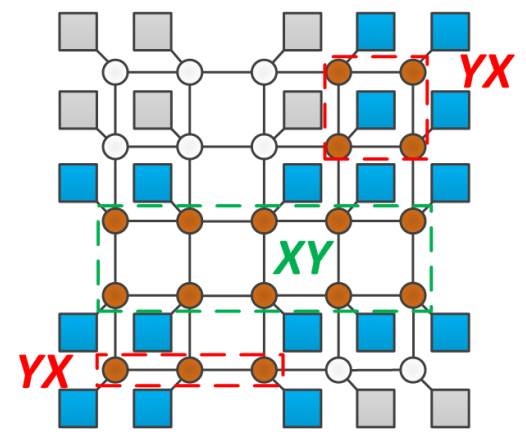

(g)

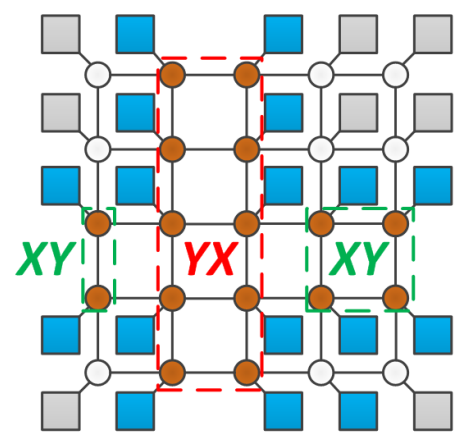

(c)

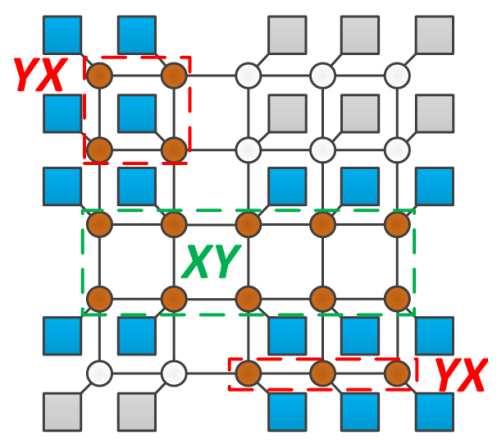

(f)
(d) 't' (16 MPs)
(f) 's' com núcleo em direção $\mathrm{X}$
(g) Simétrico do (f)

(a) 'd'

(b) ' $\mathrm{p}$ '

(c) '+ '

(e) 's'

Fonte: (Autor, 2014).

a malha 5x5 é que, por ser uma malha com poucos roteadores, as distâncias médias estão muito próximas em todas as topologias, tornando estas diferenças pouco relevantes.

Nos resultados de Latência Máxima, conforme à Figura 65, as topologias 't' e '+', por terem os seus caminhos mais longos com menos roteadores, ainda apresentam baixos valores. 
Figura 63: Latência Média vs. Taxa de Injeção, para as topologias irregulares com dezessete (17) MPs ativos para uma malha de $5 \times 5$.

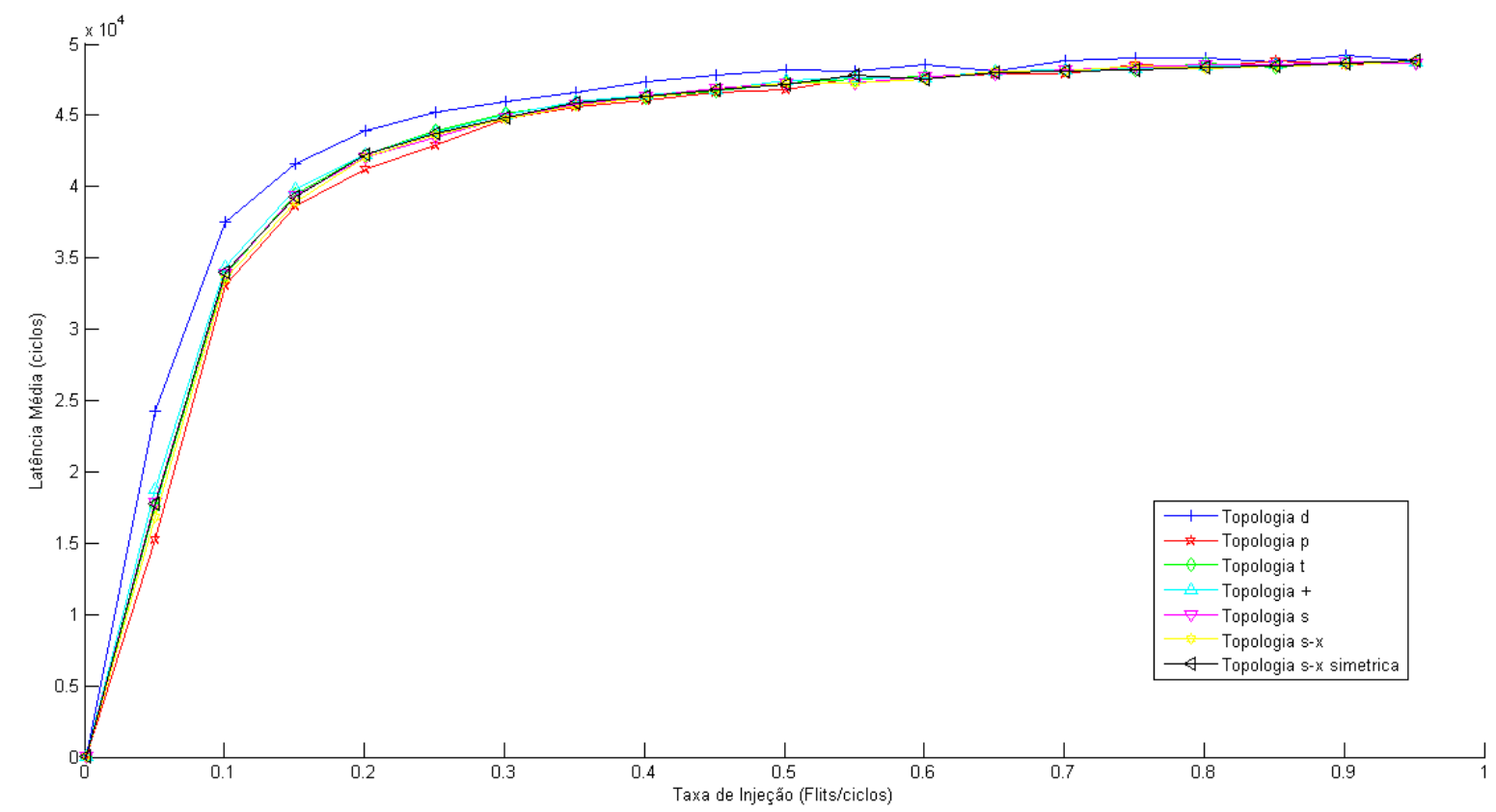

Fonte: (Autor, 2014).

Figura 64: Throughput Médio vs. Taxa de Injeção, para as topologias irregulares com dezessete (17) MPs ativos para uma malha de $5 \times 5$.

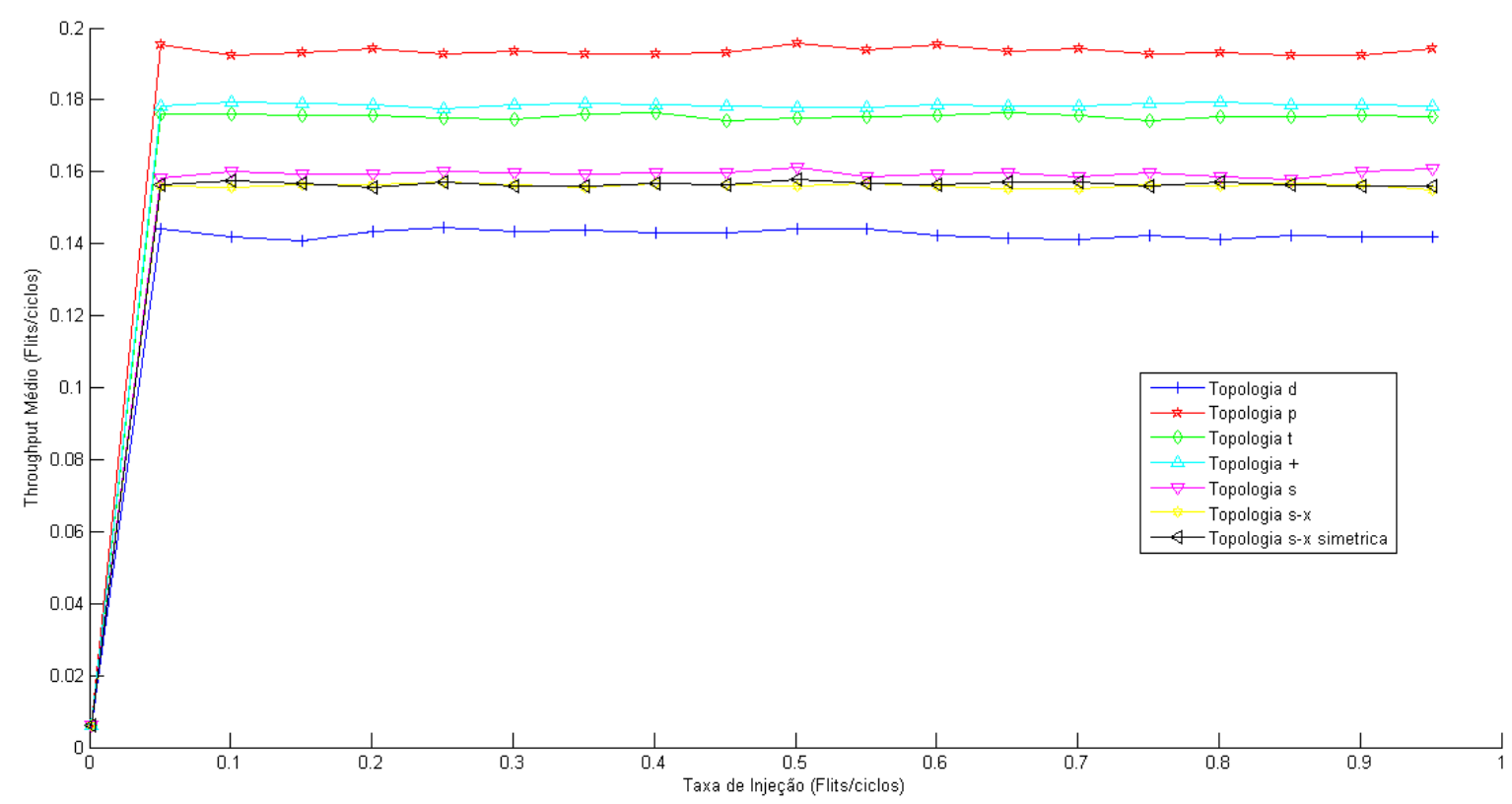

Fonte: (Autor, 2014).

Entretanto, a presença de poucos roteadores tem também efeitos nos demais resultados - para todas as outras topologias, os efeitos particulares de bloqueios e prioridade tornam-se relevantes, dificultando uma análise a partir dos parâmetros de influência que foram introduzidos no 
Figura 65: Latência Máxima vs. Taxa de Injeção, para as topologias irregulares com dezessete (17) MPs ativos para uma malha de $5 \times 5$.

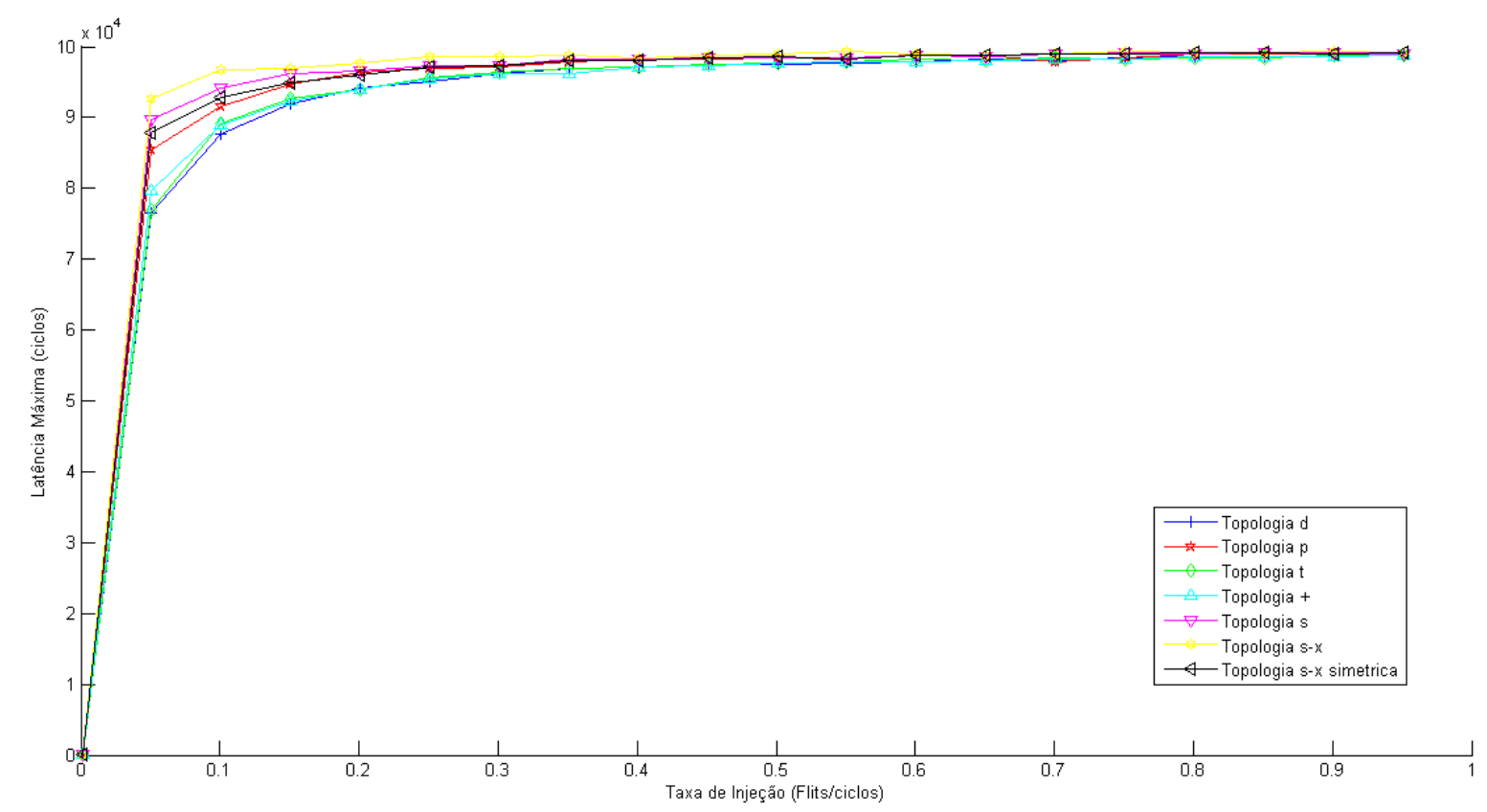

Fonte: (Autor, 2014).

início da seção 3.1 .

Os resultados de Throughput vs. Taxa de Injeção para diferentes topologias são apresentados na Figura 64, sendo totalmente consistente com os resultados e discussões apresentadas para a malha $8 \times 8$. O único aspecto a ressaltar ocorre para os casos das topologias ' + ' e 't', que agora apresentam uma pequena diferença nos seus valores de throughput. A primeira apresenta um melhor resultado, pois, pode-se observar pela Figura 62(d), que há ocorrência menor de pacotes em trânsito pela linha de congestionamento nas bordas internas do núcleo, já que os pacotes são transmitidos para o núcleo em ambos sentidos, superior e inferior sobre o eixo Y, dividindo o tráfego em duas direções, reduzindo o congestionamento.

Um segundo conjunto de simulações foi feito para as mesmas topologias e as mesmas dimensões da rede $(5 \times 5)$, mas com uma quantidade maior de MPs, neste caso dezenove (19) MPs. Poucas modificações ocorreram em relação aos resultados da malha 5x5 com 17 MPs aqui apresentados; mais detalhes em relação ao novo jogo de simulações podem ser acompanhados no Apêndice B. 


\subsubsection{Efeitos de posicionamento de módulos no desempenho da DRNoC}

Nesta seção, é avaliado o desempenho da DRNoC, em uma situação de reconfiguração parcial dinâmica, onde pode-se evidenciar a importância o posicionamento dos módulos de processamento nos diferentes contextos.

É bem conhecida, em trabalhos anteriores com NoCs estáticas, a importância da tarefa de mapeamento/posicionamento de módulos para o desempenho em NoCs (HU; MARCULESCU, 2003; LEI; KUMAR, 2003; SRINIVASAN; CHATHA, 2005; MARCON et al., 2007; CARVALHO; CALAZANS; MORAES, 2007; CHOU; MARCULESCU, 2007; RANA et al., 2010; BERETTA et al., 2010; BERETTA et al., 2011). O problema do posicionamento em DRNoCs é um tanto mais complexo, pois envolve vários contextos, cada um com novos módulos posicionados. Por exemplo, um primeiro contexto, contendo um posicionamento que corresponda a um bom desempenho na transmissão de pacotes, pode, ao passar para um novo contexto, conter um posicionamento de novos módulos que leve a um desempenho extremamente pobre. A forma oposta pode ocorrer também.

A necessidade de se tratar o posicionamento de forma global, monitorando-se todos os contextos, será ilustrada através de exemplo. Como o número possível de posicionamentos nos diversos contextos (há uma dependência a partir do primeiro contexto) é muito alto, torna-se inviável, por meios manuais, compará-los de forma abrangente. Assim, como no mapeamento estático, algoritmos de otimização devem ser utilizados na busca de melhores soluções de posicionamento.

A Figura 66 ilustra o problema com um exemplo de mudança de contextos. Um contexto envolve o esquema lógico, ou seja a configuração lógica, e o posicionamento. Isto significa que uma mesma configuração lógica pode ser implementada por dois contextos diferentes devido a posicionamentos diferentes. O exemplo consiste de uma rede $8 \times 8$ de roteadores, que dinamicamente passa de uma configuração lógica, para outra, após a troca de partições reconfiguráveis. Para esta transição de reconfiguração, há dois casos de posicionamento: 


\section{Caso 1}

Mudança do contexto $\mathrm{C} 1$ para o contexto $\mathrm{C} 2$ : o que se pretende neste caso é obter dados de simulação pelo Noxim e verificar como a mudança de contexto afeta negativamente o desempenho da rede, isto é o contexto C2 terá pior desempenho na transmissão de pacotes que o contexto $\mathrm{C} 1$.

\section{Caso 2}

Mudança do contexto C1p, de mesma configuração lógica de C1, para o contexto C2p, de mesma configuração lógica de $\mathrm{C} 2$ : neste caso, verifica-se como a mudança de contexto afeta positivamente o desempenho da rede, isto é o contexto $\mathrm{C} 2 \mathrm{p}$ terá desempenho melhor na transmissão de pacotes que o contexto $\mathrm{C} 1$.

Na Figura 66 para os dois casos, os módulos M2 e M3 são substituídos pelos módulos M8 e M9 e os módulos M6 e M7, pelo módulo M10. Cada um destes módulos tem um ponto de acesso na rede, o qual é um roteador, mesmo cor dos módulos, que recebe os pacotes pelo porto local. A regra principal para o posicionamento é que os pontos de acesso devem estar o mais perto do centro da malha bidimensional, conforme a Figura 66.

Os contextos $\mathrm{C} 1$ e $\mathrm{C} 1 \mathrm{p}$ da figura correspondem a diferentes posicionamentos de MPs para a mesma configuração lógica, que resultam no contexto $\mathrm{C} 1 \mathrm{p}$ com menor desempenho na transmissão de pacotes que o $\mathrm{C} 1$; e o contexto $\mathrm{C} 2$ p possui a mesma configuração lógica que o contexto C2, só que com diferente posicionamento de MPs, o que faz que C2p possua melhor desempenho que o contexto C1p.

A situação acima é verificada por simulação em cada contexto, cujos resultados são apresentados pelas Figuras 67 e 68, de Latência Média e Throughput Médio, respectivamente. Na Figura 67, fica evidenciado que o valor de Latência Média do contexto C1 é menor que no caso do contexto C2, enquanto a Figura 68 apresenta que o valor de Throughput Médio do contexto $\mathrm{C} 1$ é maior que o contexto $\mathrm{C} 2$, ou seja, o desempenho na transmissão de pacotes de C1 é melhor que C2. Por outro lado, o desempenho do contexto C2p é melhor do que o C1p, já que os valores de Latência Média são menores e os valores de Throughput Médio são maiores. 
Figura 66: Mudança de contextos por reconfiguração parcial dinâmica para dois casos

C1

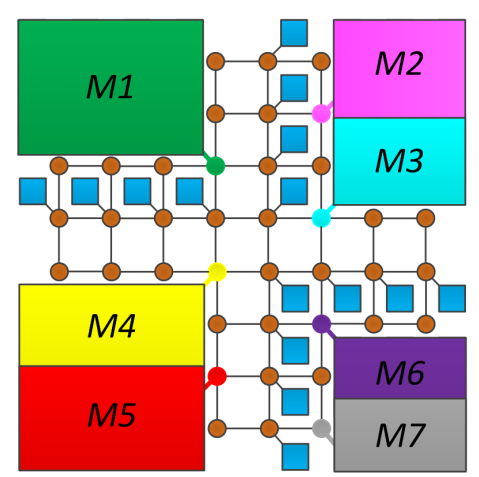

$\mathrm{C} 2$

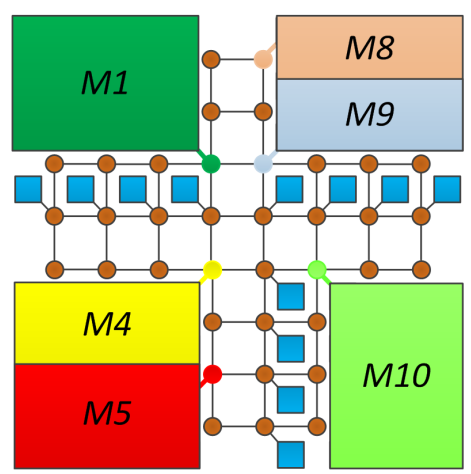

(a) Caso 1

C1p

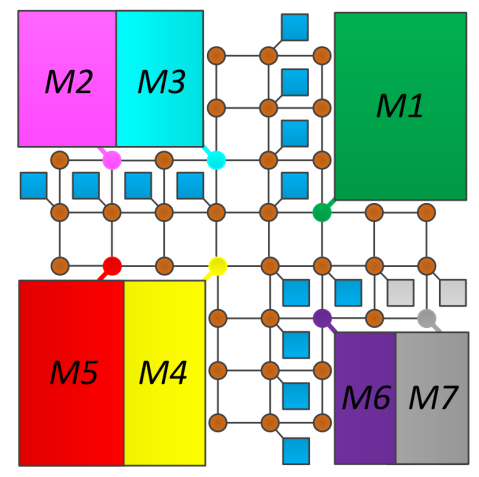

\section{$\mathrm{C} 2 \mathrm{p}$}
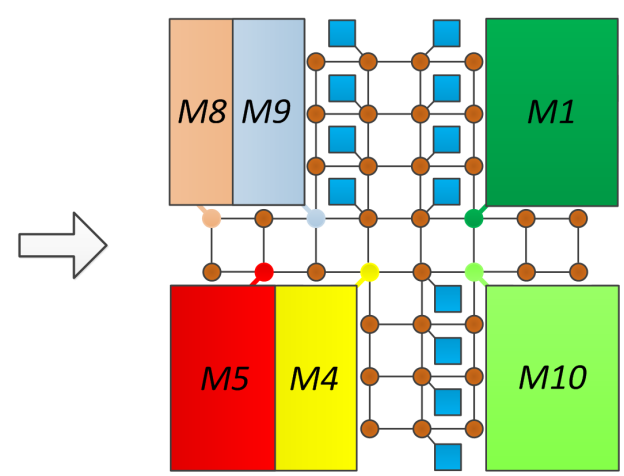

(b) Caso 2

Fonte: (Autor, 2014).

O dado interessante é que a simulação do contexto C1p têm pior desempenho que no caso de C1 tendo como resultado, um maior valor de Latência Média e um menor valor de Throughput Médio. De forma oposta, simulações apresentam que o desempenho com o contexto $\mathrm{C} 2 \mathrm{p}$ é melhor que o de $\mathrm{C} 2$.

Este exemplo evidencia um fato muito importante do posicionamento em DRSs: a definição do posicionamento para uma configuração lógica impõe restrições para o posicionamento dos novos MPs na configuração lógica seguinte. Devido a esta situação, para mudanças de configuração lógica, um contexto com bom desempenho inicialmente pode impor um desempenho pobre no contexto seguinte, enquanto um contexto inicialmente com baixo desempenho pode apresentar um bom desempenho no contexto seguinte. 
Figura 67: Resultados de Latência Média vs. Taxa de Injeção.

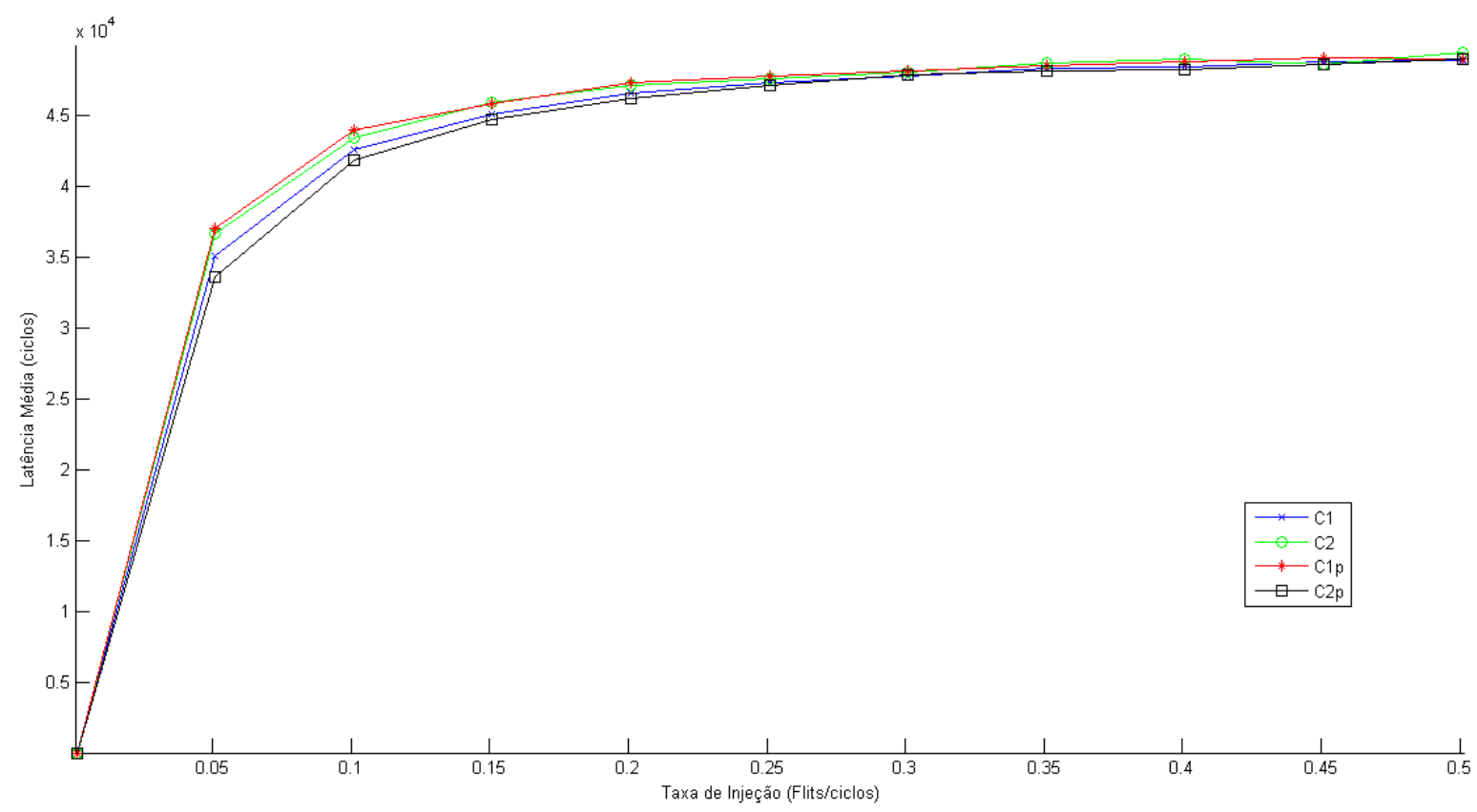

(a) $\mathrm{C} 1->\mathrm{C} 2$

(b) $\mathrm{C} 1 \mathrm{p}->\mathrm{C} 2 \mathrm{p}$

Fonte: (Autor, 2014).

Figura 68: Resultados de Throughput Médio vs. Taxa de Injeção.

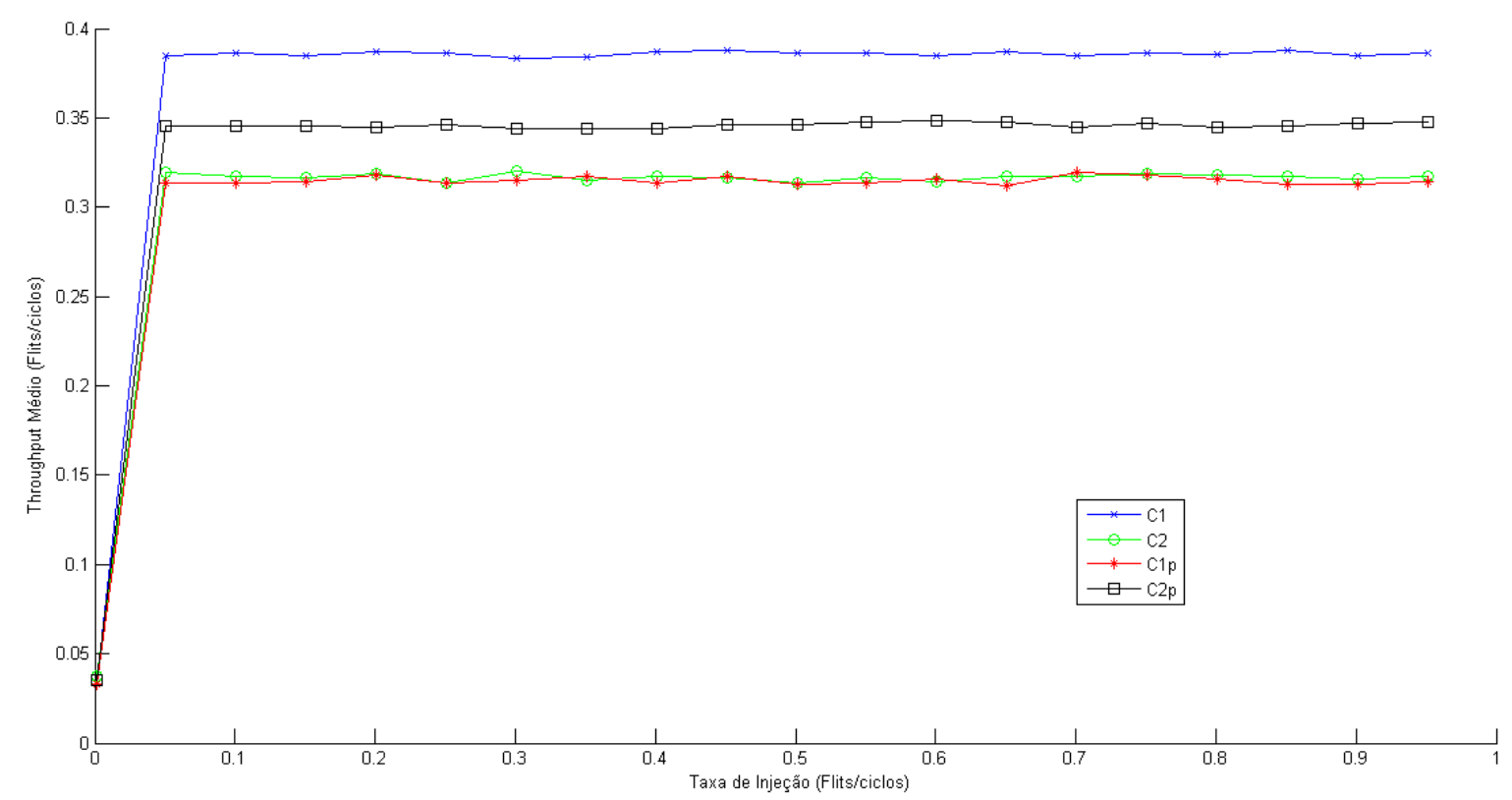

(a) $\mathrm{C} 1->\mathrm{C} 2$

(b) $\mathrm{C} 1 \mathrm{p}->\mathrm{C} 2 \mathrm{p}$

Fonte: (Autor, 2014).

A partir destas simulações podemos concluir que o posicionamento dos módulos de processamento sobre a rede é importante para estabelecer um bom desempenho na transmissão de 
pacotes. Para o projetista, a tarefa de escolher o melhor posicionamento de forma global tornase tarefa bastante complexa, sendo necessário ter à disposição ferramentas de otimização para este fim.

\subsection{Resultados da Síntese da Arquitetura da estrutura de DyAFNoC}

Para poder determinar o desempenho na transmissão de dados é importante avaliar a máxima frequência de operação da arquitetura de DyAFNoC. Esta frequência de operação do sistema depende, além da arquitetura do sistema, da tecnologia que está sendo utilizada para sua implementação, neste caso do dispositivo FPGA que está sendo utilizado. Como o DyAFNoC está destinado a ser implementado em um dispositivo dinamicamente reconfigurável, então o processo de síntese será feito para um DRFPGA da Xilinx.

A síntese foi feita para as malhas 2-D de dimensões 5x5, 8x8 e 12x12, já que foram os casos que foram simulados em alto nível para avaliar seu desempenho na transmissão de dados. Com a finalidade que as comparações sejam em condições similares, utilizou-se o dispositivo Virtex 6 (XILINX, 2013a) uma vez que a quantidade de Slices utilizada pela rede de 12x12 é grande, acima da capacidade de outros dispositivos como Virtex 7 (XILINX, 2013b), apesar deste dispositivo ser de uma tecnologia mais avançada de $28 \mathrm{~nm}$, se comparada com a tecnologia de 40nm utilizada na família Virtex-6.

Os resultados de síntese são apresentados na Tabela 5 para os três casos de malha, junto com a porcentagem de recursos utilizados, evidentemente, os casos com maiores dimensões utilizaram-se de maior quantidade de recursos de hardware. Adicionalmente, também são apresentados valores de frequência máxima obtidos pela análise de restrições de tempo da ferramenta ISE da Xilinx, com os quais é possível calcular a vazão de pacotes considerando a latência expressada em número de ciclos.

Para poder analisar a quantidade de recursos de hardware utilizados para implementação do algoritmo FDOR, foi realizada a síntese do bloco MRCS para os três casos: 5x5, 8x8 e 
Tabela 5: Tabela de Resultados de Síntese da arquitetura de DyAFNoC para os casos 5x5, 8x8 e 12x12 sobre o dispositivo Virtex-6.

\begin{tabular}{|c|c|c|c|}
\hline \multicolumn{4}{|c|}{ Resultados de Síntese de DyAFNoC para o dispositivo Virtex-6 } \\
\hline \hline & $\mathbf{5 x 5}$ & $\mathbf{8 x 8}$ & $\mathbf{1 2 x 1 2}$ \\
\hline \hline Slice FFs & $5928(6 \%)$ & $16271(17 \%)$ & $38003(40 \%)$ \\
\hline LUTs & $5308(11 \%)$ & $14386(30 \%)$ & $33912(72 \%)$ \\
\hline Slices & $2091(17 \%)$ & $6450(55 \%)$ & $11585(99 \%)$ \\
\hline \hline \multicolumn{4}{|c|}{ Restrições de Temporização } \\
\hline \hline Frequência Máxima (MHz) & 301,459 & 216,876 & 205,887 \\
\hline
\end{tabular}

Fonte: (Autor, 2014).

Tabela 6: Tabela de Resultados de Síntese para o MRCS (5x5, 8x8 e 12x12), PDRCS e o Roteador de 5 portos no dispositivo Virtex-6

\begin{tabular}{|c|c|c|c|c|c|}
\hline \multicolumn{6}{|c|}{ Resultados de Síntese para o dispositivo Virtex-6 } \\
\hline \hline & Roteador & PDRCS & MRCS(5x5) & MRCS(8x8) & MRCS(12x12) \\
\hline \hline Slice FFs & 302 & 21 & 81 & 201 & 438 \\
\hline LUTs & 304 & 48 & 140 & 367 & 817 \\
\hline Slices & 360 & 31 & 121 & 284 & 542 \\
\hline
\end{tabular}

Fonte: (Autor, 2014).

12x12. Os resultados são apresentados na Tabela 6 , onde fica evidente que menores recursos de hardware foram consumidos na rede de $5 \times 5$ e maiores na rede de $12 \times 12$. A tabela apresenta também os resultados de síntese de um roteador de 5 portos com a finalidade de demonstrar que a implementação do MRCS não utiliza uma grande quantidade de recursos em comparação com a unidade básica da rede como o roteador. Adicionalmente, também são apresentados os resultados de síntese do bloco PDRCS, o qual tem um baixo custo de implementação; ocupa menos de $1 \%$ dos recursos disponíveis no dispositivo Virtex-6, uma vez que sua lógica está baseada em uma simples máquina de estados finitos.

Estes resultados de síntese demonstraram que a implementação da lógica AFDOR não apresenta um alto custo em termos de recursos de hardware. A Figura 69 apresenta um gráfico comparativo entre os recursos utilizados para a implementação do roteador, os módulos MRCS para os três casos e o módulo PDRCS. Pode-se observar que a diferença de custo de implementação não é elevada, já que são comparáveis com o custo de implementação do roteador unitário. 
Figura 69: Gráfico Comparativo dos resultados de síntese para o roteador de 5 portos, o módulo PDRCS e o MRCS nos casos $5 \times 5,8 \times 8$ e $12 \times 12$.

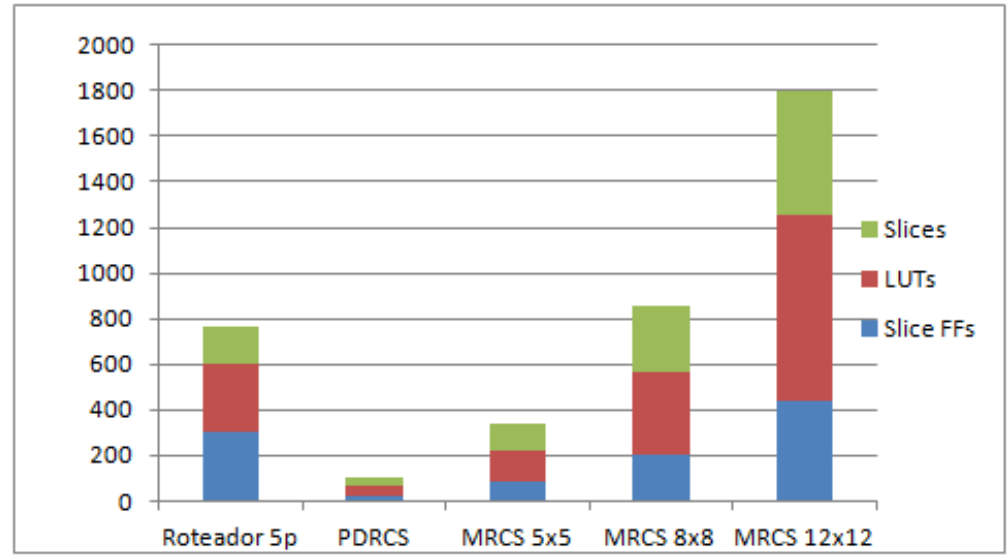

Fonte: (Autor, 2014). 


\section{CONCLUSÕES}

Várias atividades foram desenvolvidas com objetivo de contribuir no desenvolvimento de DRNoCs que fossem livres de deadlock e eficientes em termos de espaço de hardware consumido e tempo de reconfiguração na mudança de contextos sem afetar o desempenho geral do sistema. O estudo desenvolvido nesta dissertação nos permitiu chegar às seguintes conclusões:

- Foi possível desenvolver um Sistema de Controle de Reconfiguração Parcial Dinâmica (PDRCS) para ser utilizado junto com o Sistema de Controle de Reconfiguração baseado na lógica AFDOR (MRCS) da NoC proposta por (MIORANDI, 2012) formando assim uma DRNoC. Os resultados da simulação do sistema resultante para diversos casos de estudo, por meio da técnica de Chaveamento Dinâmico de Circuitos, demonstraram o funcionamento desejado.

- Conseguimos construir uma ferramenta, denominada DRSimGen, para a geração do código em VHDL da arquitetura de DyAFNoC, com seus respectivos testbenches necessários para a sua simulação, baseada na técnica de Chaveamento Dinâmico de Circuitos. A ferramenta foi escrita utilizando scripts de MATLAB $®$, a partir dos parâmetros anteriormente mencionados. A ferramenta DRSimGen demonstrou ser de grande aporte para o projetista no processo de simulação RTL pré-síntese de um DRS baseado em DyAFNoC.

- Os resultados da simulação utilizando a técnica de chaveamento dinâmico de circuitos demonstraram o correto funcionamento do código VHDL da arquitetura de DyAFNoC, o qual foi gerado para diversos projetos baseados em MPs de operações aritméticas básicas. Além disso, as simulações demonstraram que o tempo de reconfiguração do algoritmo de 
roteamento, para uma mudança de contexto, depende basicamente do tempo de drenagem de pacotes da rede, uma vez que o bloco MRCS é baseado em lógica combinacional pura, o qual só precisa de um ciclo de relógio para carregar a nova configuração FDOR sobre a rede. Com o correto funcionamento verificado, a ferramenta pode também ser utilizada com outros MPs de um sistema de aplicação real específica.

- Os resultados da análise de desempenho demonstram que as topologias irregulares permitidas pelo algoritmo FDOR têm, entre si, diferenças de desempenho na transmissão de pacotes pelos seguintes fatores: a forma das topologias determina regiões de tráfego mais intenso, devido a mudança de algoritmo de roteamento, o esquema de arbitragem presente em cada um dos roteadores e a quantidade de MPs ativos. Com isto, conclui-se que o projetista deve levar em conta que topologias irregulares utilizar durante o posicionamento de MPs para formar um contexto, para que o desempenho na transmissão de pacotes seja o adequado aos requisitos da aplicação.

- Também, demonstrou-se através de um exemplo que o posicionamento de MPs também influi no desempenho devido à mudanças de contextos. Ficou evidente que a reconfiguração parcial dinâmica pode afetar o desempenho na transmissão de pacotes no novo contexto, para melhor ou pior, de acordo com o posicionamento inicial dado. Tal fato ilustra a importância de se ter um planejamento de posicionamento realizado observando-se todos os contextos.

- Os resultados da síntese da arquitetura de DyAFNoC demostram que o uso de um Sistema de Reconfiguração baseado no algoritmo FDOR é uma solução adequada para DRSs, uma vez que seu custo de implementação em hardware é baixo.

Apesar de vários resultados satisfatórios terem sido obtidos, ainda estão presentes alguns pontos pendentes que não foram devidamente avaliados nesta dissertação, por falta de tempo. Destacamos dois:

1. Há uma inflexibilidade persistente no sistema, dado que a DyAFNoC só pode imple- 
mentar as topologias permitidas pelo algoritmo FDOR, limitando-se as possibilidades de posicionar-se módulos de processamento. Um exemplo fácil de perceber é a impossibilidade de se ter algum módulo no meio da rede (isto é, que não esteja na borda).

2. A dificuldade de projetar uma aplicação específica real que possa adotar a DyAFNoC como interface de comunicação. Isto deve-se à falta de exemplos disponíveis para uso e, também, à dificuldade de se criar um novo exemplo. Isto deve-se à complexidade do processo de particionamento de um sistema complexo de hardware em diferentes contextos, levando em conta as suas dependências. 


\section{TRABALHOS FUTUROS}

Considerando as deficiências e problemas que não chegaram a ser tratados nesta dissertação, propomos como tópicos de trabalhos e pesquisas futuras:

1. Seguir na linha de trabalho de (MIORANDI, 2012), que propõe flexibilizar o algoritmo FDOR em termos de topologias permitidas. É proposta uma NoC com uma estrutura baseada em malhas 2-D hierárquicas ligadas entre si por meio de uma rede hierárquica de switches, conforme a Figura 70. Cada submalha possui um sistema de reconfiguração baseada na lógica AFDOR, porém os MPs poderiam pertencer a mais de uma submalha. Um modelo simplificado da rede hierárquica, sem o controle de reconfiguração, foi construída, porém não foi suficientemente caracterizado o seu desempenho. Acreditamos que esta estratégia pode ser interessante para casos de grande número de MPs.

Figura 70: Arquitetura de uma rede de submalhas hierárquicas.

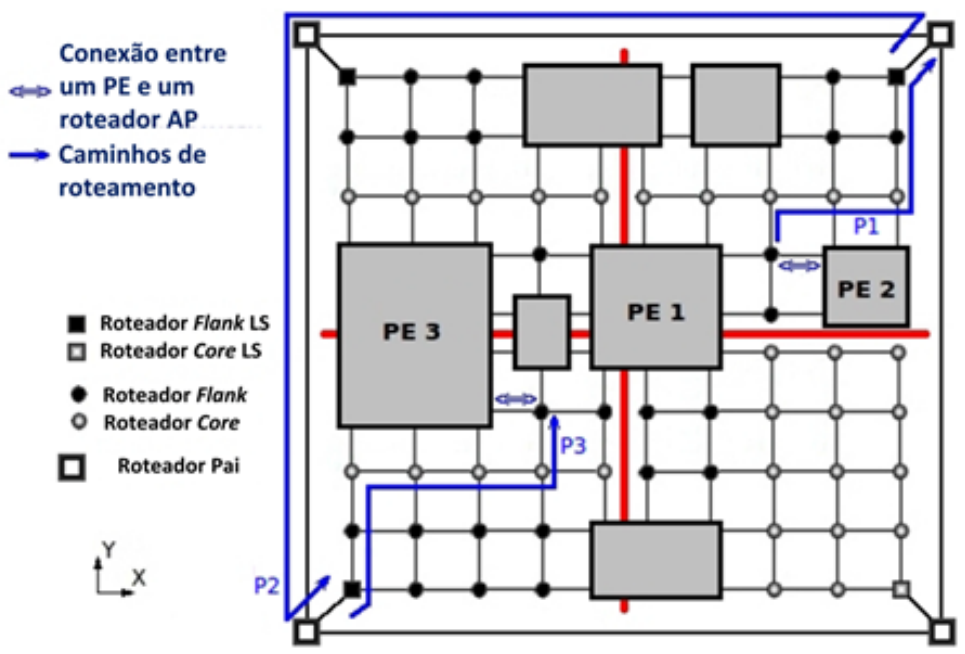

Fonte: (Autor, 2014). 
2. Propõe-se como trabalho futuro, desenvolver um Sistema Complexo Real em Hardware que possa utilizar a DyAFNoC como interface de comunicação entre seus módulos, fazendo-se o particionamento em diferentes contextos, e utilizando-se a ferramenta DRSimGen para sua verificação e simulação. Finalmente, poder-se-ia implementá-lo sobre um dispositivo DRFPGA, utilizando as ferramentas de projeto de DRS da Xilinx do PlanAhead (XILINX, 2012c) o qual permitiria definir as regiões reconfiguráveis sobre a área de silício do dispositivo e construir os arquivos de bits de cada cenário para ser implementados sobre estas regiões. 


\section{REFERÊNCIAS}

ANDRIAHANTENAINA, A.; GREINER, A. Micro-network for soc: implementation of a 32-port spin network. In: Design, Automation and Test in Europe Conference and Exhibition, 2003. [S.1.: s.n.], 2003. p. 1128-1129. ISSN 1530-1591.

BENINI, L.; MICHELI, G. D. Networks on chips: a new soc paradigm. Computer, IEEE Computer Society Press, Los Alamitos, CA, USA, v. 35, n. 1, p. 70-78, jan. 2002. ISSN 0018-9162.

BENINI, L.; MICHELLI, G. D. Networks on chips : technology and tools. Amsterdam, Boston, Paris: Elsevier, 2006. (The Morgan Kaufmann series in systems on silicon). ISBN 0-12-370521-5.

BERETTA, I. et al. Run-time mapping of applications on fpga-based reconfigurable systems. In: Circuits and Systems (ISCAS), Proceedings of 2010 IEEE International Symposium on. [S.1.: s.n.], 2010. p. 3329-3332.

. A mapping flow for dynamically reconfigurable multi-core system-on-chip design. Computer-Aided Design of Integrated Circuits and Systems, IEEE Transactions on, v. 30, n. 8, p. 1211-1224, Aug 2011. ISSN 0278-0070.

BOBDA, C. Introduction to Reconfigurable Computing: Architectures, Algorithms, and Applications. [S.1.]: Springer, 2007. ISBN 1402060882, 9781402060885.

BOBDA, C.; AHMADINIA, A. Dynamic interconnection of reconfigurable modules on reconfigurable devices. Design Test of Computers, IEEE, v. 22, n. 5, p. 443-451, Sept 2005. ISSN 0740-7475.

BOBDA, C. et al. A dynamic noc approach for communication in reconfigurable devices. In: BECKER, J.; PLATZNER, M.; VERNALDE, S. (Ed.). Field Programmable Logic and Application. [S.1.]: Springer Berlin Heidelberg, 2004, (Lecture Notes in Computer Science, v. 3203). p. 1032-1036. ISBN 978-3-540-22989-6.

BRUNELLI, L. Abordagem para Redução de Complexidade de RNA usando Reconfiguração Dinâmica. Tese (Doutorado) - Centro de Ciências e Tecnologia, Universidade Federal de Campina Grande, Campina Grande, Brasil, 2005.

CARVALHO, E.; CALAZANS, N.; MORAES, F. Heuristics for dynamic task mapping in noc-based heterogeneous mpsocs. In: Rapid System Prototyping, 2007. RSP 2007. 18th IEEE/IFIP International Workshop on. [S.1.: s.n.], 2007. p. 34-40. ISSN 1074-6005.

CHIU, D. M. et al. Deadlock-free routing based on ordered links. In: Local Computer Networks, 2002. Proceedings. LCN 2002. 27th Annual IEEE Conference on. [S.1.: s.n.], 2002. p. 62-71. ISSN 0742-1303. 
CHOU, C.-L.; MARCULESCU, R. Incremental run-time application mapping for homogeneous nocs with multiple voltage levels. In: Hardware/Software Codesign and System Synthesis (CODES+ISSS), 2007 5th IEEE/ACM/IFIP International Conference on. [S.1.: s.n.], 2007. p. 161-166.

DALLY, W.; TOWLES, B. Route packets, not wires: on-chip interconnection networks. In: Design Automation Conference, 2001. Proceedings. [S.1.: s.n.], 2001. p. 684-689. ISSN 0738-100X.

DUATO, J.; YALAMANCHILI, S.; LIONEL, N. Interconnection Networks: An Engineering Approach. San Francisco, CA, USA: Morgan Kaufmann Publishers, 2002. ISBN 1558608524.

ESQUIAGOLA, J. Reconfiguração dinâmica de um controlador Bluetooth. Dissertação (Mestrado) - Departamento de Engenharia Elétrica - Escola Politécnica da Universidade de São Paulo, Universidade de São Paulo, São Paulo, Brasil, 2006.

FILHO, J. G. Aplicação de técnicas de reconfiguração dinâmica a projeto de máquina de vetor suporte (SVM). Dissertação (Mestrado) — Departamento de Engenharia Elétrica - Escola Politécnica da Universidade de São Paulo, Universidade de São Paulo, São Paulo, Brasil, 2010.

FILHO, J. G.; CHAU, W. J. Exploring the problems of placement and mapping in noc-based reconfigurable systems. In: Reconfigurable Computing and FPGAs (ReConFig), 2013 International Conference on. [S.1.: s.n.], 2013. p. 1-4.

FLICH, J.; DUATO, J. Logic-based distributed routing for nocs. Computer Architecture Letters, v. 7, n. 1, p. 13-16, Jan 2008. ISSN 1556-6056.

GUERRIER, P.; GREINER, A. A generic architecture for on-chip packet-switched interconnections. In: Design, Automation and Test in Europe Conference and Exhibition 2000. Proceedings. [S.1.: s.n.], 2000. p. 250-256.

HAIYUN, G. Survey of dynamically reconfigurable network-on-chip. In: Future Computer Sciences and Application (ICFCSA), 2011 International Conference on. [S.1.: s.n.], 2011. p. 200-203.

HAUCK, S. The roles of fpgas in reprogrammable systems. Proceedings of the IEEE, v. 86, n. 4, p. 615-638, Apr 1998. ISSN 0018-9219.

HU, J.; MARCULESCU, R. Energy-aware mapping for tile-based noc architectures under performance constraints. In: Design Automation Conference, 2003. Proceedings of the ASP-DAC 2003. Asia and South Pacific. [S.1.: s.n.], 2003. p. 233-239.

JANTSCH, A.; TENHUNEN, H. (Ed.). Networks on Chip. Hingham, MA, USA: Kluwer Academic Publishers, 2003. ISBN 1-4020-7392-5.

JOVANOVIC, S. Architecture reconfigurable de système embarqué auto-organisé. Tese (Doutorado) - Ecole doctorale Informatique Automatiqué Electroniqué Electrotechnique Mathématiques - Université Henri Poincaré, Nancy, França, 2009.

JOVANOVIC, S. et al. Cunoc: a dynamic scalable communication structure for dynamically reconfigurable \{FPGAs\}. Microprocessors and Microsystems, v. 33, n. 1, p. 24 - 36, 2009. ISSN 0141-9331. Selected Papers from ReCoSoC 2007 (Reconfigurable Communication-centric Systems-on-Chip). 
JOVANOVIC, S.; TANOUGAST, C.; WEBER, S. A new high-performance scalable dynamic interconnection for fpga-based reconfigurable systems. In: Application-Specific Systems, Architectures and Processors, 2008. ASAP 2008. International Conference on. [S.1.: s.n.], 2008. p. 61-66. ISSN 2160-0511.

JOVANOVIC, S. et al. Cunoc: A scalable dynamic noc for dynamically reconfigurable fpgas. In: Field Programmable Logic and Applications, 2007. FPL 2007. International Conference on. [S.1.: s.n.], 2007. p. 753-756.

KARIM, F.; NGUYEN, A.; DEY, S. An interconnect architecture for networking systems on chips. Micro, IEEE, v. 22, n. 5, p. 36-45, Sep 2002. ISSN 0272-1732.

KARIM, F. et al. On-chip communication architecture for oc-768 network processors. In: Design Automation Conference, 2001. Proceedings. [S.1.: s.n.], 2001. p. 678-683. ISSN 0738-100X.

KOJIMA, L. Metodologia de projeto de sistemas dinamicamente reconfiguráveis. Dissertação (Mestrado) - Departamento de Engenharia Elétrica - Escola Politécnica da Universidade de São Paulo, Universidade de São Paulo, São Paulo, Brasil, 2007.

KUMAR, S. et al. A network on chip architecture and design methodology. In: VLSI, 2002. Proceedings. IEEE Computer Society Annual Symposium on. [S.1.: s.n.], 2002. p. 105-112.

LEI, T.; KUMAR, S. A two-step genetic algorithm for mapping task graphs to a network on chip architecture. In: Digital System Design, 2003. Proceedings. Euromicro Symposium on. [S.1.: s.n.], 2003. p. 180-187.

LYSAGHT, P.; DUNLOP, J. Dynamic reconfiguration of field programmable gate arrays. In: The 1993 International Workshop of Field-Programmable Logic and Applications. [S.1.: s.n.], 1993. p. 82-94.

LYSAGHT, P.; STOCKWOOD, J. A simulation tool for dynamically reconfigurable field programmable gate arrays. Very Large Scale Integration (VLSI) Systems, IEEE Transactions on, v. 4, n. 3, p. 381-390, Sept 1996. ISSN 1063-8210.

MARCON, C. et al. Evaluation of algorithms for low energy mapping onto nocs. In: Circuits and Systems, 2007. ISCAS 2007. IEEE International Symposium on. [S.1.: s.n.], 2007. p. 389-392.

MARESCAUX, T. et al. Interconnection networks enable fine-grain dynamic multi-tasking on fpgas. In: Proceedings of the Reconfigurable Computing Is Going Mainstream, 12th International Conference on Field-Programmable Logic and Applications. London, UK, UK: Springer-Verlag, 2002. (FPL '02), p. 795-805. ISBN 3-540-44108-5.

MAXFIELD, C. The Design Warrior's Guide to FPGAs. Orlando, FL, USA: Academic Press, 2004. ISBN 0750676043.

MIORANDI, G. Progettazione di una Architettura Gerarchica di tipo "Sea-of-Switches"e Relativo Controllore per la Riconfigurazione Dinamica di un FPGA. Dissertação (Trabalho de Formatura) - Dipartamento di Ingegneria, Universitá Degli Studi Di Ferrara, Ferrara, Italia, 2012. 
MORAES, F. et al. Hermes: an infrastructure for low area overhead packet-switching networks on chip. Integration, the \{VLSI\} Journal, v. 38, n. 1, p. 69 - 93, 2004. ISSN 0167-9260.

OLDFIELD, J. V.; DORF, R. C. Field-programmable Gate Arrays: Reconfigurable Logic for Rapid Prototyping and Implementation of Digital Systems. New York, NY, USA: Wiley-Interscience, 1994. ISBN 0-471-55665-3.

PALESI, M.; PATTI, D.; FAZZINO, F. Noxim - An Open Network-on-Chip Simulator. 2007.

PANDA, P. R. Systemc: A modeling platform supporting multiple design abstractions. In: Proceedings of the 14th International Symposium on Systems Synthesis. New York, NY, USA: ACM, 2001. (ISSS '01), p. 75-80. ISBN 1-58113-418-5. Data de Acesso: Fev, 2014. Disponível em: <http://doi.acm.org/10.1145/500001.500018>.

PANDE, P. et al. Design of a switch for network on chip applications. In: Circuits and Systems, 2003. ISCAS '03. Proceedings of the 2003 International Symposium on. [S.1.: s.n.], 2003. v. 5, p. V-217-V-220 vol.5.

PIONTECK, T. et al. Adaptive communication architectures for runtime reconfigurable system-on-chips. Parallel Processing Letters, v. 18, n. 02, p. 275-289, 2008.

PIONTECK, T.; KOCH, R.; ALBRECHT, C. Applying partial reconfiguration to networkson-chips. In: Field Programmable Logic and Applications, 2006. FPL '06. International Conference on. [S.1.: s.n.], 2006. p. 1-6.

QUILICI, A. Uma metodologia de projetos para circuitos com reconfiguração dinâmica de hardware aplicada a support vector machines. Tese (Doutorado) - Escola Politécnica da Universidade de São Paulo, São Paulo, Brasil, 2006.

RAFFO, M. Desenvolvimento de um Sistema Dinamicamente Reconfigurável Baseado em Redes Intra-Chip e Ferramenta para Posicionamento de Módulos. Dissertação (Mestrado) Escola Politécnica da Universidade de São Paulo, São Paulo, Brasil, 2010.

RAFFO, M. et al. A placement tool for a noc-based dynamically reconfigurable system. In: Programmable Logic Conference (SPL), 2010 VI Southern. [S.1.: s.n.], 2010. p. 47-52.

RANA, V. et al. A reconfigurable network-on-chip architecture for optimal multi-processor soc communication. In: PIGUET, C.; REIS, R.; SOUDRIS, D. (Ed.). VLSI-SoC: Design Methodologies for SoC and SiP. [S.1.]: Springer Berlin Heidelberg, 2010, (IFIP Advances in Information and Communication Technology, v. 313). p. 232-250. ISBN 978-3-642-12266-8.

ROBINSON, D.; LYSAGHT, P. Methods of exploiting simulation technology for simulating the timing of dynamically reconfigurable logic. Computers and Digital Techniques, IEE Proceedings -, v. 147, n. 3, p. 175-180, May 2000. ISSN 1350-2387.

SKEIE, T. et al. Flexible dor routing for virtualization of multicore chips. In: System-on-Chip, 2009. SOC 2009. International Symposium on. [S.1.: s.n.], 2009. p. 073-076.

SRINIVASAN, K.; CHATHA, K. A technique for low energy mapping and routing in network-on-chip architectures. In: Low Power Electronics and Design, 2005. ISLPED '05. Proceedings of the 2005 International Symposium on. [S.1.: s.n.], 2005. p. 387-392. 
STRANO, A. et al. Osr-lite: Fast and deadlock-free noc reconfiguration framework. In: Embedded Computer Systems (SAMOS), 2012 International Conference on. [S.1.: s.n.], 2012. p. 86-95.

WACHTER, E.; MORAES, F. Mazenoc: Novel approach for fault-tolerant noc routing. In: SOC Conference (SOCC), 2012 IEEE International. [S.1.: s.n.], 2012. p. 364-369. ISSN 2164-1676.

WU, A.-Y. Noxim Laboratory Manuals. [S.1.], November 2009. Data de Acesso: Maio, 2014. Disponível em: <http://access.ee.ntu.edu.tw/noxim/index.html >.

XILINX. Virtex-II 1.5V Field-Programmable Gate Arrays. [S.1.], 10 2001. DS031-1 (v1.7) Rev. 1.2. 4.2 . Virtex-II Pro and Virtex-II Pro X FPGA User Guide. [S.1.], 09 2007. UG012 (v4.2) Rev. . Virtex-4 FPGA Configuration User Guide. [S.1.], 06 2009. UG071(v1.11)Rev. 1.2. Version). Introduction to Partial Reconfiguration Methodology. [S.1.], 2012. MicroBlaze 14.2 . Partial Reconfiguration of Xilinx FPGAs Using ISE Design Suite. [S.1.], Maio 2012. 8 p. WP374 (v1.2). . PlanAhead User Guide. [S.1.], 04 2012. UG632 (v14.1).

. Virtex-5 FPGA Configuration User Guide. [S.1.], 10 2012. UG191 (v3.11).

. Virtex-6 FPGA Configuration User Guide. [S.1.], 2013. UG360(v3.7). . Virtex-7 FPGA Configuration User Guide. [S.1.], 10 2013. UG470 (v1.7).

ZHANG, X.; NG, K. W. A review of high-level synthesis for dynamically reconfigurable \{FPGAs\}. Microprocessors and Microsystems, v. 24, n. 4, p. $199-211,2000$. ISSN 0141-9331.

ZHAO, W. et al. Tas-mram based non-volatile fpga logic circuit. In: Field-Programmable Technology, 2007. ICFPT 2007. International Conference on. [S.1.: s.n.], 2007. p. 153-160. Evaluation of a non-volatile fpga based on mram technology. In: Integrated Circuit Design and Technology, 2006. ICICDT '06. 2006 IEEE International Conference on. [S.1.: s.n.], 2006. p. 1-4. 


\section{APÊNDICE A - SIMULAÇÕES DO COMPORTAMENTO DE DYAFNOC}

Neste apêndice é dada continuidade da simulação RTL apresentada na seção 6.1 do capítulo 6.

A Figura 71 apresenta a simulação da implementação do módulo multiplicador x2 a partir do momento em que MPs unitários S4, S5 e D1 terminam sua tarefa até que o processo de reconfiguração parcial dinâmica finaliza. Também são apresentados os sinais correspondentes ao cenário 1 e 2 da região reconfigurável RR3 especificamente nos portos do roteador com coordenadas $(3,3)$.

Para o caso do cenário 1, os nomes do sinais terminam em_rm1_l33 e no caso do cenário 2,_rm2_l33. Quando começa o processo de remoção da configuração do FPGA, os sinais do cenário 1 passam de um valor lógico (0 ou 1) para um valor desconhecido (' $X$ '), enquanto que os sinais do cenário 2 que estão em estado de alta impedância ' $Z$ ' passam a ter um valor lógico devido a que agora estão conectados ao porto local do roteador. Quando começa o processo de carga da nova configuração, os sinais do cenário 1 passam do valor ' $X$ ' para ' $Z$ ', enquanto que os sinais do cenário 2 passam a um valor ' $X$ ' emulando que o bitstream está sendo configurado sobre o dispositivo e que os sinais não têm um valor definido ainda. Finalmente, quando o processo de reconfiguração parcial dinâmica terminar, o sinal de reset da região reconfigurável faz que os sinais do cenário 2 fiquem inicializados com valor lógico ' 0 '.

Depois de ter implementado o módulo multiplicador x 2 sobre a rede, o envio e a transmissão de dados é feito pelos MPs fonte: $\mathrm{Sx} 4$ e Sx2, até os roteadores ligados aos módulos 
Figura 71: Simulação da implementação do módulo multiplicador a partir do processo de reconfiguração da malha com o novo mapa de configuração e o processo de reconfiguração parcial dinâmica do módulo multiplicador $\mathrm{x} 2$.

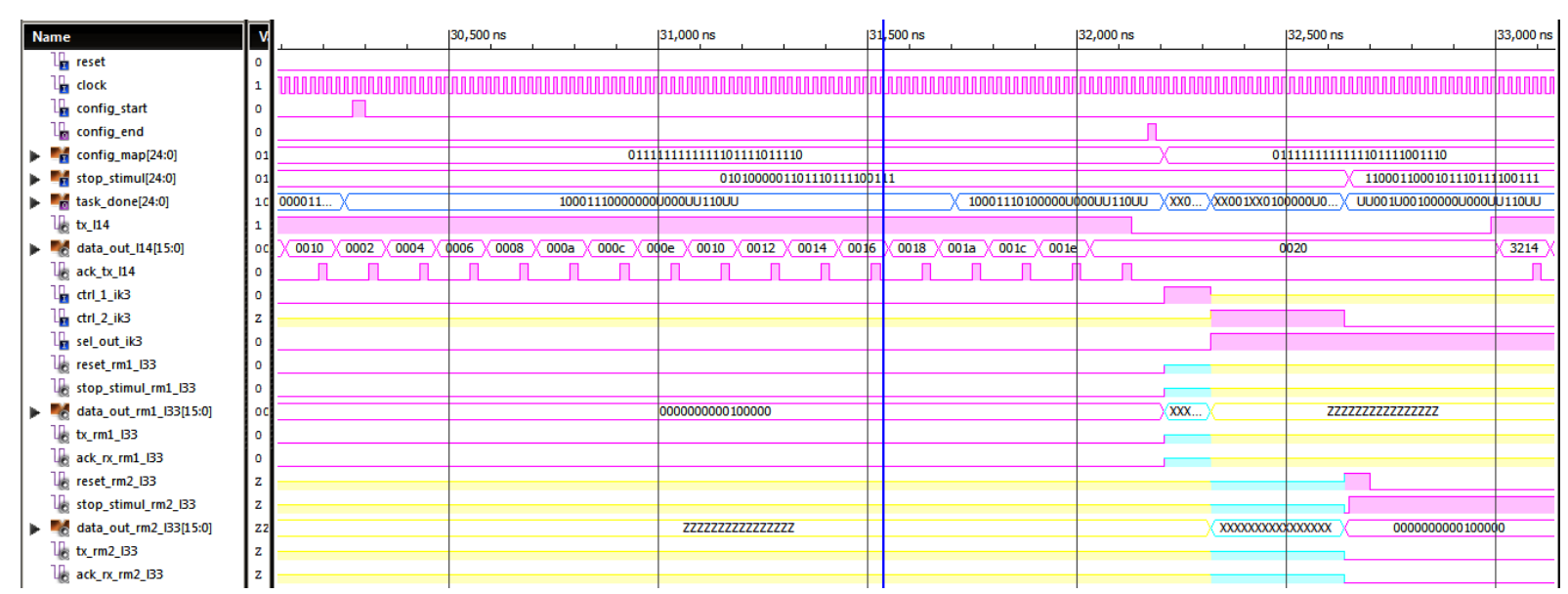

Fonte: (Autor, 2014).

multiplicadores x4 e x2 respectivamente. Na Figura 72, é apresentado o resultado da simulação da transmissão de pacotes dos MPs fontes até os pontos de acesso dos módulos multiplicadores. Os pacotes contêm como dados, números pares os quais são enviados na ordem 02, 04, 06, 08, 0A, ... para ambos multiplicadores.

Figura 72: Simulação do envio e transmissão de pacotes a partir dos MPs fonte (Sx2 e $\mathrm{Sx} 4)$ até os portos locais dos módulos multiplicadores $\mathrm{x} 2$ e $\mathrm{x} 4$ respectivamente.

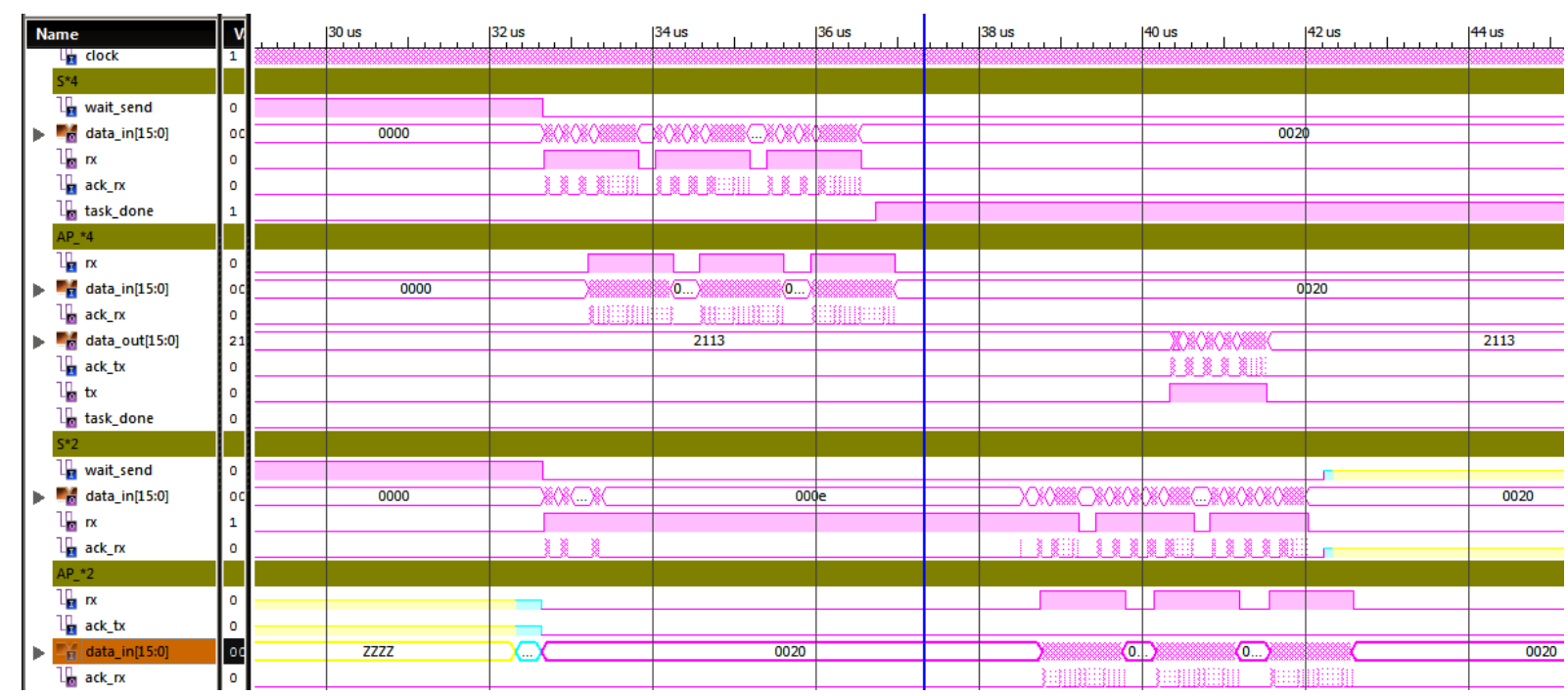

Fonte: (Autor, 2014).

Quando os pacotes chegam aos módulos multiplicadores, os dados são processados e depois são enviados em pacotes aos seus respectivos MPs de destino através da rede. A Figura 73(a) apresenta o resultado do processamento do módulo multiplicador $\mathrm{x} 4$, enquanto que a Figura 
73(b) apresenta o resultado do processamento do módulo x2.

Figura 73: Formas de onda das simulações.

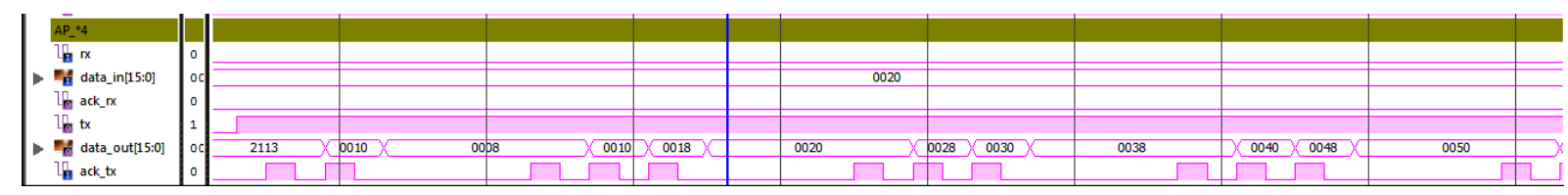

(a) Simulação do processamento do módulo x4

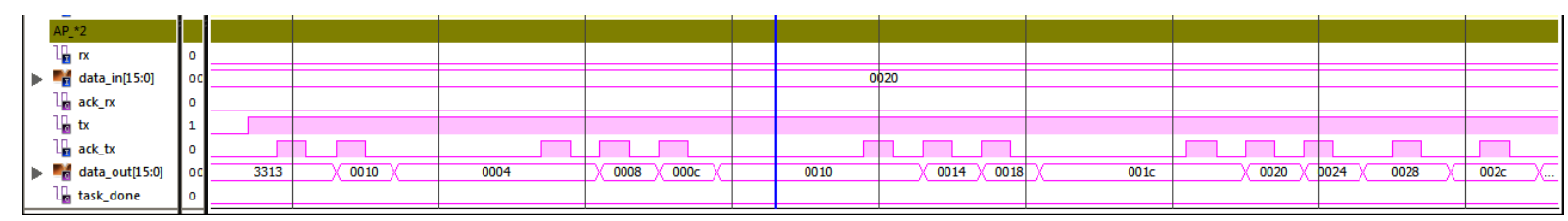

(b) Simulação do processamento do módulo x2

Fonte: (Autor, 2014).

Depois que os dados foram processados pelos módulos multiplicadores, os pacotes são enviados ao módulo subtrator que está ligado com o roteador de coordenadas $(2,3)$ para ser processados novamente. O comportamento do módulo subtrator consiste em esperar os pacotes provenientes dos multiplicadores e subtrair seus dados, isto é o módulo x 4 envia $N$ pacotes A e o módulo B envia $N$ pacotes B, então o resultado da subtração serão $N$ pacotes com dados de valor A - B. A Figura 74(a) apresenta a simulação do processamento do módulo subtrator no momento em que os dados do módulo multiplicador x4 chegam, enquanto que a Figura 74(b) apresenta os dados do módulo multiplicador x2. A simulação da Figura 74(c) apresenta os resultado do processamento.

As simulações ilustradas até agora mostram o funcionamento dos MPs e principalmente a simulação do funcionamento do sistema de reconfiguração do DyAFNoC junto com as chaves de isolação, emulando os processos de reconfiguração parcial dinâmica. Os processos restantes consistem nos mesmos passos mostrados até agora, não consistindo a apresentação dos demais processos nenhum aporte para a análise do funcionamento do sistema. 
Figura 74: Resultados de Forma de Onda.

\begin{tabular}{|c|c|c|c|c|c|c|c|c|c|c|c|c|}
\hline Name & $\mathrm{v}$ & & $41,100 \mathrm{~ns}$ & & $41,200 \mathrm{~ns}$ & $41,300 \mathrm{~ns}$ & $41,400 \mathrm{~ns}$ & 41,500 ns & $41,600 \mathrm{~ns}$ & 41,700 ns & 41,800 ns & |41,900 ns \\
\hline g reset & 0 & & & & & & & & & & & \\
\hline clock & 0 & こ几ロ几 & Пロா & П & 几几几几 & ウ几ロ几 & Пロ几ா & 几ロ几几 & П几几П & 几ロ几几 & 几П几ா & 几几 \\
\hline r ring data_in[15:0] & of & $0 0 0 0 \longdiv { 2 1 1 3 }$ & $0010 \times$ & 0008 & 0010 & 0020 & 0030 & 0038 & 0048 & 0058 & 0060 & 058 \\
\hline en $x$ & 1 & 5 & & & & & & & & & & \\
\hline fock_r & 0 & $\square$ & $\sqrt{\square}$ & $\square$ & 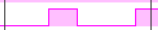 & $\square$ & $\sqrt{\square}$ & $\square$ & $\square$ & $\square$ & $\square$ & 乙 \\
\hline ack_tx & 0 & & & & & & & & & & & \\
\hline
\end{tabular}

(a) Entrada dos dados do módulo multiplicador x4 ao módulo subtrator

\begin{tabular}{|c|c|c|c|c|c|c|c|c|c|c|c|c|}
\hline Name & v & $46,400 \mathrm{~ns}$ & $46,500 \mathrm{~ns}$ & & $46,600 \mathrm{~ns}$ & $46,700 \mathrm{~ns}$ & 46,800 ns & $46,900 \mathrm{~ns}$ & 47,000 ns & 47,100 ns & $47,200 \mathrm{~ns}$ & $|47,300|$ \\
\hline a reset & 0 & & & & & & & & & & & \\
\hline clock & 1 & ПП几П & 几ா & こ几 & ППூロ & ПП几П & Пா几П & ПロПП & ПூПП & ПோП & ППாП & $\Pi$ \\
\hline 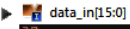 & oc & $0080 \times 3313 \times 0010$ & 00004 & 000 & $08000 \mathrm{c}$ & 0014 & 0018 & 0020 & 00240028 & $002 c>00$ & $0,030 \quad 0034$ & 0038 \\
\hline 愐 $\mathrm{x}$ & 1 & 万 & & & & & & & & & & \\
\hline Tfock_nx & 0 & $\square \square \square$ & $\Gamma$ & & $\square$ & $\sqrt{\square}$ & 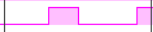 & $\sqrt{\square}$ & $\sqrt{\square}$ & $\square$ & 几 & 5 \\
\hline ln ack_tx & 0 & & & & & & & & & & & \\
\hline
\end{tabular}

(b) Entrada dos dados do módulo multiplicador x2 ao módulo subtrator

\begin{tabular}{|c|c|c|c|c|c|c|c|c|c|c|c|}
\hline Name & $\mathrm{v}$ & & $67,500 \mathrm{~ns}$, & 67,600 ns & $67,700 \mathrm{~ns}$, & 67,800 ns & $67,900 \mathrm{~ns}$, & 68,000 ns & 68,100 ns & $168,200 \mathrm{~ns}$ & 168,300 ns \\
\hline Te reset & 0 & & & & & & & & & & \\
\hline clock & 1 & 几几 & †几几几 & 几ロ几几 & こ凸几ロ & 凸几几几 & ロ几几几 & П几ா几 & 几ロ几几 & Пこ几П & ロ凸几 \\
\hline - Fid data_in[15:0] & oc & & & & & & 040 & & & & \\
\hline $\begin{array}{l}\text { en } x \\
\text { lof ack_nx }\end{array}$ & 0 & & & & & & & & & & \\
\hline - 갵ㅁ data_out[15:0] & oc & 1341 & $\sqrt{0010} \times$ & 0004 & $\sqrt { 0 0 0 8 } \longdiv { 0 0 0 c }$ & 0010 & $0 0 1 4 \longdiv { 0 0 1 8 }$ & $001 c$ & 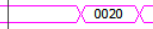 & $024 \times$ & 028 \\
\hline 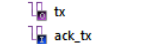 & $\begin{array}{l}1 \\
0\end{array}$ & & $\square \square$ & $\square$ & $\square \square$ & & $\square \quad \square$ & & $\square \quad \square$ & 7 & $\square$ \\
\hline Tork taske & 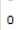 & & & & & & & & & & \\
\hline
\end{tabular}

(c) Resultado do processamento do módulo subtrator

Fonte: (Autor, 2014). 


\section{APÊNDICE B - MALHA 5X5 COM DEZENOVE MPS}

Um segundo conjunto de simulações foi feito para as mesmas topologias e as mesmas dimensões da rede $(5 \times 5)$ do estudo com Noxim, apresentado na Seção 6.3 do Capítulo 6, porém com uma quantidade maior de MPs. Neste caso, as topologias contêm dezenove (19) MPs, portanto, com uma concentração de módulos na rede ligeiramente maior que o estudado anteriormente. Similar à seção 6.3.1.3, as regiões de núcleo contém roteamento Y-X (em vermelho) como mostrado nas Figuras 75 (a), (b), (c) e (d), com excepção das topologias das Figuras 75(e) e (f), onde encontramos núcleos com roteamento X-Y (em verde). Na Figura 75 são ilustradas as topologias 'd' (a), 'p' (b), '+' (c), 's' (d), 's-x' (e) e seu simétrico (f). A topologia 't' não foi testada porque a quantidade de MPs mais próxima que se pode conseguir nesta topologia foi dezesseis (16).

A finalidade foi de verificar o efeito do número maior de MPs e a consistência das análises anteriores quanto à influência da topologia adotada. Na realidade poucos pontos relevantes puderam ser observados.

Os resultados da simulação Noxim para estas topologias para Latência Média, Throughput Médio e Latência Máxima vs. Taxa de Injeção são apresentados nas Figuras 76, 77 e 78 respectivamente. Os resultados indicam um comportamento similar às simulações com dezessete (17) MPs para os casos das topologias 'd' e 'p', que continuam sendo os casos, pior e melhor, para os resultados de Latência e Throughput Médios. Para as outras topologias, os resultados também foram similares.

Os resultados de Throughput Médio da Figura 77 mostram que a topologia '+' é o segundo 
Figura 75: Topologias irregulares permitidas pelo algoritmo FDOR com dezenove (19) MPs ativos.

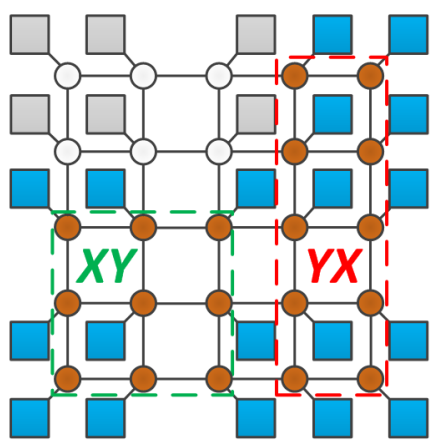

(a)

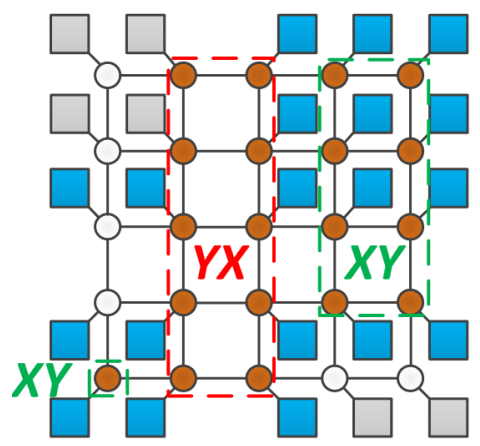

(d)

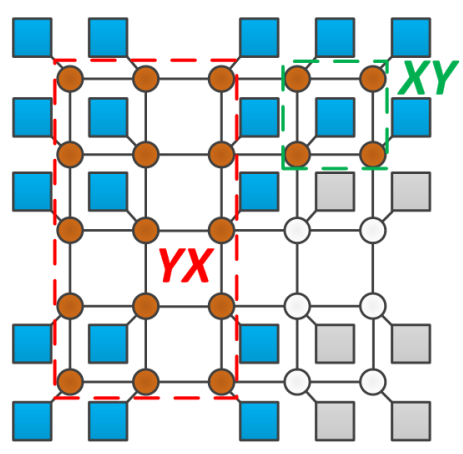

(b)

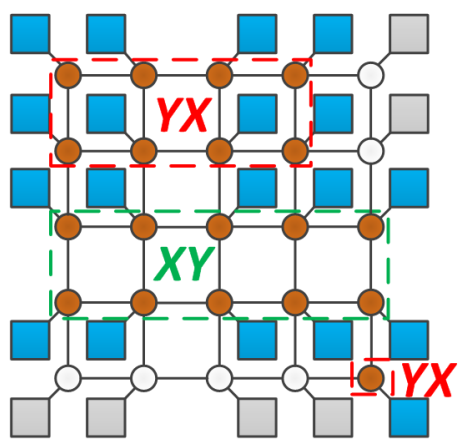

(e)

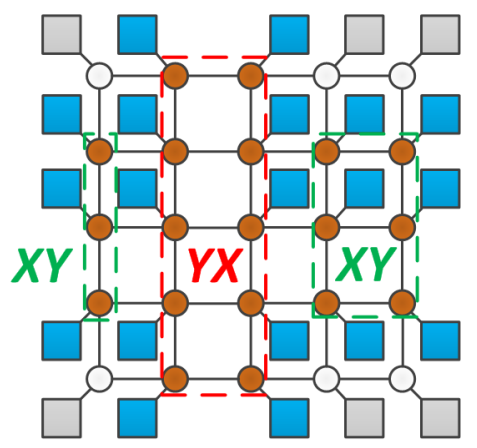

(c)

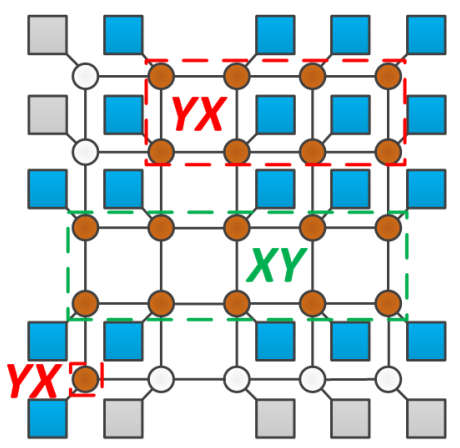

(f)
(a) 'd'
(b) 'p'
(c) ' + '
(d) 's'
(e) 's' com núcleo em direção X
(f) Simétrico do (e).

Fonte: (Autor, 2014).

melhor resultado da simulação, uma vez que sua forma permite que muitos dos pacotes dos MPs pertencentes às alas sejam transmitidos na mesma linha de roteadores, sem realizar mais de uma virada. Isto permite que o seu throughput seja maior que para os casos das topologias 's', 's-x' e seu simétrico, uma vez que nelas, os pacotes precisam, em geral, fazer duas viradas para se comunicarem entre si, aumentando a latência na transmissão. Além disto, há o aparecimento da linha de congestionamento. Por esta razão, estas topologias apresentam valores similares de Throughput Médio para todo o intervalo de Taxa de Injeção como mostrado na Figura 77.

Com respeito à Latência Máxima para a rede com dezenove MPs, pode-se observar que os maiores valores são para os casos das topologias 's', 'p' e 's-x' simétrica, diferente do observado nas simulações do caso de dezessete (17) MPs ativos, quando os maiores valores foram das topologias 's-x', 's' e 's-x' simétrica. Neste caso de dezenove (19) MPs, a topologia 'p' 
Figura 76: Latência Média vs. Taxa de Injeção, para as topologias irregulares com dezenove (19) MPs ativos para uma malha de $5 \times 5$.

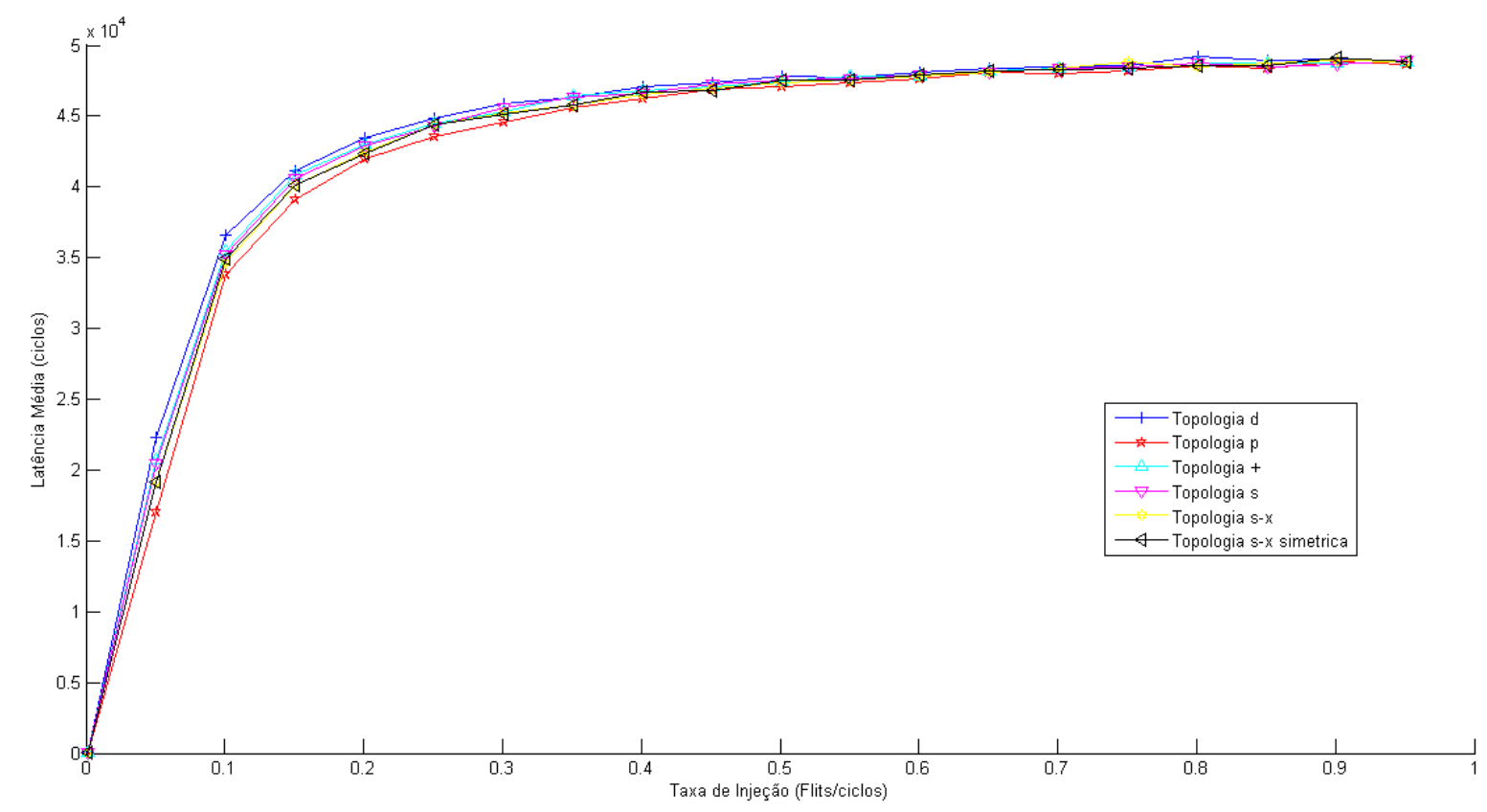

Fonte: (Autor, 2014).

Figura 77: Throughput vs. Taxa de Injeção, para as topologias irregulares com dezenove MPs (19) ativos para uma malha de $5 \times 5$.

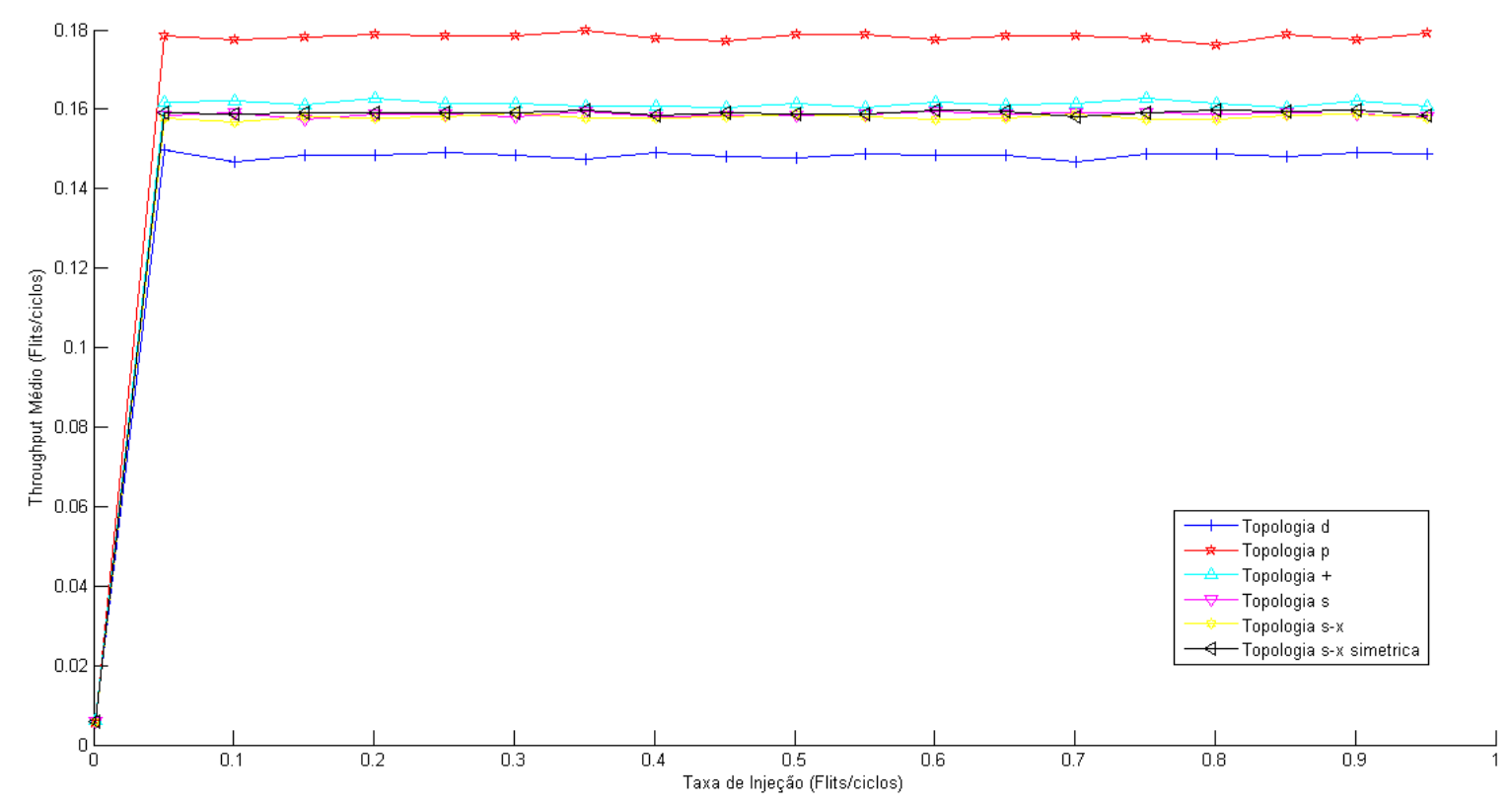

Fonte: (Autor, 2014).

apresentou aumento nos seus valores de latência máxima devido ao número de MPs na região da ala X+ que é maior que o caso anterior de dezessete (17) MPs, o qual gerou mais congestionamento na coluna de roteadores da região do núcleo mais próxima à ala $\mathrm{X}+$. Isso ocorre no 
intervalo de valores $[0,05 ; 0,3]$ (ver Figura 80 ), que apresenta detalhamento maior; para valores de taxa de injeção mais altos, todos os casos começam a ter valores similares.

Os casos das outras topologias como 'd' e '+' continuam com os menores valores de Latência Máxima como na simulação com dezessete 17 MPs. A diferença verifica-se com a topologia 's-X' que passou a ser o segundo conjunto dos menores valores. A razão para tal é o esquema de arbitragem dar maior prioridade à direção NORTE e OESTE, onde estão a maioria dos MPs, como a região de ala $\mathrm{Y}+$, fazendo que a latência máxima seja menor.

Figura 78: Latência Máxima vs. Taxa de Injeção, para as topologias irregulares com dezenove (19) MPs ativos para uma malha de $5 \times 5$

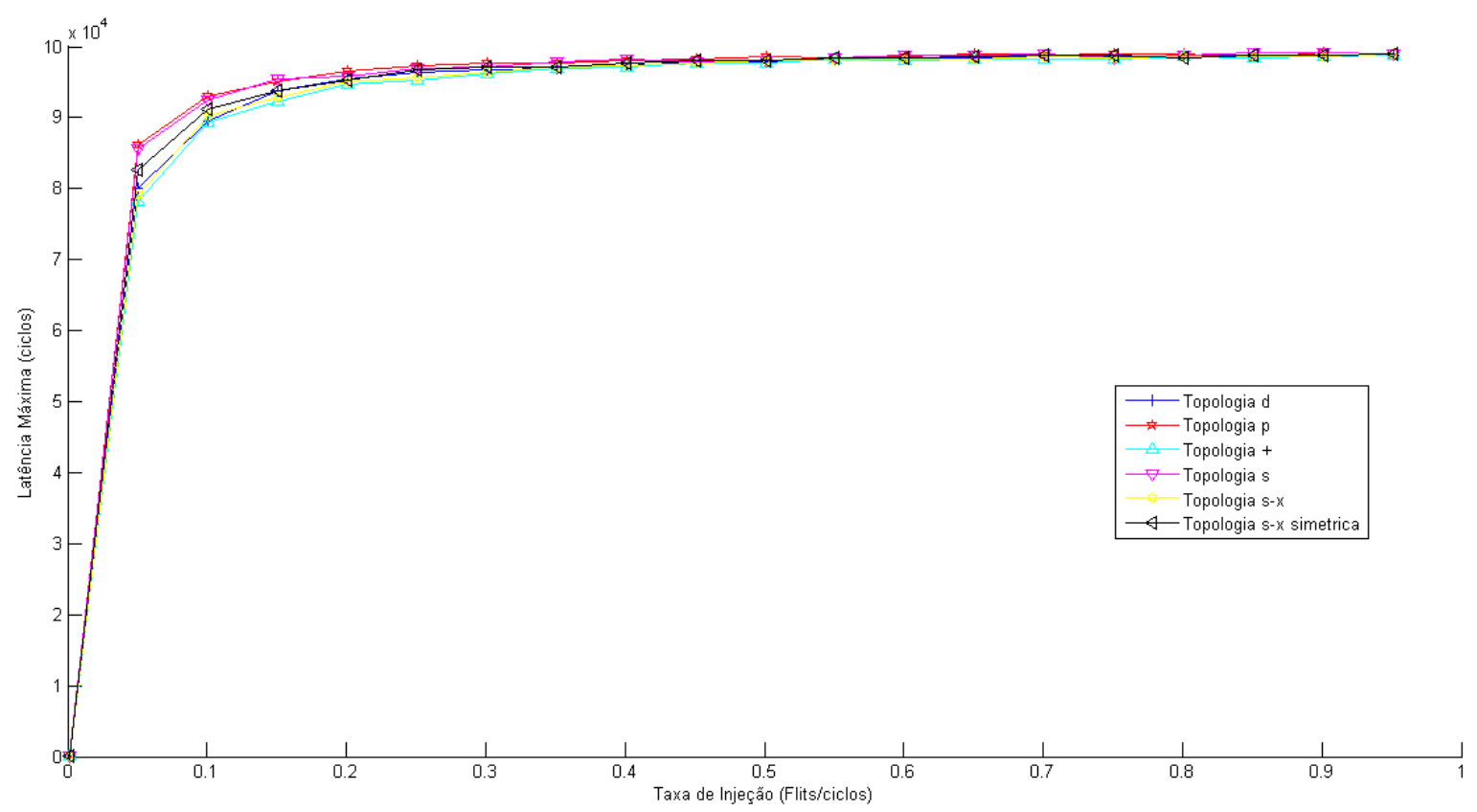

Fonte: (Autor, 2014).

As Figuras 79 e 80 apresentam as curvas com resolução da taxa de injeção de pacotes no intervalo $[0 ; 0,4]$ podendo-se observar melhor as diferenças entre os valores obtidos, situações já discutidas nos parágrafos anteriores. 
Figura 79: Latência Média vs. Taxa de Injeção, para as topologias irregulares com dezenove (19) MPs ativos para uma malha de $5 \times 5$ no intervalo de $[0 ; 0,4]$ flits/ciclos para taxa de injeção

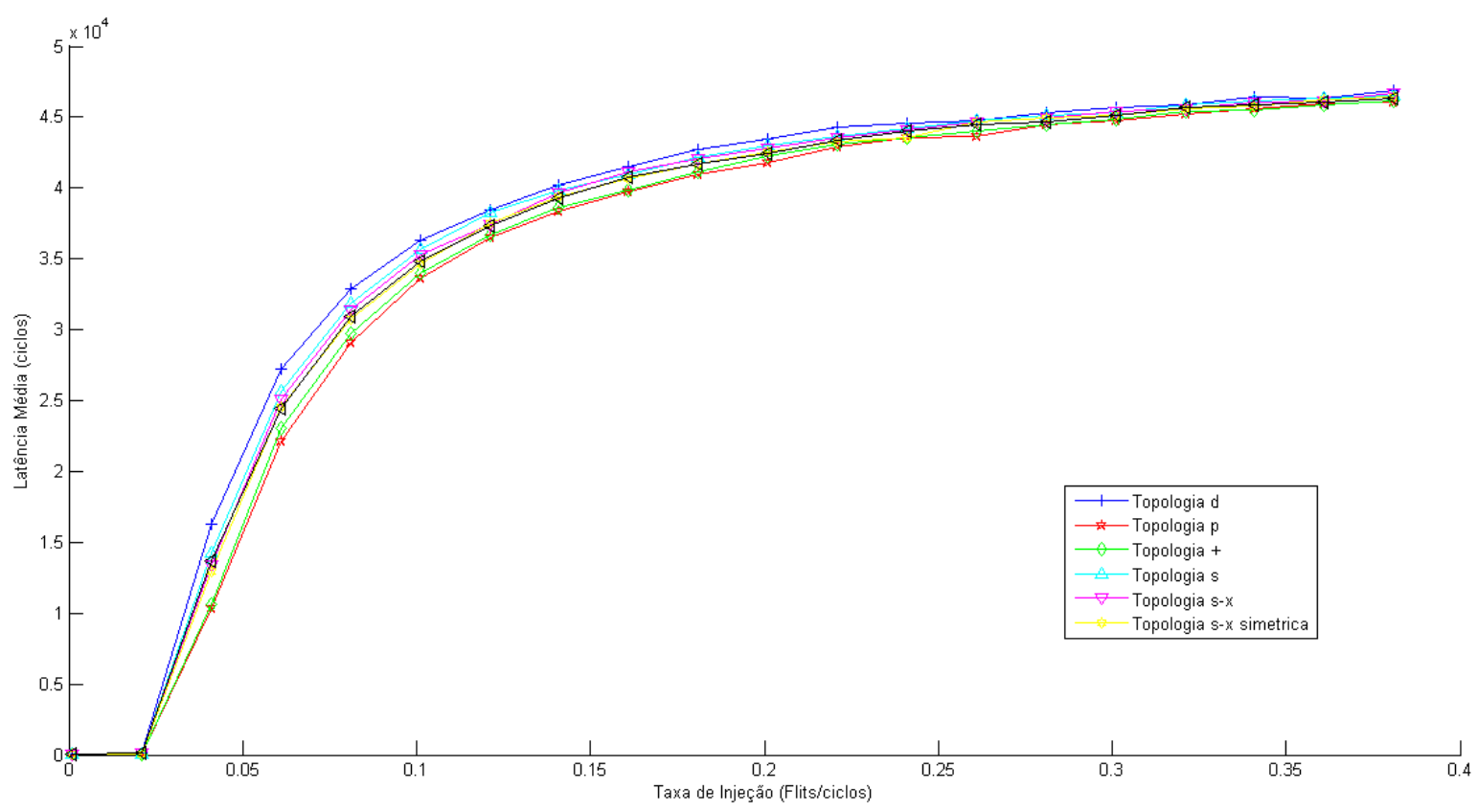

Fonte: (Autor, 2014).

Figura 80: Latência Máxima vs. Taxa de Injeção, para as topologias irregulares com dezenove (19) MPs ativos para uma malha de $5 \times 5$ no intervalo de $[0 ; 0,4]$

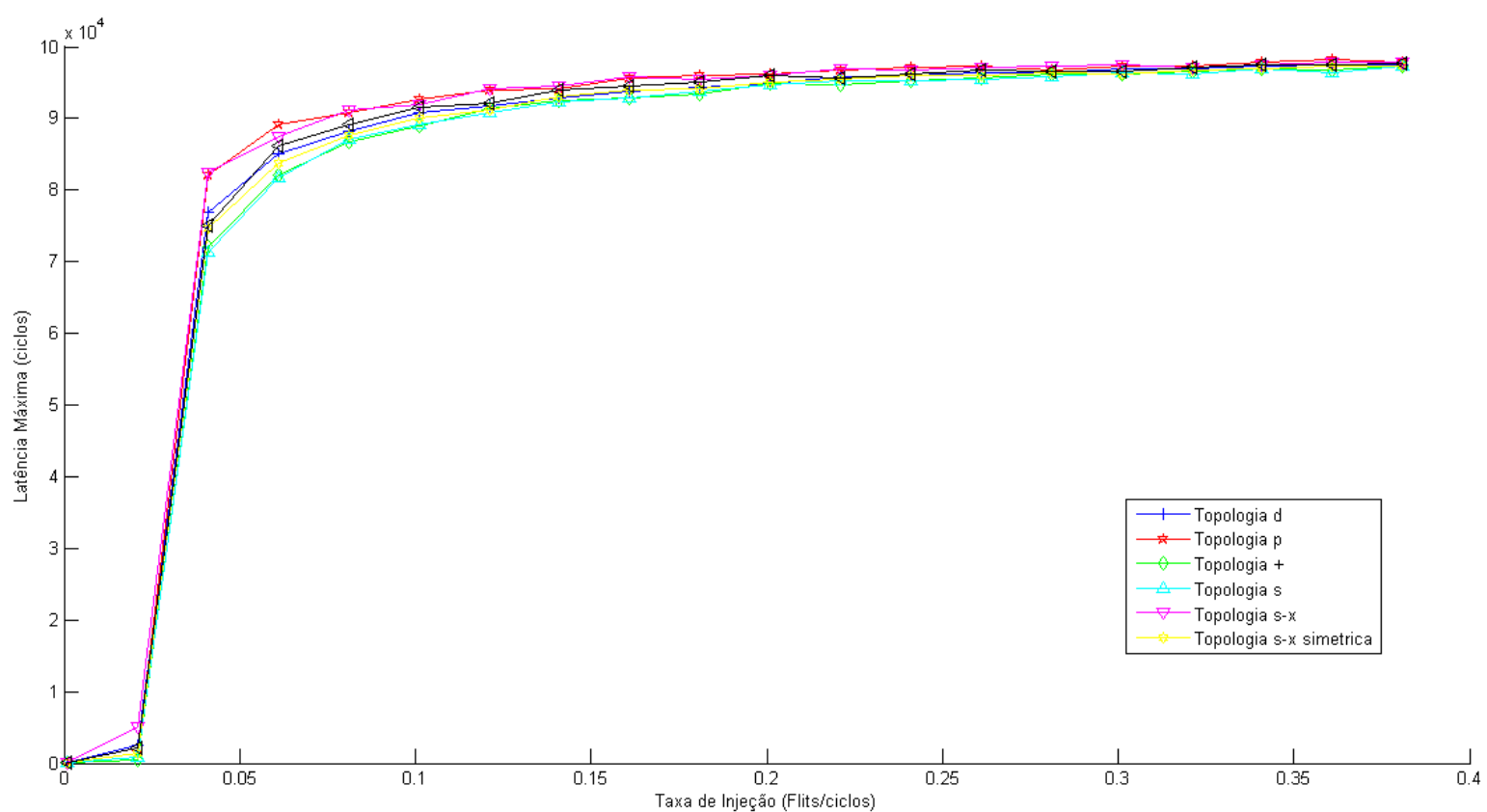

Fonte: (Autor, 2014). 